\title{
RETHINKING MĀORI ACADEMIC DEVELOPMENT IN NEW ZEALAND UNIVERSITIES
}

\author{
BY \\ MEEGAN HALL
}

\begin{abstract}
A thesis
submitted to Victoria University of Wellington in fulfilment of the requirements for the degree of

Doctor of Philosophy in Māori Studies
\end{abstract}

Victoria University of Wellington 2014 



\begin{abstract}
Indigenous scholars have called for a rethinking of the cultural interface of Indigenous people within the academy. For Māori academics, their culture often has a significant impact on their work, career goals and academic development requirements, yet the academic development literature is largely silent on the needs of Māori academics. Thus, the views of Māori academics could be better reflected in the scholarship and practice of academic developers.
\end{abstract}

This thesis explores the realities of Māori academic staff in New Zealand universities. It presents a literature review about the experiences and preferences of Māori and other Indigenous academics. It also shares three case studies involving seven participants from two different New Zealand universities. The interviews for the case studies were conducted in accordance with kaupapa Māori methodology and using interpretative phenomenological analysis.

In addition, this thesis proposes an integrated framework for conceptualising and delivering culturally relevant academic development to Māori academics. Entitled Te Kōtuinga Mātauranga: A Māori Academic Development Framework, it highlights four dimensions that emerged from the case studies and literature as key to Māori academic development: tuakiritanga (identity), pūkengatanga (skills and knowledge), whanaungatanga (relationships) and tikanga (values and practices). It also reflects the holistic nature of Māori academic work and the demand for individual and collective academic development opportunities.

The visual portrayal of the framework draws on the traditional Māori weaving style of tāniko. The woven motif serves as a metaphor for both the interconnectedness of the Māori academic development framework and the importance of understanding academic development from an Indigenous viewpoint. Ultimately, this thesis calls for a rethinking of how academic development can be theorised and delivered to centre the cultural 
aspirations, preferences and practices of Māori academics, and encourages academic developers to be more inclusive in their practice. 


\section{Acknowledgments}

This thesis begins and ends with a play on the idea of marginalia, the notes that readers often make in the margins of books. Within this thesis, I have acknowledged the insight and symbolism of those scribbled comments and the importance of those on the margins. In a similar way, I want to pay tribute here to the people who have been on my 'margins', adding depth, colour and sustenance, as I have woven this thesis together.

Firstly, to my children Ahikaroa and Te Waiamio, if it was not for your daily question, "Have you finished your Pah-Hah-Duh yet?" I honestly do not know if I would have completed this thesis. As my two unofficial supervisors, your support and patience have meant a lot to me and I am looking forward to being able to return the favour by giving you more of my undivided attention. As you are now tween/teenagers, I am not sure if you are going to enjoy that as much as I will.

To my partner, Pete, thank you for being my sounding board, my coffee maker and for having faith in me throughout.

To my Mum and Dad, Wendy and Harry Hall, thank you for raising me to think that going to university was a natural pathway and that learning was fun.

To my supervisors, Dr Ocean Mercier and Dr Kathryn Sutherland, thank you for letting me figure out this thesis my own way and for knowing how and when to share your wisdom.

To my friend and colleague, Dr Rawinia Higgins, thank you for trying really hard to relieve me of other work while I was finishing this project, and for being a sympathetic ear when it all got too much.

To my interviewees, it is such a shame that you cannot be named because there would be no thesis without you. Thank you for your candour, your courage and your commitment. You each make a valuable contribution to te ao Māori every day and your universities would be lesser places without you. 
To my colleagues at the Centre for Academic Development, both current and former, thank you for your support of my work and for your interest in my PhD journey.

Lastly, I want to give huge thank you to all of the people who have been by my side along the way, including my Write on Site whānau for meeting on Friday afternoons to write (and eat) together, to MAI ki Pōneke and the Office of the PVC Māori for your tireless support of Māori postgraduates, to the 'Māori Studies Dissertation Group' for your solidarity, to Ani-Oriwia and Wiremu Adds, and to Christine McCarthy, Selena Shaw and Natasha Perkins from Te Ohu Tiriti o Te Kura Waihanga for the thoughtful and timely care packages.

He mihi aroha tēnei ki a koutou katoa. 


\section{Table of Contents}

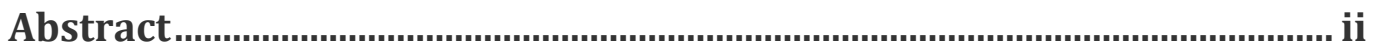

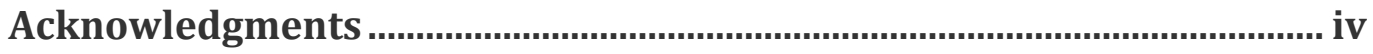

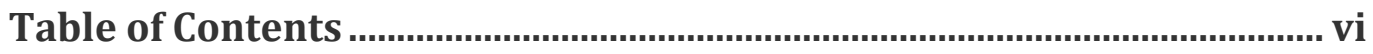

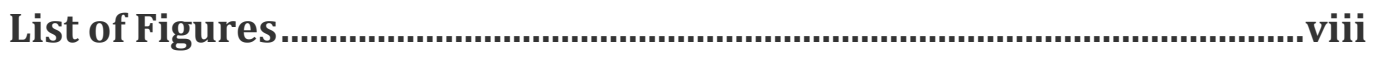

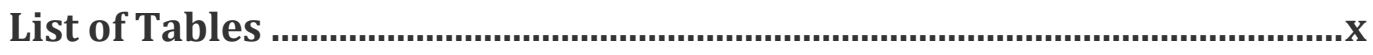

Chapter One: Introduction........................................................................ 1

1.1 Māori and the New Zealand university environment..............................2

1.2 Māori academic development as a research topic ................................. 10

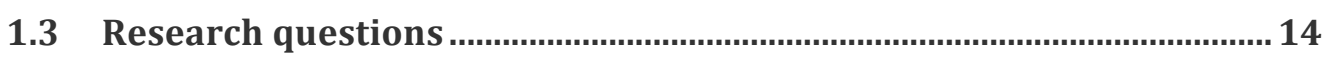

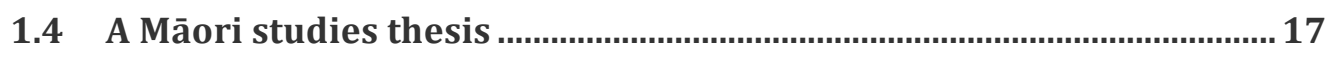

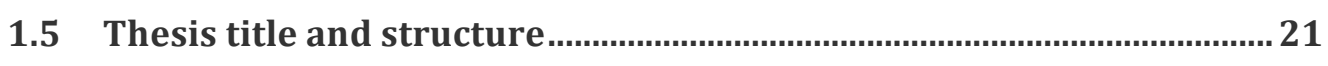

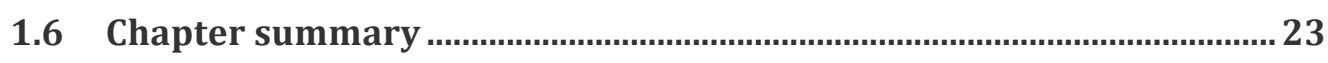

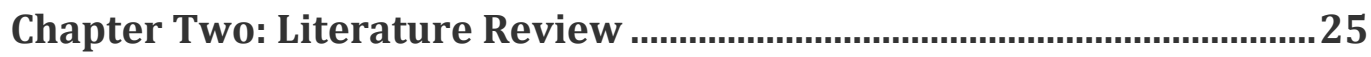

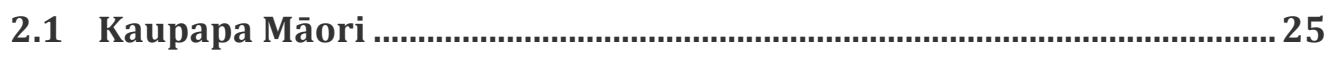

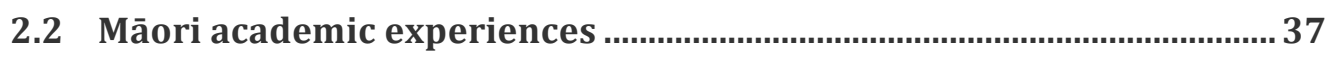

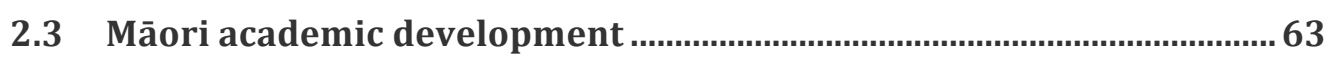

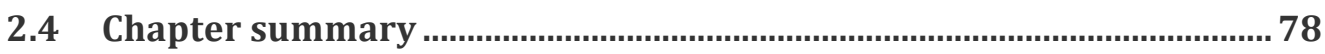

Chapter Three: Methodology and Methods................................................81

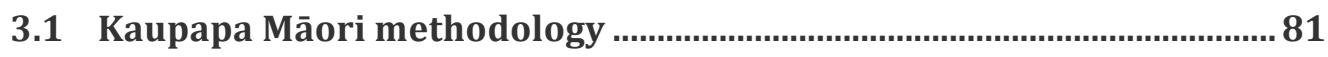

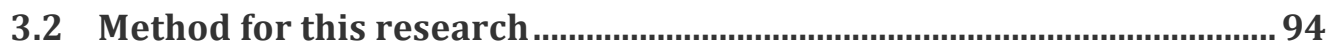

3.3 Ethical considerations for this research ................................................ 109

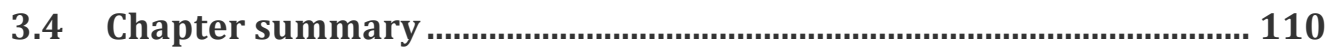

Chapter Four: Case Studies.................................................................... 111

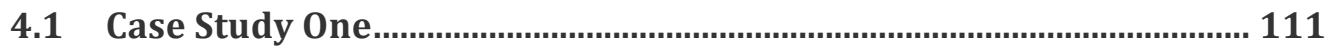

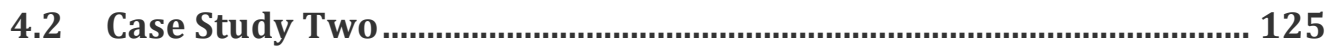

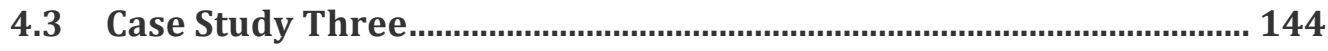

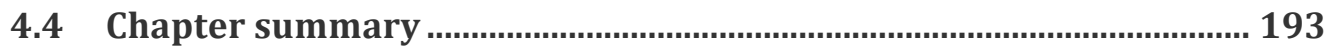

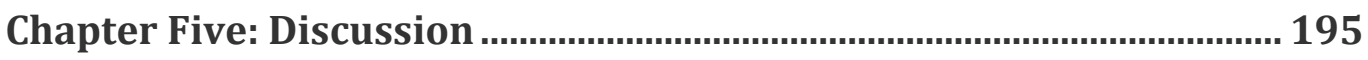

5.1 Rethinking the Mãori academic space …............................................. 196

5.2 Constituting a framework for Māori academic development........... 214

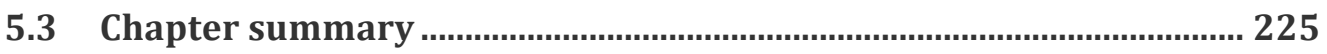


6. Chapter Six: Conclusion

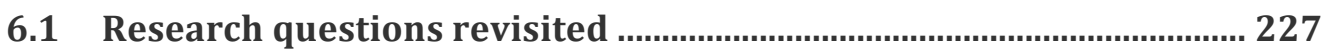

6.2 Limitations of this research project .......................................................... 230

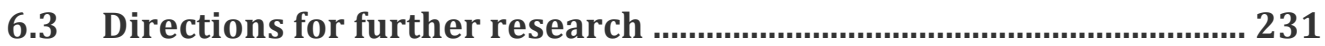

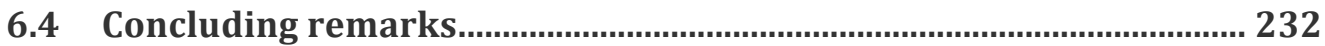

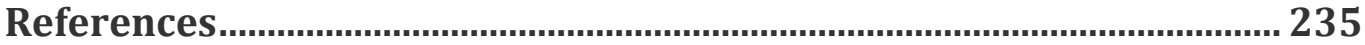

Appendix A: Human Ethics Committee Approval ................................. 257

Appendix B: Participant Information Sheet ........................................... 259 


\section{List of Figures}

Figure 2.1 An example of the ISIS model analysis depicting institutional orientation towards educational development (Blackmore, 2009, p. 671)

Figure 3.1 Brief description of the three case studies on which this thesis is based.

Figure 3.2 Screenshot of the NVivo software once the case study recordings had been loaded and the transcripts had been analysed

Figure 3.3 Screenshot of coding using the NVivo memo tool 105

Figure 3.4 Screenshot showing how the NVivo software allows for different nodes to be set up and grouped together to enable the identification of overarching themes. 107

Figure 4.1 Diagram of superordinate themes and sub-themes for Case Study One.

Figure 4.2 Diagram of superordinate themes and sub-themes for Case Study Two.

Figure 4.3 Diagram of superordinate themes and sub-themes in Case Study Three.

Figure 5.1 Screenshot of part of the Superordinate Synthesis Table developed in Microsoft Word.

Figure 5.2 The evolution of tāniko patterns (Buck, 1926, p. 144).

Figure 5.3 An example of the aronui pattern (H. M. Mead, 1999, p. 64)...... 216

Figure 5.4 An example of the whakarua kōpito pattern (H. M. Mead, 1999, p. 64)

Figure 5.5 Te Kōtuinga Mātauranga: A Māori Academic Development

Framework. 'Tu' refers to tuakiritanga (identity), 'Pu' refers to pukengatanga (skills), 'Ti' refers to tikanga (values and practices) and 'Wh' refers to whanaungatanga (relationships). Further elaboration about the structure and meaning of this diagram are provided in the text.

Figure 5.6 Four key dimensions of Māori academic development 
Figure 5.7 Provision for academic development for Māori individuals (I) and

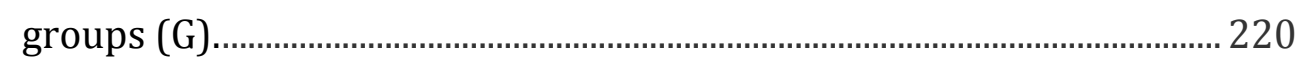

Figure 5.8 Direction of Māori academic career development and progression. 221

Figure 5.9 Te Toka Āhuru Framework (Davies \& Eruera, 2009, p. 1) .......... 222

Figure 5.10 Te Kōtuinga Mātauranga profile based on the ISIS model........ 225 


\section{List of Tables}

Table 1.1 Māori academic staff employed at each of the universities in New Zealand

Table 3.1 Key principles of the kaupapa Māori methodology ("Rangahau", n.d.)

Table 3.2 Guidelines for conducting kaupapa Māori research (Cram, 2001, pp. 42-49; 2009, pp. 313-317). 



\section{Chapter One: Introduction}

The capacity of traditional institutions, such as universities and the professions, to provide their members with dominant or legitimising identities may be less secure. Individuals, for their part, may decide they have other choices in how they define themselves. For example, identities generated in the emergence of cultural politics in the name of resistance to or transformation of entrenched power and centred in gender, race, ethnicity and religion may become more important in the lives of individuals, their definitions of themselves and their epistemologies.

(Henkel, 2005, p. 153)

Marginalia is the practice of scrawling comments in the margins of books. A number of famous people in history did it, either as a conversation with the author, to highlight their favourite passages or because they lacked stationery (Johnson, 2011). Often those scribbled comments are "more illuminating than the books they're written in" (Smithies, 2011, p. F28). As the only full-time Māori academic developer currently working in a New Zealand university ${ }^{1}$ I know from both first-hand experience and my review of the relevant research literature that the academic experiences and development of Māori academic staff have so far been relegated to the proverbial margins. Much of the academic development ${ }^{2}$ literature assumes generic academic identities and experiences and, like marginalia, Māori perspectives have thus far remained on the fringes where they are difficult to find. Even discussion about fluid academic identities, such as Henkel's quote above, downplays or ignores ethnicity as a significant factor. Henkel

\footnotetext{
1 Throughout this thesis, any reference to 'universities' in New Zealand will relate to one or more of the University of Auckland, Auckland University of Technology (AUT University), the University of Waikato, Massey University, Victoria University of Wellington, Lincoln University, the University of Canterbury and the University of Otago. Unless specifically noted, it does not include whare wānanga (such as Te Wānanga o Aotearoa, Te Wānanga o Raukawa and Te Wānanga o Awanuiārangi) that are akin to universities, in that they offer tertiary qualifications, but are required by Section 162 of the Education Act 1989 to be called 'wananga', as distinct from universities.

${ }^{2} \mathrm{~A}$ fuller discussion of the term and practice of 'academic development' is provided in the Chapter Three literature review; however, a useful definition for the purpose of this thesis is the "responsibility for guiding the academic community toward better practice - most commonly, with respect to learning and teaching applications" (Debowski, 2011, p. 17).
} 
only suggests that ethnicity may have an impact on academic identity formation in the future, a notion that is in complete contradiction to the experiences of many Māori academics.

The aim of this thesis is to explore the experiences, identities, aspirations and needs of Māori academic staff working in New Zealand universities. Its ultimate purpose is to put forward a kaupapa Māori approach to universitybased academic development that promotes Māori academic success, in ways that are both professionally and culturally appropriate. This thesis exposes existing academic practices in New Zealand that can, intentionally or not, marginalise Māori academics and uses Māori academics' words from the 'margins' to reshape their own academic development. By chronicling the experiences and development opportunities of current members of the Māori academic community, this thesis contributes to a stronger and less 'marginalised' pathway for future generations of Māori academic staff.

The remainder of Chapter One introduces the key research questions for this thesis and provides some background to the thesis topic. It discusses the Treaty of Waitangi context of the New Zealand university environment, the current levels of Māori and Indigenous academic staff recruitment and retention, and the impact of Māori academics on Māori student achievement and the university environment. It also explains the origins of this research topic, before outlining the thesis structure and discussing its place within the academic field of Māori studies.

\subsection{Māori and the New Zealand university environment}

The Treaty of Waitangi is often described as the founding document of New Zealand ("Ministry of Social Development", n.d.; "The Governor General", n.d.; Health Research Council of New Zealand, n.d.; Ministry for Culture and Heritage, n.d.-a, n.d.-b; Waitangi Tribunal, n.d.). It has come to be regarded as forming a partnership (albeit a contested one) between Māori and the British Crown. A set of principles drawn from the Treaty has since been integrated into New Zealand educational policy and legislation (Department 
of Justice, 1989). This has manifested in a requirement for tertiary institutions to meet a distinct set of Māori-related obligations and goals. On a national scale, the New Zealand Tertiary Education Strategy 2010-2015 called for tertiary providers to "improve progression to, and achievement at, higher levels" for Māori students (Tertiary Education Commission, 2010, p. 12). Māori students were identified by the Tertiary Education Commission (TEC) as a priority group for the five years to 2015 - a testament to the government's interest in Māori achievement in tertiary study in New Zealand (Tertiary Education Commission, 2010, pp. 11-13).

\subsubsection{Māori-related university goals}

While the TEC sets national goals, each university is required to devise its own Māori-related governance statements and strategy objectives to match its context. Victoria University of Wellington (Victoria) enacted a Treaty of Waitangi Statute to enshrine a university-wide culture that "strengthens the position of Māori within the University", "commits to Māori student recruitment, retention, and achievement", and "commits to building Māori staff capability"(Victoria University of Wellington, 2009b, pp. 3-4). In addition, Victoria's Strategic Plan declared a commitment to "Māori student recruitment, retention, and achievement", "the contribution of mātauranga Māori (Māori knowledge) to scholarship across disciplines" and "the contribution of te reo Māori and tikanga Māori to the culture of Victoria" (Victoria University of Wellington, 2009a, p. 5).

Victoria is not alone in setting these high-level, Māori-related objectives. All of the eight New Zealand universities have considered their responsibilities and goals in relation to Māori student and staff achievement within their institutions. Objective 11 in the University of Auckland Strategic Plan 2013 included actions to:

Develop and implement policies and processes which promote Māori presence, participation, and achievement in all aspects of University life. 
Promote and support excellent teaching, learning, and research for Māori intellectual, cultural and economic advancement across all relevant disciplines.

Develop and implement policies and processes to improve Māori staff recruitment, promotion, reward, and retention.

Develop and implement strategies to improve Māori student participation, success, retention, and completion rates in all disciplines. (The University of Auckland, 2012, p. 13)

The AUT University Strategic Plan 2012-2016 set a number of Māori-related priorities, including to "expand the participation and success of Māori across disciplines and levels of qualification", promote "research by Māori for the benefit of their communities", and ensure "increasing appointments of Māori and Pacific staff in academic and senior roles" (AUT University, 2011, p. 4 \& 5). In its Strategic Plan, the University of Waikato described its distinctive "University of Waikato experience" as being based on the three themes of "Leadership, Māori and Sustainability" (The University of Waikato, 2010, p. 5). Massey University produced an entire strategy entitled Mãori @Massey, which set a range of goals and objectives to make Massey "a Māori-relevant university" and work towards the "enhancement of Māori academic capacity" (Lilley \& Field, 2005, p. 1; Massey University, 2003, p. 1 \& 4). Lincoln University developed a Māori Plan to, amongst other things, address its "insufficient Māori staff capacity" (Lincoln University, 2013b, p. 11). The University of Canterbury set goals to increase their Māori student enrolments, improve the educational performance of their Māori students, and "develop postgraduate research programmes that impact indigenous knowledge economies, culture and identities, reflect kaupapa Māori perspectives and contribute to Māori development aspirations" (University of Canterbury, 2012, pp. 18, 20, 22). Finally, the University of Otago drafted a Māori Strategy Framework 2007-2012 to "increase the recruitment, access, participation, retention, development and success of Māori staff and students" (The University of Otago, 2007, p. 7). 
While each New Zealand university appears to have identified high level Māori-related goals, many of them focus on Māori deficiencies rather than opportunities. Also, it is unclear what processes have been put in place to achieve each goal, including the strategies to develop the capabilities of Māori academic staff.

\subsubsection{Kaupapa Māori and New Zealand universities}

Despite these governance-level attempts to address the retention and achievement of Māori staff and students in higher education, there remains a view that educational policies and practices in New Zealand are developed "within a pattern of power imbalances which favours cultural deficit explanations" (Bishop, 2003, p. 221). Durie (2009), a leading Māori scholar and professor of psychiatry, described how:

Intermittent Māori participation in universities began in the 1890s but generally with scant regard for learning preferences shaped by culture or by bodies of knowledge built on indigenous experience and indigenous ways of knowing. Nor was there previous involvement of Māori community leaders in university management or governance. (pp. 2-3)

Successive New Zealand governments have attempted to mitigate this imbalance through the imposition of educational philosophies, such as assimilation (1800s-1950s), integration (1960s), multiculturalism (1970s) and biculturalism (1980s-2000s) - all with limited success (Tooley, 2000). Bishop (2003), the foundation professor of Māori education at the University of Waikato, concluded that the key failing of each was that they,

collectively can be labelled 'deficit theories', in that they blame the victims [Māori] and see the locus of the problem as either lack of inherent ability, lack of cultural appropriateness or limited resources; in short, some deficiency at best, a 'pathology' at worst. The general pattern of the solutions that they propose suggests that the 'victims' need to change, usually to become more like the proponents of the theories (p. 223).

To combat this history of educational imposition, Bishop (2003) argued for the uptake of kaupapa Māori theory and practice, which he described as "the 
reassertion of indigenous Māori cultural aspirations, preferences and practices" (p. 223). Johnston (2004), a professor and Head of Indigenous Graduate Studies at Te Whare Wānanga o Awanuiārangai, extended this idea by arguing that the presence of Māori academics in universities "has signalled a clear challenge to academic communities that the socially constructed hierarchical knowledge categorisation and belief systems that reside within University contexts, can no longer be taken for granted as being the only valid knowledge systems" (p. 4). Thus it appears timely to consider what a model for Māori academic development could look like, based on kaupapa Māori philosophies and informed by the current experiences of Māori academics.

\subsubsection{Māori academic staff in New Zealand universities}

A common experience of the current cohort of Māori academics in New Zealand universities is to be reminded of illustrious predecessors, such as Sir Apirana Ngata, Te Rangihiroa Peter Buck and Sir Maui Pomare, and their early contributions to Māori scholarship (Hall, 2010b; L. T. Mead, 1996; S. M. Mead, 1997). Ngata was the first Māori person to graduate from university in 1893 and later went on to gain Law and Master's degrees, an Honorary Doctorate of Literature, and publish significant ethnological research (Puketapu, 1966; Te Momo, 2010). His contemporary, Pomare, gained a medical degree in 1899 and went on to publish health research, while Buck too trained to be a doctor before becoming the first Māori to work as an academic. He went on to garner the largest international profile of the three for his vast anthropological scholarship, both in New Zealand and abroad (L. T. Mead, 1996, p. 99). Each of these scholars has served as a role model and set high expectations for Māori academics today.

Not only are there high scholarly expectations placed on the shoulders of Māori academics, recent research compared the experiences of Māori and Indigenous Australian academics and concluded that both continue to face challenges and carry obligations in addition to those of their non-Indigenous colleagues (Asmar, Mercier, \& Page, 2009). Māori academics were found to 
make a valuable contribution to the recruitment, retention and achievement of Māori students, which continues to be a significant issue for all New Zealand universities (Airini. et al., 2010; Bishop, Berryman, Cavanagh, \& Teddy, 2009; Callister, 2009; Coxhead, 2006; Ross, 2010). One study found that "if an effective teacher had experienced the same, or similar, cultural and family experiences [the teacher will] have an advantage, providing they can establish the appropriate relationship" (Hawk, Cowley, Hill, \& Sutherland, 2001, p. 6). Other research concluded that "Māori staff can not only give support in academic matters but most importantly help to establish a whānau environment in the University and act as role models for students" (Gallhofer, Haslam, Nam Kim, \& Mariu, 1999, p. 790). Woods (2008), a Māori law lecturer at the University of Waikato, concluded that "an increase in the number of Māori academics allows for the increase of consideration of Māori culture within the institution" and, in turn, this is thought to benefit Māori students (p. 7). Thus, Māori academics have been found to have a positive impact on the culture of the university environment which, in turn, has had a positive impact on the learning experience of their Māori students (Gorinski \& Abernethy, 2007, p. 231).

Despite having a strong commitment to supporting Māori student success, these additional duties often come at a personal cost to the Māori academics' own teaching and research programmes. The performance pressure placed on Māori academics extends into their research activity. In a report on the national Performance-Based Research Fund 3 (PBRF) process, the reviewers found that a higher proportion of Māori research was "in areas of national importance and priority" but, on balance, the authors concluded that Māori research "receives lower quality scores because of, perhaps, the cultural characteristics of their research" (P. White \& Grice, 2008, p. 6). Exactly what they meant by "cultural characteristics" was not explained in the paper but

\footnotetext{
3 The TEC established the PBRF in 2003 to assess and reward research performance in the tertiary education sector. All New Zealand universities participate in the process, along with research-active industry training providers, wānanga and private training establishments. Funding is allocated based on performance in three areas: quality evaluation (of research outputs), research degree completions, and generation of external research income.
} 
it may have been a reference to the speed in which Māori research can be produced, or the spheres in which it can be disseminated. Another review of the PBRF Assessment Process found that "Māori researchers are equitably assessed but disproportionately 'new' to research and have lower average outcomes" (Adams, 2008, p. 8). Some of this disparity was attributed to the PBRF model itself, which does "not [...] respond as readily to research that is less consonant with that scientific paradigm" (Adams, 2008, p. 19). The reviewer concluded that a more inclusive PBRF system was needed, that was able to "encompass different modes of research (both basic and more applied, translational, policy-orientated and practitioner-related), different fields of research (including the social sciences, the humanities and creative arts) and different research cultures (including Māori and Pasifika)" (Adams, 2008, p. 41 \& 19). One Māori response was to initiate an alternative way to highlight Māori and Indigenous journals as a way to bring greater recognition to that kind of scholarship (Hall, 2010d; Hobson \& Hall, 2010). Another was to both challenge the PBRF system and also encourage Māori academics to more actively target research outlets and forms that receive higher PBRF weighting (Roa, Beggs, Williams, \& Moller, 2009).

Despite a strategic demand for more Māori academics, the number working in universities is still comparatively small to non-Māori staff, although this is difficult to gauge exactly as official figures are hard to locate and their accuracy is not guaranteed. One official report suggested that in 2006 there were 321 PBRF-eligible Māori academics working at universities in New Zealand (P. White \& Grice, 2008). Another reported that there were 309 (Çinlar \& Dowse, 2008, p. 79). However, both reports agreed that the overall ethnic profile changed little from 2003-2006, with Māori academics making up just $6 \%$ of the total number of academics in New Zealand, compared to Census 2006 figures for Māori at 14.6\% of the New Zealand population (Statistics New Zealand, 2006).

Table 1.1 compares the number of Māori academic staff with the total number of academic staff employed at each of the universities in New Zealand. In 2013, there were 36 Māori at Victoria who were known to be on 
academic contracts ( 24 full time permanent, two part-time permanent, and 10 fixed-term appointments) out of a total academic staff pool of 807, which equated to $4.5 \%$ of the academic staffing. The largest cohort of Māori academics is at the University of Auckland, which is not surprising given that it is also the largest university and is located in a city that has the biggest Māori population. Their figures for 2011 recorded that they employed 110 FTE (full time equivalent) Māori academic staff from a total pool of 2050 academic staff, equalling 5.4\% (Manuel, Dunphy, \& Hema, 2011; The University of Auckland, (n.d.)). Despite this higher percentage, University of Auckland researchers found that in order to gain parity with the student to staff ratio experienced by non-Māori academics, the University would need to employ a further 42 Māori academics (Manuel, Dunphy, \& Hema, 2011).

Table 1.1 Māori academic staff employed at each of the universities in New Zealand.

\begin{tabular}{|l|c|c|c|c|}
\hline \multicolumn{2}{|l|}{ Institution } & $\begin{array}{c}\text { Māori } \\
\text { academics }\end{array}$ & $\begin{array}{c}\text { Total } \\
\text { academics }\end{array}$ & Percentage \\
\hline $\begin{array}{l}\text { University of Auckland } \\
\text { (Manuel et al., 2011; The } \\
\text { University of Auckland, } \\
\text { (n.d.)) }\end{array}$ & 2011 & 110 & 2050 & $5.4 \%$ \\
\hline $\begin{array}{l}\text { AUT University } \\
\text { (AUT University, 2013, p. } \\
\text { 118) }\end{array}$ & 2013 & Not available & 1018 & \\
\hline $\begin{array}{l}\text { University of Waikato } \\
\text { (University of Waikato, } \\
\text { 2013) }\end{array}$ & 2013 & Not available & 637 & \\
\hline $\begin{array}{l}\text { Massey University } \\
\text { (Massey University, 2013, } \\
\text { p. 93; Ward, 2013) }\end{array}$ & 2012 & 59 & 1072 & $5.5 \%$ \\
\hline $\begin{array}{l}\text { Victoria University of } \\
\text { Wellington (Hall, 2013; } \\
\text { Victoria University of } \\
\text { Wellington, 2013, p. 17) }\end{array}$ & 2012 & 36 & 807 & $4.5 \%$ \\
\hline $\begin{array}{l}\text { Lincoln University } \\
\text { (Lincoln University, 2013a, } \\
\text { p. 84; Shadbolt, 2013) }\end{array}$ & 2013 & 8 & 234 & $3.4 \%$ \\
\hline $\begin{array}{l}\text { University of Canterbury } \\
\text { (Kahi, 2013; University of } \\
\text { Canterbury, 2013) }\end{array}$ & 2013 & 52 & 547 & $9.5 \%$ \\
\hline $\begin{array}{l}\text { University of Otago } \\
\text { (Brunton, 2009; The } \\
\text { University of Otago, (n.d.) }\end{array}$ & 2009 & 49 & 1175 & \\
\hline
\end{tabular}


The issue of relatively low numbers of Indigenous academics in universities is not unique to New Zealand. Census data from Canada in 2001 showed that of the 52,160 university professors surveyed, only 340 self-identified as an Aboriginal person, which equated to $0.65 \%$ (Roland, 2011, p. 4). In 2006, a report by the Australian Vice Chancellors Committee noted,

an increase of $16 \%$ in the number of Indigenous people employed in teaching and/or research roles in Australia. However, an additional 700 similar types of positions would need to be created in order to achieve parity. (Trudgett, 2009, p. 13)

In addition to the low numbers of Indigenous academics in Australia, a secondary issue is that "only $15 \%$ of indigenous academics hold a doctoral qualification, compared to $57 \%$ of non-indigenous academic staff" (Trudgett, 2009, p. 13). Also, the majority of the Australian Indigenous academic staff has been clustered in their universities' Indigenous Centres (Gunstone, 2008, p. 104). There is no comparable data about this for Māori academics but a cursory check of university websites suggested that Māori academics are similarly clustered around Māori studies and Māori education units in New Zealand universities.

Despite the trail blazing of Ngata, Pomare, Buck and their ilk, nearly 100 years on Māori are still under-represented in university academic appointments, and the PBRF rankings of Māori academics lagged behind non-Māori in the first two rounds (Adams, 2008; P. White \& Grice, 2008). Nonetheless, the number of Māori academics has increased overall, and the potential for Māori academics to interact, collaborate and support each other remains.

\subsection{Māori academic development as a research topic}

In late 2006, I started working as a lecturer in the academic development unit at Victoria with a specific focus on providing support to Māori academics. I soon set about the seemingly perfunctory task of identifying all of the Māori academic staff employed there. This was not a straightforward 
activity, however, as the records that had been collected and maintained by the University's Human Resources unit were deficient and misleading, omitting well-known Māori academic members of staff while including numerous part-time, short-term research assistants. This error was partly because of the optional nature of the ethnicity question in employment documentation and also because the collection of ethnicity data had only occurred at the University since the year 2000 and no effort had been made to update earlier records.

By the end of my search in 2007, I had identified 38 Māori academic staff engaged in a range of significant teaching and research duties across Victoria's four campuses, representing $4.7 \%$ of the then total number of academic staff. Thirty-six of these Māori academic staff were full-time, permanent appointments with teaching and research responsibilities and a further two were part-time, permanent appointments. The Māori academic staff had never before been gathered together en masse and up until this point there was not even an email or communication list with which to contact them all.

\subsubsection{MANU-Ao at Victoria University of Wellington}

In 2007, the TEC provided funding for a national MANU-Ao (Māori Academic Network at Universities in Aotearoa) project which, amongst other things, provided money for each of the eight universities in New Zealand to provide professional development opportunities for their Māori academic staff. The staff development programmes arose from the MANU-Ao Project's 'Deliverable 4' requirement to establish a University-based Māori staff Academic Forum.

In September of that year, I initiated and convened a workshop at Victoria for Māori academic staff to talk about their academic development goals and interests. The workshop was held as part of Ako Victoria, a one-day learning and teaching event. I framed the session as a Māori Academic Staff Forum to discuss options for using the MANU-Ao funding for some professional development for Māori academic staff. 
The meeting began with a discussion about the six core goals that were attached to the funding: sharing innovative teaching models; increasing research participation and productivity; developing theoretical and applied bodies of knowledge; academic career acceleration; enhancing academic collegiality; and building high levels of scholarship. During the workshop, the participants considered each of these goals in turn and then promptly set them all aside in favour of a new over-arching vision. The consensus reached by the attendees was that, ultimately, their academic development goal was "to be Māori academics with integrity" (Hall, 2007). This key vision statement rested on the premise that any academic development programme would need to support and encourage them to be high performing academics without having to compromise any of their cultural integrity as Māori people. This idea resonated with the meeting participants because they all shared, in a variety of ways, a desire to be able to engage in robust, scholarly activities but to do so in ways that were consistent with tikanga Māori (Māori cultural practices), that acknowledged te ao Māori (the Māori world) and that were also valued within the University community.

With this academic development goal in mind, the resulting MANU-Ao funded activities at Victoria ranged in type from externally provided training to internal-staff led workshops. They included course design workshops, writing retreats, sessions about research funding, and media training. Two of the more obviously cultural elements of the MANU-Ao programme were the inclusion of wānanga reo (Māori language immersion block courses) and tikanga hui (Māori cultural practices block courses). The purpose of the wānanga reo was to give staff an opportunity to immerse themselves in te reo Māori over an extended period of time. This approach was firmly situated within Māori teaching pedagogy but also fit the limitations caused by the busy calendars of the Māori academic staff. In a similar vein, the tikanga hui were designed to support Māori staff in their engagement with Māori students and their Māori research.

Between September 2007 to June 2008 there were 20 MANU-Ao activities held for Victoria that attracted 229 enrolments - the vast majority were 
Māori academic staff but there was also significant involvement of Māori general staff and Māori postgraduate and undergraduate students. However, while well-received, the activities were essentially ad hoc and lacked a coherent framework on which to build a comprehensive Māori academic development programme.

\subsubsection{MANU-Ao programmes at other universities}

While there are eight universities in New Zealand, and all eight have some form of teaching development unit or centre, only two have dedicated Māori staff employed to work with and support Māori academic staff (Victoria and the University of Auckland). Historically, professional development opportunities that have been designed or delivered to or for Māori academic staff have been relatively ad-hoc, often opportunistic and usually part of a mainstream offering that paid little, if any, heed to the culturally-specific goals or needs of Māori academics.

The conditions of the MANU-Ao funding were such that each university had the autonomy to determine their own processes for allocating funding and initiating activities. This resulted in a range of approaches and outcomes at each of the other seven universities in New Zealand. Some set the funding as a contestable pool whereby Māori staff could propose self-directed initiatives. Others made decisions on behalf of their Māori staff and funded university-wide resources, like websites and research symposia. While many of the universities used their funding creatively and effectively, none of them developed a comprehensive research-based framework on which to continue their Māori academic development after the MANU-Ao funding ended. Thus, when the MANU-Ao project drew to a close in 2012, there was still no acknowledged academic development framework for Māori academic staff in New Zealand universities.

\subsubsection{Inspiration for this thesis}

The inspiration for this thesis came from the collective vision, coined by Victoria's Māori academic staff in 2007, of being Māori academics with 
integrity. I realised that there needed to be greater understanding about what it was like to be a Māori person pursuing an academic career. I wanted to explore whether there were any commonalities in their experiences or aspirations. I then wanted to use the insight I gained from learning more about Māori academic experiences to see how it could inform academic development theory and practice. In due course, I wanted to understand how academic development could better support the goals and needs of Māori academic staff, rather than Māori academics having to fit a generic academic development mould.

Prior to this research I did not recall ever being part of a conversation about how we see ourselves as Māori academics and how that influences what we do. We did not talk about those things in staff meetings. We talked about upcoming events, we planned, we discussed challenges, we even celebrated successes, but articulating all of that around our sense of identity? That was something we did not openly do, at least until now. Leading Torres Strait Island scholar, Martin Nakata (2006) has called for the development of "an Indigenous intellectual community" (p. 266). I hope that the focus on Māori academic development in this thesis can add a crucial dimension to that community's growth and function.

\subsection{Research questions}

Both my work experience as a Māori academic developer and my understanding of the university context as it related to Māori led me to develop two research questions that have guided this thesis:

- What are the key aspects of the current Māori academic staff experience in New Zealand universities?

- How could those key aspects inform a kaupapa Māori academic development framework to support Māori academic staff at New Zealand universities? 
These research questions are important and relevant to me for five reasons. Firstly, as Māori scholar Dr Kathie Irwin (1997) suggested, "much needs to be done to reform the current state of New Zealand universities so that they may become equitable institutions of higher learning" (p. 66). She argued that Māori needs are not being met within the academy, and that more should be done to ensure greater equity of opportunity and support. Taking a somewhat different approach to the plight of Māori academics within universities, Māori educationalist Graham Hingangaroa Smith’s (2011) position was that Māori academics have allowed themselves to be compromised by not advocating more clearly and strongly for opportunities and support. He espoused what he called the 'Politics of Truth' and encouraged Māori to own up and understand where compromises are being made so that informed decisions can be taken about Māori futures. As a Māori academic developer in a New Zealand university, I am committed to using my research resources, skills and time to shed light on and improve the current experience of Māori academics. I want my work on Māori academic development to be about no longer compromising on what Māori academics can expect for their academic development and instead be about 'owning up' to the reality of the Māori academic experience in New Zealand universities, to ensure that "we do not participate in our own invisibilisation" (Te Punga Somerville, 2007, p. 34).

Secondly, I believe that there is still a great deal that universities in New Zealand can learn from kaupapa Māori. Bishop (2003) contended that "it is through the reassertion of Indigenous Māori cultural aspirations, preferences and practices, here termed Kaupapa Māori theory and practice (after Smith, 1997, and Smith, 1999), that historical and ongoing power imbalances will be addressed" (p. 223). In keeping with this idea, I have taken a kaupapa Māori approach to this research with a view to reasserting Māori cultural aspirations, preferences and practices, in this case in relation to Māori academic development within New Zealand universities. ${ }^{4}$ This thesis is an attempt to engage in the kind of Indigenous theorising that

\footnotetext{
${ }^{4}$ Further detail of this kaupapa Māori approach is provided in Chapters Two and Three.
} 
Smith alluded to when he challenged Māori academics "to hang some Indigenous theoretical tools and methodologies on the wall of the Academy" (G. H. Smith, 2011).

Thirdly, the international growth in Indigenous Studies programmes within universities, the proliferation of research projects that focus on Indigenous communities and experiences, and the strategic institutional goals that have sought to increase Indigenous student participation in tertiary study have all prompted a demand for more Indigenous academic staff. Yet, despite this apparent need, Indigenous staff are still notoriously under-represented in places such as New Zealand, Australia, the United States, and Canada, and universities have been accused of not doing enough to address this problem (Gunstone, 2008; Indigenous Higher Education Advisory Council, 2008; Merchanta \& Bishr Omaryb, 2010; Roland, 2011; Soldier \& Flechs, 1999; Trudgett, 2009; Umbach, 2006). If, as Gunstone (2008) suggested, "the involvement of Indigenous staff, students and communities in university governance can significantly improve several broad areas, including access and success rates of Indigenous students, curriculum development, university-Indigenous collaborative research and, more broadly, Indigenous self-determination" (p. 104) then this thesis can make a positive contribution to the broad topic of Indigenous academic development.

Fourthly, as an academic developer, I have been interested in exploring Tinto's (2002, p. 4) proposition that, "student learning drives student retention". If that is so, then what role could learning have in the retention of academic staff? More specifically, this research has sought to demonstrate how learning, in the form of academic development, could be used to support, retain, and develop Māori academic staff in a mainstream tertiary institution.

Fifth and finally, as noted earlier, I have had a long association with Victoria having been a student or staff member for most of the last 20 years. In choosing a topic for my research, I was persuaded by the whakatauki: 
Matua whakapai i tou marae, ka whakapai ai i te marae o te tangata.

First clean up your own marae before you clean up another's (Kohere, 1951).

\subsection{A Māori studies thesis}

This is a thesis about Māori academic development but it is also a thesis situated within the academic programme of Māori studies. That may seem like an unusual location for such a topic and some may think it better suited to an education programme. So, what makes this a Māori studies thesis?

Dean of Māori Studies at the University of Otago, Professor Michael Reilly (2008) provided one reason in his review of the history of Māori studies in New Zealand universities. In it, he suggested that,

the autonomy of Māori Studies creates a site not only for research but also for the everyday practice of culture in which Māori staff and students from elsewhere can participate. Māori Studies in an institutional sense serves as the mauri Māori within the academy, protecting and supporting the work of Māori scholars wherever they may be located. (p. 23)

As a Māori academic working on a Māori kaupapa (topic), this notion of Māori studies providing a space and place for the work of Māori scholars offered the first link for locating this research within this field of study.

A further reason for this being an appropriate thesis topic and approach also came from Reilly (2011), through his articulation of one of the defining features in the field of Māori studies. He explained:

Māori studies differs from other academic subjects in that it stresses praxis-both the theory and practice of indigenous knowledge-as part of its mandate to pass on learning to new generations of scholars, and thereby to return some balance to the educational structures of New Zealand that still bear the imprint of their colonial past. (Reilly, 2011, p. 347)

This thesis has directly engaged with the new generation of Māori scholars to whom Reilly is alluding. It is also directly related to developing new 
theory and practice around Māori academic development that contests the colonial imprint of a one-size-fits-all approach to academic development in New Zealand.

The first Professor of Māori Studies at Victoria University of Wellington, Professor Hirini Moko Mead, provided another reason that this is a Māori studies thesis. In a keynote address that he delivered to a conference of Te Matawhānui, a national association of Māori university staff that originated in the late 1980s, he declared that, "measures need to be taken to lift the status of Māori studies", and that, "the task needs to be faced with some imagination, otherwise we will be forced to wait for racism in New Zealand to decline" (S. M. Mead, 1997, p. 43). He also broadened his call to action to include improving "the status not only of Māori studies as a university discipline, but also of Māori university teachers generally" (1997, p. 48). Clearly, in Mead's view, scholarship and other work towards enhancing the performance of Māori academics generally fell within the purview of Māori studies; hence this thesis about Māori academic development also fits within the realm of Māori studies.

In the same keynote address, Mead (1997) explained how,

Māori studies belongs to the international group of studies variously called native studies, black studies, indigenous studies or aboriginal studies, all of which have sprung up in Fourth World countries. The emergence of these studies reflects the need of various indigenous groups to make the university systems work for them and to use the resources, skills and status of the institution to give a better understanding of and respect for the cultures of the native peoples. (p. 43)

The linking of Māori studies to a broader Indigenous network of scholars resonated with the approach taken in this thesis. In recognition of this thesis being based in the field of Māori studies, it relies heavily on Māori and Indigenous scholarship. This is also an approach advocated by Māori literary scholar, Alice Te Punga Somerville (2007) who suggested that, 
our bibliographies...should be thick and fat with the names of Māori and other Indigenous scholars, and if they do not currently brim in this way then it is our job to go out and hunt this work down and bring it into view. (p. 34)

The relevant literature produced by high-profile Western scholars has not been ignored but, by drawing predominantly on their scholarship, in this thesis the work of Māori and other Indigenous scholars has been intentionally centred. To make that even more apparent, when they are first mentioned in this thesis, I have included brief descriptions of the Māori and Indigenous scholars from whom I have drawn.

The assertion that this is a Māori studies thesis also aligns with a view articulated by Nakata. Writing about Indigenous studies in Australia, he suggested the following:

The field of Indigenous Studies is part of a broader landscape that includes not just Indigenous Studies but higher education for Indigenous students and the rebuilding of Indigenous communities and futures. For us, these are not entirely separable. (Nakata, 2006, p. 265)

Applying this notion to the Mãori studies context means that the field is part of the broader landscape of higher education for Māori students and includes the rebuilding of the Māori academic community, and its future, which is the central topic of this thesis.

Locating this thesis within the cultural context of Māori studies is as much a strategic contribution as an academic one. It works to counter the small but vocal criticism that Māori studies is an out-dated relic from a time when Māori people and practices were studied under an anthropological microscope with a colonial lens (Royal, 2009). It also addresses Pacific scholar Teresia Teaiwa's (1995) lament that, "native peoples...have for a very long time been simply objects of scholarly discourse...written about, talked about, photographed, medically dissected, biologically and anthropologically classified... our bones have been displayed in museums" (p. 59). Instead, it provides an example of what U.S.-based Māori academic, 
AnnaMarie Christiansen (2000) wished for Indigenous scholarship generally, "from being an absent presence in the academy to being a subjective presence validating all that we are" (p. 188). This thesis could be an illustration of what Nakata (2006) described as "Indigenous knowledge production in the academy" that counters "our co-option into the academic disciplines as a 'knowable' subject of study" (p. 266). It is thus offered as an example of 'new knowledge' that derives from the field of Māori studies but also relates to other disciplines.

In addition, this thesis makes a political statement of the kind advocated by George Dei, a Ghanaian traditional chief and Professor of Sociology at the University of Toronto. Like Dei's (2000) work about Indigenous knowledge, this thesis on Māori academic development has been approached "with a deep concern about the historical and continuing deprivileging and marginalizing of subordinate voices in the conventional processes of knowledge production" (p. 113). Also the goal in this thesis has been "to affirm Indigenous knowledges" and "to assert that Indigenous knowledges have a place in the academy" (Dei, 2000, p. 113). As Dei (2000) noted:

The goal of integrating (i.e. centering) Indigenous knowledges in the academy is to affirm this collaborative dimension of knowledge and, at the same time, to address the emerging call for academic knowledge to speak to the diversity of histories, events, experiences and ideas that have shaped human growth and development. And, if one recognizes that knowledge is not static but rather constantly being created and recreated in context, then Indigenous knowledges need to be an integral part of the ongoing cocreation and re-creation of academic knowledge/work. (p. 113)

That belief is what has driven this thesis and supported both its location within the field of Māori studies, and within a New Zealand university. It is a collaboration of Māori knowledge and academic development knowledge, with an intention to 'center' the Indigenous knowledge. Also, as academic development knowledge within the academy is not static, this thesis is an attempt to ensure that Māori are an integral part of its ongoing co-creation and re-creation. 


\subsection{Thesis title and structure}

Initially this thesis had a working title of 'Reasserting Kaupapa Māori Academic Development'. It was meant to highlight Bishop's (2003, p. 223) assertion that kaupapa Māori is essentially about re-establishing Māori interests, values and people and placing them at the centre of any development in New Zealand, hence the notion of reassertion. The original title did not mean to suggest that universities in New Zealand have ever historically 'asserted' kaupapa Māori but it alluded to a pre-colonial period when kaupapa Māori were central to everything in Aotearoa ${ }^{5}$. Unfortunately, since that full explanation could not be provided on the title page, the phrasing proved problematic.

Instead, the word 'rethinking' has been used, which was a concept raised in Nakata's (2007) work, Disciplining the Savages, Savaging the Disciplines. Nakata suggested that the cultural interface of Indigenous people in the academy, "first requires a rethinking of the space in which Islanders interact with others" and "second...requires deeper consideration of the ways in which the specificities of Islander experience are constituted in that space" (p. 196). Therefore, the notion of rethinking those spaces is both useful and relevant for the title and approach of this thesis. It signals that this thesis is about how to reconceptualise academic development in New Zealand universities in a way that provides space for Māori.

This thesis is made up of six chapters. To address the two key research questions and consider the ideas outlined earlier, the rest of this thesis is organised as follows:

\section{- Chapter Two: Literature Review}

Chapter Two contains a review of relevant literature on the topics raised by the key research questions of this thesis. It begins by canvassing the literature about kaupapa Māori, considering its origins and range of definitions, and summarising the criticisms and challenges often faced by

\footnotetext{
${ }^{5}$ Aotearoa is a Māori name often used as an alternative to the colonial name 'New Zealand'.
} 
kaupapa Māori research and researchers. It then goes on to review existing literature about the experiences of Māori academic staff, how they have formed their academic identities and what impact that has on them and their work. It also considers the challenges and goals identified in the literature in relation to Māori academic practice, particularly regarding the key activities of teaching and research, and it extends into Indigenous and other perspectives on all of those subjects. Finally, this chapter examines the existing and potential Māori academic development models identified in the literature, before closing with a brief summary.

- Chapter Three: Methodology and Methods

The third chapter focuses on the methodologies and methods used to conduct the research that underpins this thesis. It elaborates on the kaupapa Māori literature introduced in Chapter Two by discussing the principles of kaupapa Māori research methodology. It then introduces the key method applied in this thesis, Interpretative Phenomenological Analysis (IPA), including a step-by-step account of the processes used to collect and analyse the research data.

- Chapter Four: Case Studies

Chapter Four presents the core data generated for this thesis and shares the results of in-depth interviews conducted with Māori academic staff based at New Zealand universities. The findings of the interviews are presented in the form of three case studies:

- Case Study One focuses on an interview with one Māori academic working at a New Zealand university;

- Case Study Two is centred on a group interview with four Māori academics who all work at the same New Zealand university; and

- Case Study Three is based on individual interviews with five different Māori academic staff who work in a New Zealand university. 
Each case study begins with an introduction that establishes the context for the study, which is then followed with a full IPA analysis of the interview data, including significant themes and relevant examples.

\subsection{Chapter summary}

Set against all of the aforementioned issues and histories, this thesis is about illuminating the Māori academic development opportunities that encourage Māori academic career progression and quality Māori scholarship, affirming Māori academic identities, and allowing Māori academics to act with an integrity that aligns with their cultural values. It continues the conversation that began with Bishop's (2003, p. 223) argument that kaupapa Māori theory and practice is about "the reassertion of Indigenous Māori cultural aspirations, preferences and practices". This thesis is an attempt to do just that, in relation to Māori academic development. Thus, not only is this thesis grounded in kaupapa Māori theory but it also provides practical strategies 
that address the challenge of retaining and supporting the success of Māori academics in New Zealand universities. It is about rethinking how academic development can be offered in ways that reassert Māori cultural aspirations, preferences and practices - and here the word reassert has been specifically selected to resonate with Bishop's point that, at one time, kaupapa Māori was the custom in Aotearoa. Therefore the rethinking in this thesis is an attempt to centre or refocus on Māori experiences and perspectives, in this case in relation to Māori academic experiences and Māori academic development, and shift the experience of Māori academics away from the margins. 


\section{Chapter Two: Literature Review}

In this thesis, I have taken a kaupapa Māori approach to the topic of Māori academic development. It meant engaging with a wide range of literature about kaupapa Māori philosophy and research, Māori and Indigenous academic identity and experiences, and academic development principles and practices. This chapter is a synthesis of the literature in those three areas as they relate to the research questions set out in Chapter One, and foregrounds the discussion to follow in Chapter Five.

\subsection{Kaupapa Māori}

The literature review for this thesis began with texts about kaupapa Māori that helped to establish the project's research paradigm, which in turn informed its theoretical framework, methodology and methods. A research paradigm is influenced by the researcher's worldviews and is underpinned by a set of guiding beliefs and principles (Denzin and Lincoln, 2011). Higgins (2004, p. 1) and Ka'ai (2000, p. 12) have both written about the centrality of kaupapa Māori to Māori studies research. Their work, kaupapa Māori was the most logical and obvious research paradigm within which to conduct a Māori studies doctoral study about the experiences and academic development needs of Māori academic staff. However that conclusion was not reached without careful consideration of the history of kaupapa Māori and its varied, and sometimes contradictory, explanations and definitions. In the process of this review, kaupapa Māori emerged as not only a research paradigm, but also a body of knowledge, a theory, a philosophy, a methodology and a call to action. In addition, a number of criticisms about kaupapa Māori research and researchers were revealed. In the following section, I discuss each of these points in turn, and provide an explanation for why I chose kaupapa Mãori as the theoretical framework for this thesis.

\subsubsection{The origins of kaupapa Māori}

Over the last 30 years, kaupapa Māori has become "an influential and coherent philosophy and practice for Māori conscientisation, resistance and 
transformative praxis to advance Māori cultural capital and learning outcomes" (G. H. Smith, 1997, p. 423). However, the notion of kaupapa Māori as a way of thinking and being Māori is not new (Mahuika, 2008; Nepe, 1991; L. T. Smith \& Reid, 2000; Taki, 1996). Credit is most commonly given to Māori academics Linda Tuhiwai Smith (nee Mead) and Graham Hingangaroa Smith (Penetito, 2005; L. T. Smith \& Reid, 2000), for the emergence and scholarly articulation of the Māori approach to research practice that has come to be known as kaupapa Māori. This is primarily because of the volume and detail of the work that they have produced or supervised in the field of Mãori education since the 1990s (G. H. Smith, 1990a, 1990b, 1991b, 1992a, 1993, 1995a, 1997, 2003; L. T. Smith, 1992b, 1992c, 1995b, 1999, 2000b). Linda Smith is particularly acclaimed for her book, Decolonising Methodologies (1999), which gained national and international attention for its rejection of Western methodologies in lieu of Indigenous research philosophies and practices. Much of the kaupapa Māori literature developed since has located itself in relation to Smith's book, either to align with it or to claim a point of difference, cementing the text's centrality and status within kaupapa Māori discourse.

The Smiths' work followed a period of massive Māori urbanisation in the 1950s and 1960s. It also coincided with a Māori cultural revival in the 1980s and 1990s that has generally been accepted as having raised "a political consciousness among Māori people that promoted the revitalisation of Māori cultural aspirations, preferences and practices as a philosophical and productive educational stance and resistance to the hegemony of the dominant discourse" (Bishop, 2010, p. 133). Increased Māori consciousness resulted in not just the development of a kaupapa Māori education system, which provided an alternative Māori educational pathway for children in New Zealand. As Professor of Māori education, Wally Penetito (2005) explained, it also had major impact on mainstream education, prompting increased Māori content and engagement in programmes from early childhood through to tertiary education (p. 45). These developments inspired many Māori people to begin "to assert transformative actions to 
deal with the twin crises of language demise and educational underachievement for themselves" (G. H. Smith, 1997, p. 171).

Scholarly work about kaupapa Māori has since broached a number of other disciplines and fields of study, such as environmental studies (Barrett-Ohia, 2006), health (Glover, 2002; Morris, 2007; Rowe, 2007; Saba, 2007; Taiaroa, 2007), law (Penehira, Cram, \& Pipi, 2003), Māori studies (Higgins, 2004), media studies (Mane, 2009; Mercier, 2007), philosophy (Warren, 2006), psychology (Thompson \& Barnett, 2007), science (Cheung, 2008; MoewakaBarnes, 2006; G. Stewart, 2007) and sociology (Eketone, 2008; Penetito, 2005). However, the primary location of literature about kaupapa Māori is still to be found within the broad field of education (see, for example, BevanBrown, 2005; Bishop, 1998, 2003; Bishop, Berryman, Cavanagh, \& Teddy, 2005; Bishop et al., 2009; Bishop \& Glynn, 1999; Cooper, 2012; Curtis, Townsend, Savage, \& Airini., 2008; Irwin, 1994; Kana \& Tamatea, 2006; Matthews, 2001; Morrison, 2000; Ratima, 2008; Royal, 2012; B. Webber, 1996; Wilkie, 2006). Thus, the education origins and emphasis of kaupapa Māori research are appropriate for this thesis topic because, although this thesis is located within the field of Māori studies, it has a strong focus on the academic development subset of higher education research.

\subsubsection{Definitions of kaupapa Māori}

Despite the relative clarity around the emergence of kaupapa Māori literature since the 1990s there is, as yet, no absolute consensus about what kaupapa Māori is or should be. At its core, the term kaupapa Māori is thought to refer to a body of Māori knowledge "that has distinct epistemological and metaphysical foundations" (Nepe, 1991, as cited in Mahuika, 2008, p. 2). Nepe (1991) described kaupapa Māori as, "esoteric and tuturu Māori" and a "knowledge that validates a Māori world view" (p. 15). Māori studies scholar, Dr Rawinia Higgins (2004), built on this notion of kaupapa Māori as knowledge by putting it within a disciplinary context, and suggested that, "from a pure Māori Studies perspective, the term Kaupapa Māori means the "groundwork" or the "medium" (H. W. Williams, 1992) 
from which Māori knowledge, including te reo me ngā tikanga Māori, can be validated" (p. 8). Tania Ka'ai (2000), a professor of Māori development, reinforced this notion of Māori studies having close connections to kaupapa Māori:

Māori Studies in the University therefore serves as a space for teaching and research to be undertaken which recovers our histories, reclaims our lands and resources, restores justice and preserves our language and traditions within a culturally specific framework called Kaupapa Māori (p. 12).

Māori academics Henry and Pene (2001) reiterated the idea of kaupapa Māori having origins in Māori traditions by describing it as "traditional Māori ways of doing, being, and thinking, encapsulated in a Māori world view or cosmology" (p. 235). From this core concept, however, have sprung multiple terms, understandings and applications of kaupapa Māori including, but not limited to kaupapa Māori philosophy, kaupapa Māori theory, kaupapa Māori methodology, kaupapa Māori praxis, kaupapa Māori pedagogy, kaupapa Māori curriculum and kaupapa Māori mana wahine (L. T. Smith \& Reid, 2000). Many of these terms refer to the application of kaupapa Māori and have been set aside for discussion in Chapter Three.

In some cases, where scholars have described kaupapa Māori as both a philosophy and a theory they have used the terms interchangeably (Mahuika, 2008; Paki, 2007). For example, Māori researcher Anaru Eketone (2008) suggested that in academic contexts kaupapa Māori "usually refers to a Māori philosophical approach" (p. 1). Later in the same text he described it as, "theory that focuses on challenging well-established Western ideas about knowledge" (Eketone, 2008, p. 1).

When some scholars described kaupapa Māori as a theory it was in the context of resisting or challenging the perceived status quo (S. Walker, Eketone, \& Gibbs, 2006). For example, Smith (1995a) described kaupapa Māori as "a theory of change" (p. 21) and Māori scholars Pihama, Cram and Walker (2002) argued that Smith selected the word 'theory' in order to 
develop "a counter-hegemonic practice" and challenge "the narrow, Eurocentric interpretation of 'theory'” as it has been applied within New Zealand education (p. 33). In a similar vein, Māori education researcher Sheilagh Walker (1996) contended that, "Kaupapa Māori Theory is a resistance against European dualistic paradigms; which challenges, critiques and poses alternatives to the discourse of violence, allowing Māori to define themselves" (p. iii). This was echoed by kaupapa Māori scholar Leonie Pihama (2001), who argued that, "Kaupapa Māori theory must be about challenging injustice, revealing inequalities, seeking transformation" (p. 110), and Māori academic Garrick Cooper (2012), who described kaupapa Māori as, "a response and challenge to the dominance of scientific methodologies and practices, and the Euro-reason that supports these" (p. 66). Thus, in order to conduct research in a kaupapa Māori way, it needs to have an element of resistance or a transformative component or quality. McMurchy-Pilkington (2001) rationalised this approach by concluding that, "kaupapa Māori can be described as critical theory at a localised level" (p. 73). Similarly, Mahuika drew on Smith's description of kaupapa Māori as "a social project" and cited Te Kōhanga Reo and Kura Kaupapa Māori as contemporary examples of such resistance and transformation (L. Smith, 2000, p. 233, as cited in Mahuika, 2008, p. 2).

The most common combination in the literature, however, is kaupapa Māori as both an underpinning set of beliefs or assumptions, referred to as a 'philosophy', a 'theory' or in some instances as a 'discourse' or 'framework' (Bishop et al., 2005; Ka'ai, 2005; Pihama, 2001), and a set of practices or actions with which to engage, in this context, in scholarly research. Many authors raised this notion of a duality in relation to kaupapa Māori. They suggested that kaupapa Māori was both a "philosophy and practice of 'being Māori'” (G. H. Smith, 1992a, p. 1), a "proactive theory and practice" (Bishop et al., 2005, p. 7), a theory and praxis (G. H. Smith, 1997), a "set of philosophical beliefs and a set of social practices (tikanga)" (Henry \& Pene, 2001, p. 237) or a "Māori way of thinking (epistemology) and a Māori way of doing things within the western academy" (Ka'ai, 2000, p. 12). 
The additional notion of kaupapa Māori as 'action' has been emphasised and expanded by many writers. Graham Smith (1997) first coined the transformative praxis element of kaupapa Māori but his idea was embraced and elaborated on by others (Bishop et al., 2005; Mane, 2009; Paki, 2007; Penetito, 2005; S. Walker, 1996). Māori education researchers Bishop, Berryman, Cavanagh and Teddy (2005) contended that kaupapa Māori, “seeks to operationalise Māori people’s aspirations to restructure power relationships to the point where partners can be autonomous and interact from this position rather than from one of subordination or dominance" (p. 8). They emphasised the active transformational capacity of kaupapa Māori to address power imbalances.

An additional element to kaupapa Māori research, often noted in the literature, revolves around the need for it to be controlled by Māori. Bishop (1999) saw kaupapa Māori as providing a form of Māori self-determination. Māori legal scholar Ani Mikaere (2011) described kaupapa Māori as "a Māori authored body of work that asserted the requirement for Māori to be participants in, rather than merely the objects of, research" (p. 30). Tawhai, Pihera and Bruce-Ferguson (2004) asserted that in order to be kaupapa Māori research, it must be "completed for Māori" and "not research that is completed with a global audience in mind" (p. 334). They drew on Smith's (1995b) proposition that kaupapa Māori research is simply research by Māori, for Māori, and with Māori - an idea recounted many times since (see, for example, Mikaere, 2011; Royal, 2012; S. Walker et al., 2006). Cunningham (2000), a Māori health researcher, developed this idea into a Māori research taxonomy. He built on the notion that kaupapa Māori research requires a high degree of Māori control. He argued that would ensure that Māori analysis occurred and would result in the production of Māori knowledge (p. 65). He located kaupapa Māori research on the far end of a Māori research continuum, preceded by 'Māori-centred research', 'Research involving Māori' and 'Research not involving Māori'. He distinguished kaupapa Māori research from Māori-centred research with the assertion that Māori-centred research had a dual accountability to both 
mainstream and Māori expectations, while kaupapa Māori research did not (p. 65). However, he also relied on Irwin's (1994) definition of kaupapa Māori research, citing that it needed to be both "culturally relevant and appropriate, while satisfying the rigour of research" (p. 27). Thus, the absolute boundary between Māori-centred and kaupapa Māori remains unclear, aside from the contention that kaupapa Māori research needs to have a high degree of Māori control and autonomy.

\subsubsection{Criticisms and challenges of kaupapa Māori}

In their literature review of kaupapa Māori research, Smith and Reid (2000) proposed that, "kaupapa Māori theory has had the dual effect of providing both the theoretical 'space' to support the academic writing of Māori scholars as well as being the subject of critical interrogation, analysis and application" (p. 6). In the spirit of the second prong, my review of literature relating to kaupapa Māori as a research paradigm would be incomplete if it failed to interrogate or at least consider the criticisms of kaupapa Māori.

One set of concerns about kaupapa Māori research relates to questions about quality (Openshaw \& Rata, 2008). Kaupapa Māori researcher Fiona Cram (1993) noted that, "the dominance of Pākehā history and culture means that Māori forms are often seen to lack 'mainstream' legitimacy" (p. 28). Kaupapa Māori critics have certainly taken that position in their writing. Rata (2007), one of the most vocal in this regard, suggested that "mātauranga Māori and kaupapa Māori have the status of science in our universities yet, unlike science, are protected from critical scrutiny" (p. 38) a view reiterated by Marie (2010) who suggested that "it is questionable whether the products of kaupapa Māori research can be said to constitute empirically validated knowledge" (p. 295). While some may believe that the idea of critiquing mātauranga Māori (Māori knowledge) or kaupapa Māori research is inappropriate, to suggest that all kaupapa Māori scholarship is not subject to high research standards and scrutiny is itself a sweeping and unsubstantiated statement, and undermines the value of the contribution 
that kaupapa Māori research can and has made in a wide range of disciplines and research areas.

Another criticism is that some of the literature, such as Pihama's (2001) articulation of kaupapa Māori as a form of post-colonial resistance, has the effect of 'othering' Māori. Lopez (1998) used the term 'standpoint theory' to describe kaupapa Māori, as well as a range of other Indigenous and minority ways of knowing. He concluded that, as a standpoint theory, kaupapa Māori is alternative or 'other'. Māori social scientist Helen Moewaka-Barnes (2000) explained how this might have happened:

Kaupapa Māori begins as a challenge to accepted norms and assumptions about knowledge and the way it is constructed and continues as a search for understanding within a Māori worldview (Bishop, 1995). Thus, kaupapa Māori is often in the position of being defined in relation to or compared with dominant paradigms, which have now become 'ordinary'. If kaupapa Māori is about taking for granted a Māori worldview (G. H. Smith, 1992a), then this discourse in itself subverts our right to be Māori ordinary. We are now the other in our own country. (p. 4)

To counter that subversion, Higgins (2004) contended that, "kaupapa Māori research should be located 'organically' from within the Indigenous worldview and not on the periphery as the 'other'” (p. 8). Thus, while writers operating within non-kaupapa Māori research paradigms may 'other' kaupapa Māori theory and research, it is important that research by Māori, about Māori and for Māori does not do the same.

Another criticism of kaupapa Māori research is that the 'insider' perspective, created as a consequence of the 'by Māori, for Māori' approach, is less rigorous. This view was hotly contested by Penetito (2005) who argued that, "insiders have as much and no less insight than outsiders with regard to perceptions about any phenomenon" (p. 204). Bishop (1999) also railed against this criticism. He described researcher involvement as a form of "personal investment" that constituted a specific "way of knowing" unique 
to kaupapa Māori, and that was "determined and defined by the research community itself" (pp. 3-4).

An additional criticism is the risk that by framing kaupapa Māori too rigidly it will, in turn, become exclusive or even oppressive (Mahuika, 2008). Māori researcher Cat Gwynne (2009) described this as a paradox and suggested that it, "raises questions around the revitalisation movement of Kaupapa Māori, and whether or not, in its very attempt to revitalize culture, it has also ironically taken on the racist exclusivity and patriarchal interpretation of gender that it sought to dismantle" (p. 8). Bishop (2003) referred to this as a form of essentialism "whereby particular groups come to be described in terms of fundamental, immutable characteristics" (p. 224). The same point was raised more provocatively by Lopez (1998), who criticised kaupapa Māori theorists for taking a position that tended to "homogenize a population in favor of essentialist totalizing narratives" and denied that, "individuals in any cultural context are multiply situated/positioned" (p. 227).

While there may well be authors, researchers and practitioners who use their knowledge and skills in te reo and tikanga Māori to alienate or disenfranchise others, Smith and Reid (2000) argued that this behaviour was not consistent with the principles of kaupapa Māori. That knowledge, they noted,

is not owned by any grouping nor can it be defined in such ways that deny Māori people access to its articulation. What this means is that Kaupapa Māori must of necessity be diverse and recognise the diversity within our people; women, men, tamariki, kuia, koroua, rangatahi, whānau, hapū, iwi, urban Māori, these are some examples of the diversity within our people and therefore Kaupapa Māori needs to be accessible and available to all. It must also ensure analysis that is able to take into account, both in principles and practice, the diversity of Māori communities. (L. T. Smith \& Reid, 2000, p. 14) 
This notion of diversity within kaupapa Māori counteracts the argument of kaupapa Māori being exclusive or essentialist.

Even though much of the literature about kaupapa Māori has been education-focussed, little has been set within the context of the Western university. Not so much a criticism, but a possible limitation on kaupapa Māori, is the notion espoused by Māori health researcher Maureen Holdaway (2002):

Essentially kaupapa Māori research should be controlled by Māori institutions (such as iwi) while Māori-centred research may be within a non-Māori organisation (such as a university). It is also reasonable to expect that kaupapa Māori research will be characterised by wholly Māori participation and the use of Māori specific methods, while these characteristics would not be a criterion for Māori-centred research. (pp. 74-75)

However, this location-based distinction between kaupapa Māori and Māoricentred work based was countered by Māori researcher Jo Mane’s (2009) assertion that, "kaupapa Māori initiatives show variability" and exist "in different settings" (p. 7). In fact, Māori neurobiologist Melanie Cheung (2008) suggested that Māori research may be enhanced by the "complementarity of having both Māori and Western worldviews to draw on" (p. 5).

Finally, another of the criticisms of kaupapa Māori is its supposed lack of provenance. Marie (2010) described kaupapa Māori research as simply a "localised variant of postcolonial studies" and rebuked its lack of "epistemic parity with standard accounts of scientific methodology" (p. 293). Her conclusion aptly demonstrated the behaviour warned against by Te Punga Somerville (2007):

A crucial dimension of the colonial gaze is the obsessive 'emptying out' of the landscape so that any space can be understood as ready to be occupied (which is why, of course, the simple fact of continued Māori existence is a powerful and anxiety-raising challenge to the colonising power). The extent to which we point to an empty landscape - including an empty 
critical landscape - is the extent to which we assent to our own removal from that landscape. (p. 35)

Instead, Māori academic Matiu Ratima (2008) considered a range of possible philosophical origins for kaupapa Māori and noted:

On the one hand, Eketone (p. 3) cites Kiro and her assertion that kaupapa Māori is quite clearly Freireian in orientation and therefore centred on Critical Theory, while on the other hand, Bishop (as cited in L. T. Smith, 1999, p. 186) states that Kaupapa Māori has developed in response to the failure of Critical Theory to deliver its emancipatory goal. In between is Graham Smith who suggests that kaupapa Māori is aligned with, but not centred on, Critical Theory (also cited in L. T. Smith, 1999, p. 186). (p. 2)

Thus, while the location of kaupapa Māori within the theoretical orientation 'landscape' is unclear, it is not for a lack of epistemology but rather due to an over-abundance of possible origins, purposes and placements.

\subsubsection{Concluding comments about kaupapa Māori}

In its original form, kaupapa Māori was known as simply a body of Māori knowledge that informed and expressed a Māori worldview (Henry \& Pene, 2001; Nepe, 1991). However, the notion of kaupapa Māori as a theory or philosophy within which Māori research and development could occur, grew out of the Māori cultural renaissance of the 1970s and 1980s. In the last 30 years, the kaupapa Māori discourse has grown to include philosophy, theory, methodology, and praxis (L. T. Smith \& Reid, 2000). Despite its strong origins as a theory in Māori education, kaupapa Māori has been actively applied in a wide range of disciplines and fields. Within Māori studies, kaupapa Māori has evolved as a foundation or cultural framework within which Māori studies scholars can conduct their work (Higgins, 2004; Ka'ai, 2000).

Kaupapa Māori has commonly been described as having dual forms, as both theory and practice (Bishop et al., 2005; Henry \& Pene, 2001; Ka'ai, 2000; G. H. Smith, 1992a, 1997). It has been viewed by some as needing to engender 
an element of resistance to the status quo (Cooper, 2012; L. Smith, 2000, p. 233, as cited in Mahuika, 2008, p. 2; McMurchy-Pilkington, 2001; Pihama, 2001; Pihama et al., 2002; G. H. Smith, 1995a; S. Walker, 1996; S. Walker et al., 2006). Others described it as having a transformative component or quality, which was seen as a way to address oppression, colonisation or power imbalances (Bishop et al., 2005; Mane, 2009; Paki, 2007; Penetito, 2005; G. H. Smith, 1997; S. Walker, 1996). The assertion that Māori must control kaupapa Māori research was another common quality noted in the literature (Bishop, 1999; Cunningham, 2000; Mikaere, 2011; Royal, 2012; L. T. Smith, 1995b; Tawhai et al., 2004; S. Walker et al., 2006).

The accusations that kaupapa Māori research lacked legitimacy because it was not open to critique, its 'insider' research practice lacked rigour, and it had no epistemic provenance, have been rebutted in this review. Instead this review found that kaupapa Māori research was subject to both scholarly and cultural critique and rigour (Bishop, 1999; Irwin, 1994; Penetito, 2005) and had an over-abundance of epistemology (Eketone, 2008; Ratima, 2008; L. T. Smith, 1999). Finally, the criticisms that kaupapa Māori could be exclusive or oppressive, could not be set within the context of a Western university, and had the effect of 'othering' Māori, are negated by the kaupapa Māori principles that the research be by Māori, about Māori and for Māori (Mikaere, 2011; Royal, 2012; L. T. Smith \& Reid, 2000; S. Walker et al., 2006).

Māori educationalist Melinda Webber (2009) noted that, "like any theory or ideology, kaupapa Māori can be liberating and it can be constricting” (p. 3). By the same token, situating this thesis within a kaupapa Māori research paradigm has both a 'liberating' and 'constrictive' effect. I have developed this thesis with the duality inherent in the kaupapa Māori theory and action dichotomy in mind. It draws on and incorporates Māori worldviews that inform Māori academic experiences (kaupapa Māori theory), and also sets out an opportunity for resistance and transformation in the realm of Māori academic development (kaupapa Māori practice). 


\subsection{Māori academic experiences}

A key focus of this thesis is the experiences of Māori academics, their academic identities, practices, challenges and goals. However, in part due to the paucity of literature about Māori academics but also because of the richness that such sources bring to the discourse, this review widens in places to include Indigenous experiences of the academic role. It encompasses not only factual aspects, such as employment parity, but also what Dei, Hall, and Rosenberg (2000) defined as a new form of Indigenous knowledge that extends beyond "traditional norms and social values" to include "mental constructs that guide, organise, and regulate the people's way of living and making sense of their world" (p. 6).

Some hints of those possible 'mental constructs' came from Māori and Indigenous academics who shared their own observations of what motivated their peers. Mead (1997) suggested that for Māori studies academics, the production of scholarship came from a desire "to build up the mana" of the subject since "no one else can do it for us" (p. 48). In contrast, an Indigenous Australian lecturer explained that her/his drive to be an academic "was fuelled by outrage at the historical and currently maintained depth of racism, ignorance and power imbalance in Australia" (Biermann \& Townsend-Cross, 2008, p. 149).

Whatever their motivation, the literature suggested that Māori and Indigenous academics had a different experience of academic life from their non-Indigenous colleagues (Page \& Asmar, 2008). For many of the scholars, this difference was viewed as a duty to their people, something to be acknowledged and carried, often regardless of personal cost (Irwin, 1997; L. T. Smith, 1992b). For others, that difference was marked by extra responsibilities, such as giving "the Māori perspective" on any Māori matter, addressing "potential problems with difficult Māori subjects or ethics" (Kukutai \& Webber, 2011, p. 6) and providing "pastoral care, extensive academic support and being a welcoming confidant who is identifiably Māori" (Nikora, Levy, Henry, \& Whangapirita, 2002, pp. 21-22). 
For some authors, the difference between Māori and non-Māori academics was marked out as a special privilege or power. For example, non-Māori academics Openshaw and Rata (2008) suggested that Māori academics had the ability to act as "politically powerful interest groups that derive their power to condemn from culturalist principles" (p. 19). Rata (2007) commented that these groups "claim a degree of 'cultural sacredness' - that is, a right not to be offended by critical enquiry, especially from those not of their ethnicity or religion" (p. 38). However, she provided no compelling evidence to support her contention that Māori academics somehow systematically and with great effect subjugate other University committees or staff. For each example of Māori 'cultural sacredness' that Rata and Openshaw (2008) gave in their article (such as, a Māori blessing of a new a university building, and the addition of a cultural safety component in a Polytechnic nursing programme) there were ample examples in other literature of equal or worse examples of anti-Māori discrimination or oppression in an academic context (Alton-Lee, 2006; Coxhead, 2006; Gallhofer et al., 1999; H. White, Oxenham, Tahana, Williams, \& Matthews, 2009). Rata's demotion of Māori to interest group status neglected the inherent Treaty relationship that exists in New Zealand, including within its universities. Her broad brushstrokes statement that, "Treaty adherence in university life is the single most effective mechanism in ensuring that culturalist ideology becomes the accepted and uncritiqued way of doing things" (Rata, 2007, p. 38) completely denied the origins of universities in New Zealand, which are all built on land either gifted by or taken unconscionably from Māori (L. T. Mead, 1996, p. 96; Mercier et al., 2011, p. 82). It was also contrary to the conclusion drawn by Indigenous Australian academic Dr Douglas Morgan (2003), who argued that Western knowledge institutions only appear to accommodate indigenous knowledge. He concluded that, "rather than Indigenous scholarship being pursued through Indigenous methodologies in higher education institutions, it is still Western methodologies which are perpetuated" (Morgan, 2003, p. 45). 
With such diversity of personalities and institutional outlooks, it would be unrealistic to assume that there was one experience of being a Māori academic working at the "cultural interface" (Nakata, 2004b) of the university environment, itself "a space of many shifting and complex intersections between different people with different histories, experiences, languages, agendas, aspirations and responses" (Nakata, 2007, p. 199). While Nakata emphasised the challenges for Indigenous academics who have to operate in that overlap between the Indigenous and academic worlds, Durie (2004) wrote about the opportunities provided by such a convergence:

Rather than contesting relative validities, there are an increasing number of indigenous researchers who use the interface between science and indigenous knowledge as a source of inventiveness. They have access to both systems and use the insights and methods of one to enhance the other. In this approach, the focus shifts from proving the superiority of one system over another to identifying opportunities for combining both. (p. 8)

This review of literature about the experiences of Māori and Indigenous academic working at the 'cultural interface' in universities reveals a number of common threads that relate to the broad areas of academic identity, the academic environment, teaching and research, and each of these is set out in the following sections.

\subsubsection{Māori and Indigenous experiences of academic identity}

The literature about academic identity is vast and varied. While having much in common, there is diversity within the Māori academic community in terms of experience, beliefs, and practices, and each of these has an impact on how individuals define and write about their identity. For example, Te Punga Somerville (2010) suggested that there are difficulties in writing about identity because "the term has acquired rather bulky luggage in the academy" (p. 41). In contrast, Nakata (2006) simply concluded that "thick skins and secure identities are an essential job requirement" for Indigenous academics (p. 266). Bishop (2003) also warned against taking an 
essentialist view that limited who was able to claim to be Māori based on a set of "fundamental, immutable characteristics" (p. 224). Despite these cautions, a number of scholars have written productively about Māori and Indigenous academic identity, as discussed below.

\subsubsection{Hybrid, multiple and fluid identities}

One of the key themes to emerge about Māori academic identity is the notion that it is prone to change and was dependent on context. Māori scholar Paul Meredith (1999) described a concept of cultural hybridity that allowed him to identify as neither Māori nor Pākehā but as Māori Pākehā. Māori writer Moeke-Maxwell (2005) built on Meredith's earlier work but applied it to Māori women, and found that a similar hybridity also emerged. Penetito (2005) explained that Māori people can develop hybridised identities that accommodate or blend both "individual identities" and “collective identities" (p. 80) - an idea reinforced by Irwin (2007) who emphasised how for Māori women "the personal is collective" (p. 182). Ballara (1998) described this phenomena as Māori "coping with multiple identities" (p. 335) - an idea that was reinforced by Webber's (2009) description of the "complex, challenging and often fraught" nature of being a

"Māori researcher, [...] teacher, mother, daughter, lecturer, language learner, and PhD student" (p. 1). Extending both the notions of hybridised and multiple identities, Christiansen (2000) suggested that the competing roles of being a Polynesian, woman, mother and scholar, required a degree of fluidity around academic identity formation and maintenance. Other Indigenous and non-Indigenous writers also highlighted the notions of hybridity, multiplicity and fluidity in relation to Indigenous academic identities (Asmar \& Page, 2009; Christiansen, 2000; Kaomea, 2001; Pewewardy, 2004; Sadao, 2003). However, Villenas (1996) warned that, "scholars/activists of color need to understand the ways in which we manipulate our multiple, fluid, clashing and colonized identities and how our identities are manipulated and marginalized in the midst of oppressive discourses” (p. 214). Her concern may extend to Māori academics. Some of the 'fluidity' of Māori academic identities may be necessary in order to 
simply survive and cope in the academy. Mead (1996) found this notion of multiple identities for Māori academic women to be "problematic" (p. 119).

For many Māori and Indigenous academics, the identities that they had developed in order to undertake their academic work were anchored by their ethnic identities. Māori demographer Tahu Kukutai and Webber (2011) explained that, "being both Māori and an academic can be challenging when both identities must be simultaneously foregrounded" (p. 17). For Irwin (1997), the idea of assimilating "into the dominant culture (Pākehā and male) of the university" was "not an acceptable option" (p. 59). Instead she found that her time as an academic often felt like she was "'caught between a rock and a hard place' - not a comfortable position to be in!" (p. 61). Corntassell (2003), reflecting on his experience as a Tsalagi person working in his first tenured position in a Western university, concluded that,

rather than adopting a "walking in two worlds" philosophy, I was Tsalagi first and foremost. My relations with friends, family, kinfolk, Tsalagi homelands, and ceremonial life helped me to cope with the artificiality of university life" (p. 170). Similarly, Black legal scholar, Williams (1991), acknowledged her multiple identities but concluded that "being black has been the most powerful social attribution in my life”. (p. 256)

In contrast, Fordham identified a phenomenon of racelessness amongst American high school students who "give up aspects of their identities and of their indigenous cultural system in order to achieve success as defined in dominant-group terms" (as cited in Christiansen, 2000, p. 192). While not a common strategy discussed in the Māori academic identity literature, Elizabeth McKinley (2002), a Maori education scholar, wrote about a Māori woman scientist who chose not to admit to her Māori ethnicity in her professional life, for fear of adverse consequences for her career. She also relayed the experiences of a second Māori woman who felt "pre-judged" because of her Māori name, and described how that impacted negatively on her perceived credibility and opportunities as a scientist (McKinley, 2002, p. 113). 


\subsubsection{Inauthenticity}

Significant questions relating to authenticity surfaced in the literature. Webber (2009) asked who has the 'right' to be a Māori academic, while Mead (1997) wondered if Māori academics, "in trying to be multi-tribal, national, international and academic in a Pākehā sense...have missed some vital lessons from our Māori heritage?" (p. 44). Māori scholar Dr Cheryl Smith (2000a) clarified this idea further:

The idea of place is critical to Māori narrative. Identity and place are intimately linked. Māori assess knowledge very often on a person's experience of that knowledge. Assessments of speakers by Māori is often made around the idea of whether or not you as a speaker are speaking from experience with a direct connection to the events that you are describing. This of course is one of the key criticisms of Māori academics. (pp. 49-50)

What was unclear from Smith's analysis was whether that criticism was valid or just an avenue to inauthenticate those seen to be "sell-out" Māori academics (S. M. Mead, 1983, p. 344). It may be part of what Mead (1996) saw as a Māori "anti-academic stance" taken by those who "privilege experience-only over any form of theory" (p. $112 \& 113)$.

In addition, the suggestion that Māori scholars need to "prove their suitability in terms of cultural competence" was criticised by others who thought "it may be largely irrelevant" (Kukutai \& Webber, 2010, p. 25). Instead, Kukutai and Webber (2011) posited that, "what makes one a real Māori, a real social scientist, or a real Māori social scientist is never clearcut, as different contexts required different discourses" (p. 9). In contrast, Te Hiwi (2007) suggested that, "when considering claims to space(s) within disciplines such as psychology, discussions of who is and is not authentically Māori [...] are vital” (p. 5).

Teaiwa (1995) wrote, "our presence in the academy [is] enabled by the absence of our authenticity as natives" (as cited by Christiansen, 2000, p. 190). Even more extreme has been the experience of Native American 
scholars in the United States who have grappled with 'identity frauds', people who claim Indigenous ancestry, without verifiable proof, and take on academic posts as native 'experts' (Pewewardy, 2004). The New Zealand literature did not suggest that this was a significant issue for the recruitment of Māori academic staff in New Zealand universities, despite ethnic identification on appointment to an academic position being based entirely on self-identification.

\subsubsection{Primacy of Māori identity}

A number of authors have written about the importance of practicing and demonstrating Māori culture in the context of building or maintaining an academic career (for example, Irwin, 1997; M. Maaka, 2004; Penetito, 2005; L. T. Smith, 1992b; M. Webber, 2009). For some authors, a key aspect of identifying as a Māori academic was about making it 'normal' (Pipi et al., 2004; Sharples, 1995; S. Walker, 1996) and challenging "the 'cultural conquest' mentality of mainstream education including universities" (Ka'ai, 2005, p. 6). As Pipi et al. (2004) explained, "to put it succinctly, at the core of Kaupapa Māori is the catch-cry, "To be Māori is normal” (pp. 143-144). Kaupapa Māori was therefore about the creation of spaces for Māori realities within wider society" (pp. 143-144). In a similar vein, Penetito (2005) noted that, "being Māori goes all the way down" (p. 306) - in other words, it is the core or root of Māori academic identities. Ratima (2008) suggested that Māori academics must continue to make space in the academy for Kaupapa Māori "until speaking, thinking, feeling, behaving and being Māori becomes accepted as 'the norm' in our country and within the Pākehā academy" (p. 3).

\subsubsection{Indigeneity}

While this thesis is focused on the experience of Māori academics working in New Zealand universities, a growing number of Māori are undertaking study and academic work overseas, and many are actively identifying with larger Indigenous groups and issues as a result. Increasingly, Māori academics are researching and publishing in the field of Indigenous studies and are 
involved in international networks of Indigenous scholars (see, for example, the work of organisations like the Centre of Research Excellence, Ngā Pae o te Māramatanga, and the Native American and Indigenous Studies Association (NAISA) and publications such as Hokowhitu et al., 2010). Giddens (1991) suggested that, "in the context of globalisation, new communication technologies and the collapse of time and space; individuals are less constrained in the construction of identity" (Giddens, 1991; as cited in Henkel, 2005, p. 152). One consequence of this phenomenon is that academics may lose their local identities as they begin to focus more globally.

\subsubsection{Connection with community}

One other element of Māori academic identity repeatedly raised in the literature was the importance of maintaining and enhancing connections with the Māori community and engaging in academic pursuits that are of benefit to them (Cram, 1993; Ka'ai, 1995; Mane, 2009; L. T. Mead, 1996). Māori academics wrote of how "genealogy, family and community connections" created a "long-standing history" that pre-dated and endured beyond the academic appointment or activity (Moeke-Pickering et al., 2006, p. 3). Villegas (2010) concluded that scholars, particularly those engaged in

kaupapa Māori work, were "not beholden to departments or disciplines" and instead had "responsibilities to other scholars and to Māori people" (p. 252). This echoed a sentiment expressed by other Indigenous scholars (Jaime, 2008). One explained that, "in entering the academy most of us hope that our skills and research will contribute to bettering circumstances for Indigenous people" (A. C. Wilson, 2004, p. 69) and another explained that "those of us who remain in the Western Academy as faculty [...] seek to render our research, teaching and service relevant to Indian country" (Gone, 2004, p. 125). Māori academic Simon Lambert (2007) described how providing opportunities for Māori communities and Māori postgraduates to work together was an extension of "the concept of scaffolding to the area of cultural resilience" (p. 76). He suggested that such an experience not only valued community knowledge but also broadened the professional 
development of the Māori scholars involved. For Māori academics, their connection and obligation to their Māori communities appears to permeate their academic identity.

\subsubsection{Academic values}

Winter (2009) identified three examples of core academic values that help to form academic identity. The first was 'academic freedom', which he regarded as a kind of shared global value that needed preservation. The second example was 'institutional autonomy', which he concluded had been eroded by the increasingly capitalist approach being taken towards university research and teaching. The third example was 'collegial governance', the notion of academics taking on managerial roles within universities. While there was ample literature about Māori cultural values (for example, H. M. Mead, 2003; Metge, 1995), there were no published works specifically about distinctive Māori 'academic' values.

\subsubsection{Māori and Indigenous experiences of the academic environment}

One of the most cited pieces about Māori academic experience is Linda Smith's (1992b), "The Dilemma of the Māori Academic". In it, she noted:

We cannot begin to describe the dilemma which faces us in our practice without first recognising that we exist in institutions which are founded on the collective denial of our existence as Māori and which not only actively continue to assimilate us but more importantly perhaps actively compete with us and the world views we represent. (p. 5)

This notion of being denied, whether in terms of pedagogy, epistemology or methodology, and experiences of racism have been reiterated by other authors since (Asmar et al., 2009; Christiansen, 2000; Deloria Jr, 2004; Jaime, 2005; Mikaere, 2011; Morrison, 2000; S. Walker, 1996; A. C. Wilson, 2004). Even if not being actively denied, Tsalagi scholar Corntassell (2003) described how stereotyping Indigenous academics into such roles as the 'activist', 'spiritual', and 'Noble Savage' had a similar effect (p. 161). 
Johnsrud (1993) found that "racism and discrimination are realities in the experience of ethnic and racial minority faculty" (p. 9), a point reiterated by Arbon (2008), who described how Indigenous knowledge was resisted in tertiary education. Fredericks (2009) simply concluded that "Universities are not the safe places we would like to think they are" (p. 14). Villegas (2010) found that, rather than seeing improvement in universities, her Māori academic interviewees suggested that, "racism has become more intense" (p. 103). Some of the prejudice manifested in the form of microagressions, such as "subtle snubs" or "hidden messages of derogation" (Sue, 2010). Mead (1996) provided examples of the "day-to-day smaller struggles over the way the university answers the phone or people type Māori words or greet Māori visitors" (p. 118) and Jefferies (1997) provided a list of problems for Māori working in a 'Pākehā institution' that included "maintaining, justifying or expanding their programmes due to gatekeeping against, and marginalisation of, Māori staff and kaupapa Māori within their organisations" (p. 133). Similarly, Gone's (2004) 'curriculum conundrum' was another form of denial whereby Indigenous students (and staff) were recruited into programmes that were not set up to support, acknowledge or train them. Thus, the denial of or lack of support for Māori academics within the university environment was an important area for further exploration, as were the other aspects of the Māori academic environment experience that follow.

\subsubsection{Pressure to assimilate}

Another often cited and well-known piece of writing about Māori academic experiences, Irwin's (1997) 'Becoming an Academic: Contradictions and Dilemmas of a Māori Feminist', provided a 'warts and all' story about her experience of starting her academic career at Victoria in 1981. While entirely autobiographical, her depiction of life as a Māori academic in a New Zealand university foreshadowed many of the key issues and challenges facing other Māori academics still working "against the odds" today (Irwin, 1997, p. 52). Irwin described her family's role in choosing her academic career path, and the responsibilities this placed on her to honour her family 
and the wider Māori community, an experience echoed by other writers (Ka'ai, 2005; L. T. Smith, 1999; Tawhai et al., 2004; M. Webber, 2009). She described the pressure to "assimilate" to the university environment and the "cultural bias" and inequity she faced as not just a Māori person but also as a woman (Irwin, 1997, p. 59). She also criticised non-Māori scholars for their inability to theorise "how Māori and women - Māori women particularly can become 'successful' and still maintain their cultural integrity and integrity in the education system" (Irwin, 1997, p. 59).

Hook (2008) reinforced the point of the pressure on Māori to assimilate into the university environment, and explained that Māori and Pākehā worldviews are "about as far apart as any two world views can get" so "for Māori engaging in employment or study in a mainstream university there are numerous compromises necessary in order to succeed" (p. 4). He warned that if a Māori person does appear to change their behaviour to better fit the university environment,

this does not mean that Māori have "seen the light" and now embrace all that Pākehā hold near and dear. Within the university setting the struggle to interweave two world views is sometimes difficult and underpins some of the struggle. The point is that Māori have to absorb two world views, but Pākehā have only to absorb one. (p. 4)

Hook suggested that while "the common ground seems to entail the willingness of Māori to learn and understand the Pākehā point of view; perhaps a greater understanding of Māori perspectives might also be of value" (p. 4). This notion of being pressured to assimilate was echoed by American scholar, Tierney (1999), who advocated for a "cultural integrity" that treated "racial/ethnic backgrounds in a positive manner" (p. 84). Ratima (2008) described this as, "a defining challenge for Māori academics" (p. 2) and cited Smith's call for Māori academics to stop leaving their culture 'at the door' in order to participate in the academy. He described Smith's recall of the introduction of Māori language and culture at Auckland University as being a process about "making Māori knowledge and beliefs 
palatable for Pākehā consumption" (Smith 2000 as cited in Ratima, 2008, p. 2).

As a Māori woman embarking on an academic career 11 years after Irwin first published her account, U.S.-based Māori scholar Michelle Erai (2008) encountered similar challenges but she drew strength from the "community of smart, committed scholars and activists, who are passionate about social issues, about transformative pedagogy, and about the political possibilities of accountable research and writing" with which she had become connected (p. 1).

\subsubsection{Dual obligation}

One possible manifestation of the differing worldviews alluded to by Hook (2008) is the notion of dual accountability. Sir Hugh Kawharu was quoted as having once said, "You can be an academic Māori or a Māori academic. To be a Māori academic always has far greater demands" (Kawharu, 2010). A similar point was made by Arohia Durie, who suggested that the pressures of research and teaching at universities provide a unique challenge for Māori academics because of their “'dual obligation' between being an academic and 'being Māori'”, which they constantly have to balance (A. Durie, 1995 as cited in; Reilly, 2008, p. 25). That balancing act can be dispiriting when Western values predominate within an academic discipline. As Mikaere (1998) observed, "It is extraordinarily difficult to maintain any degree of integrity as an indigenous person within an institution which requires such daily compromise" (p. 13). Similarly, Mercier, Asmar and Page (2011) found that "Māori academics felt the weight of expectations from many different quarters: including community, whānau, students, and the university" (pp. 87-88). This was a view echoed in their research about Indigenous Australian academics, which found that "their strong commitment to culture and community comes directly up against endemic institutional responses to their work - and to their very ways of being" (Page \& Asmar, 2008, p. 115). Similarly, Native American scholars have observed 
the tensions in balancing Native community and academic expectations and obligations (Jaime, 2008; James, 2004, p. 51).

In a related vein, former Māori studies scholar, Dr Godfrey Pohatu (1998) argued that Māori university staff are taonga or treasures because of their "dual edged accountability" both to their university and to their Iwi (p. 329). On a grander scale, Misa (2009) cited Professor Sir Mason Durie as having said that "the purpose of ethnically based preferential entry schemes is not simply to have more Māori or Pacific doctors, but for educational institutions to make a contribution to society" (para.23). By the same token, the need to recruit, retain and support the achievement of Māori academics, can be seen as another way to make a contribution to society.

\subsubsection{Cultural space in universities}

Graham Smith (2011) argued that kaupapa Māori intervention has two components: first is the critical element of creating space for Māori and, second is getting involved in it. Mead (1996) had previously asserted that, "making space within institutional structures is a necessary part of Māori academic work" (p. 117), while Māori Professor Te Ahukaramū Royal (2012) suggested that "kaupapa Māori was deliberately evoked as a 'strategy', or 'a plan of action' to 'make space' for Māori people, culture, knowledge and values in the academy (p. 31). However, Māori postgraduate Andrea Morrison (2000) pointed in her thesis to the difficulties that present themselves in trying to create Māori space in a university environment, and reiterated a point made by Mead (1996) that most Māori academics work in departments as the 'minority' voice. She explained:

Many are employed because they are Māori, but are expected to teach Mãori perspectives on topics that continue to reflect the theoretical interests of Pākehā. Reprioritising and 'bringing to the centre' topics which may interest Māori represents the 'special battleground' mentioned by Fanon. In present-day terms this battleground is spatial. It is about theoretical spaces, pedagogical spaces, and structural spaces. It is also about culture, history and power, about making sense of, transforming, 
struggling against, the institutions within which we work. (L. T. Mead, 1996, p. 116)

Dr Cheryl Smith (2000a) extended this idea by acknowledging that alongside "claims for separate space being made by Māori" there was also a challenge for Māori academics "to more strongly bring forward into our work and lived reality, the epistemologies that we so often put to one side as separate spheres or relegate to formalised ritual" (p. 50). Thus the call for Māori space within university environments should be understood as moving beyond physical structures to include theoretical, pedagogical and structural spaces necessary to better nurture and support Māori academics and Māori scholarship.

Earlier attempts to make university environments more Māori 'friendly' have brought mixed results. Nakata (2006) warned that, "in the academy, any Indigenous space is always circumscribed by, and in a sense implicated in, non-Indigenous systems of thought" (p. 270). Johnston (2001) concluded that such efforts as minimal Māori representation on committees and the slight use of te reo Māori in teaching "contribute little towards addressing the needs and interests of Māori, but instead are more about 'ticking boxes'" and "being seen as sensitive and understanding towards Māori" (p. 5). She argued that the move towards Māori-friendly positions was about creating comfort zones for Pākehā to safely navigate potential Māori cultural pitfalls rather than encouraging Māori involvement or success (P. Johnston, 1998). It was against that backdrop that Mead (1997, p. 45) argued for more tino rangatiratanga or self-determination for Māori within universities.

\subsubsection{Sense of isolation}

A consequence of holding a minority worldview while working as an academic is feelings of isolation and loneliness (Jaime, 2008; Palepu et al., 1998). As Irwin (1997) mused, "If I didn't look or speak like a 'normal' academic, that was no loss because I didn't feel like one either" (p. 59). Mead (1997) anticipated that loneliness and warned: 
As we assert our identity as Māori people with increasing confidence, as we press for proper expression of the notion of 'tino rangatiratanga' everywhere, including the universities....as we strive to alter some of the structures within universities and as we move towards iwi development and self-determination, it could well be the case that we will find ourselves standing more and more alone. We should prepare for that to happen. (p. 45)

This notion of Māori academics feeling disconnected or isolated from the university community ran counter to Winter's (2009) idea that academic identity is defined by the extent to which an academic feels connected to their institution, such as their university, or their academic discipline. Instead, as Māori academics have noted, a sense of isolation both within their institutions and amongst other members in their field of study can permeate their experience of academia, without diminishing their identities as Māori academics (Irwin, 1997; L. T. Smith, 1992b).

This situation is not unique to universities in New Zealand. In their study of Indigenous Australian academics, Page and Asmar (2008) found a similar sense of disenfranchisement and concluded that, "an individual's commitment to their Indigenous culture, identity and community comes up against, and may collide with, institutional norms which are entrenched or endemic" (p. 116). A similar experience was borne out by other Indigenous scholars, such as Kuokkanen (2007) who explained that,

many indigenous people contend that notwithstanding its rhetoric of welcome and hospitality, the academy is not a good host. Their experiences attest to the ways in which the academy is an inhospitable and sometimes even a hostile host with only a weak commitment to indigenous people. (p. 3)

Furthermore, in her Canadian study, Roland (2011) identified "a significant lack of acknowledgement, support, and valuing of different knowledge systems" as one of the reasons for Indigenous academics not feeling welcome in universities. She cited one study participant, Gahutneo, who explained: 
[T] here is no Aboriginal intellectual critical mass in many universities in Ontario. We are isolated and marginalized because our epistemic realities conflict with the academies....it has to, I mean the word university literally means "one song" and I sing a different song. (p. 131)

Similarly, Umbach (2006) cited international research that concluded social isolation and lack of mentoring impeded the professional progress of faculty of color (p. 319). The same conclusion was reached in Smith's (1991a) synthesis of the diversity literature, which found that, "in higher education, the condition of diversity is all too often a condition of alienation" (p. 130). This was reiterated in Jaime's (2005) research on the experience (and isolation) of Native American women in academia.

\subsubsection{Māori and Indigenous experiences of university teaching}

Another element gleaned from the literature was the suggestion that there were distinctive or common Māori teaching characteristics, perhaps encouraged by the fact that "teaching appears to have a particular salience for Indigenous academics" (Asmar \& Page, 2009, p. 392). However, much of the literature on this topic was in the context of primary or secondary level education (Bevan-Brown, 2005; Gorinski \& Abernethy, 2007; Paki, 2007), leaving ample room for more research in the area of Māori teaching practice in higher education.

Webber (2009) shared her experience that, "the teaching workload associated with being one of few Māori academics in the 'mainstream' university programmes can be exhausting" (p. 3). The idea of an increased teaching workload was reiterated by other scholars (Asmar \& Page, 2009; Page \& Asmar, 2008), including James (2004) who argued that Indigenous academics also suffered "under the burden of having to educate academic colleagues and administrators about the cultural realities of Native people" (p. 63), a view reinforced in research about Native American women academics (Jaime, 2008). 
Others have written about the advent of marae on university grounds and how they, amongst other things, facilitated the teaching of tikanga and te reo Māori (Adds, Hall, Higgins, \& Higgins, 2011; Ka'ai, 2008; Lilley, n.d.; Morrison, 1999, 2000; Penetito, 2005; Roa \& Tuaupiki, 2005). Ka'ai (2005) suggested a number of practices that she believed underpinned what it meant to be a Māori academic teaching in a western institution, including: the use of Māori pedagogies and practices; the valuing of Māori language and culture and the instilling of that value in students; and the commitment to recovering Māori histories and ensuring Māori cultural futures (pp. 4-5). Each of these points, while positive and affirming, were only general indications of Māori teaching practice within a university environment.

Other Indigenous authors confirmed the lack of literature about Māori tertiary teaching practice. There has been some effort to articulate the tensions of teaching Indigenous studies within a Western university (Jaime, 2008; Nakata, Nakata, Keech, \& Bolt, 2012). Some have written about the negative consequences on the careers of Indigenous Australian academics caused by their extra teaching administration workloads (Whatman, McLaughlin, Willsteed, Tyhuis, \& Beetson, 2009, p. 124) . Ultimately, though, within the literature to date there has been,

a lack of engagement with Indigenous pedagogical concepts by Indigenous academics. While Indigenist research methodologies and Indigenous epistemologies have featured heavily as topics of Indigenous students' postgraduate writing over the past two decades, there has not been...a similar focus and emphasis on Indigenous pedagogies or teaching methodologies. It seems that as an important part of the circle of knowledge, teaching has not been part of the reclaiming of Indigenous philosophies. (Biermann \& Townsend-Cross, 2008, p. 146)

As a current gap in the literature, this is an area to explore further and consider in terms of how it may influence the direction of a Māori academic development programme. 
Some international research found that, just by their presence, minority academics make a positive contribution to the learning experience of minority students (Anderson, Bunda, \& Walters, 2008; G. H. Smith, 1991b; Umbach, 2006). One study found that "faculty of color" provide both “benefits to students and benefits to institutions" (Umbach, 2006, p. 319). Other studies found that "academic performance and career aspirations are enhanced when students of color have minority faculty who serve as role models for them" (Cole \& Barber, 2003; Hurtado, Milem, Clayton-Pedersen, \& Allen, 1999 as cited in; Umbach, 2006, p. 320)).

However, in light of the lack of documented material about Indigenous teaching pedagogies in higher education, prior to this thesis research I coconstructed a project with other Māori academics about their experiences regarding their teaching in a mainstream university (Hall, 2009). The research project set out to identify what, if any, distinctive and common characteristics could be found within a sample of Māori academics teaching at Victoria, and what positive effects, if any, their 'Māori-ness' had on their students. The qualitative study looked at the course design and teaching delivery approaches used by individual Māori academics working in a range of disciplines and explored a series of research questions, namely: are there any distinctly "Māori" approaches that Māori academic staff in mainstream tertiary institutions take in their teaching? How, if at all, do Māori academics in mainstream tertiary institutions cater for their Māori student cohort? And finally, how do Māori academics know that what they are doing in their teaching is working for their Māori students, or any of their students?

Through the course of interviews it became clear that there was reluctance to the notion of 'one' Māori teaching approach, just as there would be similar resistance to the idea that all Māori students have the same learning styles. However, there were six common experiences or approaches that resonated with the participants in the project and which came through strongly in their interviews. Many of the findings of this project aligned with earlier work by Bevan-Brown (2005, pp. 153-154) about how to create a culturally responsive learning environment. 
The first was the notion of Māori as educators. Many of the interviewees came from what they described as teaching whānau (families), which meant that working as educators was "in the blood" (Hall, 2009). Others believed their family background in teaching meant that they had an innate sense of how Māori people learn, or provided them with strong role models to emulate.

The second common element to their teaching approach was the desire to contribute to the preservation and protection of the Māori culture and society. Some were motivated to teach in universities because of the threat of 'extinction' that had once hung over the Māori language. Others cited their interest in sharing knowledge of things Māori with Māori youth, to ensure the continuation of cultural practices and beliefs. A number of participants talked about how they were also patently aware that when students were learning te reo Māori there was often a difference between Māori learners and non-Māori learners. The Māori students tended to be learning the language to help with their personal journey to find their identity, which was quite a different goal from getting a university degree.

A third commonality was the drive to empower students to be able to make a positive contribution to Māori society. Project participants spoke of measuring their teaching performance not only against what the university expected a good course to look like, but also of being consciously aware that whatever they did in class, and whatever their students produced, and whatever their students went on to become, was measured against the expectations of the Māori community. Many spoke about using their own variation of backwards course design (Wiggins \& McTighe, 1998) whereby they focused on what the Māori students needed to be doing at the end of or beyond the course, and planned their course accordingly to help those students achieve the required level. They spoke of wanting to produce graduates who could contribute to Māori society and of having a duty to the Māori community to get Māori students thinking about the 'whys and the hows' so that they could make a positive contribution when they graduated. Others admitted to not considering they were working for the University but 
rather that they were working for the Māori community within an institution that allowed them to do that.

A fourth common, teaching-related trait was the motivation to provide a learning experience for their Māori students that would counter any earlier, negative experiences of education. They spoke of a deliberate philosophy of teaching to the Māori students in their classes and thereby reversing the experience for Māori students in other parts of the University. They encouraged their Māori students to be more confident in class by helping them realise, "Here's a person who's actually talking to us" (Hall, 2009). They cited hooks' (1994) belief that the classroom provided the "most radical space of possibility in the academy" (p. 12) and added that things that get taken for granted in other courses are not taken for granted in theirs. They also, possibly unknowingly, reinforced the position taken by Te Kapunga Dewes 35 years earlier, who argued that "the cultural or psychological violence that had been perpetrated on Māori students required Māori scholars to "put back into Māori minds, hearts and souls those things that were psychologically bruised in earlier generations"'” (Dewes, 1975, p. 66; as cited in Reilly, 2011, p. 347). As an example, the Māori academics spoke of the concept of whakamā or shame and described how it can be one of the biggest barriers to Māori student learning. While they acknowledged the possible discomfort of Pākehā students, they spoke of having to 'nurture them through' without making it unsafe for Māori students and of being prepared to take criticism from other students in order to protect and support their Māori students. Even for those Māori academics who primarily taught non-Māori students in their courses, they spoke of a belief that they were simply teaching Māori students through others or, as one interviewee put it, "I'm teaching Pākehā students who will go on to teach Māori students"(Hall, 2009).

A fifth teaching trait found to be common amongst Māori academics was a holistic view of the learning environment. This is not unique to Māori but it was a shared view of the interviewees that learning does not only occur within the classroom and that individual courses are just one small part of a 
whole student learning experience and environment. They also emphasised that their responsibilities towards their students did not end when they left the lecture theatre. They spoke of their roles "leaking" out of the classroom because the Māori students "know them as the Māori that they can go to for help", while others described how building rapport with their students was just "being Māori" (Hall, 2009). Some of the interviewees even talked of paying their students' travel costs just to help them get to class. They also shared innovative approaches to help engage Māori students in the learning process, from getting them involved in 'real' research at an early stage, to providing opportunities for embodied learning whereby the students completed assessment in context. Others spoke of the highly transformative nature of Māori language learning and the importance of setting assessment that can both extend students while still being achievable and conscious of their personal pressures. The use of personal narratives was common among the Māori academics, as was a tendency to blur disciplinary boundaries, such as assessing science topics through creative writing. They also made an effort to help Māori students feel less alone or marginalised in their study by providing opportunities to collaborate with other students studying indigenous topics in New Zealand and overseas.

The sixth and final common teaching trait found amongst Māori academics involved in this project was that they understood and engaged with the politics of Māori teaching. While they cautioned that there was no one 'Māori' way to teach or learn, they did suggest that the context in which they teach, which some likened to a 'battle zone', created a shared experience. They put forward that it was this political dimension of being a Māori teacher in a university classroom and the 'politics' of Māori students learning, that created a common bond and impacted on Māori teaching pedagogy and practice, right down to the deliberately provocative teaching practice of some Māori academics.

Nakata (2006) wrote that, "underpinning Indigenous academic involvement in Indigenous Studies is a definitive commitment to Indigenous people first and foremost, not to the intellectual or academic issues alone" (p. 266). 
Ultimately, the research project about Māori approaches to tertiary teaching uncovered two overarching tenets that set Māori apart from other academics and also supported the achievement of Māori students. The first was that the Māori academics involved in this study taught to the Māori students (or at least with Māori in mind), which raised the status of mātauranga Māori, put the Māori students at the centre, front loaded the information (and put the onus on the other students to catch up), took a proMāori standpoint, and recognised that the way Māori academics teach deeply influenced their students. This manifested in course design, course content selection and even teacher disposition, which are all important areas of interest for any academic development programme.

The other is that Māori academics taught for the Māori community - not in a direct, line-management sense, but rather as a form of cultural accountability that went beyond the immediacy of student retention and achievement within the course, and related more to the future impact and contribution of the Māori graduates. They were concerned about whether Māori students met the standards and requirements of the Māori community. They saw it as their job to produce people who contributed positively to Māori society and wanted to be proud of the calibre of students that they put back out in the community and of the contribution that those students were making. They believed that their relationship with the Māori community was a stronger connection than the relationship they had with their university and, in addition, saw that their relationship with the university was formed through their relationship with the Māori staff and Māori students. Each of these points had the potential to impact on the effectiveness and success of a Māori academic development programme.

\subsubsection{Māori and Indigenous experiences of university research}

Research was a prominent and popular dimension of the academic workload enjoyed by many Māori academics. While not unique to Māori, Mead (1997) suggested that, for Māori academics, the drive to undertake research came from a duty "to help make the world more coherent for the Māori public by 
providing theories, analyses, commentaries and ideas to help give some order to a rapidly changing world" (p. 39). Canada-based Māori academic Makere Stewart-Harawira (2007) described Māori research as a process of "writing back" that enabled "the recentring of Māori ways of being and knowing" (p. 126). Both understandings fit within Rigney's (1999) notion of "indigenist" research and its principles of resistance, political integrity and "privileging" of Indigenous voices (p. 116).

The experience of conducting Indigenous research, with all its "competing spatialities and positionalities" (Rossi, 2008, p. 404) has significant consequences for Māori and other Indigenous academics. Battiste (2008), reflected on how universities have treated Indigenous knowledge and research in the past, and concluded that, "Eurocentric education and political systems and their assimilation processes have severely eroded and damaged Indigenous knowledge" (p. 497). She described the tensions carried by Indigenous academics who have been saddled with, "unravelling the effect of generations of exploitation, violence, marginalisation, powerlessness, and enforced cultural imperialism on Aboriginal knowledge and peoples" and must operate within, "a modern conventional education system that has taught them not only to mistrust their own Indigenous knowledge and elders' wisdom but also their own instincts, creativity and inspirations" (Battiste, 2008, p. 497).

Back in New Zealand, Kidman (1999) wrote about the cultural assimilationist policies and practices that have affected the evolution of universities in New Zealand, including the way that research priorities have been set. She concluded that,

where there is a dislocation of cultural values, particularly those of indigenous peoples, it is more likely that the prevailing educational practices will adopt other referents (such as British or Europe). This was the case in New Zealand universities, where Eurocentric research priorities predominated until the 1980s. (p. 79) 
While Kidman believed that the university research agenda had started becoming more localised and incorporating of Māori and the Pacific values in the 1980s, later research by Asmar, Mercier and Page (2009) gathered feedback from Māori academics about their research experience and found that, "overall Māori participants perceived a lack of institutional recognition for their work and research" (p. 156). While there had been an increase in outputs relating to kaupapa Māori research, many of the key theorists still decried a lack of institutional support (Cram, 1993; Irwin, 1994; Powick, 2002; L. T. Smith, 1999). They also expressed concern at the continued research-related challenges faced by Māori working at what Johnston described as the "unnamed frontier (a universalised neutral frame) research that is based on unchallenged and unquestioned 'norms' represented as scientific and pure", the "colonial frontier (the identified frame) - homogenising grand narratives, meta narratives recognising other through the filters of its own validity checks" or the "indigenised frontier (the cultural additive frame) that subsumes/consumes Māori within their research frameworks" (P. Johnston, 2001, p. 4).

Unquestionably, the advent of the PBRF process provided some additional research challenges and opportunities for Māori academics. The critics of the system were particularly scathing of its lack of recognition for Māori research topics and practices (Hobson \& Hall, 2010; Roa et al., 2009; Tawhai et al., 2004). In fact, Roa, Beggs, Williams and Moller (2009) listed 14 different problems for Māori-related research that stemmed from the PBRF process, including its 'outputs' over 'outcomes' focus, its encouragement of publication in 'international' journals, and its emphasis on self-promotion. The PBRF-related and other research pressures on Māori academics are an important dimension to be addressed in relation to any framework for Māori academic development.

\subsubsection{Concluding comments about Māori academic experience}

This section of the literature review has focussed on the views, experiences and differences of Māori and Indigenous academics working at the cultural 
interface of the university environment. It has provided a summary of the motivations of Māori academics to build up the mana of Māori knowledge within the academy, to counter racism and discrimination (Alton-Lee, 2006; Coxhead, 2006; Gallhofer et al., 1999; H. White et al., 2009), to contribute to the preservation and protection of the Māori culture and society, to empower students to be able to make a positive contribution to Māori society, to counter any earlier, negative education experienced by Māori students, and to engage with the politics of Māori teaching (Hall, 2009).

This section has explored how Māori and Indigenous scholars described their multiple, often competing, roles borne of their cultures, genders, family memberships, scholarship, and engagement in global Indigenous networks, which required them to have a fluidity or hybridity in their academic identity formation and maintenance. It has also highlighted how having Māori academic identities can cause discomfort and stress (Irwin, 1997; Kukutai \& Webber, 2011; McKinley, 2002) but can also be a source of strength and power (Corntassell, 2003; Irwin, 1997; M. Maaka, 2004; Penetito, 2005; L. T. Smith, 1992b; M. Webber, 2009; P. J. Williams, 1991). It canvassed Māori-specific authenticity issues related to concerns about cultural competence (Kukutai \& Webber, 2010; L. T. Mead, 1996) and highlighted the importance of maintaining Māori community connections and pursuing academic projects that benefit and represent Māori communities (Cram, 1993; Irwin, 1997; Ka'ai, 1995; Kukutai \& Webber, 2011; Mane, 2009; L. T. Mead, 1996; Moeke-Pickering et al., 2006; Nikora et al., 2002; L. T. Smith, 1992b).

In relation to working within university environments, this section summarised how Māori and other Indigenous scholars have written about their experiences of racism and discrimination, of being denied, stereotyped, resisted, excluded, alienated, marginalised, unsupported, unwelcome and unsafe (Arbon, 2008; Asmar et al., 2009; Christiansen, 2000; Corntassell, 2003; Deloria Jr, 2004; Fredericks, 2009; Gone, 2004; Jaime, 2005, 2008; Jefferies, 1997; Johnsrud, 1993; 2007; L. T. Mead, 1996; Mikaere, 2011; Morrison, 2000; Palepu et al., 1998; Roland, 2011; D. G. Smith, 1991a; L. T. 
Smith, 1992b; Villegas, 2010; S. Walker, 1996; A. C. Wilson, 2004). It has discussed the pressure on Māori academics to assimilate to the university environment (Irwin, 1997), compromise on their cultural beliefs (Hook, 2008; Mikaere, 1998; Page \& Asmar, 2008), and face challenges to their cultural integrity (Irwin, 1997; Mikaere, 1998; Ratima, 2008; C. Smith, 2000a; Tierney, 1999). It has also described the burden of having dual accountabilities and obligations (Page \& Asmar, 2008; Pohatu, 1998) to both their universities and their Māori communities and culture, and their struggle to balance two worldviews (A. Durie, 1995; Hook, 2008; Jaime, 2008; James, 2004; Page \& Asmar, 2008). The need to create both physical and metaphorical space for Māori within the university environment was also raised - as was the difficulty of doing so (P. Johnston, 1998, 2001; L. T. Mead, 1996; Morrison, 2000; Royal, 2012; C. Smith, 2000a; G. H. Smith, 2011) - which precipitated the argument for Māori tino rangatiratanga within universities (S. M. Mead, 1997).

In regards to teaching, this section acknowledged the tensions for Māori and Indigenous academics around teaching Indigenous subjects within universities (Jaime, 2008; Nakata et al., 2012; C. Smith, 2000a). It explained how Māori and Indigenous academics carry heavy workloads (Jaime, 2008; James, 2004; Kawharu, 2010; M. Webber, 2009), often to the detriment of their academic careers (Whatman et al., 2009, p. 124). In addition, it described how Māori academics use Māori pedagogies, practices and places in their university teaching (Adds et al., 2011; Hall, 2009; Ka'ai, 2005, 2008; Lilley, n.d.; Morrison, 1999, 2000; Penetito, 2005; Roa \& Tuaupiki, 2005) and how they teach to their Māori students and for their Māori communities (Hall, 2009).

Finally, this section linked to Rigney's (1999) notion of "Indigenist" research, and explored what Māori scholars have written about how research enables Māori academics to provide coherence for Māori people (S. M. Mead, 1997) and recentre Māori knowledge and understanding (Stewart-Harawira, 2007). This was particularly evident in the surge of kaupapa Māori research over the last 30 years but institutional support for this work has been slow 
(Asmar et al., 2009; Cram, 1993; Irwin, 1994; Powick, 2002; L. T. Smith, 1999) and there was a lack of recognition for Māori research topics and practices within the national PBRF process (Hobson \& Hall, 2010; Roa et al., 2009; Tawhai et al., 2004).

\subsection{Māori academic development}

For many tertiary education providers, the recruitment and retention of Māori academic staff is an ongoing issue. But what are institutions doing to support their Māori staff to achieve their personal and professional goals, maintain their cultural integrity, and still retain them in their academic roles? This review canvased literature about academic development to identify key concepts and issues that relate to what Māori academic staff want and need in terms of academic development. A synthesis of that literature is presented below.

\subsubsection{Origin of academic development}

As a relatively new field of study, there is still a great deal of scholarly activity being undertaken around establishing the history, focus and scope of academic development work (Clegg, 2009; Hicks, 2005). Even the term 'academic development' is not universal - for example, it is often called 'faculty development' in the United States or 'educational development' in South Africa (Clegg, 2009). Descriptive overviews of academic development exist for the United Kingdom (Brew, 1995; Land, 2001) and the United States (Gaff \& Simpson, 1994). In the New Zealand context, a preliminary publication on the origins of at least one New Zealand university's academic development unit (Barrow, Grant, \& Brailsford, 2010) emanated from a broader project examining the history of academic development in New Zealand, Australia and the United Kingdom, which is currently underway (Grant et al., 2009). As with some of the kaupapa Māori scholarship, academic development has been described as having "transformational" capacity, particularly in more recent years as the focus has switched in some academic development centres towards strategic, large scale intervention 
(Clegg, 2009, p. 408). Despite variations in histories and interests, and continued contestation and contradiction (Peseta \& Grant, 2011), one clear thread in the literature is a view that academic development revolves around teaching and learning-related theory and practice for academics working in tertiary education institutions (for example Baalawi, 2008; Brew, 1995; Debowski, 2011; McFarlane \& Hughes, 2009).

While there is no one, definitive text on the scope of the field of academic development, a recently published Higher Education Research and Development Anthology provided an overview and introduction to the conceptual cornerstones of higher education teaching and learning literature (Kandlbinder \& Peseta, 2011). In it, the authors devoted a chapter to each of the five key concepts that they identified for higher education teaching and learning in Australasia and the United Kingdom. The topics were: reflective practice, constructive alignment, approaches to learning, assessment for learning and scholarship of teaching. These concepts also represent the key areas in which academic developers are said to be currently teaching and conducting research. Each of these concepts has dominated and informed the international academic development discourse (Kandlbinder \& Peseta, 2011).

\subsubsection{Academic development as academic practice}

Despite the attempts to develop an overview of academic development, Gosling (2009) described academic development as still being "a field of activity which has no strong boundaries, is unstable and necessarily required to respond to the environment in which it operates" (p. 6). In addition, teaching-related professional development has to compete for time with other academic pressures, such as maintaining subject knowledge and engaging in research (S. Johnston, 1997 as cited in; Viskovic, 2005, p. 2). So, while one key school of thought in the literature has suggested that academic development primarily focusses on specific elements of higher education learning and teaching, another has argued that academic development should be cast more broadly. While acknowledging that the 
concept of development is difficult to define, Blackmore and Castley (2006) offered the definition that 'capability development' was the "provision and processes that are designed to enhance the efficiency and effectiveness of individuals, groups and the organisation. It is intended to be inclusive, taking in all development activity" (p. 15). They divided capability development into a number of subsets that included "staff development, educational development (development of curriculum and assessment), academic development (the development of academics' expertise), faculty development (development of academic staff, usually relating to teaching, in the USA), and organisational development (focused at an institutional level) (Blackmore and Castley (2006) as cited in Blackmore, 2009, p. 664). Thus, this definition located academic development as a category of capability development and gave it a focus on the development of expertise to fulfil the academic role. It did not narrow academic development further to only teaching (or teaching and learning) expertise, but was worded broadly enough to include all aspects of what was considered to be the domain of an academic. Similarly, Rowland (2003) explained the relationship between academic development and academic practice as follows:

Academic practice includes research as well as teaching, and the learning which results from both. Academic development is then the development of academic practice. It depends largely upon learning about academic practice: learning, that is, about research as well as learning about teaching and learning about learning. (p. 13)

Thus, academic development can be understood as being about more than just teaching but also research and development around academic practice generally. This was reflected in recent name changes to two academic development units in New Zealand universities; the University Teaching Development Centre at Victoria became the Centre for Academic Development in 2011, and the former Centre for Academic Development at the University of Auckland changed its name in 2012 to the Centre for Academic Practice. 
Blackmore (2007) provided another argument for a broader interpretation of the term 'academic development' by suggesting that,

there is a pretty extensive literature and a lot of empirical evidence that the 'traditional' notion of the academic role is, to say the least, under some stress, that the 'ideal' of teaching, research and administration or service is coming apart in many places - an international trend. We might consider whether an exclusive concern with teaching and learning actually contributes to that separation and whether it simply looks out of date in a world that has grown too complex. (p. 10)

His view was that any separation between teaching and research or service was artificial and outdated. Similarly, Jones (2010) concluded that the realm of academic development had matured to the extent that,

as a field, academic development began with a focus on the teaching practice of individual academics, evolved to a more strategic and institution-wide focus, and most recently reflects a concern not just with teaching and learning, but with academic practice more broadly. (p. 241)

Thus a narrow definition of academic development has become inconsistent with the lived experiences of academics. Instead, academic development has been broadened to include academic practice more generally.

Blackmore (2009) took his broader definition of academic development and created a way to analyse how different universities approach the development of their staff. His ISIS model considered:

(a) Inclusion, i.e. a focus on all staff, not just those on academic contracts. Such an inclusive approach, he argued, provided a "means of promoting equity of treatment across the wide range of staff in an institution, so that no group gains a disproportionate share of attention, in relation to others";

(b) Strategy, i.e. any development approach needed to align with the institution's strategic priorities; 
(c) Integration, i.e. that academic work needed to be looked at holistically, rather than as a fragmented or tense relationship between teaching, research and the kind of "public scholarship" otherwise known as service; and

(d) Scholarship, i.e. the encouragement of "more scholarly approaches to the development of practice". (Blackmore, 2009, pp. 665-666)

Blackmore used these four factors to analyse the orientation of an institution's capacity and approach to academic development.

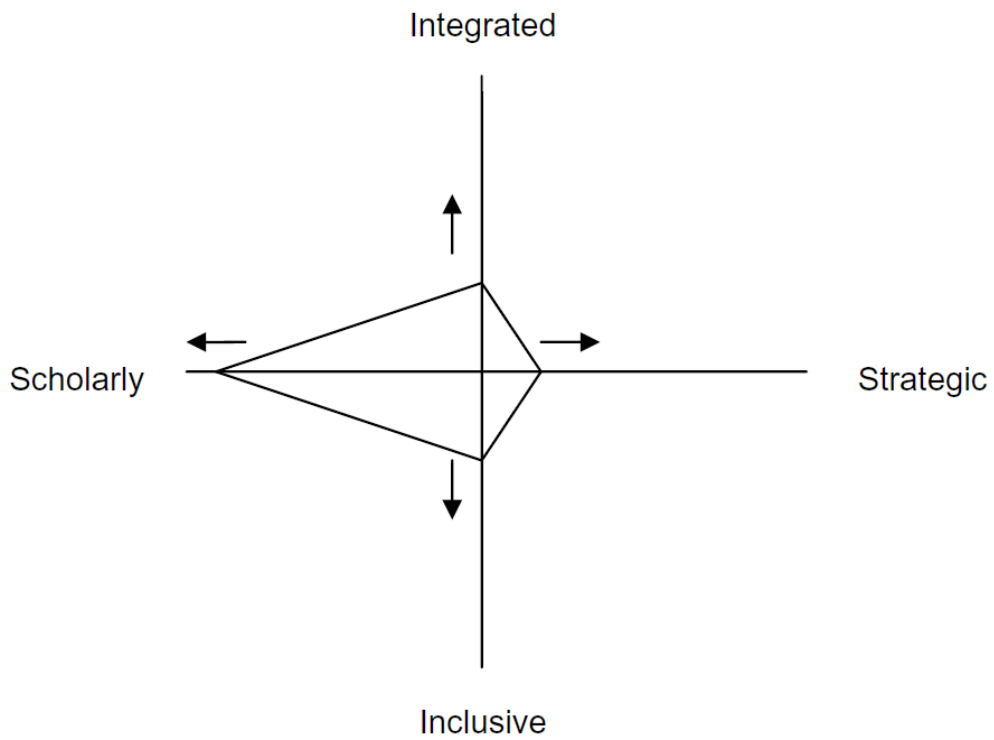

Figure 2.1 An example of the ISIS model analysis depicting institutional orientation towards educational development (Blackmore, 2009, p. 671).

Figure 2.1 provides a visual depiction of Blackmore's ISIS model. The degree to which an institution engages with each of the four elements of staff development can be mapped out on the quadrants. The resulting shape gives an immediate indication about the institution's strengths and weaknesses. In this example, the institution is clearly oriented towards the scholarly dimension of staff development but has capacity to improve in relation to how inclusive, strategic and integrated its programme could be.

Another approach to academic development emerged from Penetito (2005), who was influenced by the work of Bawden (1991) and his identification of three ways of knowing: learning to be, learning to know, and learning to do. In this context, the 'learning to be' related to the experiences, processes and 
culture of the academic environment, 'learning to know' related to the technical knowledge or content required for learning success, whereas 'learning to do' related to the skills necessary to reproduce or create new material. This is similar to one of the descriptions of kaupapa Māori as Māori ways of doing, being and thinking (Henry \& Pene, 2001). Penetito (2005) saw potential for this approach within the articulation of a philosophy for Māori education, but the tri-partite model of knowing could also apply to an approach to Māori academic development. Such a framework would need to address what it is like to 'be' a Māori academic, what a Māori academic needs to 'know' and what a Māori academic needs to learn to 'do'.

In a related context, studies of workplace learning noted the importance of social context in the process of developing expertise. Billet (2001) found that expertise was relational to a particular workplace or a "community of practice" (Billett, 2001, pp. 64-65 as cited in; Viskovic, 2005, p. 325). Thus, in the context of understanding and exploring the potential of Māori academic development, Billet's findings suggest that there needs to be close investigation of the experiences of Māori academics as they operate in their immediate working environments and communities of practice.

\subsubsection{Communities of practice}

The phrase 'communities of practice' appears frequently within the academic development literature. Credit for coining this concept has been given to Lave and Wenger (1991), although Wenger $(1998,2000)$ has published and developed the concept further and defined it as "communities that share cultural practices that reflect their collective learning" (Wenger, 2000 , p. 229). He identified three key characteristics of a community of practice:

- The domain. In order to qualify as a community of practice a group must have a shared domain of interest; 
- The community. In the pursuit of their shared interest members of the community build relationships that support and encourage their ongoing learning; and

- The practice. What differentiates communities of practice from other interest groups is the practitioner emphasis, whereby members develop shared resources and experiences in the course of learning together. (Wenger, 2006)

In addition, Wenger, McDermott and Snyder developed the idea of trajectories (peripheral, inbound, insider, boundary and outbound) to describe how people can change and move over both time and location but still stay within their communities of practice. They explained that "because communities of practice are organic, designing them is more a matter of shepherding their evolution than designing them from scratch" (Wenger, McDermott, \& Snyder, 2002, p. 51). These notions of shared interests, relationship building, and learning together all resonate with the concept of Māori academic development.

\subsubsection{Māori and Indigenous approaches to academic development}

In a 1987 report to the New Zealand Vice Chancellor's Committee called 'New Zealand Universities: Partners in National Development', the authors recommended that the New Zealand university system needed to undergo major change as it had not equitably served the interests of Māori (Irwin, 1997, pp. 57-58; Watts, Herbison, Johnston, \& Myers 1987). Despite this finding, the closest there has ever been to a vehicle that promoted widespread Māori academic staff development and success was, firstly, Te Matawhānui, an association of Māori university staff established in the late 1980s and, more recently, the MANU AO Academy, established through funding from the Tertiary Education Commission (TEC) in 2009. Both of these organisations were initiated by Māori and for Māori and acted as the kind of mediating structures that "stand between the individual in his [sic] 
private sphere and the large institutions of the public sphere" (Berger, 1979, p. 169 as cited in; Penetito, 2005, p. 115).

Te Matawhānui was created as a forum for all Māori university staff, both academic and general, to discuss issues of national interest and to support each other in their endeavours as university employees. It was an important tool in the 1990s for incubating ideas about Māori-related university practices and goals, such as the establishment of Pro-Vice Chancellor Māori positions at New Zealand universities. Ironically, once these positions were established in some universities, there was less need for an advocacy group such as Te Matawhānui and the association quietly fell into abeyance. In its heyday, however, Te Matawhānui gatherings were an outlet for key Māori thinkers and strategists interested in the potential and development of Māori academics. For example, Mead's (1997) expectations regarding the performance of Māori studies academics were made clear in his speech to a Te Matawhānui Conference in 1990:

A professional attitude is necessary, and this should be reflected not only in the manner we [Mãori Studies academics] present ourselves to the world at large but also, in particular, to the students we teach. Students need to know that we are competent, committed, professional and demanding people who in our very attitudes reflect what we want Māori studies to be. If Māori studies is to be a professional, high profile academic discipline, we should act as though it is. (S. M. Mead, 1997, p. 44)

While Te Matawhanui is no longer active, some years later another initiative sought to prioritise the advancement of Māori academics and professionals. The beginnings in 2007 of the Māori Academic Network in Universities in Aotearoa (MANU-Ao) project were described in Chapter One. After the initial pilot, the full name was dropped in 2009 and the project became known as the MANU AO Academy. The acronym MANU AO took on its own meaning, represented in the logo of a bird (manu) spreading its winds to explore the world (ao). Funded for three years, MANU AO was overseen by Te Kāhui Amokura, a sub-committee of the New Zealand Vice Chancellors Committee made up of Pro Vice Chancellor Māori or their equivalents from 
all eight New Zealand universities. According to its website, the MANU AO Academy had three main objectives:

- Accelerating Māori leadership;

- Strengthening the links between Māori academics and professionals; and

- Advancing Māori scholarship (MANU AO Academy, 2010).

It set out to achieve each of these goals through a variety of activities and initiatives that included a weekly online seminar series that showcased Māori scholarship, public lectures with high-profile Māori scholars, workshops and courses focused on academic leadership, and a series of fora to discuss issues of Māori academic relevance. The Academy programme also included the establishment of university chapters, located in all eight New Zealand universities, which were provided with MANU AO funds and charged with co-ordinating a programme of local activities for Māori academics at each institution.

As a national, strategic initiative MANU AO was successful at establishing a brand and mobilising thinking and participation around Māori academic leadership and advancement (Matthews, 2011). At a local level MANU AO also encouraged an increased level of development activity amongst Māori academics. However, the degree and focus of that activity varied greatly across institutions, dependant largely on the vision and enthusiasm of their various Māori senior managers, the demographics of their Māori academic communities, and the expertise and authority of the nominated MANU AO chapter coordinators. While well funded and managed, the MANU AO initiative was not engaged in research-based practice or informed by academic development literature. In part, this was because of a lack of expectation from the funding agency and because of a lack of research specifically about Māori academic development from which to draw. When the funding for the MANU AO Academy drew to a close in 2012, there was no national Māori academic development replacement. 


\subsubsection{A Māori academic development model}

The first published text to explicitly describe a Māori academic development approach was a short paper by Te Whare Wānanga o Aotearoa employees, Davies and Eruera (2009) called, 'Te Toka Āhuru: An Indigenous framework for whakaako (academic development)'. Written specifically for the wānanga context, this paper promoted a model centred on the concept of ako and was informed by the notions of tuakiri (identity), wānanga (learning) and kaupapa (purpose). It described a reflective development process that was intrinsically motivated and independent from performance management (Davies \& Eruera, 2009, p. 2). While thought-provoking and welcome, this framework was limited in its transferability to the university environment and lacked some logic in its final conclusions. For example, the authors contended that the relationship between kaiako (academic staff) and kaiwhakaako (academic developers) "must be completely confidential" (Davies \& Eruera, 2009, p. 2). This limited the option to bring Māori academic staff and developers together collectively to share ideas, experiences and challenges.

Davies and Eruera did, however, make a strong case for establishing Māori models of academic development, amongst other things to avoid what Moewaka-Barnes (2006) cited Durie as describing as "how cultural views other than the dominant culture 'tend to be grafted on as perspectives but within conventional disciplinary frameworks'” (p. 12). This suggests a need for a kind of radical transformation of the likes discussed by hooks (1994) and Smith (1997). However, in the context of academic development in the university environment, there is some usefulness in exploring what is happening at the 'interface', a term used by Moewaka-Barnes and Durie to talk about the place where Indigenous and scientific knowledge come together - and also used by Nakata (2004a) to describe the cultural interface in the university context between Indigenous and non-Indigenous ideas and people. 
Working at the interface of Māori academic development within the University of Auckland, Māori academic Dr Robyn Manuel (2010) has written about tika (correct) approaches to small group teaching, and her article is an example of the beginnings of kaupapa Māori academic development. Her former colleague, Ratima, also wrote about his work, "to develop and deliver a collaborative programme of development for Māori staff (Māori staff advancement)" (Ratima, 2011, p. 91). He convened a forum to identify Māori academic staff needs and developed a programme that included: Māori language classes, writing retreats, tutor training, mentoring, promotion support and leadership training (Ratima, 2011, pp. 92-93). He faced a number of challenges in the provision of this wide-ranging programme, including deciding where, within the university structure, the programme should "belong" and how its impact could be measured (Ratima, 2011, p. 94).

Outside of the University of Auckland, Victoria is currently the only other university to employ a Māori academic developer. In that capacity, I have presented on academic development topics at a number of conferences and seminars (for example Adds, Hall, Pohe, \& Rata, 2012; Hall, 2008, 2009, 2010a, 2010c, 2010d, 2011a, 2011b, 2012; Hall \& Sharman, 2012; Te Punga Somerville, Pirini, \& Hall, 2010) and published work on such subjects as Māori teaching pedagogy and specific aspects of Māori academic development (Adds et al., 2011; Chinlund \& Hall, 2010; Hall, 2011c; Higgins \& Hall, 2011; Hobson \& Hall, 2010; Mercier et al., 2013). While this body of work has added to the Māori academic development discourse, it will be substantially strengthened by the outcomes of the research in this thesis.

Calls for more support of Māori scholars and scholarship within the university environment are not new (Hook, 2010; Robust, 2007). Woods (2008) advocated that development opportunities be extended to Māori post-graduate students as a means of moving more into academic careers. Massey University developed a strategy "to position itself to make a positive contribution to Māori development" (Lilley \& Field, 2005, p. 1) via its Te Mata o Te Tau Māori staff forum (Villegas, 2010, p. 215). Te Atiawa scholar 
Dr Gary Hook (2010) suggested that a new national university be "built upon culturally friendly and culturally appropriate values [that] could enhance Māori academic achievement" (p. 1). His ideas go well beyond the scope of this research topic but have the potential to address some of the same concerns.

Smith (2011) suggested that Wānanga, "are often challenged that we're just replicating the structures that we're fighting against". While this may be a criticism levelled at Wānanga, it is also a challenge for Māori academics in all New Zealand universities. Māori academics have been criticised for doing kaupapa Māori research with 'Western' methods and merely following a "checklist" (Mikaere, 2011, p. 31). The challenge is to work in a way that is not merely "Māori friendly" and "more about 'ticking boxes' being seen as sensitive and understanding towards Māori" but instead to be "Māoricentred" so as "to encompass Māori aspirations for autonomy and self determination as a means to establish the forms and forums for Māori participation" (P. Johnston, 2001, p. 5). This is particularly relevant to the Victoria context where the academic development model to date has been more Māori 'friendly' than Māori 'centred'.

Reilly (2011) described how one of the strengths of the University of Otago Māori Studies programme was its collective approach and its conceptualisation of its staff as "a community of scholars, where everyone has a contribution to make to the life of the School" (p. 30). He credited this academic collegiality and development to the traditions and practices of whare wānanga:

This is also a philosophy found within the ancient whare wānanga; an ancestral form which today's Wānanga and Māori Studies programmes affiliate to. Māori Marsden (2003: 78-79) described how a student dedicated to Tāne went into the forest for two weeks 'to meditate and fast' before facing an examination from his teachers at the wānanga. When asked what the spirit of Tāne had taught him, he described how he had sat under some kahikatea trees, and reflected on why these trees had such a shallow root system. He had a flash of insight. He realised kahikatea trees 
grow together so that in storms one tree 'is held in place by the roots of another'. Just so, the student realised, a person who is part of a group will be supported by them all 'standing together'. (Reilly, 2011, p. 30)

This analogy from Māori Marsden serves to emphasise the potential and importance of a collective approach to Māori academic development, which seems especially relevant in regard to the development of any new model or approach. It echoes the whakawhanaungatanga (relationship building) concept emphasised in the Te Ataarangi model of Māori language acquisition (Paipa, 2010). Paipa (2010) wrote about how important it was for Te Ataarangi learners and tutors to develop positive relationships, leveraging off the notion of whakapapa connections, in order to have a positive learning experience centred within the kaupapa Māori context of a whare wānanga. It also matches the findings of a study of the Ngā Pae o Te Māramatanga project to produce 500 Māori PhD graduates in 10 years (Villegas, 2010). The researcher found that relationships were central to the approach that was developed to achieve the 500 Māori PhDs goal. She concluded that those relationships were encapsulated in "cultural standards of scholarship" that relied on the "three pillars of whanaungatanga, kaupapa and whakapapa, which are all informed by and based on mana motuhake and a culture of right relationships" (Villegas, 2010, p. 255 \& 256).

A number of scholars have explored the notion of indigenising the academy. Smith (2011) explained that it was about exploring the intersections between 'the academy', 'scholarship' and the Māori 'community', in other words the 'transformation triangle'. Christiansen (2000) argued that, "we need to shape the academy so that it is a place where academic business-asusual includes our business-as-usual" (p. 194). Native American scholars (Alfred, 2004; Pewewardy, 2004; A. C. Wilson, 2004) have also theorised the notion of indigenising the university space, with Gone (2004) noting that it appeared to be a compromise about what "we are willing to adopt from the Western University tradition, what we are willing to adapt of our own epistemological traditions, and which aspects of these disparate traditions we are prepared to omit from the transaction altogether" (p. 134). This is 
similar to the idea that Penetito (2005) wrote about in his thesis where he advocated for a form of imbrication or overlapping to occur between Māori and Pākehā education systems. These approaches also share ideas with other Indigenous examples of academic development (Baalawi, 2008; Bunda \& White, 2009; Fredericks, 2008). Johnsrud (1993) gave three suggestions for how institutions could retain Indigenous and minority academic staff and encourage their success. Her 'propositions' were that,

(a) Institutions must ensure that the appropriate supports and incentives for research, service, and teaching are available and accessible to women and minority faculty;

(b) Institutions must create structures that enable department chairs and senior faculty to facilitate the success of women and minority faculty; and

(c) Institutions must attend to the climate of their campuses and create a culture that honors gender and ethnic diversity. (Johnsrud, 1993, pp. 9, 10 $\& 12)$

Each of these propositions relates directly to a possible framework for Māori academic development.

Another consideration relevant to this topic is the evolving notion of dual tradition scholarship. At Trent University in Canada, academic appointments, tenure decisions and promotions all validate expertise in Indigenous knowledge and methods, such as "knowledge of language and traditional customs, rites, rituals, and teaching of a particular group of Aboriginal people or peoples" (Sheridan, 2004; P. Stewart, 2010). Under that regime, Shirley Williams, of the Nishnaabe-kwe people, became the first person in Canada to be promoted to full professor on the basis of her knowledge of the Anishinaabeg traditions and contributions to the Ojibway language (Sheridan, 2004). Thus, scholarly competence as assessed by relevant peers was on the basis of Western expertise, Indigenous knowledge and skills, or a combination of both (P. Stewart, 2010). This is one more element to consider in the articulation of a Māori academic development framework. 


\subsubsection{Concluding comments about Māori academic development}

Despite being a relatively new field of study, the term 'academic development' has been understood to mean teaching and learning-related theory and practice for academics working in tertiary education institutions. However, there is still a great deal of academic attention on this topic, and an alternative view has emerged that academic development should focus on more than just teaching and also include academic practice more broadly. Bawden's (1991) three ways of knowing, combined with Henry and Pene's (2001) kaupapa Māori definition, provide a useful frame for considering what it is like to 'be' a Māori academic, what a Māori academic needs to 'know' and what a Māori academic needs to learn to 'do'. In addition, Blackmore's (2009) ISIS model offers some guidance about inclusive principles that can underpin university approaches to academic development. Similarly, Wenger's $(1998,2000)$ concept of communities of practice also highlights the power of the collective and the impact that such groups can have on their own development - a point reiterated by Billet (2001) who stressed the importance of social context in considering how to assist others to develop expertise. Thus, it is important that any development plans acknowledge the experiences of Māori academics in their university environments and groupings, and their social contexts and preferences.

Te Matawhānui and the MANU AO Academy have both provided opportunities and leadership around Māori academic development in the past but neither was cohesive enough to provide a comprehensive academic development programme for Māori staff. Limited research has been published to date about Māori academic development (Hall, 2008, 2011a, 2011b; Manuel, 2010; Ratima, 2011, pp. 92-93) and none of it has outlined a comprehensive, research-based framework for conceptualising and delivering academic development for Māori academic staff in New Zealand universities. While Davies and Eruera's (2009) Māori academic development model presented a possible approach, its wānanga context limited its applicability to universities. 
Some Māori scholars have called for more Māori-centred university structures and development opportunities (Hook, 2010; P. Johnston, 2001; Lilley \& Field, 2005; Robust, 2007) and for more support to help Māori postgraduate students to transition into academic roles (Woods, 2008). Others have described the importance of Māori cultural concepts and practices, such as whanaungatanga, whakapapa and mana motuhake, within university environments (Paipa, 2010; Reilly, 2011; Villegas, 2010), and the need to provide appropriate supports, incentives, structures and a climate that encourages Indigenous academic development and success (Johnsrud, 1993). For example, the notion of dual tradition scholarship raised the possibility of academic promotion on the basis of Western expertise combined with Indigenous knowledge and skills (P. Stewart, 2010). Each of these elements can inform a possible framework for Māori academic development; one that applies to the 'transformation triangle' of the academy, scholarship and Māori community (G. H. Smith, 2011) and includes, merges or overlaps with Indigenous norms (Baalawi, 2008; Bunda \& White, 2009; Christiansen, 2000; Fredericks, 2008; Gone, 2004; Penetito, 2005).

\subsection{Chapter summary}

Irwin (1997) advocated for the role of academic "critic and conscience" to be turned inwards, and for the workings of the university system to be scrutinised from Māori perspectives. This chapter is about interrogating the existing literature about kaupapa Māori, Māori academic experiences and Māori academic development with a view to informing a kaupapa Māori approach to Māori academic development within New Zealand universities. It has identified a number of key elements and factors to take into account in the development of a new approach to Māori academic development, and also exposed a range of questions and areas in need of further research.

The review of kaupapa Māori literature revealed a range of disparate and diverse definitions, understandings and applications, from both Māori and non-Māori scholars. One potentially constricting kaupapa Māori-related 
challenge for this thesis is whether it can be defined as a kaupapa Māori project when it is 'by Māori' (i.e. conducted by a Māori researcher), 'for Māori (i.e. focussed on Māori academic development), and 'with Māori' (i.e. drawing on Māori academic interviewees), yet is located, physically and conceptually, within the auspices of a university. On balance, this analysis of the kaupapa Māori literature determined that it is possible, provided the project is essentially controlled by Māori, and is engaged in gathering or creating Māori knowledge, challenging Western assumptions and/or seeking positive transformation for Māori communities. Thus, this thesis has taken a 'kaupapa Māori as ordinary' research approach within a university setting (Moewaka-Barnes, 2000). While these additional qualifiers could be better incorporated into Cunningham’s (2000) kaupapa Māori research taxonomy, drawing on kaupapa Māori theory as the philosophical basis for this thesis has shaped its format and methodological choices, the implications of which are discussed in Chapter Three.

A number of "mental constructs" (Dei et al., 2000) emerged while reviewing the literature about the experiences of Māori academics. It became clear that being Māori is a key part of their academic identity, which has both positive and negative impacts on their work within and enjoyment of the university context. Similarly, the desire to contribute towards, preserve and protect the Māori culture, society and people emerged as a common motivation for Māori academics. Some of the literature highlighted experiences of racism and discrimination within universities, which led Māori academics to either resist or assimilate to varying degrees. Others wrote of needing space to be Māori, and of wanting to teach and conduct their research in ways that were underpinned by their particular Māori beliefs.

Clegg (2007) suggested that, "understanding academic identity is important because it helps to explain both the resilience of certain beliefs and the ways in which academics act" (p. 9). Thus, focusing on Māori academic identity in the literature proved relevant for this thesis, as understanding both the beliefs and actions of Māori academics is crucial to the goal of developing a Māori academic development framework. Similarly, understanding the 
other motivations, beliefs, and academic practices that underpin Māori academic experiences is also essential.

The review of relevant academic development literature revealed the need to recognise the social context of the communities in which Māori academics operate, and to develop a Māori-centred framework based on Māori understandings of what is tika. Such a framework would provide an alternative to the current grafted on approach whereby support and training for Māori about academic practice is simply a reproduction of what is offered for all academic staff. The review also revealed a number of elements that need to be factored into the creation of a more inclusive Māori academic development space. These include a focus on what it was like to 'be' a Māori academic and what they should 'know' and 'do' (Bawden, 1991; Henry \& Pene, 2001), which, based on the Māori academic experience literature, can be quite different to other academics. Other factors include the importance of relationships, the need for a degree of Māori autonomy, and the creation of opportunities for Māori academics to succeed as Māori.

Overall, this literature review demonstrated that more work is needed to determine exactly how Māori academic identities, cultural practices and relationships can and do impact on the development of Māori academics. It also identified a gap to be explored around the potential for conceptualising and delivering academic development for Māori academics that is cognisant of the 'cultural interface' operating within the university context. The remainder of this thesis addresses both of these areas. Chapter Four shares interviews with Māori people who talk in detail about their experiences as academics in New Zealand universities. It focuses on what Nakata (2007, p. 216) described as "what is left unsaid in the everyday", such as what it is like being the only Māori academic in the class, programme or meeting and how that impacts on their actions, beliefs, and enjoyment of their work. Later in the thesis, Chapter Five presents the overarching themes that emerged from those interviews, a synthesis of the interview themes with the key ideas that emerged from the literature review, and a comprehensive, research-based Māori academic development framework. 


\section{Chapter Three: Methodology and Methods}

This chapter sets out the principles and processes used to conduct the research for this thesis. It canvases the underpinnings of kaupapa Māori research methodology, introduces Interpretative Phenomenological Analysis (IPA) and gives a step-by-step description of the various stages to collect and analyse the data for this project.

\subsection{Kaupapa Māori methodology}

Despite having already discussed a great deal about kaupapa Māori in the previous literature review chapter, the material about kaupapa Māori research processes has been reserved for this section on methodology. Along with all its other descriptors (see Chapter Two for details), kaupapa Māori has been described as a methodology, "wherein research is conceived, developed, and carried out by Māori, and the end outcome is to benefit Māori" (S. Walker et al., 2006, p. 331). This is often truncated simply to research "by, with and for Māori" (Tawhai et al., 2004, p. 335). As a research project conducted by a Māori researcher, about the development of Māori academics, and for the benefit of the Māori academic community, this thesis therefore aligns with kaupapa Māori methodology. As a methodology, kaupapa Māori aligns within Rigney's (1999) broader notion of 'Indigenist' research. His conceptualisation of research as "emancipatory, incorporating activist dimensions of resistance, political integrity and the privileging of Indigenous voices" is inclusive of kaupapa Māori and resonates with the design and purpose of this research (Asmar \& Page, 2009, p. 390).

\subsubsection{Selecting kaupapa Māori as my methodology}

I chose kaupapa Māori as the overarching methodology for this research for a number of reasons. One was to validate the knowledge and experiences of Māori academics, without minimising their voices or framing them within a Western paradigm. Such an approach would not have produced research that fully reflected the aspirations and needs of Māori academics. 
Another reason for taking a kaupapa Māori methodological approach was explained by Irwin, who also wanted to undertake "research as a Māori academic, not as an academic who happens to be Māori" (Irwin, 1994, p.27). As a project led by a Māori academic about Māori academics it was important that this research was also undertaken in a scholarly Māori way.

While selecting the methodology for this research was straightforward, a question remained about how to conduct this sort of kaupapa Māori research. There is a range of views espoused in the literature about this because, "just as Māori are diverse, the approaches used will also be diverse" (Mane, 2009, p.7). Thus, the next part of this chapter discusses kaupapa Māori methodology and practice, particularly as it relates to this research.

\subsubsection{Applying a kaupapa Māori methodology}

Smith and Reid (2000) noted that, "kaupapa Māori research is not singular nor should it be given the diversity of our experiences and backgrounds; however it can be argued that there are key tenets that inform Kaupapa Māori research" (p. 18). Initially articulated by Graham Hingangaroa Smith (1990b) as six elements, those key aspects of kaupapa Māori methodology have since been expanded by other kaupapa Māori researchers to include eight principles, as depicted in Table 3.1 ("Rangahau", n.d.).

Table 3.1 Key principles of the kaupapa Māori methodology ("Rangahau", n.d.).

\begin{tabular}{|l|}
\hline Principles of kaupapa Māori research \\
\hline 1. Tino rangatiratanga (self-determination) \\
\hline 2. Taonga tuku iho (cultural aspiration) \\
\hline 3. Ako Māori (Māori ways of learning and teaching) \\
\hline 4. Kia piki ake i ngā raruraru o te kainga (socio-economic mediation) \\
\hline 5. Whānau (extended family structure) \\
\hline 6. Kaupapa (collective philosophy) \\
\hline 7. Te Tiriti o Waitangi (Treaty of Waitangi) \\
\hline 8. Āta (respectful relationships) \\
\hline
\end{tabular}


The first principle underpinning kaupapa Māori research processes is tino rangatiratanga, the principle of self-determination ("Rangahau", n.d.). The term tino rangatiratanga derives originally from the Māori text of the Treaty of Waitangi and alludes to the notion of "absolute sovereignty" or "unqualified chieftainship" (R. Maaka \& Fleras, 2005, p. 97; Ryan, 1997). As a principle of kaupapa Māori research and activity, the inclusion of tino rangatiratanga resonates with the emancipatory nature of kaupapa Māori theory (Bishop, 1998). The overarching aspirations, held by many iwi (Māori tribes) and individuals, of gaining Māori self-determination within New Zealand match a similar desire for autonomous and culturally appropriate practice in kaupapa Māori research. In fact, Bishop and Glynn (1999) took the broad notion of self determination and applied it in relation to kaupapa Māori research, suggesting that it was about Māori power and control over the research processes of "initiation, benefits, representation, legitimacy and accountability" (p. 106). Kana and Tamatea (2006) described it as, "a collaborative approach to power sharing" that "demands that ownership and benefits...belong to the participants" (p. 10). In a similar vein, Tawhai, Pihera and Bruce-Ferguson (2004) explained that kaupapa Māori research needed to be initiated and disseminated by Māori, to benefit Māori and honour their voices and realities, and that researchers needed to be accountable to their Māori community (p. 336).

The second overarching principle of kaupapa Māori methodology is taonga tuku iho, the principle of cultural aspiration ("Rangahau", n.d.). In its general sense, this is cognisant of the Māori cultural revitalisation that gained traction in the 1980s and continues into the present (Moon, 2009). The cultural renaissance period began with concern over the survival of the Māori language and soon flourished into other domains, such as Māorimedium education, Māori broadcasting and Māori performing arts. In its research context, it relates to the requirement that kaupapa Māori research seeks to make a positive contribution to Māori knowledge and practice.

The third principle of kaupapa Māori methodology is ako Māori, which relates to the reciprocal nature of Māori learning and teaching practices 
(Greenwood \& Te Aika, 2009). This notion of Māori pedagogy was expounded in the work of Māori scholar Rose Pere (1982) who wrote of the interconnection between the teacher who learns and the learner who teaches. In a kaupapa Māori research content, it has been defined as practices that are "able to closely and effectively connect with the cultural backgrounds and life circumstances (socio-economic) of Māori communities" (G. H. Smith, 1991b, p.21).

The fourth principle of kaupapa Māori research methodology is kia piki ake i ngā raruraru o te kainga, the principle of socio-economic mediation ("Rangahau", n.d.). In New Zealand's post-colonial era, Māori people have historically and collectively suffered from low socio-economic status (Cram, 2011). Addressing this imbalance and making a contribution to the transformation of Māori society has become a goal for kaupapa Māori research and researchers, either directly or indirectly (Bishop, 1998).

The fifth principle is whānau or the principle of the extended family structure, which pays tribute to the traditional Māori social organisation ("Rangahau", n.d.). The whānau structure of grandparents, parents, children, aunties, uncles, and cousins was a key social network for Māori in the precontact period and provided the support and sustenance required to survive in the challenging climate and environment of Aotearoa (Herbert, 2011; Metge, 1995). In a research sense, the concept of creating, nurturing and relying on a supportive and extensive Māori network is a key element of kaupapa Māori methodology.

The sixth principle is kaupapa, the principle of collective philosophy ("Rangahau", n.d.). This denotes an understanding of Māori epistemologies and ontologies and an adherence to tikanga Māori practices. In relation to kaupapa Māori methodology, it is what elevates the research from merely Māori-friendly to Māori-centred (P. Johnston, 2001).

The seventh principle is Te Tiriti o Waitangi, the principle of the Treaty of Waitangi ("Rangahau", n.d.). The use of both the Māori and English names suggests that this principle relates to both versions of the Tiriti/Treaty 
("Treaty of Waitangi," 1840) or even the more recent Treaty principles articulated by the Crown (Department of Justice, 1989). Nevertheless, given the nature and focus of kaupapa Māori research, this principle has a strong connection to the Māori version, Te Tiriti, which has an emphasis on the tino rangatiratanga and protection of taonga (treasures) guaranteed to Māori in Article Two, and the Crown's Article One right to kawanatanga (governorship). Thus, in a kaupapa Māori research context this principle establishes a platform on which Māori-centred research is valued and interactions with the Crown are approached from a position of Māori authority or, at the very least, partnership.

The eighth and final principle is āta, the principle of growing respectful relationships. Traditional Māori society was hierarchical and highly regulated by tikanga Māori (Māori practices) and a well-defined set of social conventions (H. M. Mead, 2003). In contemporary New Zealand society, many of those formal Māori structures and functions are no longer prominent, except in specific tribes and/or geographical areas. There are, however, still many Māori cultural practices that instil respect for others including, for example, the mana (reverence) given to kaumātua (the elderly), the manaakitanga (hospitality) shown to manuhiri (guests), and the aroha (love) shared with tamariki (children). The principle of àta applies to kaupapa Māori research in both the way that research projects are convened and managed, and how the research team interacts with each other. It also applies to the positive relationships that develop and are maintained with research participants and communities, and the respect with which their data and knowledge is handled (McIntosh, 2003).

\subsubsection{Application of kaupapa Māori principles to this research}

In the context of this research project, the principle of tino rangatiratanga is somewhat constrained by the limitations of the Western academy - this research is about academic development within a university and is presented in the form of a doctoral thesis. However, a limited form of selfdetermination was achieved by this research via the re-conceptualisation of 
academic development practices to take into account the needs and experiences of Māori academics. Also, the applied form of tino rangatiratanga described by Bishop and Glynn (1999, p.106) is reflected in the design of this research. The project was initiated in partnership with Māori academics, and it is these and other Māori academics that will benefit. The interviews and the process used to analyse them have ensured that the voices of the Māori academics are central. The research also focused on the 'realities' of the Māori academics involved and the project has been accountable to the Māori academic community.

In the context of this research project, the principle of taonga tuku iho relates to whatever aspirations the Māori academics involved in the project chose to articulate. Similarly, the third principle of ako Māori is closely aligned with the aims of the project because of its focus on developing an approach to academic development that aligns with Māori understandings of what it means to be an effective and successful academic. The connection between this research and the fourth principle of socio-economic mediation is less obvious. However, as education is key to achieving Māori socioeconomic success, this project supports the development and success of Māori academic staff who will go on to educate Māori students.

While this research project was not set within a family context, arguably the strong sense of belonging and connectedness within the Māori academic community, and the collegial approach taken with this research, emulates some of the whānau principles of providing nurture, sustenance, guidance and companionship (Metge, 1995). The kaupapa principle also applies to this research in a number of ways, such as the new approaches to academic development identified as a result of gaining a greater understanding about the collective experiences and needs of Māori academics, and the quest that initiated this project to ensure that the support provided to Māori academics is culturally enhancing and appropriate.

New Zealand universities, as government-funded institutions, are subject to Section 181(b) of the Education Act 1989 and have a duty to take into 
account the principles of the Treaty of Waitangi. This includes making good decisions in the best interests of Māori staff and students. In relation to this thesis, those Treaty obligations extend to the provision of culturally appropriate and well-supported academic development for Māori staff, which is the primary focus of this thesis. Also in the context of this research, the àta principle can be seen in the way that interviewees were recruited, personal relationships with each person were maintained before, during and after interviews, and feedback and follow-up academic development opportunities were provided based on the research findings.

\subsubsection{Additional principles of kaupapa Māori methodology}

In addition to the eight principles already discussed, Smith (1999) also outlined what she believed to be key elements of kaupapa Māori methodology. She highlighted whakapapa, te reo Māori, tikanga Māori and, once again, rangatiratanga. She explained that the inclusion of whakapapa (genealogy) related to Māori epistemology, which connects Māori people to each other, the atua (gods) and all living things (R. Walker, 1992). Royal (1998) and Graham (2009) also advocated the use of whakapapa as a Māori research tool.

While each of these points adds important detail to the kaupapa Māori discourse, not all were relevant to this research. For another research topic, perhaps something encompassing a more traditional Māori or Māori-centric community or context, using whakapapa as a research tool may be entirely relevant and appropriate. Many of the interviewees in this project spoke about their whānau connections but whakapapa was not used as a research tool for this thesis.

Furthermore, it was also not appropriate for this research to be conducted in te reo Māori. A number of the Māori academics who agreed to give an interview for this project were unable to express themselves well entirely in the Māori language. However, all of the interviewees were comfortable expressing themselves in English and te reo Māori, as they saw fit, and many of them used Māori language terms and phrases throughout their interviews. 
In a similar vein, this research was not conducted in strict adherence with tikanga Māori. For example, the interviews were not conducted on marae and did not begin and end with karakia (prayers). Interviewees were not given additional koha (gifts) at the end of interviews. However, the interviews were held in places chosen by the interviewees, either in their offices or at a nearby café, so that the venue was convenient and comfortable for them. Also, in lieu of koha, kai (food) was provided at every interview as an expression of manaakitanga and gratitude for the interviewees giving up their time to share their experiences. Each interviewee also received a transcript of their interview and many of them responded to say that they were grateful to have a written record of their academic journey to date and their career aspirations and goals.

Cram (2009, pp.313-317) drew on Smith's earlier work and elaborated on her initial principles. She provided a list of seven guidelines for conducting kaupapa Māori research, as depicted in Table 3.2.

Table 3.2 Guidelines for conducting kaupapa Māori research (Cram, 2001, pp. 42-49; 2009, pp. 313317)

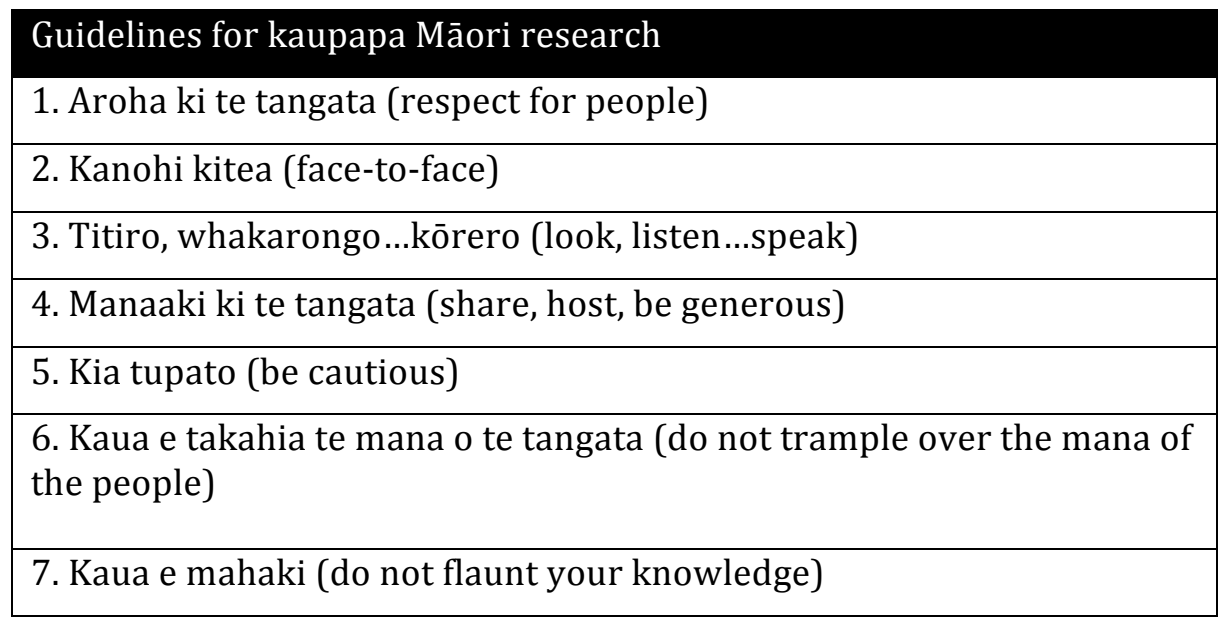

Cram's (2009) first guideline is aroha ki te tangata, which she described as "a respect for people" (p. 313). This is similar to the āta principle outlined earlier ("Rangahau", n.d.). In this research, it was manifested in the way that the interviewees were respected and treated with care. It was also evident in the way the project was framed to not take a deficit approach (B. Jones, Ingham, Davies, \& Cram, 2010, p.1) - for example, it was carefully structured 
so as not to be about what was 'wrong' with Māori academics or fall prey to a 'cul-de-sac' theory that blames Māori and offers no acceptable Māori explanations (Bishop, 2003, p.223).

Cram's (2009) second guideline, kanohi kitea referred to the need to "present yourself face-to-face" (p. 314). This aligns with the decision to gather data for this research through interviews instead of a survey. Surveys can be a very valuable vehicle for collecting data about a range of Māori topics; however, this particular research was strengthened by the fact that the participants' stories were collected face-to-face and were not written on a form, typed online or given to a stranger. The interviewees were able to give richer explanations and answers, and the ability to ask follow-up questions in the interviews allowed for lines of enquiry to be followed in a way not possible by pre-determined survey forms.

For another project, the kanohi kitea guideline may be less relevant. Recent research about Māori use of social media has suggested that online forums have become a comfortable sphere for many Māori to share their intimate experiences and beliefs (O'Carroll, 2013). Thus, the kanohi kitea concept may eventually become subsumed into the earlier notion of $\bar{a} t a$, the requirement to develop 'respectful relationships', whether that be in person or virtual form.

Cram's (2009, p. 315) third guideline, "titiro, whakarongo...kōrero", which she described as 'look, listen...speak', alluded to letting the research participants lead the process (Cram, 2009). This was a challenge during the data collection phase of this project as there was a temptation to share with the participants the ideas that had been generated during the literature review process, and to empathise with them and swap similar experiences. The complexities of being an 'insider' researcher are discussed later in this chapter (Section 3.1.5). On reflection, however, the familiarity created by forming respectful relationships and engendering a whānau environment, which are both encouraged by kaupapa Māori methodology, did not undermine the participants' abilities to tell their own stories in their own 
ways.

Cram (2009) described her fourth guideline, manaaki ki te tangata, as sharing with and hosting people, and being generous (p. 315). As noted earlier, interviewees for this project were given refreshments and transcripts. The reminder to 'be generous' though can be extended through to the research dissemination phase, where the findings from this research will, hopefully, be used to benefit the Māori academic community.

The final three guidelines in Cram's (2009) list - kia tupato (be cautious), kaua e takahia te mana o te tangata (do not trample over the mana of the people) and kaua e mahaki (do not flaunt your knowledge) - all had relevance from both cultural and scholarly perspectives (Cram, 2009, pp. 316-317). They acted as reminders in this research not to over-extend the research brief, over-use or over-expose the research participants, or overstate the research findings.

While each of Cram's guidelines seem reasonable and achievable, MoewakaBarnes (2006, p. 6) warned against limiting what is considered to be 'authentic' kaupapa Māori research simply to that which is regarded as 'traditional'. While recognising the historical preference, for example, "given to kanohi ki te kanohi (face-to-face) methods and qualitative rather than quantitative approaches", she suggested that care be taken "not to compartmentalise and limit Māori" (Moewaka-Barnes, 2006, p. 6). By the same token, while this research fits within the broad descriptors, its location within a Western university setting may appear inauthentic to some exponents of kaupapa Māori research (Holdaway, 2002). However, in line with Moewaka-Barnes' challenge to avoid compartmentalising Māori research, this topic provided an opportunity to grow kaupapa Māori research in a new area. The measure of this research is not whether it 'ticked the boxes' but how it reinvented and reshaped those boxes to this study-specific enactment of kaupapa Māori.

Bishop (2003), another of the key authors on kaupapa Māori research methodology and a contributor to the principles espoused earlier, 
developed a model based on the concept of whakawhanaungatanga that he described as the researcher's, "connectedness, engagement and involvement with others in order to promote self-determination, agency and voice" (p. 228). He elaborated on the concept, suggesting three factors that facilitated such an approach, namely: the establishment of whānau of interest; researchers who understand themselves to be involved somatically in the research process; and participatory research practices (Bishop, 2003, pp. 228-229). In relation to this research project, the 'whānau of interest' is the Māori academic community - its members were active participants in the project itself and they will reap the benefits - and thus the project matches Bishop's whakawhanaungatanga factors.

Finally, Ka'ai (1995, pp.110-111) published an extensive list of kaupapa Māori research procedures. They are highly prescriptive and appear somewhat inflexible, although many are consistent with the core kaupapa Māori principles espoused earlier ("Rangahau", n.d.; Bishop, 2003; Cram, 2009; L. T. Smith, 1999). Aligning with the tino rangatiratanga and āta principles ("Rangahau", n.d.), Ka'ai (1995) recommended that the Māori research community "must be consulted about the nature of the research", their agreement must be received before the research begins, and all sources of knowledge must be cited in the text of the research (pp. 110-111). She also recommended that the research, "be mutually beneficial to that community and the researcher" (Ka'ai, 1995, p. 110), which is in keeping with the principle of socio-economic mediation, kia piki ake ingā raruraru $o$ te kainga ("Rangahau", n.d.). Ka'ai (1995) advised that kaupapa Māori researchers must "regularly inform, consult and update" their Māori community about research methodology and outcomes, and also recognise "the honour and privilege of accessing Indigenous knowledge" (p. 110). Both of these ideas were mirrored in Cram's (2009) philosophy, kaua e takahia te mana o te tangata.

Applying the principle of ako Māori ("Rangahau", n.d.), Ka'ai (1995) advocated that "the researcher accepts unconditionally that there are reciprocal obligations to the Māori community in agreeing to their research 
to proceed" (p. 111). Similarly, in her interpretation of the kaupapa principle ("Rangahau", n.d.), Ka'ai (1995) recommended that kaupapa Māori researchers observe Māori protocol "at all times” (p. 111). Finally, in keeping with Cram's (2009) manaaki ki te tangata principle, Ka'ai (1995, p. 111) endorsed the provision of koha aroha (gifts of appreciation) and advised that the final research output be given to the Māori community.

There are many synergies between Ka'ai's protocols and this research project. For example, the topic evolved from academic development issues that were raised by Māori academic staff themselves, and participation in this research was voluntary. The participants' responses have been attributed, although the use of pseudonyms has protected their privacy. The results of this research have direct benefits for the Māori academic community and do not only benefit the researcher. The interviewees were kept informed about the research progress. As noted earlier about the application of Smith's (1999) tikanga Māori principle, where appropriate, Māori customs were followed, including the provision of koha in the form of food and transcripts.

\subsubsection{Etic and emic}

Higgins (2004) wrote that, "Indigenous researchers believe that all ethnographic research should be based upon and informed by a participatory or insider position, rather than on one which remains detached or outside that society" (p. 18). While this may be a view shared by other kaupapa Māori researchers, a lingering concern remains about whether the resulting research will be considered robust and valid by other scholars. Weighing in to that debate, Williams' (2010) work about 'traditional' Māori research provided some interesting conclusions that apply equally to contemporary Māori research topics, such as this thesis. He highlighted some of the limitations of relying solely on outsider (etic) sources or perspectives but warned equally of the dangers of overly privileging insider (emic) insight. Instead, he argued for an integrated methodology that acknowledged the etic and the emic, creating an 'etmic' 
approach to Māori research whereby "the researcher can see both the wood and the trees" (J. Williams, 2010, p.108).

In the context of this research, it may be criticised by those who think that it offers too much 'insider' perspective due to my familiarity with the interviewees and a vested interest in the research outcomes. However, another person without any personal connections may not have been able to gain enough of the interviewees' trust for them to be comfortable sharing their fears and dreams. Also, if an 'outsider' had gained their trust, that person may not have been able to understand their perspective or interpret their responses in an accurate social or historic context. In addition, any 'insider' limitations were mitigated by my commitment to following a rigorous and transparent method for the analysis of the interview transcripts. These circumstances combined so that my 'etmic' perspective became something akin to what Freire (1974, p. 134) referred to as a "concrete reality" located somewhere between subjectivity and objectivity.

\subsubsection{Challenges of a kaupapa Māori methodology}

Applying a kaupapa Māori methodology is not without its inherent challenges but it also requires additional processes and checks not demanded of the university doctoral programme. For example, it requires an appropriate mechanism for disseminating this research back to the Māori community, in a way that also shares the rewards (Kana \& Tamatea, 2006; Lopez, 1998). It also requires knowing whether and how agreement from my research community has been maintained, as per Ka'ai's advice. Trudgett (2009) observed that, "a lot has been written about protocol in Indigenous communities but not much about protocol in the Indigenous academic community" (p. 12). She wondered if that was because "appropriate protocols are not easy to define, due to the diversity of personalities governing Indigenous higher education" (Trudgett, 2009, p. 12). Based on this research experience, another factor may be that the familiarity that Māori academics have with research processes makes some of the more formal protocols seem redundant or, at the very least, not need explanation. 
Another challenge derives from Moewaka-Barnes' (2000) proposition that kaupapa Māori theory and methodology is simply about positioning Māori views and experiences as 'ordinary'. If this research was about Māori academic development within a Māori environment, such as a wānanga, then kaupapa Māori methodology would reflect the lived reality and any resulting methods would be both consistent with kaupapa Māori theory and with the principles and values of the wānanga. The methodology of this thesis would also be familiar to the supervisors and examiners. However, this thesis, while produced using kaupapa Māori methodology and on the topic of Māori academic development, is located within the non-Māori paradigm of the Western academy. Its quality assurance mechanisms, such as external examiners and oral defences, are not generally aligned with kaupapa Māori methodology or Māori beliefs, values and practices, which creates a challenge.

Finally, it is heartening to note that the aspects of conducting kaupapa Māori research that are challenging, and the continuing development and refinement of kaupapa Māori methodology, are not surprising or unusual. Webber (2009) explained that, "all theories and methodologies need to evolve, to ensure they address the changing time, space and cultural contexts. Thus, further revisions of how research might proceed - for, with and by Māori - need to be embraced" (p. 4).

Just as the articulation of kaupapa Māori methodology has evolved, so too has the application of kaupapa Māori methodology within this research project. This adaptation occurred in part because of the context in which this research has taken place, namely the university environment, but also as a result of the research topic developing and the kaupapa Māori literature becoming more familiar to me.

\subsection{Method for this research}

For all of the underlying principles that are provided for kaupapa Māori research, huge flexibility is allowed in the selection of methods that can be 
used. As Moewaka-Barnes (2000) noted, "methods are likely to be subordinate to the issues and utility of the research and may be drawn from a range of methodologies", because the "usefulness and ownership of the research are of paramount importance" (p. 5). However, despite that assurance, it was still important that the methods selected for this project were consistent with the kaupapa Māori principles espoused earlier.

In keeping with the nature of the kanohi kitea and whānau principles so central to the kaupapa Māori methodology, it was appropriate to conduct indepth interviews with Māori academic staff in order to find out about their experiences (see Chapter Four). That then necessitated the selection of a method for analysing and making sense of the interview data that was consistent with the principles of kaupapa Māori methodology but also provided a systematic process to follow. This was important because, as Maaka (2004, p.5) noted, "whoever controls research methodology, controls knowledge" (p. 5). In order to produce a piece of kaupapa Māori research, the control of the knowledge had to remain Māori. The challenge was to find an appropriate method to code the interview data that suited a kaupapa Māori methodology.

\subsubsection{Interpretative phenomenological analysis (IPA)}

After reading and learning about a number of approaches that might be compatible with kaupapa Māori methodology (Eketone, 2008; B. Jones et al., 2010; Mane, 2009; Ratima, 2008; L. T. Smith, 1999), I selected IPA as the method to analyse the interview data for this thesis. IPA offers the flexibility to be able to observe the protocols necessary for kaupapa Māori research, while also offering enough structure to ensure that the research findings are rigorous and valid, and it has been used in at least one other kaupapa Māori research project (B. Jones et al., 2010).

Another of the reasons I selected IPA was because it is deemed to be "particularly suited to researching in 'unexplored territory,' where a theoretical pretext may be lacking" (Reid, Flowers, \& Larkin, 2005, p.23). While there is already much theorising and research about academic 
development, there is very little written work about the experiences of Māori academics and even less about Māori academic development, so in that sense IPA seemed a suitable method.

\subsubsection{Origins of IPA}

IPA is a qualitative method that evolved out of psychology research in the mid-1990s and emerged on to the academic landscape with a paper published in Psychology and Health (J. Smith, 1996). It has since grown and expanded into other fields of enquiry including, for example, cultural identity studies (Timotijevic \& Breakwell, 2000), e-learning (Mayes, 2006), computing industry training (Hitchcock, 2006), occupational therapy and film studies (J. Smith, Flowers, \& Larkin, 2009). The key element that links IPA research, in whatever field it is being conducted, is that "IPA's core interest group is people concerned with the human predicament" (J. Smith et al., 2009, p. 5).

\subsubsection{IPA approach}

Three distinct philosophical areas inform IPA: phenomenology, hermeneutics and idiography. The first of these, phenomenology, "is a philosophical approach to the study of experience" (J. Smith et al., 2009, p. 11) and is concerned with how people "make sense of their personal and social world" (J. Smith \& Osborn, 2007, p. 53). As the initiators of IPA noted, "when people engage with 'an experience' of something major in their lives, they begin to reflect on the significance of what is happening and IPA research aims to engage with those reflections" (J. Smith et al., 2009, p. 3). The idea of a phenomenon or experience having major significance in people's lives is relevant for this research. Being a Māori person in an academic position is a major life experience and is therefore a suitable topic in which to take an IPA approach.

The second philosophical area of knowledge that informs IPA, hermeneutics, is manifest in the interpretative dimension of the IPA approach.

Hermeneutics began with the interpretation of biblical texts but has since 
evolved to include a wide range of material. Three key hermeneutic theorists have heavily influenced its development (Schleiermacher, Heidegger and Gadamer) but at its centre is the notion of using interpretation to uncover the intentions or original meanings of authors (J. Smith et al., 2009).

Some authors have described IPA as involving a double hermeneutic or a two-stage interpretation process: firstly "the participants are trying to make sense of their world" and secondly, the researcher is trying to gain an "insider's perspective" by "trying to make sense of the participants trying to make sense of their world" (J. Smith \& Osborn, 2007, p. 53). This hermeneutic influence on IPA can be best seen in relation to the analysis of interviews. First the interviewees have to interpret the interview questions to their own understanding or interest. Then they have to try to explain their experiences and then, since IPA is "concerned with examining how a phenomenon appears", the analyst has a role in interpreting the interview transcripts in an effort to make sense of the phenomenon (J. Smith et al., 2009, p.28).

The third and final philosophical area informing IPA is idiography. As Smith, Flowers and Larkin (2009) wrote, "Idiography is concerned with the particular" and in the context of IPA that has impact in two distinct ways (p. 29). The first is that the IPA approach is concerned with getting into the detail of an experience. Unlike other research methodologies that attempt to establish 'truths' that can be applied across populations, IPA is more focused on deep analysis. The second is that IPA is interested in the particular experience, process or relationship as it is experienced by a particular person, and is comfortable with the notion that no two experiences will be alike when considered from the participants' unique perspectives. As a consequence of this highly personalised approach, IPA studies are designed to have small samples that are "purposively-selected and carefully situated" (J. Smith et al., 2009, p. 29). Again, that approach resonates with the focus of this thesis because it is not concerned with canvassing a large sample of Māori academics in order to try to assert broad and largely generic claims 
about their experiences and needs. Instead it is interested in a small sample with which to explore the details of Māori academic experiences.

Finally, in addition to its philosophical underpinnings, IPA takes, "an inductive approach (it is 'bottom up' rather than 'top down'). It does not test hypotheses, and prior assumptions are avoided. IPA aims to capture and explore the meanings that participants assign to their experiences" (Reid et al., 2005, p. 20). That is another one of the important reasons why IPA suits this research. This thesis is not framed around an expectation about what should be happening in Māori academic development. Instead it is geared to finding out more about the experience of being a Māori academic so that new and relevant academic development opportunities can be developed that resonate with Māori academics. The latter part takes IPA further than it intends but the former, understanding the experience, aligns squarely with the IPA method.

\subsubsection{IPA project design}

Having decided to conduct interviews with Māori academics in order to get a better understanding of Māori academic experiences, a decision needed to be made about the sample size. The literature about phenomenological research and IPA methodology was instrumental here in guiding the setting of sample size and, to a certain extent, the selection of interviewees. In relation to sample size, Smith, Flower and Larkin (2009) suggested that, "the issue is quality and not quantity, and given the complexity of most human phenomena, IPA studies usually benefit from a concentrated focus on a smaller number of cases" (p. 51). Groenewald (2004) reiterated this point by noting that for phenomenological studies, "two to 10 participants or research subjects [are] sufficient to reach saturation" (p. 11).

In addition to a small sample size, IPA studies seem to work best when the sample is considered to be fairly homogenous. As Smith and Osborn (2007) noted, "the basic logic is that if one is interviewing, for example, six participants, it is not very helpful to think in terms of random or representative sampling" (p. 56). Another reason for selecting a similar 
sample group is that it provides an opportunity, using an IPA approach, to "examine convergence and divergence in some detail" (J. Smith et al., 2009, p. 3). An additional factor came not from IPA or related literature but from higher education research that "pointed out the limitations of national-level research for illuminating the local conditions that shape faculty experiences" (Ambrose, Huston, \& Norman, 2005, p. 805). The advice in this instance was to focus on institution-specific groupings, again, reinforcing the notion of working with a similar group to minimise the impact that significantly different working environments may have on experiences of Māori academics.

Given that this research project needed to satisfy the requirements of a doctoral thesis, it was encouraging to find that Smith, Flowers and Larkin (2009) had written about how many interviews were required for a PhD. As a general guide they suggested a model of three self-contained but related case studies in the form of "a single case study, the second to offer a detailed examination of three cases, and the third to examine a larger sample" (J. Smith et al., 2009, p. 52). As a result of those guidelines, the case study model depicted in Figure 3.1 was developed for this research project:

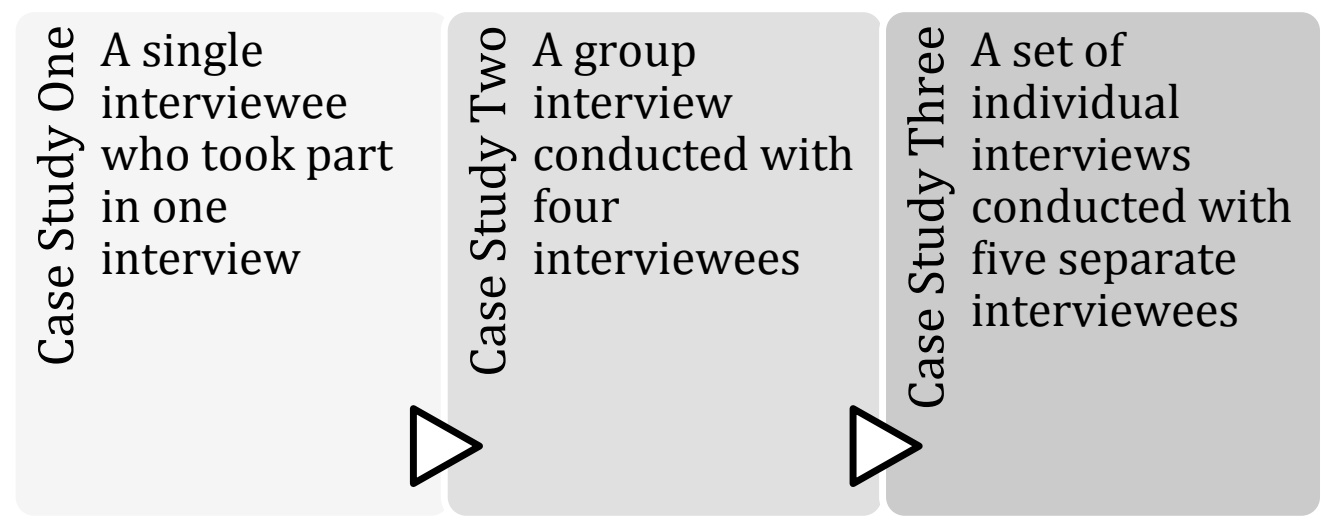

Figure 3.1 Brief description of the three case studies on which this thesis is based.

Each case study in this project was designed to build on the previous one, to test out different, but related, interview questions and to provide an opportunity to develop and refine the IPA processes. In keeping with the research literature, the interviewees in Case Study Two were all from the same institution, as were the interviewees in Case Study Three. The total 
number of interviews analysed for this project was seven (with one interview involving four interviewees). The group interview trialled for Case Study Two followed the advice that, "the use of focus group interviews supports a situational case study method" (Bogdan \& Biklen, 1998; cited in Roland, 2011, p. 8). Three of the participants in the Case Study Two group interview were also involved in the more in-depth interviews of Case Study Three. The interviewees in all three case studies were Māori academics employed in similar academic roles that required them to teach, conduct research, and provide service to the academic community. The interviewees were all recruited using purposive sampling to identify a group of full-time Māori academic staff, and they were invited to participate in the project via email and a follow-up telephone call. The semi-structured interviews, which varied in length from 50 minutes to over two hours, were all digitally recorded and then transcribed.

\subsubsection{IPA analysis}

The IPA process for analysing interview transcripts is clearly laid out in the literature but still allows for variation, depending on the subject and content of the transcripts. IPA practitioners are emphatic about the need to maintain an element of flexibility, and avoid "the danger of 'methodolatory' (the glorification of method)", suggesting that the IPA methodology literature should be seen as "guidelines and recommendations for getting started rather than as permanent prescriptions" (J. Smith et al., 2009, p. 5).

The details of the interview transcript analysis for this project can be found in Chapter Four; however, the principles behind the analysis process are an important consideration. For example, the IPA approach is committed to using verbatim transcripts as the basis for analysis and published IPA work relies heavily on the presentation of verbatim excerpts from the data (Reid et al., 2005). In keeping with the 'I' in IPA, a successful analysis is considered to be one that is "interpretative (and thus subjective) so the results are not given the status of facts" (Reid et al., 2005, p. 20). Therefore, as the author of this thesis, the analysis of the data is mine alone. In order to be considered 
rigorous and scholarly, the analysis is supported by enough evidence to justify the arguments but, ultimately, it relies on one person's interpretation of the interview data (Reid et al., 2005).

Structurally, IPA enables an evaluative process that produces sets of themes, derived from the interview transcripts, which are then ordered into hierarchies and models. This provides opportunities to note commonalities and divergences within the participants' accounts, which all inform the analytical commentary (Reid et al., 2005). Applying this approach in this research project, the focus was to identify hierarchical categories that describe ways of thinking about the phenomenon of Māori academic experience and Māori academic development.

In the key IPA literature, when the authors described the details of their process for analysing their interview transcripts, they wrote of printing out transcripts with wide margins that left room for their scrawled notes and comments. Some authors have rejected outright the possibility of using computer software to aid with the data analysis process, in one instance stating that they "do not help with doing phenomenology" (Groenewald, 2004, p. 20).

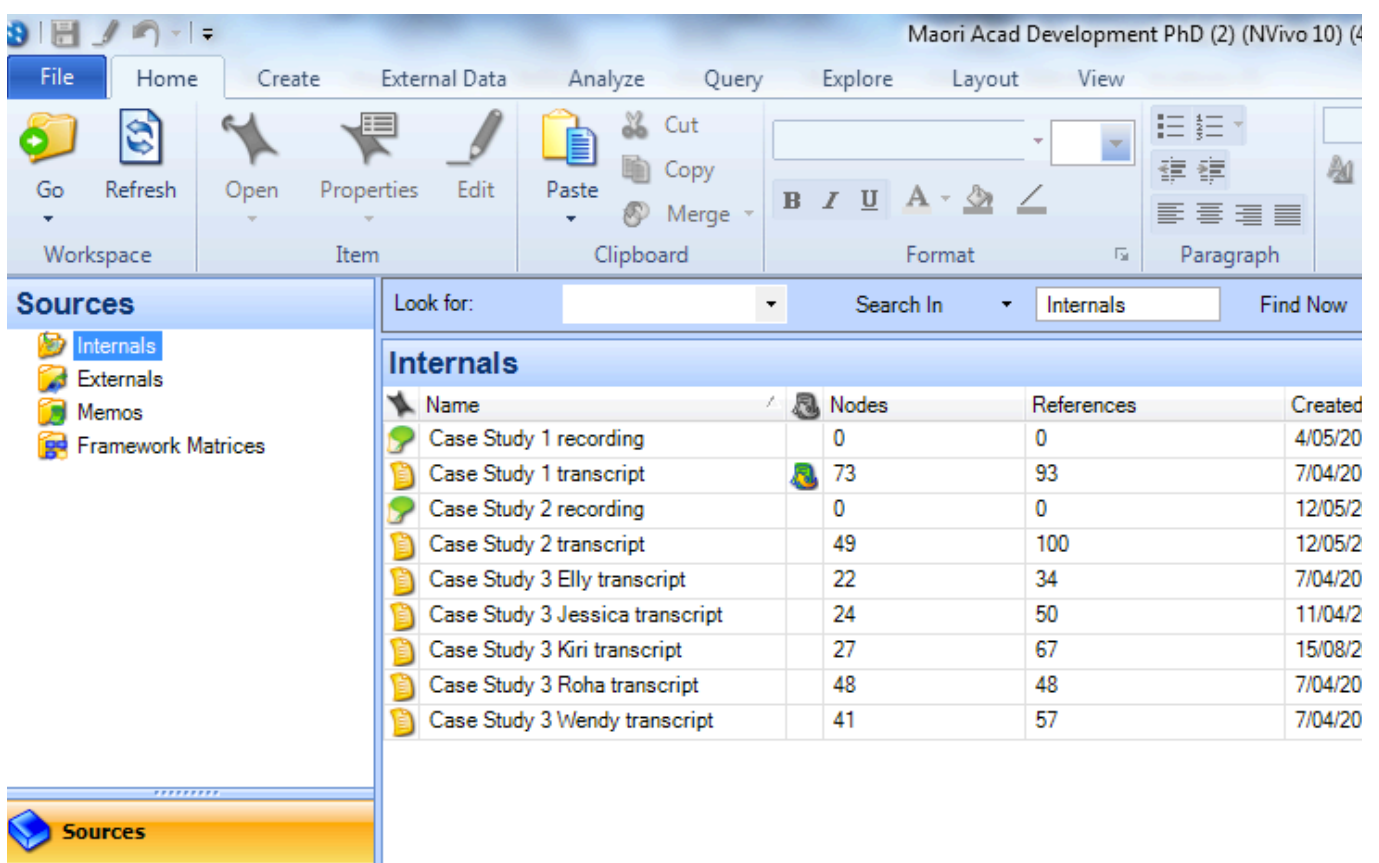

Figure 3.2 Screenshot of the NVivo software once the case study recordings had been loaded and the transcripts had been analysed. 
However, I used the NVivo computer software qualitative analysis tool to store interview recordings and transcripts electronically. Figure 3.2 is a screenshot taken after each of the interview transcripts had been transcribed and saved into NVivo. It shows that coding of the transcripts had begun; for example, the Case Study One transcript already had 73 nodes (i.e. themes) that were connected to 93 references within the transcript. The NVivo software was easy to use and I was able to add new data as the research project developed, to record initial notes about and identify themes within and across transcripts, and to create models to demonstrate the various hierarchies and relationships that emerged between themes.

\subsubsection{IPA and kaupapa Māori methodology}

Leonard (1994) lamented that:

Too often, researchers facilely seize on a method without considering the more profoundly important philosophical assumptions that undergird the method and whether those assumptions are consistent with the researcher's own view of what it means to be a human being. (p. 44)

After considering the philosophical bases that underpin the IPA method, they seemed highly complementary to kaupapa Māori methodology. For example, in IPA research there is an acknowledgement that interviews are not a neutral means of data collection. The interpretivist aspects of the analysis mean that the "interviewer is understood to work with the respondent in flexible collaboration, to identify and interpret the relevant meanings that are used to make sense of the topic" (Rapley, 2001; Reid et al., 2005, p.22). This fits with the kaupapa Māori notions of whakawhanaungatanga and meant that there was support for the interviewer maintaining a relationship with the people being interviewed. In fact, a further endorsement of the suitability of an IPA approach arose from its use in another kaupapa Māori project, 'Whānau Tuatahi', and its authors' belief that IPA, "did not compromise good science or cultural appropriateness" (B. Jones et al., 2010, p.3). 


\subsubsection{Etic and emic and IPA}

Having already canvassed the various etic and emic positions in relation to kaupapa Māori methodology, the issue arose again in relation to IPA. As it emerged, it is not a prerequisite of IPA that the researcher have an 'insider' relationship with the interviewees or topic but there is "certainly a rich tradition of qualitative research carried out from the position" (J. Smith et al., 2009, p.42). Thus, another synergy between kaupapa Māori methodology and the IPA process is that in phenomenological research, "the researcher cannot be detached from his/her own presuppositions and [...] should not pretend otherwise" (Groenewald, 2004, p. 7). That understanding resonates with this research because it acknowledges and makes no apologies for any 'insider' positioning.

Even if the researcher did not begin with an 'insider' perspective, the IPA process, with its inductive and iterative nature, encourages the researcher to develop an 'insider' view (Reid et al., 2005, p. 22). In addition, IPA advocates also recognise that while the researcher may take an 'insider' stance in the initial analysis process where they hold "the participants' worldview at the core", they also create an "interpretative account" of each transcript that makes sense of the participants' experiences (Reid et al., 2005, p. 22). This has been likened to "a balance of 'emic' and 'etic' positions" (Reid et al., 2005, p. 22) or, as Williams (2010) would describe it, an 'etmic' approach.

\subsubsection{Criticisms and challenges of IPA}

Possibly the most common criticism levelled at IPA research, along with other forms of phenomenological research, is that the researcher's lack of neutrality somehow diminishes the validity of the findings. This suggestion was refuted by Rapley (2001), who declared:

Whatever ideals are practised, no single practice will gain 'better data' than the other practices. The 'data' obtained are highly dependent on and emerge from the specific local interactional context which is produced in and through the talk (and concomitant identity work) of the interviewee 
and interviewer. An awareness of this local context of data production is central to analysing interview data whatever analytic stance is taken when analysing the data. (p. 303)

More problematic in this project was the common practice amongst IPA practitioners of conducting research with more than one researcher in order to ensure a form of quality assurance triangulation. Since this is a $\mathrm{PhD}$ thesis in Māori studies, it is required to be a solo effort so there is no capacity to triangulate the data analysis with a co-researcher. Reid, Flowers and Larkin (2005) provided a potential resolution with the suggestion that crossvalidation could be achieved via independent analysis audits. Griffiths (2009) established a form of IPA audit with her supervisor for her PhD, and that process was emulated for this research. My supervisors were shown samples of interview transcripts and the corresponding IPA coding, and they then gave detailed feedback on the draft analysis write-up. In addition, the feedback loop created with the interviewees by providing full transcripts for their approval also helped to mitigate any inferred bias.

\subsubsection{IPA analysis of interviews}

The analysis of the interviews began with Case Study One. The orthodox IPA advice about how to analyse the data suggests transcribing the interview, printing out the transcript, re-listening to the interview, and then identifying themes in the transcript margins (Conroy, 2006). That entire process was followed for this Case Study, with one exception. After transcribing the interview, and becoming fully familiar with the material, the transcript was then uploaded into NVivo. However, care was still taken to read and re-read the transcript on the computer screen, while also replaying the interview recording to highlight linguistic elements like tone, pace and intonation.

Once the interview content was very familiar, the initial noting phase began. This entailed slowly going through the text, highlighting any phrasing or comment that was interesting, either for its "semantic content" and/or "language use" (J. Smith et al., 2009, p. 83). It required being almost overly thorough in this initial process, noting anything that might give an insight 
into the meaning and experience that the interviewee had described. At the same time it was important not to anticipate which notes were likely to be indicative of an eventual theme.

During this initial noting phase, the NVivo memo tool was used to highlight sections of text and then add any related notes. Figure 3.3 shows how the NVivo software enabled sections to be highlighted electronically and allowed them to be linked to coding notes. This process generated a list of numbered comments that, if clicked on, led directly to the corresponding text in the interview transcript.

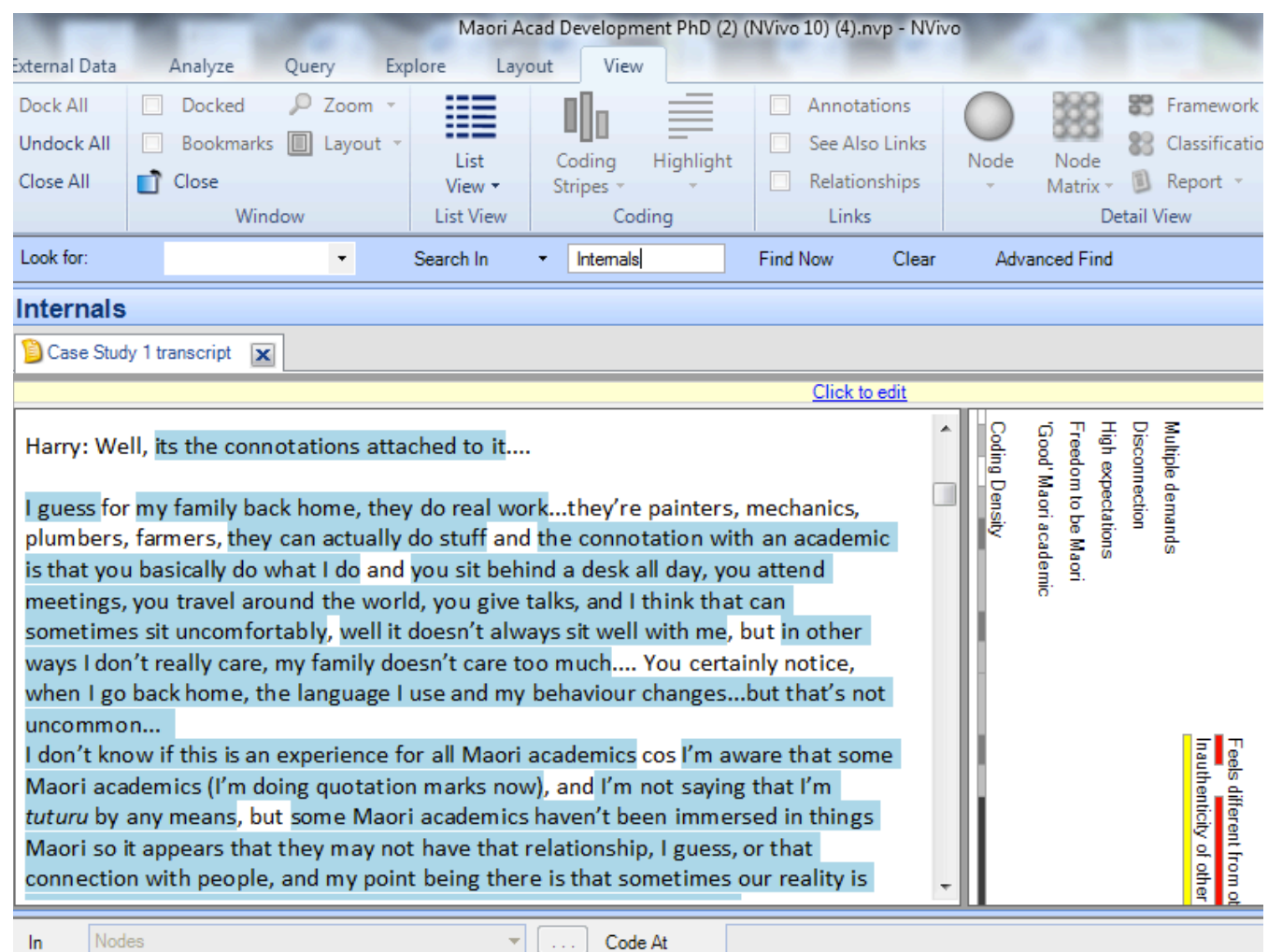

Figure 3.3 Screenshot of coding using the NVivo memo tool.

A further stage of the initial noting process was to indicate if any of the descriptive, linguistic or conceptual comments had any specific kaupapa Māori elements. This modification of the IPA process was straightforward to apply but kept the kaupapa Māori methodology to the forefront and enabled a consistent write-up process.

Following the IPA method, each note was categorised into one of three types: descriptive, linguistic or conceptual. 'Descriptive' notes were about the 
content or subject of the interview, such as what it was like for the interviewee to experience being a Māori academic. 'Linguistic' notes highlighted any language-related aspects, such as unusual or telling phrasing that belied emotion or feeling not overtly articulated in the response. 'Conceptual' notes related to interpretations of the interview text, what the wording meant or how the interviewees' words related to their experiences.

The initial noting process for Case Study One occurred over a number of days. Even though the transcript was only 3,087 words long, the tripartite analysis process generated 87 individual notes, which each required further consideration and organisation. Once the initial noting process was complete, the next phase in the IPA approach was to begin identifying emergent themes. Each of the 87 comments for Case Study One was reconsidered to identify any overarching themes. Again using the NVivo technology, this involved establishing and grouping the comments into separate 'nodes' based on potential themes. It also prompted an organic vetting process of the initial analysis. For some comments, it was relatively straightforward to identify encompassing themes within which they might fit. For others, possible themes were less clear and, on reflection, it sometimes emerged that the initial comments were less warranted or supported by the text than originally thought. In those few cases, the initial note was not progressed. However, almost all of the notes were eventually linked to one or more emergent theme.

The fourth step in the IPA analysis process is to search for connections across the emergent themes that have been identified. For this project, that step was made simpler because the NVivo tool allowed the creation of 'parent nodes' within which initial themes could be grouped. Figure 3.4 shows how the NVivo tool enabled the initial coding for Case Study One to be organised under 'parent nodes'. For example, the overarching theme around stress included seven subthemes, one of which was 'not meeting own expectations', which has been linked to two direct excerpts from the transcript. 


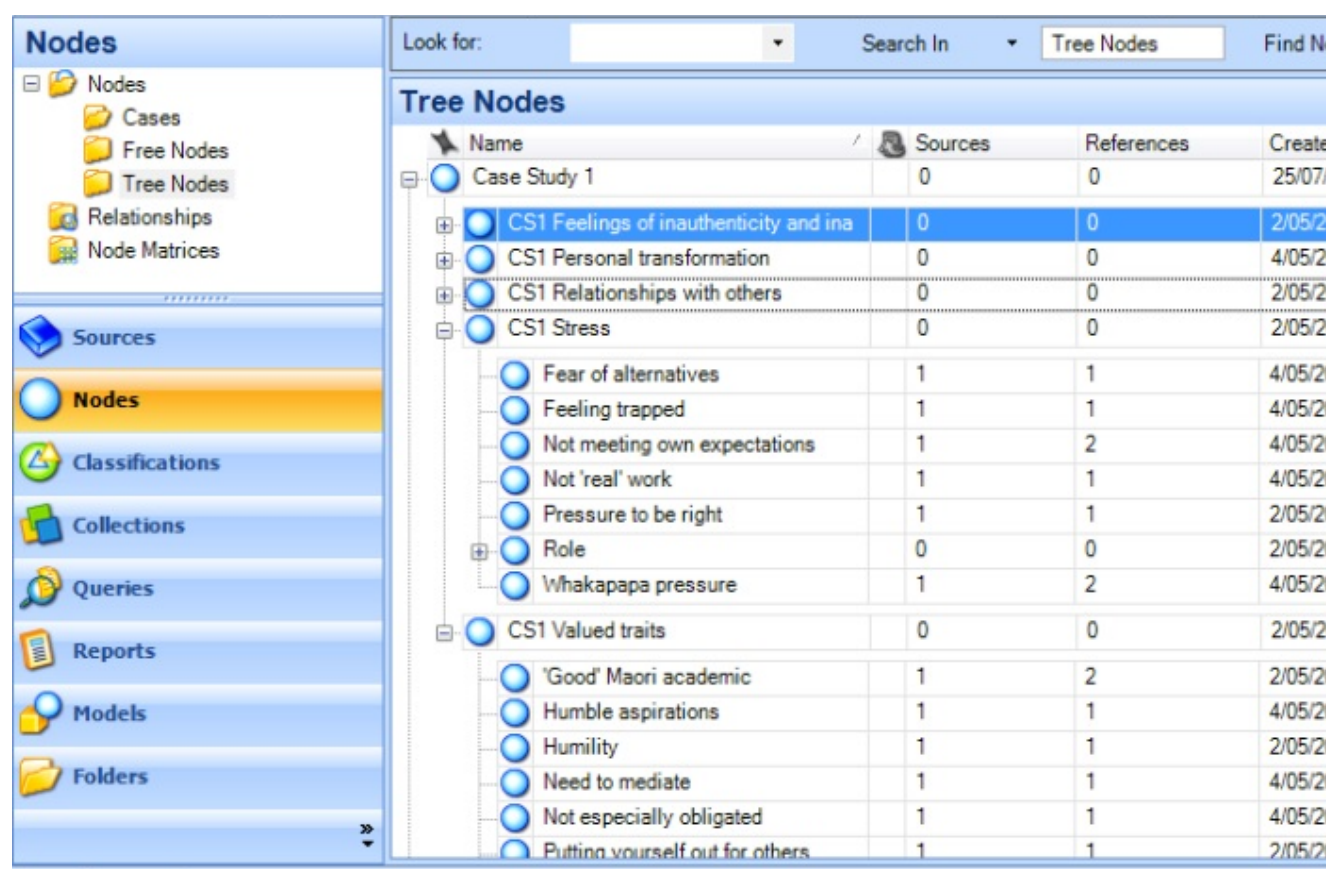

Figure 3.4 Screenshot showing how the NVivo software allows for different nodes to be set up and grouped together to enable the identification of overarching themes.

The IPA literature provided six different ways in which these 'parent' or, to use IPA terminology, superordinate themes could be generated. The first was by abstraction, in other words, "putting like with like" in order to create related clusters (J. Smith et al., 2009, p. 96). The second was by subsumption, which meant elevating one of the emergent themes and gathering other comments together underneath (J. Smith et al., 2009, p. 97). The third approach, polarization, required looking through the transcript comments for "oppositional relationships", that is, to link parallel or similar themes together and pose opposites at the far ends of the spectrum (J. Smith et al., 2009 , p. 97). A fourth option was to apply contextualization, and group the themes around the context in which they occurred such as, for example, specific events or experiences that had been recounted (J. Smith et al., 2009, p. 97). The fifth approach was numeration, which simply involved noting the frequency with which a theme appeared and creating superordinate themes based on "patterning" (J. Smith et al., 2009, p. 98). The final option provided was to group the themes based on function, as in, how the interviewee wanted to be seen by the interviewer (J. Smith et al., 2009, pp. 98-99).

In practice, options 3-6 were quite difficult to apply to Case Study One, primarily because of the content of the interview transcript. There was little 
oppositional material with which to apply the polarization approach. There were too few events with which to apply contextualization, and the numeration and function approaches were redundant for Case Study One's single, relatively short transcript.

Fortunately, the IPA literature included reassurances about the appropriateness of using any or several of these options to analyse transcripts (J. Smith et al., 2009, p. 99). Thus the Case Study One transcript (and later, Case Studies Two and Three) was analysed using the abstraction and subsumption approaches. Together these approaches produced a set of superordinate themes within which each remaining comment could be linked.

One other aspect of the fourth phase of the analysis process was the suggestion from the literature to, "explore spatial representations of how the emergent themes relate to each other" (J. Smith et al., 2009, p. 96). Once again, the NVivo software was invaluable for its ability to generate models based on the results of the coding process. These models are reproduced in the Chapter Four Case Studies.

Once the analysis for Case Study One was completed, the process was duplicated for Case Studies Two and Three. One of the challenges of repeating this process with the other transcripts was the temptation to simply transfer the themes identified in Case Study One or, at the very least, bear them in mind during the initial noting process. However, because of the "IPA idiographic commitment" (J. Smith et al., 2009, p. 100) and the warning given in the IPA literature to avoid doing just that, it was important to set aside the ideas that emerged from Case Study One and to consider each additional transcript as if it was the first to be analysed.

Once the analysis process had been completed for every transcript, the final step was to look for patterns across all three Case Studies. The common ideas that appeared across all three case studies are presented in Chapter Five as the final set of shared superordinate themes. Not only are they the 
result of detailed analysis but they are also the basis for the later discussion of a kaupapa Māori framework for Māori academic development.

\subsection{Ethical considerations for this research}

Positioning this thesis within a kaupapa Māori research paradigm meant engaging with a range of Māori ethical considerations and practices that go above and beyond what is currently required by the Victoria University of Wellington Human Ethics Committee (HEC) (Battiste, 2008; Cram, 1993; Denzin, Lincoln, \& Smith, 2008; Higgins, 2004; Pipi et al., 2004; Powick, 2002; M. Webber, 2009). Nevertheless, this research, as Webber (2009) suggested, is "bound to [the] institution's ethics approval processes" (p. 3) so, in order to conduct interviews with Māori academic staff for this project it was important to get approval from the HEC. This was duly given (see Appendix 1 for approval notice) and it enabled the collection of data to begin. Due to the face-to-face nature of the interviews, the interviewees were not anonymous but their details were kept confidential and their informed consent was obtained through a signed consent form (see Appendix 2 for a copy of the Participant Information Sheet).

An additional ethical consideration for this project was the concern that personal relationships with some of the interviewees would bias the research findings. Many of the interviewees had been my colleagues for some time. As noted earlier in this chapter, this concern was reconciled by the selection of research paradigm, methodology and method. A large part of the decision to conduct this project as kaupapa Māori research, and the selection of IPA as the method, revolved around their acceptance of, and indeed preference for, 'insider' research perspectives. Māori researchers, because they are part of the researched community, often need to develop

and maintain lifelong relationships with their research participants (L. T. Smith, 1999, p. 5). Rather than attempting to mask or moderate any personal connection with the research subject and participants, instead the approach for this research was to recognise it, declare it, and use it to produce something of benefit. 
A final ethical requirement that I needed to consider was the obligation to protect the universities in question from the release of information that may be considered critical. While the employers of the interviewees in this project were never specifically noted, readers may well make assumptions about the location of the research participants. Ultimately, while some accounts of specific incidents do not paint the participant's institutions in an entirely favourable light, all three Case Studies also include many positive comments about the workplaces of the interviewees.

\subsection{Chapter summary}

Overall, this chapter has provided a summary about how kaupapa Māori methodology has been articulated in the literature and how it was embedded and acknowledged in this research. Expanding on the material about kaupapa Māori theory noted in Chapter Two, it has explained how the principles and values underpinning kaupapa Māori research were adhered to or modified in the process of conducting and analysing the interviews for this project. Furthermore, the IPA method, chosen for its complementarity with kaupapa Māori methodology, was also explained in detail, in both principle and practice. The results of the blending of kaupapa Māori methodology with IPA analysis are presented in the next chapter. 


\section{Chapter Four: Case Studies}

In accordance with the methodology outlined in the previous chapter, this chapter shares the findings of three case studies that sought to explore the experiences of being a Māori academic in a New Zealand university. Pseudonyms have been used to protect the identities of the participants in the interviews. All of the pseudonyms are names from people in my family and none of them are similar or linked to the real names of the interviewees in these case studies. All of the quotes have been transcribed verbatim from the interview recordings and kept in context, and the only changes have been made in order to protect the interviewees' identity or the identity of other people mentioned in the interviews.

\subsection{Case Study One}

Case Study One consists of only one transcript of an interview with a Māori academic working in a New Zealand university. This interview served as a pilot for the research, both as a means to test out the semi-structured interview approach and also to explore the research topic as a viable area of enquiry.

The interviewee, Harry, was asked one central interview question, "What does it mean to you to be a Māori academic?" Follow-up questions were then devised during the interview to elicit more information. These questions included: What does the term 'Māori academic' mean to you? What are the attributes of a Māori academic? What do you think are the biggest challenges or issues for Māori academics? What sorts of development opportunities would help you?

From this one interview transcript, and using an IPA approach, five superordinate or over-arching themes were identified about Harry's experience of being a Māori academic: the nature of relationships with others, feelings of inauthenticity and inadequacy, the experience of personal transformation, valued Māori academic traits, and experiences of stress.

Figure 4.1 shows how the over-arching themes relate to a set of subthemes 
that emerged directly from the interviews. Both the superordinate and subthemes will be elaborated on throughout this chapter section.
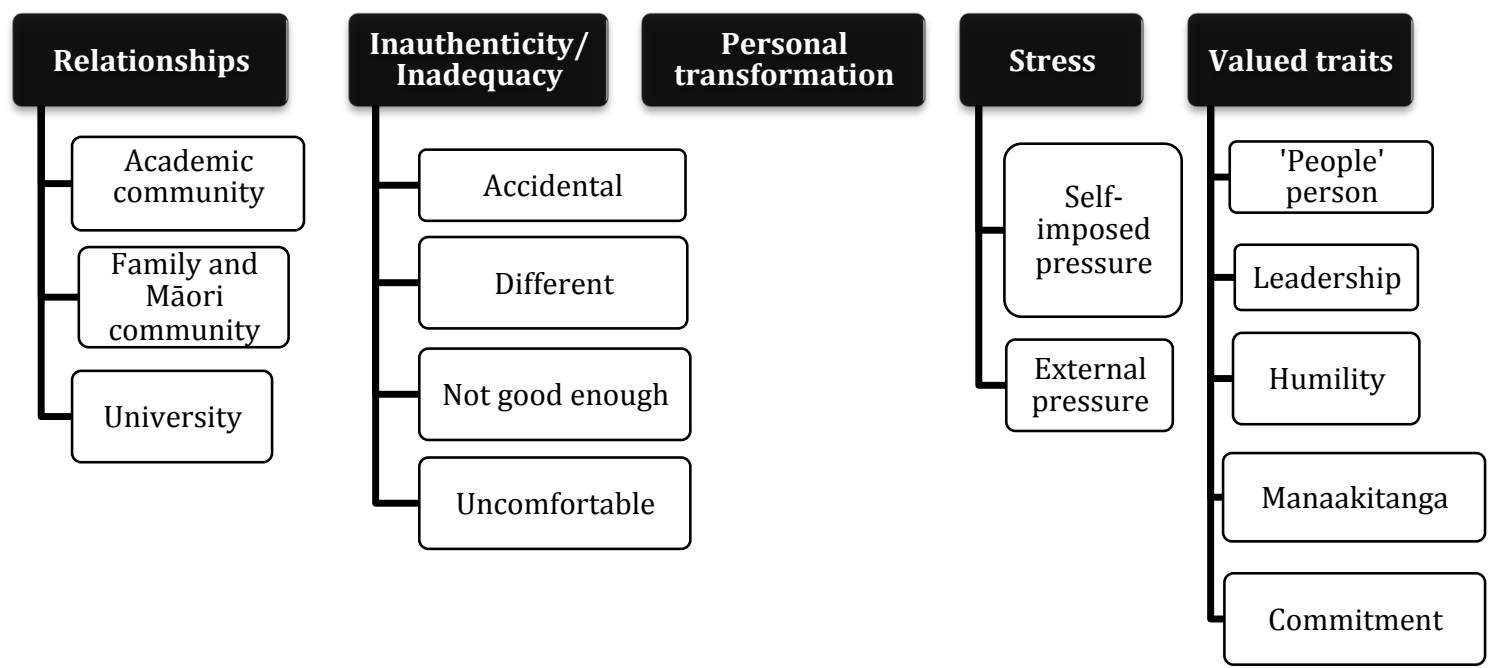

Figure 4.1 Diagram of superordinate themes and sub-themes for Case Study One.

\subsubsection{Relationships with others}

One of the most dominant features of Harry's interview transcript was the varied and extensive relationships that he had developed with a range of academic and Māori groups, both inside and outside of the university environment. He spoke at length about his collegial relationships with other Māori and Indigenous academics, his familial relationships and connections within the Māori community, and his sense of relationship with the university, as his employer.

\subsubsection{Academic community}

Harry's comments about his involvement within the academic community focussed on two main groups, the first of which was the Māori academic community. He was positive about the relationships that he had developed with other Māori academics, noting that he enjoyed "a lot of collegiality" and "a lot of interaction with Māori academics" both inside and outside of work hours. Some, but not all, of that closeness he credited to whakapapa connections, suggesting that, "a lot of us are related somewhere" and that, "outside of the formal academic environment there are numerous 
interactions". This suggests that Harry understands the Māori academic role to be more than just a salaried position with a role description but also something bound by kinship ties and expectations that connect him to the Māori academic community and beyond.

Despite the prominence of familial connections within the Māori academic community though, Harry also reflected on the differences within the cohort:

I think it's quite diverse. I think we'd like to think that all Māori academics have a passion for Māori development. That would be something that I would intuitively identify, I think that might be the case but the level of their enthusiasm would vary.

The second group that Harry spoke about was the Indigenous academic community. While his primary affiliation was to the Māori academic community, Harry also saw benefits in working with other Indigenous academics, suggesting that, "meeting other Indigenous researchers gives you a greater appreciation of your place in the world and sometimes it's comforting to know that other people have similar struggles and it gives you a reality check". He explained the importance of relationships with other Indigenous academics as being about developing a sense of affinity - "I think they're fundamentally built on relationships....so you make connections with people not because you have a common interest in a certain issue but because you resonate with them" - and also developing a sense of place - it "feels good to be part of the Pacific".

\subsubsection{Family and the Māori community}

Harry's thoughts about his connections with his family and the wider Māori community, in relation to his role as a Māori academic, wavered between the positive and negative. In his more positive moments during the interview, Harry described his family's unconditional acceptance and how that gave him the confidence to not worry about other people's views - "In other ways I don't really care. My family doesn't care too much". He also talked about heading "back home" and going "back to my own community" 
indicating a sense of membership and belonging.

However, this familial bond was not without its complicating factors, the first of which was Harry's strong sense that, in comparison with the activities of his other family members, his academic work was not as meaningful. This was evidenced by his admission that, "my family back home, they do real work". In another instance he indicated a sense of being a misfit within his family with the comment that, "they can actually do stuff" like work as plumbers and mechanics, suggesting a view that academic work, in comparison, is a less useful occupation. In addition, despite feeling loved and accepted by his family, Harry also felt moments of disconnection. For example, he noted the irony of the Māori development work that he has been involved with, in contrast to the lived reality of his own community members who are just "worried about putting food on the table". He noted the irony of his academic work about violence in Māori homes and then his experience of going "back to my own community and hear[ing] my friends that I went to school with talking, saying all sorts of things which raise the eyebrows a bit". He also noted the irony of teaching about and doing research based on the Treaty of Waitangi and knowing that members of his own Māori community “wouldn't even know what date it was signed”.

Harry concluded that as a Māori academic he believed, "that sometimes our reality is completely and totally detached from the vast majority of our people". In another part of the interview he suggested that Māori academics, are, "rather detached from the realities of our people", almost suggesting a feeling of guilt about being better off than or not staying more closely connected to his Māori community.

Despite feeling detached, in some instances, from his extended Māori family and community, Harry also divulged a sense of carrying an overriding obligation to them, that he could not avoid. In his own words, Harry concluded that, "there's no escaping your community", indicating a sense of entrapment but also a commitment to his whakapapa connections and his duty to contribute to Māori development. 


\subsubsection{Relationship with the university}

Despite having misgivings at the start of his career, Harry was satisfied with the niche he had managed to carve out within his university environment and was careful to acknowledge the opportunities afforded him. He relished the "reasonably well-paying job" that gave him a "huge amount of flexibility and freedom", including, in his experience, the freedom to be Māori. As an example, he described being "thankful of the fact that my uncle died...and I just dropped everything and left and came back to work whenever I felt like it [knowing] others would cover". He also noted the "freedom in the institution to host people" in a culturally appropriate manner.

Harry stopped short of calling the university a Māori-friendly environment but he did conclude that, the "institution does allow me to be Māori and express myself as Māori", especially when "compared to my cousins who are working in the freezing works, that are plumbers, that are mechanics". He extended this comparison with the suggestion that his university, "provides a framework where things Māori are able to be expressed, and on campus, so I think sometimes when we have issues with the challenges, go try working overseas, go try working in the freezing works. We're given significant opportunities".

Even though he was positive about his relationship with the university he worked in, when asked if he felt more allegiance to his institution or his discipline he responded that he does not "feel closely wedded to the institution or my field. I'm more pragmatic". He also admitted that, despite highlighting the flexibility afforded by the university environment, "the university hasn't given me a free run", suggesting that he still feels some constraints. While he had personally "never felt any sort of pressure from 'the man'”, he recognised that all academics (not just Māori) come under some level of pressure at different times in their careers.

\subsubsection{Feelings of inauthenticity and inadequacy}

Despite holding a senior role and being an accomplished and well regarded 
academic with considerable experience, throughout his interview Harry gave hints of feeling unorthodox when compared with other academics, Māori included. He projected a belief that he was not quite doing a good enough job. This was evidenced in four sub-themes that emerged from his transcript that related either to his sense of being inauthentic as an academic, or having feelings of inadequacy in some aspect of his role: feeling that his academic career has all been accidental; feeling different from others; feeling like he was not good enough; and feeling uncomfortable in the role.

\subsubsection{An 'accidental' academic}

Harry described his journey into academia as having happened largely by accident. He recounted not having had much of a drive to be an academic, adding that he "went to University by mistake". Harry seemed uncertain about whether going to university was right for him, and explained that, "I didn't know I was going to University" and he was not sure if it was the "right time or the wrong time". He credited others with making the arrangements for him to go. His accidental academic narrative continued with an admission that his appointment into an academic role was, "just something I fell into" and that he continued to have, "no sort of grand plan or fundamental motivation" for the role. It even extended to his assessment of his own academic success, with that too being 'accidental': “I don't have a five year plan but things seem to work out quite well for me". By characterising his academic career as an accident, Harry set himself apart from other 'real' academics, raising questions about his feelings of authenticity and value.

\subsubsection{Feeling different}

Harry's sense that he was different from other Māori academics came through in the transcript in a number of ways, both positive and negative. For example, when recounting one experience of being a Māori academic, Harry qualified his comment by saying, "I don't know if this is an experience for all Māori academics", thereby distinguishing himself from other Māori 
academics. In another instance, he differentiated himself from other Māori academics who work in 'Pākehā' universities and decry that, "they can't live or be Māori and you know 'the man' comes down on them too often". Instead Harry said, "That's not my experience". He also reiterated his sense of being different in the form of a compliment, by noting the increase in "really good, passionate, young Māori academics coming through that will have a different experience to me".

At times, Harry's beliefs about being different extended into whether he felt more or less authentic than other Māori academics. In one part of the interview, he condemned Māori academics who, "haven't been immersed in things Māori so it appears that they may not have that relationship, I guess, or that connection with people", but he excluded himself from this criticism. In another part, he gestured with his fingers to do quotation marks while referring to Māori academics, to indicate his beliefs about the authenticity of their Māori-ness. At one point he even quipped, "I'm not saying that I'm tuturu (real, authentic) by any means", but his use of te reo Māori in that phrase, and differentiating himself from other Māori acadmics, suggested that he felt otherwise.

\subsubsection{Not good enough}

Throughout the interview, Harry gave indications of feeling inferior to other academics, particularly specific high performing Māori academics. This seemed to impact on his sense of identity as a Māori academic. He shared how he did not initially get his first academic appointment - "I applied for it...didn't get it" - which fed his fear that he was not up to the required standard. However, he was hired on short-term contracts that were rolled over repeatedly, so, despite the rocky start, his self-doubt was mitigated somewhat by the length of time that he had been able to maintain his academic position. While he did not claim that the position came easily, his track record indicated that he was performing in the role, hence the repeat rollover, which suggested recognition of his work by others.

While characterising his academic success largely as accidental, Harry was 
inclined to take responsibility for his perceived shortcomings. For example, he explained away workload stresses and performance limitations as being "my fault" and carried this sense of self-blame into his career planning and academic goal setting. When comparing himself with other high-performing Māori academics he noted that, "most people I know, including myself, don't meet that sort of challenge". Instead he admitted that he, "gave up trying to aspire to it [academic high performance]" to avoid being "faced with disappointment".

\subsubsection{Feeling uncomfortable}

Harry was clear about what he thought of the label 'Māori academic', saying "I'm uncomfortable with the term". What was not so clear from his interview was why he felt that way. He began to stammer and search for words when trying to explain his position - "I think there's...again, I don't..." - providing linguistic evidence of his underlying difficulty in articulating the meaning of the Māori academic role. He eventually concluded that it was, "the connotations attached" to the term Māori academic that he was most uncomfortable with, which suggested that Harry's discomfort may not be with the work itself but with how it is perceived by others. He also noted that, "it [the 'Māori academic' term] doesn't always sit well with me", suggesting a view that others may be more comfortable with the term and role and indicating a sense of dislocation from other Māori academics.

Despite his reservations about the term, the first time he described himself as an academic he said that, "the connotation with an academic is that you basically do what I do. You sit behind a desk all day, you attend meetings, you travel around the world, you give talks, and I think that can sometimes sit uncomfortably". Thus, while he described himself as an academic he was also deriding what an academic does.

\subsubsection{Personal transformation}

Another aspect of Harry's experience of being a Māori academic related to the way he portrayed himself and the degree of personal transformation 
that he perceived himself to have undergone. In his academic role, he spoke of transforming from a younger, less confident academic into an older, more confident one, saying, "I know that the older I get, the less I'm concerned about. When I was younger I was worried about not forcing my opinion but now I just don't care as much". In another instance, that transformation appeared to have been less proactive and more reactive. In relation to whether Harry had maintained a passion for Māori development, he admitted to becoming battle weary and said that, "I suppose maybe earlier on I was like that, before I got it knocked out of me".

The changes to Harry's personal approach were not limited only to the professional realm. He spoke about having to change his persona depending on the context so, for example, when he went "back home" to the family and Māori community in which he was raised, he noted that, "the language I use and my behaviour changes" but he suggested "that's not uncommon" for Māori academics.

\subsubsection{Stress}

Harry's account of his experiences as a Māori academic was riddled with references to perceived stresses and pressures - "the thing I do know is that there's quite a bit of stress that's attached to it...in my own role". The stresses have been differentiated in this analysis to reflect whether they have been imposed personally or by others.

\subsubsection{Self-imposed pressure}

Some of Harry's stresses appeared self-inflicted, such as his sense of not meeting his own expectations. In his work, he reported feeling frustrated because he thought he was, "just doing enough to get it done". Even in the interview process, he said that he had, "struggled with the question" in an effort to figure out the right answer. Another self-imposed pressure came from Harry's admission that he had a tendency to over-commit himself "half of what I do is probably not even in my job description or is outside of my work hours" - and that he carried significant academic service duties 
that left less time for his core research work. He described feeling compelled to be on "just about on every committee going", which he thought was "not really part of my role". This added further pressure on him as, after the committee meetings, he returned to a backlog of "real work to do".

\subsubsection{External pressure}

Other times, it appeared that Harry's stresses were imposed by external factors, such as a high workload - "sometimes I feel like I'm doing a halfarsed job because I just haven't got the time" and "I haven't had time to take leave" - or fear of losing his job - "job security is a big issue. It's not [just] a big issue for Māori academics. It's a big issue for everyone working in the university". Another external factor was the "multiple demands on their time" that Harry thought were "something that Māori academics might be faced with", although he clarified this point later by noting that the pressure of multiple demands was not unique to Māori academics. Harry also alluded to a form of whakapapa (genealogy) pressure brought on by the inability to escape the expectations of his Māori colleagues and community.

"No matter how much stress there is", Harry was also keen to acknowledge that "it's not a bad life" and that "it's helpful to reflect on what I could be doing, no matter how bad it gets". He certainly saw his work as an academic as better than other career options.

\subsubsection{Valued traits}

Harry identified another person that he saw as a mentor and role model for what it meant to be a 'good' Māori academic. While this person served to inspire Harry, their relationship also set burdensomely high expectations for what Harry should be doing and achieving. Harry described his Māori academic mentor as, "a huge person, works hard, extremely bright, nice person and has done a lot for people, very unselfish". By working with this role model, Harry had identified the types of skills and behaviour that he coveted and respected as being the markers of a successful Māori academic. 


\subsubsection{A 'people' person}

One of the attributes that Harry was particularly positive about when he recalled what made someone a good Māori academic was the way that they relate to other people. He described the need to be "always helping people", having "a sense of humour" and creating "a really positive work environment", to go "over and above", "to encourage others", and to be someone "you can trust" who "has a lot of empathy, and fundamentally I think has your best interests at heart". Harry understood what it meant to be a successful Māori academic as not only achieving intellectual and professional success but also having the capacity to make an exceptional gesture of support and put yourself out for others.

\subsubsection{Leadership qualities}

Harry noted that successful Māori academics were able to inspire those around them by their "work ethic", by "being robust and rigorous", and by "treating people how you would like to be treated yourself". He also held in high regard the ability to mediate, and seemed to value "a reputation of not causing trouble" within the academic community.

\subsubsection{Humility}

Throughout the interview Harry made self-deprecating comments and down-played his academic success. His lack of "grandiose plans" or "high expectations" for himself, coupled with his deference to other high performing academics, denoted a belief in the need to appear humble, to have humble aspirations and to not overstate your worth or success.

\subsubsection{Manaakitanga}

Another measure of what it meant to be a good Māori academic, in Harry's estimations, was the ability to extend manaakitanga, to show care and respect towards guests and host people appropriately. This extended beyond just academic colleagues to include family members and friends as well. For example, Harry recounted stories of how his academic role model 
had demonstrated this important Māori trait.

\subsubsection{Commitment}

Another valued trait that emerged from Harry's interview was the notion of commitment - to Māori development, to Māori communities and/or to producing robust academic work. As an example, Harry reflected on his experience of other Māori academics and concluded that, "there are some academics that are really, really good, passionate, they work hard, and there are others that are less inclined". While emphasising a diversity within the Māori academic community he also reinforced the notion that commitment, evidenced by passion and hard work, was an admired quality.

\subsubsection{Academic development}

The key focus of this interview transcript analysis process was how Harry perceived his experience as a Māori academic. However, the ultimate goal of identifying all of these themes and understandings about Māori academic experiences was to use the information to inform academic development theory and practice as it applies to Māori academics. To that end, this final section of the analysis picks up the comments Harry made during his interview that relate directly to aspects of academic development.

Despite admitting to feeling over-worked and wanting "more hands" to help him achieve what he wanted to get done, Harry also seemed reticent about asking for help. This seemed to stem from his comparison with other Māori academics who were able to carry heavy workloads and still publish prolifically - "so if I'm grumpy and thinking I need more time, I need more help and then he's always smiling and always doing". This reinforced Harry's insecurities and made him reluctant to ask for development support in case it was seen as a failing.

Harry also indicated, during the interview discussion about successful Māori academics, that he had a sense that others knew a secret to success that he had never grasped. This led him to share that he would, "be interested if you interviewed people like that. How can they be so prolific? Where do they 
find the time?" This suggests a possible academic development opportunity looking at high performing Māori academics and sharing their practices as a way to provide academic development support to Māori academics.

Harry concluded that his role model has been the greatest single influence on his career and the fortuity of finding a successful Māori academic and forming a close relationship with him had been the most influential aspect of Harry's academic development. Given this experience, it would seem relevant to consider this further for its academic development potential.

\subsubsection{Case Study One summary}

In summary, close analysis of Harry's interview transcript showed that he felt like he had not followed the standard path into an academic role, "falling", by his own admission, into the university system "by mistake". He spoke bluntly to get that admission out, he was in doubt about whether going to university was right for him, and he was reluctant to take full responsibility for his academic career (despite applying for his role twice). Perhaps this emphasis was a demonstration of the kind of humility that Harry also valued in other Māori academics? He did not want to appear to have tried too hard or thought too highly of himself, or to have intentionally sought an academic role.

Harry's discomfort with his career beginnings linked to the present, where he remained uncomfortable with the term Māori academic and was not sure if it was a good or bad thing, or whether he was good or bad at it. This suggested an underlying belief that he felt unworthy of being a Māori academic and linked to his fears of inauthenticity and inadequacy. He used self deprecating comments to highlight his perceived weaknesses - but then also provided ample evidence of being quite competent at his job.

Harry wanted to differentiate himself from other Māori academics while still linking with them at the same time. He highlighted the diversity within the Māori academic cohort and yet, in another context, emphasised the strong collegiality he found within that community. He also found relief in his 
engagement with the global Indigenous academic community, and admitted to feeling more confident from the realisation that other Indigenous peoples shared his struggle.

For the most part, Harry felt connected to his Māori community outside of the university, although he felt an element of unease about the value of his work as an academic, particularly when compared with the employment paths taken by other family members. He also had moments of feeling alienated from family and friends because of his academic skills and knowledge.

Harry was tolerant of the university environment within which he operated, recognising that "it's not perfect, I'm not saying it's perfect" but being resigned to the notion that "sometimes we get caught up with what's going wrong, as opposed to what's going right...and it's never ever going to be right". Harry was unwilling to complain about his inability to express himself as a Māori at all times, partly because of his concerns about job security. He had also developed a sense of inevitability about the monocultural context of the university institution.

Finally, while not an overarching theme, in relation to Harry's academic development needs he drew both strength and pressure from interactions with Māori academic role models who inspired him to achieve more while also causing him to doubt himself. He cited "more time...more help" as his primary development need yet was reluctant to appear like he was unable to cope, particularly in comparison with others who he saw as high performing Māori academics.

Overall, the IPA findings for Case Study One identified five superordinate themes that emerged from Harry's interview about his experiences of being a Māori academic in a New Zealand university. Together these themes form a representation of Harry's experience, in terms of his Māori cultural identity and his position as an academic, and the impact that they both have on his personal values and practices, and his connections with others. Each of the themes has been explained in turn in this section: the nature of 
relationships with others, feelings of inauthenticity and inadequacy, the experience of personal transformation, valued Māori academic traits, and experiences of stress. Not only did these themes emerge as significant, they were also interconnected - for example, the traits that Harry valued in his Māori academic role models were also related to the inadequacies that he saw in himself, despite the personal transformation that he had already undergone. Similarly, despite his many positive relationships with others, they also caused him some stress and at times added to his sense of inadequacy. Together they represent a complex set of factors that need to be carefully mediated in the development of a culturally and professionally relevant academic development programme.

\subsection{Case Study Two}

Case Study Two is based on one interview conducted with a group of four Māori academic staff. At the time of the interview they were all experienced Māori academics employed in lecturer or senior lecturer roles in a range of academic units within one New Zealand university. To protect their privacy the four interviewees have been given the pseudonyms of Wendy, Roha, Elly and Hotene.

The group interview format was used for this case study even though it is unusual to take a group interview approach with IPA research. Firstly, it drew on the kaupapa Māori principle of whakawhanaungatanga by providing an opportunity for the interview participants to share their ideas collectively and become more comfortable with and learn more about their colleagues. It also provided an opportunity for the interview participants to participate in a form of academic development, through the articulation and development of their challenges, aspirations and practices as Māori academics, during the interview process.

Despite the many benefits of the group interview, the limitations of this approach included the possibility that interviewees were persuaded or influenced by others in the group to change their ideas or share less about 
their opinions and experiences. This phenomenon has been described in the research literature as groupthink, whereby group responses and decisions are skewed due to the group's susceptibility to peer pressure (Janis, 1982). In this instance the groupthink effect was mitigated by a number of actions. For example, each interviewee was asked to consider their answer to the central interview question beforehand, which gave them an opportunity to form their own responses without any impact from others. Also, once in the interview, each participant was given a turn to express their ideas, which ensured that the interview time was shared fairly evenly across the participants and the opportunity for any one participant to dominate the discussion was reduced. In addition, during the interview analysis process, care was taken to not disregard dissenting or isolated comments. In other words, the analysis that follows is not based soley on the frequency or commonality of comments but, rather, represents the full range of views and ideas espoused by the interviewees.

The interviewees were posed the same question that was asked for Case Study One, namely, "What does it mean to you to be a Māori academic in a New Zealand university?" Throughout the interview the participants moved fluidly between discussion about their work and their ability to perform the full extent of their academic role, and discussion about how they saw themselves and their senses of identity as Māori academics. The following analysis captures both of these dimensions as they emerged in the interview responses.

The interview transcripts were coded using the IPA process explained in Chapter Three; however, as this was a subsequent interview (that is, both the interview and the coding took place after the Case Study One analysis) it did raise a new element to the analysis process. In the IPA literature, coders are instructed to set aside their findings from earlier interviews, to "bracket" the themes that have been identified earlier, and to try to approach the new coding like it is their first time (J. Smith et al., 2009, p. 100). However, while clearly articulated in the IPA literature, this process is difficult to actually follow and it was a struggle not to default to the themes that had been 
identified in the coding from Case Study One when looking at the transcript for Case Study Two. It required constant focus and attention not to draw comparisons or make connections across case studies at this early phase and yet, despite this effort, it was inevitable that some of the same themes would emerge. This too is recognised in the IPA literature and is explained as a natural consequence of the hermeneutic process whereby the coder's "fore-structures" or pre-knowledge influences their interpretations. In this instance, given that the Case Study One and Two interviewees were asked the same question, similar themes were likely to emerge. Also, because of the group interview dynamic, Case Study Two interviewees were able to add to and further develop each other's accounts of being Māori academics, thereby extending the range of answers and providing more opportunity for overlap with the Case Study One responses. Thus, the Case Study Two analysis contains some of the sub-themes identified in Case Study One and some new themes specific to Case Study Two.

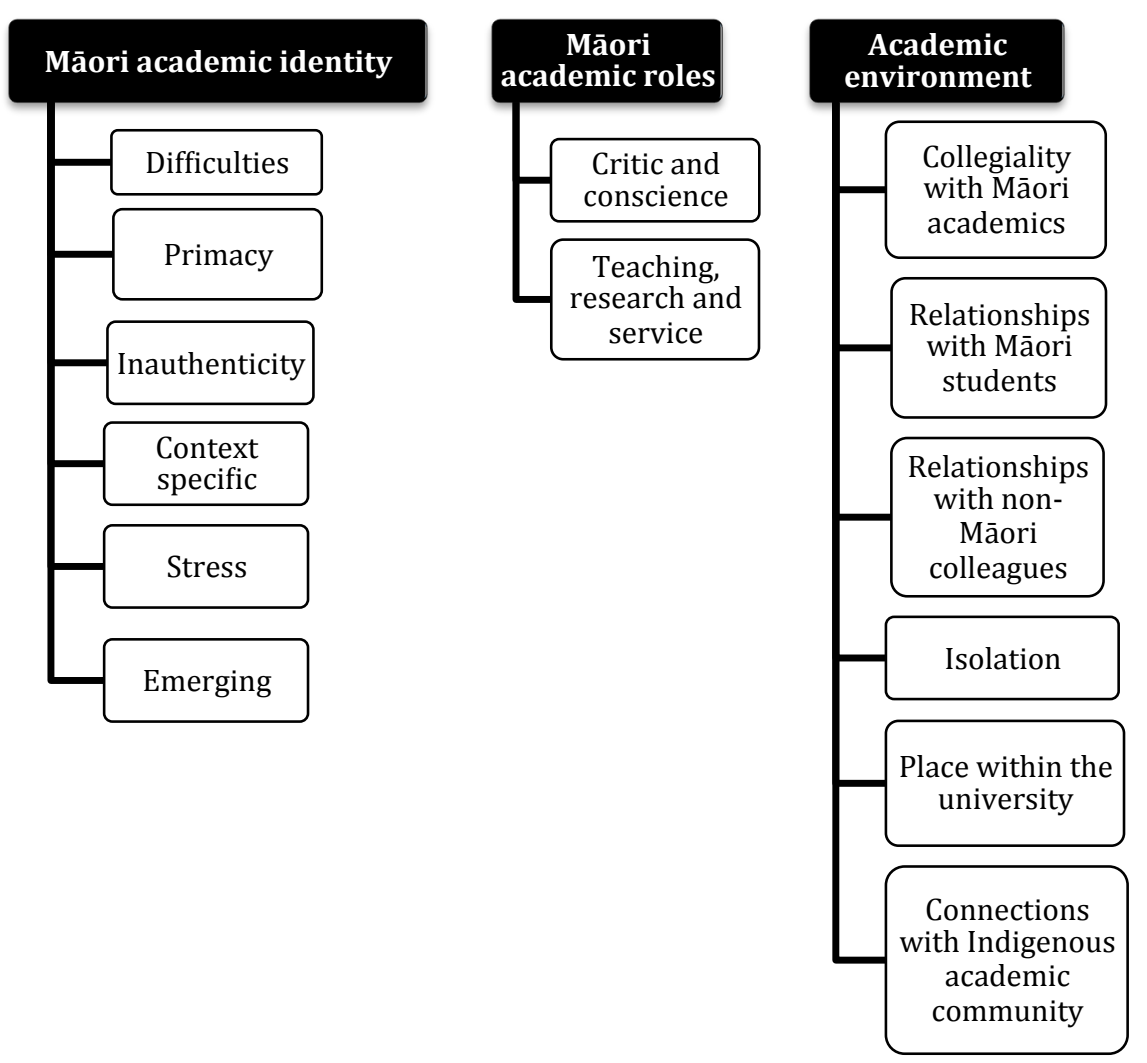

Figure 4.2 Diagram of superordinate themes and sub-themes for Case Study Two.

The IPA analysis of the interview transcript for Case Study Two identified three superordinate themes, namely: difficulties with Māori academic 
identity, challenges of the Māori academic role, and coping within the academic environment. Figure 4.2 depicts the relationship between the three superordinate themes and their various sub-themes.

\subsubsection{Māori academic identity}

The complexity of being both Māori and employed in an academic role was raised by all of the participants throughout the interview. They discussed a variety of identity-related topics that ranged from the challenges to the benefits of their Māori identity.

\subsubsection{Difficulties with Māori academic identity}

One of the overarching findings for this Case Study was that the interviewees were uncomfortable with the term Māori academic. In fact, one of the interviewees, Hotene, admitted that 'the word 'academic' has always been a bit problematic for me", even without the 'Māori' precursor. Elly, reflecting on the biggest challenge she faced being a Māori academic, concluded that it was, "accepting the label of Māori academic". For some, the discomfort with the Māori academic label derived from the perceived connotations associated with the terms - such as, what it means to be a Māori, who is an academic. For others it appeared to derive from a lack of confidence about their abilities to meet the expectations of the Māori academic role. This led Wendy to wonder aloud whether,

sometimes we [Māori academics] are still measuring ourselves and it goes back to that, are you an academic? Are you a Māori academic? Or are you a Māori who is an academic? Or are you an academic who just happens to be Māori?

Roha admitted that, "I don't actually feel like I'm a Māori academic" and preferred to call on examples of other Māori academics during the interview rather than use her own experiences. She was reticent to identify herself as part of a Māori academics cohort, instead choosing to draw "on people that I know and who I acknowledge as Māori academics". After describing the attributes that she thought were exemplified by Māori academics, Roha was 
asked whether her own students would see those traits in her. Her response was, "I think there's some of those things that they may see but it was really based on ones that I knew, and that's how I see them" reinforcing the notion that she struggled to see herself as a Māori academic.

\subsubsection{Primacy of Māori academic identity}

During their discussion, the interviewees talked about different kinds of academic identities, differentiating 'disciplinary', from 'institutional' or 'Indigenous' academic identities. They were unanimous in their assertion that their Māori academic identities were their primary ones and were more prominent in their university work. What was less agreed, however, was the degree of impact this had on their experiences as academics, and the accounts varied for each of the interviewees.

Wendy spoke about the influence that her Māori identity had on her academic identity and suggested that it was about,

not looking at it [academic identity] with that classic academic focus but more the Māori side of it and maybe there are other things that are more important than just saying, you know, research, teaching and wearing all those different academic hats.

Elly was less convinced about the impact that being Māori had on her identity as an academic but she did conclude:

I see things with a different lens, and that's the case of being a Māori academic anyway, you see things differently to your general colleagues because you see things that they miss, and that's just the way it is and the reo just adds a different dimension.

\subsubsection{Feeling inauthentic as a Māori academic}

Despite believing in the primacy of their Māori academic identity, that did not stop some of the interviewees from feeling inauthentic as Māori academics. For example, Roha admitted to feeling like she was, "in a continuous cycle of being an imposter...that imposter syndrome". Similarly, 
Elly revealed that, "sometimes when I'm in the middle of Māori colleagues I don't feel quite at home there either". She spoke of there being, "this intersection between my Pākehā (self), learning to be Māori”. She explained further that, "there's a lot of insecurity for me in being a Māori academic and I'm not sure what will fix that". In another part of the interview she admitted that, "I don't know if I've got enough 'creds' to be considered a good Māori academic or just an academic who tags herself Māori to get free feeds". Despite this, Elly also revealed that, "one of the great things that's happened to me in the last few years has been the revolution in my life brought about by the reo", which indicated a connection between increased competence in te reo Māori and a growing sense of authenticity as a Māori academic.

\subsubsection{Māori academic identity is context specific}

Hotene suggested that the degree to which a person identified as a Māori academic was varied and highly contextual. He noted:

Sometimes I happen to be a Māori person that's working at a university. Sometimes I happen to be a Māori academic who's promoting Māori issues. And sometimes I don't want to do any Māori stuff and...I read other things and write other things.

Nevertheless, Hotene did conclude that this degree of flexibility "depends a little bit on which [unit] you are in". In his view, there was more of an onus on being seen to be a Māori academic for people working in,

Māori Studies [because] I think necessarily you have to give prominence to that Māori dimension whereas I suspect that a Māori person going into a [academic unit] that wasn't necessarily a Māori [academic unit] might not need to do that and therefore has an option..."I don't think I'll assert my Māori-ness so much".

However this view was counteracted by another perspective. Elly was "not so sure that it's a choice" and disputed how much ability Māori academics have to hide or reveal their Māori identities or personas. In her view it was, "impossible to separate out being Māori from being an academic" even in a 
non-Māori environment. In her experience, even if she was working in a non-Māori unit, it would still be important for her to identify as Māori.

\subsubsection{Stress of being 'out' as a Māori academic}

The interviewees identified a sense of obligation that they perceived came with outwardly identifying as a Māori academic. Elly described it as a “definite sense of responsibility that we have when you are 'out' as a Māori academic - and with the responsibilities is the guilt for not meeting them". Wendy recalled her experience of knowing other academics who,

you knew were distinctively Māori and they had Māori names but you know, they'd come on the odd occasion and say, "Well, if we hang out with you we'll never be regarded as decent scholars", so they'd kind of stay in that and they never wanted to be tagged Māori, so they didn't want to have to do anything about the Māori lectures and stuff like that, and you'd try to be supportive and say, "Well, we can help you" but, "No, we don't want a bar of it because then we'll be tagged Māori, and seen as Māori and have to do the responsibility of Māori".

Hotene agreed, and noted that, "there are plenty of Māoris that work in this place that choose not to be Māori".

\subsubsection{Emerging academic identities}

Tied to their discomfort with the term Māori academic was the belief by three of the four interviewees that they were still emerging academics, despite all having been in academic roles for a significant period of time. Regardless of her multiple years in the role, Roha described herself as still "kind of emerging" and categorised herself as not a full academic. In another instance, Roha used the emerging label as a reason for not understanding the key academic roles, suggesting that, "I guess because I'm still emerging, it (teaching, research, service) wasn't at the forefront of my mind".

Elly reiterated Roha's point with the comment that, "this notion of being an emerging academic is pretty important". She explained that she had been in her current academic role for “years now and I don't feel that my place is 
really any stronger than it was a few years ago". She connected her sense of having an emerging academic identity with the length of time a person had in a role but also related it to having a sense of place, and even a degree of power or authority or level of influence within an academic unit.

Connected with their sense of still being 'emerging' was a lack of confidence about whether they were able to perform all that was expected of them in the academic role. Elly admitted that she often felt lost but she did not know,

if that's because of my experience as a Māori academic or if it's because of my insecurity as an academic full stop because I still feel very much like I'm emerging and I don't have very much credibility, so when you feel that way it's difficult to find your place.

She shared an excitement about her academic work and its potential but was frustrated by what she perceived as her lack of competence, saying that, "it's cool and it's frustrating and when the hell am I going to be an expert on anything?"

Like Elly, Roha also shared that, “maybe [I] ...haven't emerged enough to know what the real world is", which denoted a lack of confidence in her ability to understand the wider academic environment. A lack of confidence also manifested in a common belief amongst the interviewees that it was easier for Māori to get academic work. Elly was of the view that "I wouldn't have gotten my job if I wasn't Māori, which is not necessarily a good thing, either". She explained her reasoning by saying that "it was easier for me to be hired than colleagues of mine at the [XX] Faculty because the Dean at the time happened to be wanting to build up Māori staff". Hotene agreed, saying that, "it is rather easy for Māori, I think, to get jobs in these institutions, compared to Pākehās". He later added that, "If I wasn't Māori I wouldn't be here. That's the reality", reflecting a sense of inadequacy felt earlier in his career that, over time, appeared to decline but was never removed entirely.

All four of the interviewees spoke about the process of becoming more comfortable in their academic roles, even if they had not managed to attain a 
level of complete comfort yet. In Elly's opinion, the transition from an emerging into a fully-fledged academic was "about confidence". She thought that gaining confidence as an academic was "not about qualification, because I don't think there's quite that focus in [academic unit deleted], but certainly there is some mythical threshold". Despite her insecurities, Elly was still "quite proud" of how far she had come and what she had achieved academically.

For Wendy, transitioning out of the emerging phase was also about time, and only occurred once someone "had the experience and the longevity" of being in a university environment. Both Elly and Wendy were concerned about how to identify when a person has 'made it' as a Māori academic. Wendy queried this threshold notion and asked whether,

in the back of our mind we've [the interviewees] kind of decided this is what an academic might be and we just might be Māori as well but I'm still emerging because I haven't quite got to that pinnacle. And what is that? What is the measure that's going to say you're no longer emerging? Will it be post $\mathrm{PhD}$ ? Will it be actually when I've been here 25 years? Will it be when I've produced 50 books or articles?

Hotene reinforced the idea that confidence to perform the academic role grew over time, and shared that he "got to the point where I just didn't care. I just didn't give a shit what they thought about me and you just do your own thing, and if you've got an opinion, offer it". Hotene explained that he no longer felt lesser than other academic colleagues but conceded that he had gained that confidence over a number of years working in an academic role.

Finally, Roha spoke about how she needed to fight against her own selfdoubts. Her transition from feeling like an emerging academic was about "getting over myself, really". In Roha's view, it was a matter of taking time to develop into the academic role "and just get on, you know, accept the fact that I'm doing this and, you know, I'll get there". 


\subsubsection{Impact of lack of qualifications and subject knowledge}

Despite considering time to be a critical factor in gaining confidence in her academic role, Wendy also considered lack of qualifications to be a significant obstacle. She spoke of being disregarded because she didn't have a PhD and said, "Being on committees, representing Māori at [name of university] and because I was just Miss [surname] then it was like, we don't really care what you think because you're not the same as us".

Elly, while not as worried about credentials, was concerned that a lack of subject knowledge held her back, revealing that “I don't think I know my shit. If I did know my shit then I could probably dispense with the attitude but I'm not sure I do know my shit". Wendy also reflected on the idea that a lack of subject knowledge affects an individual's confidence about their ability to be an academic, and wondered aloud, "whether on one level subconsciously you're [other interviewees] measuring yourselves against the rest of the academy....you're not feeling like you've got to that point to be able to say, “I'm [academic's name] and I'm not emerging because I've been here a while and I know my stuff and I'm backing myself'”".

\subsubsection{Challenges of the Māori academic role}

A significant amount of the interview time was spent talking about what drove the interviewees to be academics, and what they saw as their key roles as Māori academics. The next section of the Case Study Two analysis is focussed on what the interviewees' identified as their key roles.

The interviewees took an holistic approach to describing their activities. The distinctive element that received the most individual attention and discussion was the notion of being a critic and conscience of society. Although only one interviewee described her role in the form of the academic triumvirate (research, teaching and service), all of the interviewees discussed aspects of each of these functions, and particularly service in relation to representing Māori on committees. 


\subsubsection{Critic and conscience role}

Hotene was clear that a key role of Māori academics was "as the critic and conscience of society", which meant that Māori academics were "kind of paid to speak out and speak our minds, based on scholarship". He explained:

In the end our job is about looking at the scholarship that's out there and saying, that's good but that's bloody rubbish and then saying why it's rubbish and then working around all that stuff. It took me a long time to realise that but having realised it, that that's what really the job is about ... and be really confident about your opinion and not be afraid to put it out there.

Hotene continued that in his view, "a big part of being an academic ... I've sort of discovered, is having the ability to disagree with people". He added that he had,

advocated for a long time that we don't restrict our role as critics and consciences of society to critiquing the bloody government. We should also be equally critiquing our own people and we often don't do that, you know, but I think it's badly needed for some things. We have got to be able to criticise ourselves, otherwise those Pākehā will do it for us.

Roha also thought that successful Māori academics were, "able to show us how they test the waters and give their opinion and put themselves out there which I think is a role model for me because I don't always put myself out there". However, Elly wondered whether, "being a critic and conscience of society as a Māori academic [was] a different thing as a Pākehā academic being a critic and conscience of society?" Lamenting what she perceived to be a lack of Māori academic commentary, Elly was moved to ponder, “I don't know if that's our role because we view that role slightly differently. We have to pass a few more checks and balances before we stick our head above the parapet, in broader society". She also added:

If you're grappling with your own cultural identity anyway, as some of us are, then to actually turn around and critique or criticise other Māori 
becomes harder because you start from, well speaking for myself, you start from slightly behind the line anyway, but that's what's needed.

\subsubsection{Research, teaching and service roles}

The interviewees discussed aspects of their research and teaching. While Elly concluded that, "it's the research that's the key thing", Roha took a different approach, and drew on her observations of her Māori academic role models to describe what she thought were the key functions of a Māori academic. She highlighted the need for Māori academics to be intelligent and astute, to challenge, to inform and to be affirming and respectful of others and she linked all of these qualities to their research, teaching and service roles. She concluded that good Māori academics,

are perceptive about others and about things. They help us. They are people that you can aspire to. They are engaging or they engage us or what they say can be engaging, so to be able to connect. They have an ability to connect us to them or that connection to Māori scholars. They are able to motivate...to stimulate thought and action. And there's a sense of compassion in there, so to have that understanding to be concerned and considerate of Māori.

Wendy concluded that Roha's description was very teacher focussed even though she had not specifically set out to describe her teaching role. Also, despite seeing a prominent research role for Māori academics, Hotene noted that the other "real" part of his job was to teach, "which you sometimes do begrudgingly".

Another dimension of Māori academic work discussed by the interviewees was the service element - both within and outside of the university community. Wendy spoke of the extra burden that often fell on Māori academics to be representatives of the Māori community on university committees and working groups. She shared a view that such representative duties tended to handled in one of two ways, "you could be the token person or you could seriously believe that you're making an impact and changing people's attitudes" and noted that, in her experience, the latter, "can, I think, 
be tiresome".

In an interesting twist, Hotene spoke of his belief that Māori academics' obligations to their communities were being overstated and he suggested:

I often wonder about this claim that we often hear that Māori people have a special obligation to be working on behalf of their community and that we're always working for our communities but I'm not sure if that's any different from any other academic in any discipline because they are arguably working in their communities too.

Elly agreed:

I don't think a sense of vision is restricted to Māori academia solely. I've got mates across the university who have this sense of where they'd like their discipline to be and they want to contribute to that, so I think that's right.

However, on reflection, Hotene also noted later in the interview that, "I think we often spend a lot of time trying to please everybody else, especially the Māori community", suggesting an element of obligation nevertheless.

All of the interviewees spoke of how they were kept busy by their teaching and service roles. However, as with their views on their identity as Māori academics, their views and experiences on workload varied too, with Hotene declaring, "I don't feel stretched" and Elly responding, "Oh, I do, but I don't know if it's because I'm a Māori academic, but I suspect that's part of it". Wendy explained how her heavy load affected her research programme and concluded, "I don't find the time to write stuff and I'm sure everyone else is in the same position". Rather than blaming her workload entirely, however, Wendy also admitted that, "it's that confidence thing" that caused her to doubt that she had the authority to produce new material in her field.

\subsubsection{Coping with the academic environment}

During their discussion, the interviewees recounted a number of examples of how the academic environment that they operated within had both 
helped and hindered their ability to function and express themselves as Māori academics. They paid particular attention to the collegiality they experienced within the Māori academic community, as well as their relationships (or lack thereof) with non-Māori academic colleagues. They discussed their views on both the restrictions and freedoms that the university environment afforded, and shared their thoughts about the Indigenous academic community.

\subsubsection{Collegiality with other Māori academics}

Positive working relationships with other Māori academics featured prominently as an important factor for coping within the academic environment. All of the interviewees had a strong motivation to undertake their academic work, and they drew support from their Māori colleagues. For Wendy, it was being part of the Māori academic community that encouraged her to continue with her work. In her words, it was, "that sense of community...that keeps you driving along and motivating". She described her experience of working with other Māori staff in her academic unit as being like "a shared collective. We're all kind of there on the same kaupapa even though we're kind of diverse in terms of our specialist fields. We all kind of believe in the same overarching kaupapa". Outside her own academic unit, Wendy also relayed having experienced a "sense of collegiality" with other Māori academics, describing it as, "having different people from different departments kind of all trying to work towards a common thing, a common goal".

Roha was also motivated by her involvement with other Māori academics, but for a different reason. For her it was more aspirational, as she worked to become like the Māori academics that she looked up to. After describing the qualities of a Māori academic, Roha noted that, "From what I've seen those are the qualities that are underlying for me, or maybe what I aspire to".

Similarly, Elly shared that, "it's MANU AO and [Māori academic community] that give me a sense of belonging rather than membership of the Faculty". In addition, Roha credited her membership within the Māori academic 
community as supporting her academic development, citing that ,"there are positives to it, like meeting you [other interview participants]. I mean I probably wouldn't have felt as safe and happy .... so I think that's a positive spin .... Just seeing what everyone else is doing".

\subsubsection{Relationships with Māori students}

One slight sense of disconnection was noted by Elly, however, when she spoke about her relationship with her Māori students. She explained that by choosing her family and lifestyle over "hanging" with students she had become removed from the Māori student community and noted:

I admire what they do and empathise with them from afar but in the same way as I feel isolated from my Pākehā colleagues I feel a bit isolated from Māori students, except when I'm face to face with them, because I'm not part of that world.

\subsubsection{Relationships with non-Māori colleagues}

Elly was particularly expressive with her frustrations about her non-Māori colleagues, and noted that she worked in a unit that was "not really a Māorifriendly environment". She explained that, "It's not like I don't like my colleagues. I like my colleagues a great deal and a couple of them very much so, but there's not a lot of gel in there". She reasoned that this was because of a lack of similar interests, noting that, "It's difficult to have collegiality there because your research interests don't gel very well with your colleagues' [research interests]". She also reflected that, "Sometimes I think the sense of isolation I might feel is actually a class thing as well as a culture thing". She shared her experiences of being misunderstood and unappreciated by non-Māori colleagues, and of being excluded from opportunities because of that lack of understanding. As Elly recalled, "I had a lot of people come up to me and say the work you're doing is fantastic but they've got no idea what the work actually is".

When Hotene reflected on his relationship with non-Māori colleagues he alluded to a lingering sense of institutional racism, and admitted: 
There always has been for me at the back of my mind always lurking there a feeling that all the other people in the university think that Māori scholars are second rate and it doesn't matter how good you are at what you do they're out there thinking "Oh well, it doesn't matter, we don't need to invite those people to our conference because what do they know anyway?" And its deeply, deeply entrenched in the system; it's sort of institutionalised to some extent and you're never going to get rid of it, so I don't care about it mostly but you just know that it's there all the time.

In response, however, Wendy questioned if Māori academics perpetuated that view and wondered, "if we kind of allow that" and permit other university staff to "look at us as second class".

\subsubsection{Sense of isolation}

The lack of collegiality with non-Māori academics culminated in a feeling of isolation for Elly. She explained that, "just being off radar is something I think that I find difficult to deal with sometimes". While she acknowledged that her sense of being ostracised was "hardly an unusual story" for Māori academics located in predominantly non-Māori academic units, she admitted to feeling "a lot of loneliness, a sense of isolation" and that she had developed a strategy of "making noise just to make sure that people know you are around". Despite the negative aspects of feeling isolated, Elly did recognise the benefits, and noted:

The isolation that I've talked about is also a positive thing because it means that I'm free. No one gives a damn so I can do what I want, which is actually a really powerful and creative thing because it gives me the freedom to think and the freedom to look at things differently, so I bitch on the one hand but on the other hand, I wouldn't want to do without it.

\subsubsection{Place within the university}

Each of the interviewees, at some point in the interview, shared what they thought of working in the university. Wendy explained that the difference between Māori academics located in predominantly non-Māori units, is that the "interface" with non-Māori criticisms or misunderstanding is "more 
localised". In contrast, she explained that for Māori academics in Māori strongholds like Māori Studies, for example, the "interface" was "more with the wider university".

While some of the interviewees had found the university environment to be isolating, they were also aware of the freedom and privilege that they were fortunate enough to enjoy in their employment as academics. Despite feeling criticised or misunderstood in some contexts, the interviewees also praised the benefits of academic freedom, and acknowledged that the ability to choose their own research interests was a key advantage of the university environment. Hotene recognised the university as a place of opportunity, particularly when compared to other careers. He shared:

For me the university is a tool to do stuff that I'm interested in. It just provides a platform and opportunity to do some stuff, and for me it's about whether it's better than doing something else potentially and having worked in other jobs I know how crap other jobs can be and coming to university you really appreciate the freedom that you've got to pursue things that you are really interested in.

Counteracting Elly's concerns about isolation, Hotene concluded that there was a link between isolation and academic freedom:

That's the same for all academics, isn't it? I mean we are, if we want to be, we can be totally isolated and we can isolate ourselves if we want to and just do what we think is bloody well right, you know, and no one will stop us doing that because that's academic freedom.

\subsubsection{Connections with the Indigenous academic community}

While all of the interviewees were positive about the growing global network of Indigenous scholarship, on an individual level they struggled to see direct relevance for their work and aspirations. In Elly's case, she admitted that, "maybe I'm just a bit slow on the uptake but Indigenous studies are useful in so far as it can inform what I'm doing but I don't really see myself...I dunno, it gets a bit navel-gazey". Hotene saw some advantages 
to Indigenous collaboration, explaining that, "we're making these international comparisons and international benchmarking and so on is what's expected in the institution, and by doing Indigenous comparative stuff it enables us to do that" whereas Elly thought:

Comparison is really useful if you can take two systems and compare them. It makes the whole more comprehendible, if you like. But sometimes I think we compare ourselves with each other for the sake of it, and to go to flash conferences overseas.

\subsubsection{Case Study Two conclusion}

In summary, the analysis of the Case Study Two interview transcript revealed that the ways in which the interviewees articulated their identities as Māori academics were at once complex and clear. They were complex in the sense that the term Māori academic was seen to be problematic and difficult to accept, led the interviewees to suffer from an 'imposter syndrome' and was deemed to add an extra level of responsibility. However, it was also clear that the interviewees held firm in their Māori identities and, when coupled with their identity as academics, their Māori identity was dominant over their disciplinary or institutional identities. Their strong Māori identities also influenced their career direction and provided a "different lens" with which to view their academic pursuits.

The interviewees also described the challenges of feeling like they were still emerging as academics, and wanted "the experience and the longevity" necessary to perform well in the academy. They cited a need for more subject knowledge in order to transition from an emerging academic stage. Their cultural identities as Māori also impacted on how they approached their academic roles. While recognising that the role of the critic and conscience of society was common to all academics, they queried whether that function was more complicated for Māori. Additionally, they conceptualised the research, teaching and service nexus quite holistically, and presented a complex set of additional responsibilities for Māori academics who took on representative roles within their institutions and 
carried obligations to their external Māori communities.

For the most part, the interviewees felt a sense of solidarity with and were inspired by others in the Mãori academic community who were "on the same kaupapa" and able to give them a sense of belonging within the academy. Also, in relation to their academic development needs, the interviewees drew inspiration and guidance from their relationships with other Māori academics. In contrast, they described being misunderstood and unappreciated by other university colleagues, at best because of a lack of understanding and at worst as a by-product of institutional racism. Being "off the radar" of their non-Māori colleagues was seen as both a contributor to their sense of isolation but also allowed an element of freedom in their work. The interviewees also thought that location mattered - it made a difference if they worked within Māori units or not, and affected their connections with the global Indigenous community.

In summary, the IPA findings for Case Study Two highlighted three superordinate themes that arose from the group interview about the experiences of being Māori academics in a New Zealand university. Those themes were: difficulties with Māori academic identity, challenges of the Māori academic role, and coping within the academic environment. Collectively, these themes formed a representation of the interviewees' experiences, in terms of how they saw themselves as Māori academics and the impact that had on both their ability to fulfill their various academic roles and the way they encountered the academic environment. As with Case Study One, these themes were both significant and interconnected - for example, despite expressing clear Māori identities, some of the interviewees struggled with feelings of inauthenticity and inadequacy within the Māori academic role. Also, in spite of their positive relationships with other Māori academics, some interviewees struggled with the responsibility of the Māori academic role to be 'critics' of both Pākehā and Māori society. Ultimately, these themes characterise a set of complementary and competing elements that need to be appropriately acknowledged within a comprehensive academic development programme for Māori academic staff. 


\subsection{Case Study Three}

Case Study Three is made up of five transcripts from interviews with five Māori academics from different disciplinary backgrounds but all working in the same New Zealand university. The interviewees have been given the pseudonyms of Wendy, Elly, Kiri, Jessica, and Roha. Wendy, Elly and Roha were all part of the Case Study Two group interview but agreed to undergo individual interviews as part of Case Study Three in order to elaborate on their specific ideas and experiences as Māori academics.

The interviews were conducted using the semi-structured interview approach trialled in Case Study One, and took place separately, at different times and places. The interviewees were asked the same questions:

- How did you come to be a Māori academic?

- What are the best things about being a Māori academic?

- What are the most challenging aspects of being a Māori academic?

- What are your academic aspirations?

- What academic development could help you to achieve your goals?

Follow-up questions were devised during each interview to elicit more information.

From these five interview transcripts, and using the IPA method, four superordinate or over-arching themes were identified about the interviewees' experiences of being Māori academics:

- The motivation to do Māori academic work;

- The key roles associated with being a Māori academic;

- The nature and impact of relationships with others; and

- The pressures faced by Māori academics. 
As demonstrated in Figure 4.3, each of these superordinate themes contain a number of sub-themes that emerged directly from the interview transcripts, and both the overarching and sub-themes will be elaborated on throughout this chapter section.
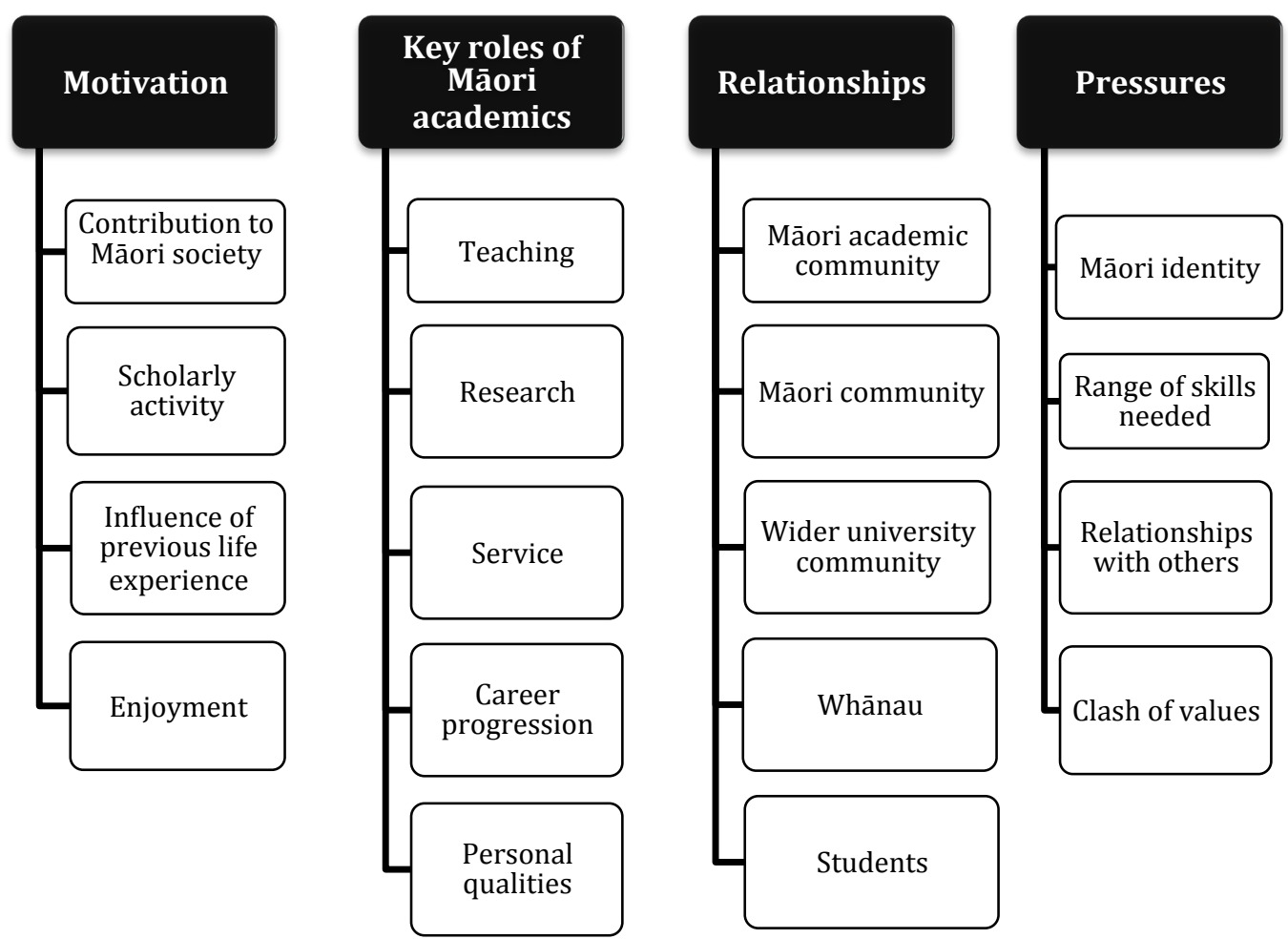

Figure 4.3 Diagram of superordinate themes and sub-themes in Case Study Three.

\subsubsection{Motivation}

Every interviewee spoke about their intrinsic motivation to be academics and, despite a wide range, their responses were able to be grouped into four broad categories:

- The contribution that they can make to Māori society and culture;

- The scholarly activity and outputs that the work allows;

- The influence that their previous life experience had on their pursuit of an academic career; and

- The enjoyment that they get from academic work. 


\subsubsection{Contribution to Māori society and culture}

One of the ways in which interviewees described why they were motivated to do academic work was as a means to make a positive contribution to Māori society. That contribution varied in scale and emphasis depending on the context but was shared across the interviewees, as demonstrated in the following analysis.

One interviewee shared the belief that by working as a Māori academic she was playing an active role in transforming New Zealand society, in ways that could improve the lives of Māori people and lead to a better understanding of Māori perspectives, experiences and beliefs. Roha talked about wanting to disseminate her research widely because of an underlying commitment to wanting "people's views to be more educated and transformed so they really see what Māori people are like". She felt driven to do research and teach her students in ways that would bring improvements to the life experiences of other Māori people. In another part of her interview, Roha spoke about not aspiring "to be the Vice Chancellor or anything" but instead to "have written things that actually support Māori communities".

As tertiary qualified Māori people, other interviewees spoke about the duty that they felt to make a contribution towards the Māori community, including choosing a career path that was considered befitting of their skills and interests. Kiri, for example, talked about initially wanting, "to be a History teacher because I felt really strongly about all that". By "all that" Kiri meant the exclusion of Māori content from the teaching of history in New Zealand schools. This intuitive sense of duty to the Māori community directed Kiri's undergraduate and postgraduate study choices, and later her career path. Like Roha, Kiri also saw the importance of setting personal goals that went beyond individual impact but also included institutional change and positive development for Māori communities. She shared her belief that, 
in 10 or 20 years things will be different, but that's when I need to be checking myself. What is my vision for 2020? What ...would that look like 20 years from now? When I retire, what do I want to see out of that?

Similarly, Jessica talked about feeling,

privileged to get the sort of things that you get here, to be able to do what it is that I love in life, to be able to make a contribution, through students, through what I can give to students that hopefully they'll take out and use out there, and also through the research and also through the other work that I do that's in the field.

Jessica was highly motivated by this sense of privilege and her belief that she was making a contribution to her students and the broader Māori community. She explained that after working in the Māori community for many years, she decided, "I've run my course, I've done what I needed to do, you know, the obligation that I'd felt wasn't there". Her sense of duty and her ability to make a positive contribution to the Māori community in that particular role had waned and she had looked for another way to reinvigorate her working life while still meeting her Māori community obligations. Jessica described how going to work in a university environment, "was really all about the research and what I could do here", noting that "it's all about making a difference and being able to find the best way to do it...and that's why I'm here". This drive to conduct research that benefitted the wider Māori community was seen by Jessica as a strategic decision to broaden the scope of her potential impact beyond the narrower role that she had previously played in the community.

Another of the motivations for being an academic was expressed by Jessica, who noted that, "One of the other strong, strong, drivers is building Māori capability, building Māori capacity". Her sense of duty to the Māori community went beyond just herself and her desire to perform well in the role, but also extended to other Māori colleagues and students, and her desire to nurture and support them into their own successful academic careers. That sense of wider responsibility led Jessica to take on a mentoring 
role, explaining that, "it's looking at who's around you, who you grow, who you can pick up and bring in to grow because there aren't enough of us". She explained how this motivated her in her work, to be constantly seeking opportunities to help other Māori scholars, to be "picking up those people and making sure that things are put in place... that's my ambition and drive". Another strong motivator was the drive to make an active contribution to Māori development. As Roha pointed out, the value of her work was in the impact that it could have on Māori children, because, as she said "I've seen our kids doing really well, being enthusiastic, making good progress, and I think, yeah, that's why". In a related point, Wendy also reflected on her career aspirations and shared a desire to make a significant contribution to Māori development. However, she saw some of her options within the university environment as being limited, particularly through what she saw as a clash between her kaupapa Māori commitment to Māori development and her pursuit of academic excellence. For example, she described how, "We [Māori academics] should be aspiring to be PVC Māori in the way that it's about Māori development. If we believe in Māori development...and nurturing more scholars to develop, I'd be keen if that was the role, but I kind of see that the institution has turned it into a high level administrator".

Some of the interviewees regarded their academic work as a type of legacy, created by them and gifted to their Māori community. For example, Kiri talked about how she saw "so much potential in leaving a paper trail..." but because of her commitment to rigorous Māori scholarship and the high expectations of Māori society she noted that she would never simply "staple my lecture notes together for a couple of classes and call that a book". She lamented the fact that other Māori academics had not published more of their work:

I think about people like [person's name]... and I adore her work but there's so little that's actually on paper and so her biggest impact has been through her teaching but really that's only a small number of people, and now what?

Kiri emphasised the importance of capturing Māori knowledge and 
scholarship on paper for future generations. However, she also recognised the tension between the immediacy of teaching and its impact on Māori students versus the importance of publishing research, creating and preserving knowledge for the future, and in the process contributing on a wider scale to Māori society and culture. Kiri also emphasised the notion of leaving an academic legacy not only for iwi and hapū, but for Māori scholarship generally. Embedded in that notion was the principle of not taking the easy pathway and her belief that Māori academic work needed to be approached as an opportunity to produce something significant and substantial.

Besides setting goals around scholarly output in relation to Māori community needs, the interviewees also spoke about how their success was shared by the Māori community - and how that motivated them to continue with their work. For example, Elly spoke about how,
the work that you do is not really yours and it is actually more of a public thing...then your promotion is not necessarily an individual promotion but it's actually a promotion for the work that you've done, not because it's yours, again, but because it's a Pākehā mark of respect to your Māori work within the Faculty.

This linked to Elly's strong sense of duty to achieve the "dual accountability" standards of performing well on behalf of the Māori community and also meeting the expectations of the Pākehā academic community.

In a related point, Roha spoke of the collective gain to be made by working with other Māori academics, and how this motivated her to continue with her work. She explained how, as part of a team of Māori academics in her unit,

you're celebrating every little thing that people are achieving, you know you get an article published or you get an abstract accepted for a conference, to me, it's not about doing it for yourself, you know, that's where you're looking. 
In other words, Roha gained inspiration for her work from the collegiality of the Māori academic community that she worked within, and her personal achievements became more important to her for the benefits that they accrued for the Māori community.

Another motivation revealed in the interviews was the idea of Māori academics acting as role models for others in the Mãori community. For example, Wendy spoke about how it was even more important that Māori in academic roles do a good job in order to "inspire more people to become Māori academics", particularly in the current context where Wendy believed it had become much more difficult for Māori people to get academic positions. This, she believed, was largely due to the more competitive environment created by processes like the PBRF and because of her observation that universities are less likely nowadays to take a risk in appointing someone based on their potential alone. Despite having assumed this role model position though, Wendy warned against the use of Māori academics of the past as yardsticks for contemporary Māori academic leadership, suggesting that, "when we talk about leadership we kind of get lost in the 'we will produce the next Ngata' and, well, actually, I don't want to be that person, I want to be my own person".

Another strong motivation for interviewees was the notion that they owed a debt to the Māori community for the privileges and successes that they had enjoyed in their lives. For example, Kiri was critical of another Māori scholar who had left the academy:

On the one hand its absolutely up to her but on the other hand when so much resource is poured into someone, on some level, at some point you actually do owe something, if you've been the one getting all the scholarships and the support.

Kiri strongly believed that choosing to draw on the opportunities provided to Māori students and scholars necessitated an obligation to repay Māori society in some way. As an extension of this belief, she linked the idea that not only was a Māori scholar beholden to the Māori community, having 
benefitted from the support and opportunities that membership provides, but that it was also a matter of their family's honour to be upheld and their mana (reputation) maintained. She spoke about how a family member had reminded her once that in accepting a Māori scholarship she was,

taking it as a Māori person, it's a Māori scholarship, it's not a Pākehā one, so it couldn't be anyone, so if it's a Māori one, every single thing that comes out of the opportunity that you've been given is not for you, it's for Māori people, and if you're not interested in making good on that then don't take it because you'll embarrass all of us.

In this example, Kiri expressed not only her personal sense of debt to the Māori community but also a sense of shared familial obligation - in other words, she understood that by not living up to academic expectations she would not only let herself down but she would also cause shame to her family. She was aware that by taking advantage of opportunities available to Māori scholars, "you're taking this as a Māori, [and] take it as part of the collective" - whether she defined that as her family, her iwi or the Māori community in general - and she believed that such an opportunity also came with reciprocal responsibilities. That sense of carrying a responsibility, as Kiri explained it, had,

kind of rung in my ears a lot, it's like anything that comes out of this...you've been given that on behalf of everybody, it's not about you and so, never mind your career choice, never mind your whatever, so anyway that's how I ended up being an academic....

Such was the extent of Kiri's belief that she must represent the Mãori community in her academic career, it was even 'ringing in her ears'.

\subsubsection{Scholarly activity}

The second broad category of motivations given by the interviewees for why they became academics focussed on the nature of the scholarly activity that they were able to engage with and the intellectual stimulation that it provided. As Kiri explained, "I love finding out the new stuff, the surprising 
stuff". She loved the creative element of the academic research role and enjoyed the benefits of doing research that created new knowledge. This sentiment was echoed by Elly who, in previous employment, had felt "intellectually stunted" and frustrated by the narrow focus of her work. She turned to a role in academia because she, "just wanted space to be able to think because I felt like my brain wasn't working, wasn't being allowed to work in the way that I needed it to". Similarly, Jessica shared her strong interest in the research aspect of her academic role and explained that, "I want to be someone who is known for the research that I do because its quality and because its useful and its helpful, not just in a national sense but in a global sense". This sense of making a contribution to society linked back to the first set of motivations but also alluded to a deep-seated desire to make a strong scholarly contribution, not just in a Māori context but on a global scale.

Despite this clear motivation to be intellectually stimulated by their academic work, some of the interviewees talked about how disciplinary parameters and practices had stymied their progress. Elly spoke of switching disciplines early in her career when she realised that,

[Discipline name] was not really an area that I could have a career in. It's never really been that interested in different voices. It's got it eyes fixed firmly on Europe and America for its source of new perspectives. It's not interested in Colonial perspectives or Indigenous perspectives.

As a result, Elly felt excluded from this discipline and was drawn towards another field in which she had completed an undergraduate degree. Interestingly, in her description of this experience, Elly talked about eyes and voices, almost personifying the discipline that she felt had excluded her.

In an unrelated but similar context, Kiri talked about having been denied academic stimulation and scholarly discussion about her research while working in an unsupportive academic unit. She spoke of being "hungry to talk about my research" and believed that such discussion was necessary to provide her with sustenance and ensure her academic survival. The denial 
of this collegial support negatively impacted on her experience as a Māori academic.

Another motivation expressed by the interviewees was the commitment to produce quality research. Roha described how her vision of success was to be able to write about her work and know that other people were interested in reading it. In her own words:

I think success for me would be to be able to write about, looking at this thesis I think, gosh there's a lot of people who are interested in it and I'd like to be able to write more about that.

Similarly, Kiri spoke of the value of Māori academic work, explaining that, "I knew that I was doing important work and it was the right thing to be doing and I mean that in a practical as well as a wairua sense and my tupuna had taken me there". She expressed a notion that not only does Māori academic work have a practical output - research gets disseminated, students get taught - but it has a spiritual element as well, that is connected with Māori ancestors and exemplifies a cultural connection that transcends the parameters of any discipline or topic of study.

One of the potential motivations that somewhat divided the interviewees was the notion of whether a professorship was an aspiration or not. Jessica admitted to having never dreamt of being a professor, asking, "What's a professor? What does that mean? I don't know...I have no clear concept of what that means...so at the moment I don't care". Instead she shared that “I've always loved learning so $\mathrm{PhD}$, yep, definitely wanna do that and part of that is for family too but mainly it's about being a researcher". Taken at face value, Jessica's motivation appeared to be more about producing research outputs than acquiring the trappings of academia but this may belie her unwillingness to share higher aspirations.

In contrast, for Wendy "the pinnacle of the academic side is the Professor" and she had no qualms about admitting that she wanted to be a Professor, sooner rather than later. She noted that, "I hopefully will become a Professor 
before I'm too old. I hope that I'm not nearing retirement, in my twilight years before that but again I know that that's some high aspirations".

\subsubsection{Previous life experience}

The third set of motivations identified by the interviewees related to the impact that their previous life experiences had on their decision to pursue academic careers. Kiri had previously worked in another part of a university and had gained firsthand experience of the value of "working with Māori staff, working with Māori students, and all the different targeted positions and stuff". She admitted, however, to initially not aspiring to be an academic, reinforcing the notion of the 'accidental' or reluctant academic and noted how she "hadn't committed to having an academic job, until [her] third or fourth year at university". Similarly, Elly spoke of how she "sort of fell into" an academic role, almost by accident, indicating a degree of luck and happenstance.

Roha spoke about how "probably because of my upbringing" her approach to academic work had been influenced in such a way that, "I don't want to see a focus on underachievement". She had rejected taking a deficit approach in her research, avoided looking for the cause of perceived 'problems' and instead sought insight from Māori successes in her field, and attributed this to a positive attitude towards Māori development engendered in her through her childhood.

Whānau (family) influence was clearly an important factor for many of the interviewees in choosing an academic career path. Kiri noted the influence of her family, citing her grandfather's influence on her to complete a postgraduate qualification and the fact that her wider family included people with $\mathrm{PhD}$ degrees, thereby instilling in her high academic expectations and a belief in her potential to be academically successful and contribute to a whānau legacy. For Kiri, her decision to study towards a PhD was influenced heavily by her family and her Māori supervisor for her MA degree. As she described it: 
My supervisor, and this is where it comes back to that get to know your students thing, my supervisor came to my graduation for my Master's and he went to my grandfather, who my parents had brought up from [geographic location] for the day, and he by then was early 80 's and he went to my granddad and he was like, "Your granddaughter has to do a PhD and blah, blah, blah" because he knew exactly who to go to. He'd heard me talk about my granddad I suppose and just figured it out. He’s a Māori guy, right.

In contrast, Jessica was not able to rely on family advice around her academic career but instead drew on someone else who she knew who was already working in a university. She explained how she,

knew someone who worked at [university name] and for some reason we'd been talking. I'd been working out where I was working and finding it hard slog so it's one of those things when you get to the space where you think if you don't leave you're going to go mad and look for something else because you don't have to be in that position.

She sought counsel from this other person and was able to be guided into a short-term academic position which eventually led her to a permanent role.

Finally, Elly shared her realisation that her previous professional career created a clash with her religious beliefs. She explained how she, "knew that if I stayed there my trajectory would sort of taper off... so I thought that being an academic would be more consistent with my faith too". Thus, she became motivated to take up academic work because she believed that it posed less of a conflict with her Christian faith.

\subsubsection{Enjoyment}

The final set of reasons given by the interviewees to explain their choice of academic career path related to their simple enjoyment of the work. As Roha noted, "I do enjoy going to work every day". This was reinforced by Jessica who said, "I love it. I do, I absolutely love it, and when people go, "How do you feel about your job?" I love my job". Roha did note that she would be even happier, "without the pressure of PBRF" but that nevertheless she did, 
"really love what [she's] doing".

Their satisfaction with their work seemed to derive from both their teaching and their research activities, with Wendy sharing that she "liked" teaching and "enjoyed being there", while also noting that she enjoyed doing research and actually preferred it over teaching. In contrast, Kiri expressed that she loved "the teaching and love the research...I'm really lucky because I know that a lot of people talk about the job as if you either are into the teaching or into the research". She noted how rare she thought that was, particularly amongst her international Indigenous colleagues because she explained:

Often people when I'm talking to them overseas, they'll identify themselves as either a research-focussed or a teaching-focussed person but for me, like I love both of them and I like totally love them and I just think it must be the right thing for me to do.

In addition to enjoying the teaching and research aspects of academic work, Wendy also admitted her enjoyment of "being around the people", the other Māori scholars and enjoying the collegiality of the Māori academic community. Jessica broadened that out even further to explain that she took great pleasure from the "bicultural, even bilingual model" that she was able to contribute to in her academic programme, noting that she took great "joy" from being part of it.

\subsubsection{Key roles associated with being a Māori academic}

The second superordinate theme to evolve from the interview analysis related to how the interviewees conceptualised their key roles as Māori academics. Much of the discussion focused on conventional aspects of academic work, including teaching, research and service but also extended to career progression and the personal qualities required of Māori academics.

All of the interviewees described busy workloads that required them to span a range of academic activities. For example, Roha shared: 
These days, you're still doing some teaching, like there's a requirement to teach 150 hours so I'm coordinating one or two courses. But the other time, because I'm trying to do my [postgraduate qualification] so a lot of it is reading for that, trying to do some writing, especially like the lit review, and currently like organising the data gathering stuff, meeting the people actually and the other time now, which is probably more critical for the PBRF, is the writing, and so like trying to write for articles and there were a couple of conferences, and in between the meetings you have, like for the [name] committee...

For Roha, getting some workload balance was an area that she identified as an academic development need.

\subsubsection{Teaching}

Some of the interviewees discussed their teaching work more specifically. Kiri shared how much she enjoyed, "the performance side of teaching", admitting to getting a "quick rush" from the immediate feedback given by students. She explained:

If you plan a good lesson or if you manage to pull your shit out when you're there and kind of make it all happen you could actually have some quite profound and really invigorating kind of feedback on the impact of what you're doing. That all is really selfish, eh, and I'm not saying that everyone's experience depends on me or...it's not quite like that, it's not like I want to be an actor and whatever and have everyone say I'm great, that's not it, but you know.

So, while Kiri described her teaching as being invigorating, and giving her immense pleasure, she also alluded to a belief that thinking of teaching as a pleasurable thing could also be selfish.

Wendy also admitted to taking pleasure from teaching in the university environment. She began tutoring as an undergraduate student and concluded, "that kind of gave me a taste of the teaching side of things, which I enjoyed". However, alongside this enjoyment, Wendy also confessed to finding aspects of teaching to be difficult, particularly in relation to 
developing and evaluating a curriculum. She explained:

I find it challenging, particularly because we don't have a set methodology, as such, we don't run a set programme...that has been challenging, although I like it because it is diverse but it makes it hard to monitor what is being taught and even when we kind of review and do stuff like that, I'm not sure whether we are actually monitoring it in a proper way.

Instead Wendy noted that much of her teaching practice was developed by instinct, having received no academic development around course design and teaching, and relied solely on her previous experience. She explained:

When I thought about how I would design a course I had no idea, so pretty much duplicated everything that we had done the year before, which is not necessarily good teaching practice or developing academic skills, so it was kind of immersion by fire.

Elly was also open about her belief that her Māori teaching pedagogy was still under development, and admitted:

One of the things I do is try to teach to the Māori students but I know I don't do that particularly clearly sometimes...so I try to do it in the ways that I organise my slides, my PowerPoints, and I've always got Māori students in the back of my mind so I try to include more Māori content than perhaps other lecturers would.

Kiri gave some insight into her teaching pedagogy when she described how she loved "disproving students" by,

having students exceed their own expectations of themselves. I love it when they're like, they crack me up when they're like, 'Thank you so much for the 'A". It's like, 'It's not my fault. I didn't write your essay. Don't blame me for your 'A".

She also explained how she wanted to empower her students to enjoy their own success and she did this by setting and maintaining high expectations. Kiri described the joy of watching how her teaching had an impact on her students. She likened herself to a "conduit" or a "catalyst" that had the 
potential to ignite an interest or a passion in her students that not only enhanced their learning experience but could also have wider consequences. She reflected on the broader effect of her teaching, beyond just the immediate classroom, and concluded that, "I just think that it's such a privilege to be able to bring this stuff to these students and when you kind of like know some of that flow-on stuff" - a reference to the potential for her teaching to have a larger scale, positive impact. Kiri explained:

One of the reasons that I really committed to being part of [subject] as a discipline and why I stayed in the Department ... is because it's an opportunity to counteract [subject] as its taught in high school...and we're always going to have a higher proportion of Māori students in high school [subject] classes than at any university class, and so it means a lot to me when I hear students talking about, oh there's a bunch of us from [interviewee's course] or whatever and they're all in their teacher training classes and telling stories about how funny it is...and they'll email me back and say, 'I've been teaching for four years now and I've been teaching your stuff and what's new?' and that stuff's just awesome.

Despite the many positive aspects of teaching, the interviewees raised teaching challenges that they faced as Māori academics. For example, Jessica complained of, "having to deal with layer upon layer of stereotype and history that people come with, and answering the same questions every year to the point that you just want to go "Aaaahhhh"!" She worried that too many of her non-Māori students were able to finish their qualifications without a full appreciation or understanding of the Māori content and concepts explored within her programme, and admitted finding it,

hugely concerning that we send people out where we send them that still have those attitudes and that can do harm and our structures don't do anything to stop that. There's nothing that stops those people who you know are going to do harm to our kids, going out there.

Her concern was about the possibility of unprepared graduates having a negative impact on the Māori community, and she was frustrated by the inability of Māori academics to stop it happening. 


\subsubsection{Research}

Many of the interviewees talked about their preference for research and the prominence that it had for them in their roles as Māori academics. For example, Roha shared how, as her confidence as an academic had grown, so had her focus on producing quality research:

$$
\begin{aligned}
& \text { More so than ever, for me it's about research and I think that when I } \\
& \text { thought of the term last year, I didn't even mention the word research, it } \\
& \text { wasn't really even in the front of my mind, but just over this last year its } \\
& \text { kind of like I understand what that term is. }
\end{aligned}
$$

She was proud of her growing interest in "reading and knowing what's going on" by keeping up to date with journals and other relevant scholarship.

In fact, all of the interviewees spoke of their love of research, and described it as a "privilege" (Elly) to be "able to make a difference" (Jessica). Elly spoke of the pleasure of being able "to research things pertaining to, especially, te reo Māori” because of the value that she placed on the Māori language. Similarly, Roha shared her happiness about her research being used by others in her field to improve the experiences of Māori youth. She recounted a story of when her work was used as the basis for professional development for a group of staff outside of her institution, and related this to her personal epiphany and growth about the role of Māori academics in disseminating their research and sharing their ideas that support Māori development.

Even further afield, Elly shared her experience of the high levels of interest in her work shown by international audiences, noting that she felt more accepted on the global stage than in New Zealand. She admitted to being somewhat surprised that,

the Mãori language experience is one that is really relevant to a lot of countries, from our Māori Language Act to the Kohanga Reo movement, so we're a bit of a role model, rightly or wrongly. It's something we've not really held up our end of the bargain in some ways, but you know, we're looked to, so what I have to say is actually listened to, which is weird. 
Kiri also shared a desire for more research "'conversations" at a local level. She described her field of academic interest as being "research poor" and thought that it included, "a lot of really bad research and not very much good research". She yearned for a point in time when "there's a bit more of a conversation...I'd love it if someone could tell me my research was lacking in certain ways or whatever". In her reflection, Kiri highlighted the strengths and weaknesses of research in her field and expressed a sense of responsibility to make it better, to represent Māori scholarship in the field, and to engage in academic conversation and critique.

While Elly did not specifically talk about a need for more academic conversation she did explain how she saw her work as contributing to a metaphorical Māori research "collective", to the extent that she felt "part of something bigger". She concluded that the outcomes of taking a collective approach were,

not so much for me personally but, thinking that the stuff I work on, could actually be reasonably important. I don't know how to judge importance actually but I feel like it matters, I don't know if it does but it feels like it matters.

In other words, Elly saw the importance of her work as transcending her personal effort, which reinforced the idea of the value and power of the Māori collective.

\subsubsection{Service}

A third aspect of the role of Māori academics that featured in the interviews was service work, both within the university environment and beyond. Kiri spoke about how she really enjoyed doing service work but admitted:

Admin is not at all a strength of mine and that is the thing I have to work on continuously because I'm not a naturally organised person, and if it was up to me, nothing would ever happen. If it was up to my natural instincts, and that's the part of this job that I struggle with the most, is feeling quite disorganised a lot of the time....and I can't be too disorganised...logically I 
can't be too disorganised, because stuff's happening...but that's what I have to work on the most.

Similarly, Roha spoke about her commitment to the service aspect of the Māori academic role but shared a reluctance to be put in the role of 'expert', preferring instead to take on a representative role and make a contribution to Māori academic development that way. She explained:

At one stage I wouldn't have been confident and I would have thought that I don't really know much but I think I feel different, that I'm there to find out what they do and....hopefully I can support us as Māori academics.

Wendy also spoke of her commitment to sitting on a number of university committees and representing Māori through her service work, but lamented the fact that it took so much time "on top of our fulltime jobs", which she believed limited her capacity to give her best performance. She noted that other academic staff appointed into management or governance roles were usually relieved of teaching duties in order to free up time for their extended service work. In her representative work, Wendy felt pressured to produce oral or written Māori responses on a range of important topics, while still being expected to produce frequent, high quality research outputs, teach her own courses, mentor other teachers, and support her iwi (tribe) and whānau. She expressed her frustration at this:

I can't prioritise it all the time so that I find it constricting because it's like, "We'll let you have a little go at it and if you succeed we might think about it", as opposed to, "We've committed to all of this, here's some money, set it up". But I suppose that's probably one of the things about being a Mãori academic is that you're kind of damned if you do and damned if you don't, and if you are committed to Māori development or supporting people and into that kind of collective support then you will be that person that will say, "I'll turn up and I'll do it for you". Sure there'll be others that won't and they'll frustrate you but you'll still go out there and champion them anyway because you believe in the bigger kaupapa, so I think that there are some restraints. 
Roha also raised another aspect of service work by discussing how she was beginning to engage with the notion of Māori academics as the critics and conscience of society. She explained that, for her:

To be successful would be to be able to articulate confidently and to be able to look at people's work and it's kind of, it's not judging it but its saying this is how I feel about it but so-and-so says this about it and I agree with them and, you know, so it's a conversation.

Roha noted that,"being able to talk more about [her work], is something I'm more confident about doing" and meant that she was able to have a positive impact on those around her, which she saw as a key role of Māori academics.

\subsubsection{Career progression}

While each of the interviewees expressed different academic aspirations (for example, Wendy was clear in her intentions to make it to professor as quickly as possible), some of them talked about feeling a duty to attain promotions through the conventional process, in order to prove their ability and merit. Elly admitted that she intended to apply for promotion in the near future, "not because I think I'm all that but because I think Māori academics need to go up the ladder in the conventional way". Kiri also confessed to wanting to go up the academic ladder and was reluctant to take any "shortcuts" because she wanted,

the opportunity to progress slowly, you know. I don't want to be like one of those tomatoes that grows too fast and doesn't have any flavour, you know. That's a strange metaphor, but you know what I mean right? You know, when you have all the right conditions your tomatoes get really big, but they don't taste like anything. I'd rather actually progress through.

\subsubsection{Personal qualities}

In addition to the more conventional elements of academic work, the interviewees noted some personal qualities that they believed were essential to fulfill the role of Māori academic. One of these qualities was the ability to contribute a Māori perspective to teaching and research 
programmes. Elly explained how, as a Māori academic:

You've always got a different view...you've always got a different perspective...and, not that I've got the Māori perspective...that would be ridiculous...but there's always room for another perspective and it's always good to have something to say.

Linked to this notion of providing a distinctive viewpoint, Roha also added that being a Māori academic was, "about transforming or making those changes, seeing what's out there and what's not out there", which emphasised an intentional, development dimension to the Māori academic role.

Finally, Kiri noted that a common quality encouraged, somewhat unofficially, amongst the Māori academic community, was humility. She concluded, "I know it's not very Māori of me or whatever to say it but that's just how it is".

\subsubsection{Relationships}

Another key theme to emerge for the interview analysis was the range, importance and impact of the relationships that the interviewees had with those around them. Interviewees particularly noted the value of the Māori academic community but also discussed their connections with the wider Māori community, their broader academic communities, as well as their relationships with their families and their students.

\subsubsection{Māori academic community}

All of the interviewees commented on their involvement in and appreciation of the Māori academic community within their university. As Elly explained, "a good thing about being a Māori academic is that there are other Māori academics on campus, so being part of a collective" was seen as beneficial. Similarly, Roha spoke about the collegiality that she had found within her Māori academic community:

What I love about being a Māori academic is the group I'm working with and the good thing is making connections at [campus and Faculty names], 
because you can be quite separate, well we were quite separate before but I think that those links are really important, for just helping to understand how the university works, and like you are more familiar with everything and know that there's those support things in place...and just hearing the conversations that go on when we meet and the different symposiums that we've been to and things that are held that just widen your whole outlook and 'wow' there's all these things going on to do with Māori and I didn't know or I wasn't aware.

In a similar vein, Jessica described how a key aspect of the Māori academic community was having the same interest in Māori development and sharing a common goal or worldview, which made her work more pleasurable. She described her enjoyment of being part of the Māori academic community, noting that,

the people that we work with here, we're lucky to have a group, and the passions are all the same. There's nothing like being in a group of people where the passion is the same.

Roha reiterated this point:

It's the whole way we [Māori academics] work together. Mind you, I've worked in staff where there's just a minority of Māori people but I think an important aspect is that we're all working together for the same goals but supporting each other.

A similar point was made by Wendy, who shared that being around other Māori academics was "a big draw card" for taking up an academic position, not just because of the social elements of their collegiality:

It helps stretch my mind in terms of different ideas, particularly here, because everyone comes from a different disciplinary background so you kind of learn about different things in different ways. You all might believe in the same things but you might look at it from different angles.

Thus, her experience of Māori collegiality was as much about the intellectual stimulation that it provided as it was about the social connections, and she enjoyed a sense of camaraderie forged by shared worldviews with other 
Māori academics.

There were some limitations, however, in the way that the interviewees were able to connect with the Māori academic community. For Elly, despite acknowledging many benefits of Māori academic community membership and finding "the idea of being part of the Māori collective" to be "really powerful", she described feeling that sometimes that membership was "more virtual than real" because of the geographical distance between campuses and units. Working in a different context, Roha spoke of sometimes feeling intimidated by other Māori academics:

It's a bit scary but only because I don't feel confident that I know enough. I think it's just about confidence and actually being confident about what I've written and what I'm doing...but I think once I know, once I've met people and I know what's involved then you feel more comfortable...when you listen to the speakers or you just see the people sitting there you think, oh wow, they've written that.

Jessica also spoke about the diversity of the Māori academic community and explained that, "we have our own arguments, debates, issues where we don't agree but it grows you, having that larger group of people and being able to go, "Well actually, I don't agree with you, I think this way"”.

Similarly Wendy discussed how the diversity of the Māori academic community had,

helped me to think about my own research and I can't just think that it's all in 'this' shape, it can be in different shapes and that diversity helps me to think more diversely in my work, which I think can only make you a better scholar.

Both concluded that, despite the diversity, Māori academics were generally still bonded by a shared passion, and Wendy particularly appreciated the multi-disciplinary nature of the Māori academic community and all that it afforded for her own academic development.

Wendy highlighted what she saw as another of the limitations of the Māori 
academic community. She shared her belief that the formal Māori academic collective in her university, could be, "a lot stronger in terms of the impact they could make on the institution". She went on to ponder,

whether a stronger commitment by all in [name of Māori academic group] would actually make more of an impact because there are people who do a lot and there are those who like to ride on the benefits of it and I find that frustrating because I think if everyone all pitched in it might make things easier because you can spread the load a bit more.

Despite these perceived limitations, the interviewees noted a number of benefits gained from their involvement with the Mãori academic community. Roha and Jessica both explained how the collegiality they had found through the formal Māori academic collective at their university had provided them with opportunities to learn and grow in confidence. Jessica concluded that, “it's that networking and it's that being with other Māori academics and talking about what they're doing and how you can see yourself growing in there". Roha highlighted the value of the formal Māori academic group at her university, and noted that it was,

really the only other group that I meet as far as support, even just support within the university because I probably wouldn't...I'm shy....and then you go along with someone and you get those links.

One of the "links" that Roha discussed was meeting another Māori academic who had developed into her mentor, which was something that she was "getting a lot out of". As Roha noted, "having support people that can mentor you and keep you on track, [...] that feedback to me is really important, so I know what I'm doing and where I'm going". Similarly, Jessica spoke of the importance of the relationships that she had formed with Māori academics from outside of her own academic unit and of how much she had come to value them as role models. As she noted:

I mean it might sound 'oogy', but having people like [name] down at [campus] and the groups of people that we've got to know, just broadening those fields...they're models...so people like [person's name], she's got a 
PhD, it's in [subject], she's like wow, you've made it, you've done what you've done, you're still doing what you do.

Within her own team, Roha also spoke of the collegiality she received from other Māori academics, "in just getting together in the staff room and actually sitting down and actually talking about what you're doing and everyone's wanting to know how you're going, and that's important". Similarly, Wendy described the closeness she felt to "the other staff more than the students, just kind of that collegiality I suppose is probably the thing that I like the most".

An added dimension to the Māori academic community at their university was the development opportunities provided by the MANU AO project. MANU AO, the three-year TEC-funded project to encourage the creation of a network of Māori academics across New Zealand, also supported the provision of localised training and events designed for Māori staff within each university (see Chapter One for details). The interviewees were virtually unanimous in their appreciation of the opportunities that MANU AO had provided, citing a range of academic development opportunities that had been helpful and supportive. Both Roha and Wendy highlighted the value that they had gained from having opportunities for regular researchrelated conversations with other Māori academics. Of particular note were the weekly seminars that MANU AO facilitated across a national video conferencing Access Grid, which were seen by Wendy as a useful "outlet for people who might be wanting to put their stuff out". She credited the national MANU AO programme with, "just raising Māori scholarship as well...knowing what's out there, knowing who's doing what... that kind of collective nationwide stuff".

Other popular MANU AO offerings were writing sessions, including specific sessions about how to complete research proposals for funding grants. As Wendy explained, the value of this sort of training was threefold; she was able to acquire new skills, in a comfortable learning environment, and the training was likely to attract more Māori staff than other 'generic' offerings: 
Understanding those sorts of things I think are important because even when they are advertised internally we have a tendency to go, 'Oh that would be interesting' and never sign up for them, whereas at least when they're done by MANU AO you have a tendency to go along because your mates are going to go, or you might not go to the other ones because you think you'll be the only one there and no one will go so, I won't go either.

According to Wendy, the increased interaction between Māori academic staff, both within and across universities, initiated by MANU AO had led to increased collaboration, particularly in the area of research. She valued this collective approach to research because, as she described, it had led to new outputs and ideas that may otherwise not have been realised and, she suspected, more rigorous research:

Having that collaboration stuff would be good because often, internally we don't actually know what everyone does and then if you have an idea someone else might have the same idea but then that idea might not germinate until the powers combine and then it might blossom into something else. Or, we spend a lot of time critiquing, 'Oh, that wasn't a very good job but if they'd done it with this it might have made it a lot stronger'.

This collaborative style was most obviously demonstrated in an approach that Wendy explained she had taken, along with some of her Māori academic colleagues, to prepare her PBRF evidence portfolio. PBRF was a process that was portrayed within her university as primarily an individual and competitive pursuit, with each academic being held responsible for determining their own research platform and presenting their work in the most flattering light. It was also viewed as a somewhat mysterious process, with a lack of clarity about exactly how the portfolios would eventually be evaluated. Instead, Wendy described her experience of working with a group of Māori academics to build, critique and enhance their Māori Knowledge and Development (MKD) evidence portfolios together, in an open, collegial way. As Wendy explained, the intention was that, "maybe that collaborative understanding might actually make MKD portfolios less of a hit and miss, because we're engaged with each other's scholarship but not on 
the 'I did this'...'Well I did this too' kind of number".

\subsubsection{Māori community}

Not only did the interviewees discuss their relationships within and around the Mãori academic community, they also noted the importance of the connections that they had with the broader Māori community, beyond the university environment. For example, Kiri discussed her career choice and explained that she, "could just see that being a history teacher would have such a bigger impact on our community so I was all fired up to be a history teacher". This demonstrated the importance that she placed on her work having a positive impact on the Māori community. By the same token, Jessica explained how working as a Māori academic allowed her to,

give everything I know back to those communities that I came out of, and I feel like I can do it in a better way, in a more focussed way, than what I was doing when I was actually in the communities.

In contrast, Roha spoke of being, "not kind of one to be out in the Māori community" and of feeling somewhat disconnected and uninvolved as a result. However she also spoke about the need for her work to have a positive impact on Māori society, disclosing a philosophical, if not a practical, connection to the Māori community.

Jessica used her research experience as an example to describe how she felt higher levels of responsibility and accountability towards the Māori community, which brought with it extra pressures. She explained:

If I go on research [leave] and I get it wrong in the community, it's not, “That woman did a stupid thing', it's "Bloody [name of tribe]". It's not just me standing there in front of them, it's all of my whānau, it's all of my hapū, it's all of my iwi, and knowing that it's kind of like, “Gosh you better get this right, and you better work with your communities". You can't come in and go, "I want to do some research", and then just leave. You can't do that but there's a lack of understanding about the time that you need to put into that. So I do other sorts of work and it's my way of going, "Yeah I'm still here. Yeah, I'm still doing the work". You know it's like being at the marae and 
being in the kitchen, so I'm trying to be in the kitchen but I also need to do my research, but I have to do the kitchen. I have to do that, that's my metaphor for it. If I don't do the kitchen, they're going to go, "Nah, you can't come here and you can't research - what are you doing for us?" That sort of thing.

While Jessica was certainly the most outspoken about the importance and complexity of her relationships with her Māori communities, it was clear that the Māori academic community and the wider Māori community outside of the university environment featured heavily in the experience of all of the Māori academic interviewees.

\subsubsection{Wider university community}

While the Māori academic and wider communities certainly loomed large in the minds of the interviewees, they also noted the influences of other nonMāori in the wider university community. For example, Kiri spoke of the influence that others had on her as an early career academic when she was still deciding on an academic pathway. She was based at another institution and noted how she,

got really good mentoring over there, some of it quite deliberate and some of it kind of accidental, just reflecting on conversations with friends of mine who were early career academics and I would kind of hear the way that they would talk about things and I would kind of realise that, yeah, this is something that I wanted to do.

Within their current institution, the interviewees also noted the support that they received through some of their colleagues and systems. Elly, for example, described a faculty-based mentoring system that she thought was quite helpful, although she did lament that accessibility to the programme was difficult and, "You've got to be quite aggressive in pursuing it". She described a campus-based women's writing group that she had recently joined, which she thought was "quite good", although, at that stage they had only met once so she was not sure about its effectiveness. Besides these formal support systems, Elly also acknowledged the informal support that 
she received through, "the conversations you can have in corridors with people who are sympathetic".

Jessica explained the informal support that she had obtained from nonMāori colleagues, which she had received rather unexpectedly. She noted how her perception of those non-Māori colleagues had changed over time, and how they had since become role models for her:

I came here and went, oh, the other people, they're all racist, bluntly, they're racist. They don't know. They don't care. And what I found was there are people who really care and they want to know, but they don't know how, and for all sorts of reasons they don't push forward, and then I found that, okay, they're PhDs, they've got their Master's or they've got their degrees, and so they've got all these letters behind their names but they don't know as much as I know, and that was empowering. That was like, okay, I can do this, I can do both worlds, they can only do one. And so the people I've been really fortunate to be mentored by are people that really get that there are two worlds, and they'd like to know more, and they'd like to contribute in their own ways, more. So they've mentored me, they're non-Māori...they've done a lot of work but also at the same time, when I go, "You've done all this, what have I done?", they go, "Well we couldn't do what we do without you". So that's also been one of the joys of being here, is just that it's a true relationship and partnership with those people.

Another of the interviewees discussed how her work was not really appreciated or valued by her non-Māori colleagues, and how she instead utilised her relationships with others in the global academic community to disseminate her research. Elly explained how, in her experience, Māori research was often more valued within the broader international environment than it is in New Zealand:

People actually do want to hear, particularly international people, and they actually do give a shit, which is really interesting because you expect to get a hearing from your New Zealand colleagues but you don't necessarily, but international people are far more interested in what you've got to say. 


\subsubsection{Relationships with whānau}

Another key relationship noted by all of the interviewees was the connection that they had with their own whānau. Many of these relationships have been alluded to earlier in this chapter, and all of the interviewees noted the influence that their families had on their decisionmaking and their lifestyles, as well as their responsibilities. For example, Wendy shared how her career path and expectations were influenced by her mother, explaining that, "Mum was a teacher, had taught te reo, and being around when she's teaching and so without thinking about it, I thought, “That's something you could do"”.

However, those family relationships also placed pressures on Māori academics who felt that they could not live up to all that their family required. Elly admitted:

I have to stop worrying about it, well not stop worrying about it but I can't...I mean I go home and my kids are reasonably happy and they're fed and they're okay and so I have to stop beating myself up [...] ...you know, they're impossibly high standards to reach, and I don't feel like I reach them but I'm sure that's incredibly common among Māori academics.

Similarly, Roha described her family as being "very tolerant", suggesting that even though she felt supported by her family to do her work, she also suspected that it placed a strain on her family because of the strain that her work placed on her.

\subsubsection{Relationships with students}

Finally, and somewhat surprisingly, the interviewees had little to say about their students, although Kiri did note how much she enjoyed teaching her students and the pride she took from their success. Roha also noted her need, "to have an understanding of where these students come from or where they're working" and shared that her teaching could be affected by a lack of empathy with the student body, particularly if she was not confident in what she was teaching. 
Wendy reflected on her own experience of being a student and acknowledged the importance that she had found of forming supportive relationships with other Māori students:

When I came to university and did the [qualification], I enjoyed it, primarily because of the cohort itself but that learning experience encouraged me to think about going on further.

She also noted some of the challenges of teaching students, particularly as a young, new academic:

Most of the students were older than me, I was only 21, and a lot of them, three quarters of the class were older than I was and if they weren't older they were the same age as me, so that was hard to get my head around.

\subsubsection{Pressures}

The fourth and final theme to emerge stemmed from experiences and issues that all of the interviewees had found challenging in the course of undertaking their roles as Māori academics. These various pressures were both diverse in form and yet common enough in experience to warrant being organised into four sub-categories: issues from identifying as Māori; concerns about the range of skills that may (or may not) be required; the impact of their relationships with others; and the challenges relating to how well their own values mesh with those of their institution. Each of these areas are discussed in turn in the remainder of this chapter.

\subsubsection{Māori identity}

The first of the sub-themes that emerged from the interviews was the connection between each interviewees' identity as a Māori person and the conflict that created with their role as an academic. Jessica explained that simply being Māori made her different. She believed that Māori have a unique experience of the academic role, and said "That's the whole thing about being Māori in this place, [...] you can't get it unless you've actually lived it". One illustration of this point was that many of the interviewees described their feelings of inadequacy - either as a Māori, as an academic 
and/or as a Māori academic. In relation to feeling inadequate as a Māori, Roha was concerned about whether she was able to give "something authentic" and "of value" when she taught her students, not directly in relation to her ability to perform her teaching role but in terms of the students' expectations or judgments of her Māori knowledge. She described being "a second-language learner of Māori" and how that "effects who I am", suggesting that Māori language skills are a key component of the Māori academic role but are also integral to her personal sense of Māori academic identity.

In a similar vein, Elly wondered if, as an urban Māori she was not authentic enough. She surmised that, "there's that standard that you can never really reach...I mean I can't stop being an urban Māori... I can't remake myself culturally", which in turn, she reasoned, meant that she had fewer rights as a Māori academic. In addition, she recounted a story of being involved in a research project with a Māori community where she had not been able to complete all she had planned. She believed that, as a result, there was "an outstanding nama (debt)" that she had not yet repaid to the community. It weighed heavily on her, restricted her from pursuing further research in the area and made her feel that she did not "have the right to go on" with advanced academic study.

Not only was Elly unsure about her adequacy as a Māori person, she also expressed some doubt about her worthiness of an academic career. She admitted to applying for her academic position only because of advice and encouragement from others, and to being willing to take a lesser position originally because of her uncertainty about the contribution that she could make. Elly was not alone in doubting her ability to take up an academic post, however, as Wendy also confessed that she, "never came to university thinking I was going to become an academic", thought herself "lucky to get that job", and doubted whether she would "make the cut" in the current environment.

At one point in her interview, Elly also confessed to feeling, "like a failure on 
two fronts" for letting her whānau down and not being productive enough in her professional life. She explained how she set herself "impossibly high standards" that she could never reach, and then felt like a disappointment but she suspected that was a trait shared by many Māori academics. Jessica described what she considered to be another Māori trait - lacking confidence in themselves because they had been brought up to believe that they were "just a dumb Māori" or that they have "got to be humble, don't let your light shine". She rationalised both of those mindsets as "a colonised way of thinking" but worried that they still had the impact of holding Māori academics back from their true potential.

Another pressure raised by the interviewees was the belief that identifying as a Māori academic meant having extra responsibilities. Wendy described how Māori academics were often required to take on roles representing Māoridom, both within and outside their institution, which meant having to attend extra meetings, "educate" her non-Māori peers, provide advice, work out strategies for consultation and generally represent Māori issues effectively. Kiri also pointed out that being a Māori academic could be "a little bit overwhelming" because it carried with it the obligation of filling all of the gaps in the literature where Māori views and experiences need to be represented. In her view, it also meant being the best - better than the rest because of the pressure to not just perform but to excel.

Kiri made another serious point about what differentiated Māori academics from other academics, and placed a significant pressure on them. In her view, being a Māori academic was very risky, for a number of reasons. The first was that by taking "the path less travelled" Māori academics were gambling on an uncertain future. The second, came from research that she had found that concluded, "women in academia are far less likely to have children and the further up they go they are less and less likely to have children than women on a similar income". The third, and decidedly more sombre, reason was because she believed that academic careers were bad for Māori people's health. She recounted how she was once challenged to name, "five Indigenous women academics who have been in the job for 
longer than five years and who aren't physically unwell" and had struggled to do so. She had been advised, early in her career, that as a Māori academic she needed to know, "that if you take this job on, it's really important that you're aware that you will die early. This job will literally, physically kill you". Kiri concluded that "sometimes it's hard to get excited about that as a career choice".

Finally, Kiri also asserted that being Māori in an academic role could provide distraction from intellectual endeavours. In her mind, the act of being a role model or advocate or problem-solver for Māori society meant that there was less time to advance her own intellectualism. She had found other Māori academics to "be so anti-intellectual, we're so busy apologising for what we do to ourselves as well as to other people that we don't actually get to go, "so what do we do?" She wondered aloud whether that was, "one of the things that prevents us from having these professional conversations".

\subsubsection{Range of skills}

The second set of sub-themes to emerge from the data related to the range of skills that the interviewees believed they should possess or had struggled to acquire in order to fulfill their roles as Māori academics. Their responses generally revolved around feeling unprepared or unqualified for their roles, having little control over their development paths, having research and/or teaching-related issues, and struggling with time management.

Three of the interviewees admitted to feeling unprepared for the roles that they were in, primarily because of their lack of qualifications or skills. Roha described how, when her team was told that everyone had to complete a PhD within a specific time period, "It didn't really sink in". She was initially unable to absorb or accept the raised stakes and had stayed in denial about what was required for the job. Roha also confessed to "working in an area that I'm not really trained in". This added to her feeling of inadequacy about the skills that she did or did not possess. She lacked the technical skills that she needed to teach a specific course but also lacked the time to upskill because of the added research pressure. In the end, Roha decided that she 
was not prepared "to take it all on board" and had struggled.

Roha was not alone in feeling unprepared for her academic position. Wendy also admitted to feeling overwhelmed and "a little bit nervous" because she had "literally just come out of being a student in Stage 3 and jumped in to being the lecturer in Stage 3". She described how the challenges of this 'baptism of fire' included dealing with older students and coping with her own lack of experience. While both Roha and Wendy had struggled at the beginning of their career, Jessica recounted how she had been accelerated into a senior role but without the qualifications behind her. She wondered, "How do you get into a position like this when you haven't got the same qualifications as other people?" She also lamented, "not really being supported fully or properly" and having to deal with "all the politics around that as well".

Feeling unprepared was one aspect of Roha's experience but feeling like she had no control over her own development was another. She described feeling "forced" to do research and teach subjects that were beyond her skill level. She also explained how she wanted to be better at both but that, in her experience, her institution did not "seem to care" that she had "a different learning rate" and she felt "really pushed into it".

The interviews yielded a lot of information about research-related pressures. In regards to Māori-related scholarship, Elly shared that she had more than enough Māori material that she could work with, in fact, so much that "it could keep me going for a lifetime in terms of research". On the one hand, she felt "really lucky" to have the opportunity to do research but she emphasised the quality of the Māori content that she had to work with, rather than the research skills that she brought to any project. In relation to her own research skills, Elly doubted if she had the requisite research track record, in a Western sense, that warranted her gaining her first academic position. She thought that her university took a 'leap of faith' in employing her, and credited others for seeing her potential. Unlike Elly, Kiri's experience was to have her scholarly rigour, research ability and potential 
doubted by her non-Māori colleagues - to the extent that even the existence of her field of study was once called into question by a colleague. Kiri recounted:

To this day I don't know whether he was 'taking the piss' and seeing how I could handle myself as a scholar or whether he genuinely meant it and I suspect that it was probably somewhere between the two.

Elly summarised her understanding of the research-related pressure that she believed Māori academics were under, by explaining the expectations of dual scholarship - as in, needing to meet both Māori and Pākehā expectations:

There are two clear ways Māori academics can fail. One is by failing to adhere to, reflect and master Pākehā methodology and Pākehā ways of doing research and doing knowledge....and the other is failing to do Māori ways of research and Māori ways of knowledge, you know, being Māori enough.

Sadly, Elly shared that she felt like she was "not very successful at either". Conversely, Wendy thought that perhaps Māori academics had a tendency not to set their expectations of themselves high enough, suggesting that, "we've got into a rut of 'it's okay, I'm happy where I am' because if I push myself a little further will I end up having to do more work and I'm barely coping as it is". She explained what she saw as a fear of setting high expectations and then having to take extraordinary efforts to achieve them and feeling unsupported by others along the way.

Not surprisingly, some interviewees referred to the PBRF pressure that they were under. For Roha the pressure came from, "not necessarily knowing what you need to do or when to do what, especially in the early days" and that the pressure had mounted as "it became more serious that 2011, 2012 
was coming closer"6. She explained how she had become more confident since working with mentors and had more of a plan in mind but she did not fully understand the implications of PBRF and the threat that it posed to her. Wendy also felt that PBRF added constraint and research pressure on to Māori academics. The uncertainty around the process meant that, in Wendy's mind, it was "all done on an assumption, like we're just kind of hypothesising that you must do all this and at the end of the day, you never know, it's all left to chance, it's still all a gamble".

While research challenges garnered a lot of the interview time, some of the interviewees noted teaching-related pressures as well. Roha described carrying a heavy teaching load, which she thought was common for the Māori academics in her faculty. She believed that her teaching load limited her ability to engage with other parts of the academic role, such as research.

Wendy suggested two areas in which she found teaching to be a challenge. The first was student motivation. She noted that she can,

find it challenging to motivate students who are doing it [her course] just to tick a box if they are not passionate about the class, and how to engender passion into students who might, particularly at 9'o'clock on Monday morning, you know a lot of them are just not interested.

Another of Wendy's teaching challenges was the use of technology. She felt that it required too much effort and ongoing attention and she was not convinced of the value that it could add for her students. In fact, Wendy saw great tension between her teaching and research roles. She wondered aloud "What do you want? Do you want a good teacher or do you want a good academic?" suggesting that they were mutually exclusive, or at least unlikely to be found in one person.

The final skills-related pressure raised by the interviewees related to time.

\footnotetext{
${ }^{6}$ A PBRF round ended in 2012, at which point all the interviewees in this study had to produce extensive portfolios to demonstrate the quality and impact of their research performance in the preceding six years. Their portfolios were considered by an external panel of experts and they received individual assessments that were also combined to produce institutional tallies.
} 
Roha reflected on the range of support mechanisms and development opportunities that were available to her but admitted that her workload and time constraints meant that it was difficult "getting along to those things". She also described feeling time pressured and unable to reallocate her workload in order to focus more on her research, whereas Wendy just simply pleaded for "more hours in the day". Wendy also admitted to struggling to fit in all of her responsibilities:

Just reflecting on my own experience of having to work full-time and study pretty much full-time as well, you have to sacrifice something and what do you sacrifice? Just make it longer, or end up getting divorced because you're not spending enough time at home.

\subsubsection{Relationships with others}

Another type of pressure that the interviewees articulated related to their interactions with others in the university environment. Kiri described immense feelings and experiences of isolation as she recounted how, "for three years no one talked to me about my research, no one at all". Her experience of isolation was twofold - both culturally, as the sole Māori in her department, but also in a scholarly context, as no one seemed interested in her Māori scholarship or in engaging with a Māori scholar. She also suffered at the hands of academic elitism, with colleagues refusing to work with her because she was not considered to be in 'their' field, which ironically was entirely ill-founded as Kiri had actually published in that field. The isolation that Kiri experienced became so extreme that she described how she would, "say, 'kia ora', 'hello', 'good morning' and people would kind of look at me and walk off, like they wouldn't even say 'hi'. They wouldn't give a shit". Her experience led one of her close friends to liken the stresses of being the only Māori academic in a non-Māori-friendly environment as akin to domestic abuse:

The way you talk about your job is the way that an abuser always talks about staying in a relationship and you talk about your students the way that those people talk about their kids and you're prepared to put up with 
anything for your students. It's quite scary for me hearing exactly the same words, exactly the same words.

Kiri's criticism of her colleagues was not limited to only non-Māori. She also took issue with Māori academic colleagues and managers who, she thought, limited the potential of other Māori academics through small-mindedness, lack of imagination and self-sabotage because, as she said, with "Māoris like this - who needs the Crown?" However, despite her criticism of them, Kiri still espoused a need for more Māori academics. She said, "I can't help but keep thinking that having more of us would make a huge difference" deducing that an increase in the critical mass of Māori academics could influence the university environment, share the collective load placed on Māori academics, and provide more opportunities for Māori academic exchange and intellectual stimulation. This was a view shared by Wendy who also suggested that her university needed, "to attract more people" into Māori academic roles.

Like Kiri, Elly also had issues with the academic colleagues in her university unit. Also, like Kiri, she had suffered the indignity of being ignored or left out by non-Māori academics and having "the work that I do, it's not even really considered, it's kind of under the radar". Elly gave her example:

I've had a couple of instances when conferences have been arranged and the topic of the conference has been really germane to what we've been doing in [project name] [...] and I've worked with people who were organising the conference, and you'd think that in the spirit of collaboration they'd say, 'This conference is coming up, would you like to attend some sessions?' but there's nothing like that.

In another example Elly recounted how a colleague, whom she respected and thought was very familiar with her work, had written a journal article that recommended that further research be done in exactly the area that Elly had been doing her research, yet did not cite Elly's work once. When Elly approached the author about it all he could say was, "Oh yeah, sorry". Elly admitted that it had all been a "bit disheartening" but concluded that despite 
working with "good people", in her experience it was "not part of their worldview what the natives are doing". She had found:

Even though some people say, 'Oh it's really important what you're doing' ... they don't really know what that means, so there's a level at which 'those Māoris, they do their Māori thing' and they don't mean to be disrespectful, it's just not part of their worldview.

Notwithstanding the positive experiences that she acknowledged, Jessica also described how maintaining relationships with non-Māori colleagues could be a burden. She described the pressure placed on Māori academics by non-Māori who wanted to draw on their Māori expertise, "because we have so much to offer...and they don't know the stuff that we know and they want it", which often led to an assumption that Māori colleagues could or would give guest lectures or provide Māori-related advice:

They think they're the only person that's come to ask you...and sometimes when you turn them down and you say, "I'm just really sorry, I can't, it's not physically possible"...get really upset...and when you try to explain, [they] don't want to know because it's just moaning.

In Jessica's view, the challenge of communicating with non-Māori colleagues in a way that they could understand was taxing, and took valuable time and energy away from her own work:

It takes up head space...when really what you want to do is get on with your work and you've got to take up all this head space to frame up a way of talking to people so that they're not offended so you're still mates and you've still got your networks working really well because people can get so offended when you say no, and it's like uggh!

Elly confided the final aspect in which relationships were seen to present a challenge for Māori academics. She described how she internalised Māori student failure and felt personally responsible for it. She recounted how she had attended a meeting to discuss Māori student performance in her programme and lamented the low pass rates, "despite all the stuff we are putting into practice, those of us who are Māori in the Faculty who are 
trying to do that". She concluded that the only way forward was for Māori academics to put even more time into "more individualised, personal attention to individual Māori students", thereby placing additional pressure on their already heavy workloads.

\subsubsection{Clash of values}

The fourth and final area of pressure that came through strongly in the interviews was a perception that the university environment and the academic role were often at odds with the values and beliefs that the interviewees held as Māori. Many of the interviewees shared stories of incidents or experiences of racism or intolerance and described a monocultural university environment that limited their ability to express themselves as 'Māori' academics. Kiri described how, in one academic role, she was, "undermined every step of the way...like every single area of the academic job, I was undermined", and shared a deep-seated belief and experience of institutional racism - whether intentional or subconscious that sought to undermine her Māori academic development and progress. From the colleagues who intentionally withheld institutional knowledge from her, to managers who undermined her research, Kiri described a hostile work environment, and concluded that, "It sucked...it was horrible...and I ended up realising that I was going to burn out, I was sick, I was grumpy, I didn't like who I was...". She likened it to being in an "inbetween space" where she had to both make and constantly protect the cultural space to be Māori. She described how earlier in her career she had "had enough" of the "white man's system" and only recommitted to an academic career because of the influence of a Māori role model.

Similarly, Jessica recounted being questioned by a non-Māori staff member about, "Why do they [Māori staff] need to spend so much time at the marae?" and being made to account for and justify the time that staff were taking to fulfil their Māori cultural obligations at the university's own marae. She lamented the "lack of trust" that she believed some senior staff had for Māori academics, who doubted, “whether we'll manage funds, whether we'll 
manage budgets...whether we'll manage our staff, whether the staff are doing things for the right reasons". She concluded that, "there are racist people still in this environment".

Jessica also highlighted a values clash in relation to research practices. In her description of her research work in Māori communities, she recounted how non-Māori colleagues have not understood how much time and effort has to go into maintaining relationships, or about Māori research practices and ethics, such as identifying your iwi connections, not just your university role or qualifications. She lamented:

There's no real full understanding of that, when you try to talk about it it's like, "Oh, there they go, moaning about their workload". Well it's not, it's just that if you tell me that I'm doing too much and you say I need to concentrate on this I'm going to go, "I can't because if I do that then I lose my research community. You want me to research, I have to do all of that". So developing as a researcher, learning about ethics, learning about methodologies, and going, umm...yeah I understand what you're talking about with methodologies in terms of the Western frameworks but if I go in there and I start talking like that with my whānau and my research communities, they're going to go, "Nah sorry, we don't, nah" and they don't talk to you. I did it once...they don't talk to me...you know, they didn't get back to me. Knowing who you are, where you stand, if you don't have that firmly under your belt when you go out there, and I'm not talking about being an academic, I'm talking about being Māori, knowing who you are within the university, so we have our marae, and when they say, "Oh, you're from a university" you go, "Well yeah, and we're from...". We always have to tack on the, "Yeah, we're from this whānau, and this is how this whānau operates". I never realised that. It took me quite a while to get that I was always tacking that on because if I didn't tack it on I'd feel like they would just go, "Nah, university, nah". Yeah, having to really tack that on, and these are my relationships with those people and those people and those people, and that's not in your ethics [application forms]....

Elly also described the research challenges that she faced in relation to the perceptions of her non-Māori colleagues. As noted earlier, she had 
experienced being passed over for research opportunities and collaborations by non-Māori colleagues who did not want to see the connections that could be made with her work. She, along with Wendy and Kiri, also spoke of the dissatisfaction of working in a non-Māori academic environment as the 'lone Māori'. Wendy disliked being the 'token' Māori on university committees that feel obliged to include Māori representation but then do not take seriously or recognise the expertise that those representatives bring. Kiri recounted that she "had underestimated how hard it would be even though I'd been given warnings" and concluded:

I wasn't ready for them and they weren't ready for me. They hadn't thought through what it would mean to have someone there doing what I do and I think they thought that I'd kind of trot in and teach some brown stuff occasionally.

She admitted that she had,

felt ripped off because in the interview I was really clear about that stuff. I was like, there's no point me coming in under a Harry Potter invisibility cloak and then going, "Ta-da! Surprise, I'm actually going to create something for the Māori students". I was really clear about where all my commitments lay and all that stuff.

In her experience, she had found that the university unit was not prepared for an outwardly Māori protagonist, even if it publically proclaimed that it was.

One of the most symbolic accounts of monoculturalism in the university environment came from Kiri, who described being interviewed for an academic job, with her mother in attendance. After the interview, she asked her mother what she thought about the interview and her mother replied, "It's going to be really hard. They didn't even give me a cup of tea". Reflecting on that memory, Kiri concluded that it had become "a metaphor for the whole experience" of working in that academic unit. The interview process had been unfriendly and lacking in common Māori courtesies, which she later saw as symptomatic of the academic environment. The lack of 
tikanga Māori (Māori values or practices) observance or even acknowledgement became indicative for Kiri of an intolerant or uncaring academic environment. The act of not even giving Kiri's mother a cup of tea extrapolated out into not showing courtesy, respect or kindness, which is exactly as the rest of Kiri's academic experience in that unit played out.

While a failure to offer a cup of tea may not seem too harmful an oversight at face value, in Māori cultural terms the tikanga of manaakitanga (hospitality) is highly regarded and routinely observed. The lack of awareness about this tikanga in the last example is also reflective of a concern that a number of the interviewees expressed about Māori values generally not being recognised, understood and applied in the university environment. In relation to the tension between the practice of showing manaakitanga and being able to do your job properly, Jessica talked about the challenge of knowing, in different contexts, "the best way to manaaki", who to manaaki, and how to convince others that it is "actually worthwhile for this university".

Wendy shared another way that Māori values can clash with the university environment. She noted that, "we constrain ourselves as Māori by not pushing ourselves out.... We suffer from the kumara syndrome". The 'kumara syndrome' relates to the Māori whakatauki (proverb), 'Kaore te kumara e kōrero mō tōna reka' (the kumara does not say how sweet it is). This humility, in Wendy's experience anyway, made Māori academics reluctant to go for promotions or research funding because of their discomfort in having to actively promote their skills and attributes.

Another example of something that impacted on the promotion and other pathways of Māori academic staff was the tuakana/teina concept. This Māori value relates to traditional Māori social structures and relies on notions of kinship and connectedness. If a Māori person is literally or metaphorically considered to be like an older sibling, then they are regarded as a tuakana. Conversely, those regarded as a younger sibling, whether by descent, age or social or professional standing, are considered to be teina. 
Wendy explained how this notion affected Māori academic behaviour in the university context, citing that if there was an older Māori person, perhaps with more experience in academia or more social standing in the Māori community (i.e. a tuakana), it was highly likely that a younger, less experienced or less connected Māori academic (i.e. a teina) would not apply for a promotion beyond the level of that first person. If, as was common, the tuakana academic did not seek promotion, it created a bottleneck in the overall Māori academic career progression within an institution.

A final example of how Māori values can sometimes conflict with university expectations is the Māori commitment to putting the good of the collective, based on the concept of whanaungatanga, ahead of their own personal need. Wendy described how there were,

Māori academics who believe in Māori development and will push that kaupapa and support it in all sorts of ways just for some kinds of equity or just because it will be of benefit to us, and a lot of effort goes into that, and I'm not sure that its often welcomed or thanked.

She recounted experiences of being a Māori representative on university committees, of the toll that it took on her workload and energy levels, and the lack of appreciation that was given. Jessica also spoke of feeling like her advocacy work for other Māori academics was like, "climbing the mountain" and would often require her to "do a wawā" (make a loud noise, or protest on their behalf) and then refocus and carry on. Despite the heavy workload Jessica said that she felt like she was, "not allowed to complain" for herself out of her sense of duty to the Māori community or her unwillingness to appear weak or difficult to her non-Māori academic colleagues. Like Jessica, Kiri saw her role as a Māori academic in an unfriendly academic environment as an arduous task, which she described as "a sense of being embattled every single day, every meeting, every single thing". For Kiri, working as a Māori academic gave her the feeling of being under siege battling the system, battling colleagues, fighting for space to speak, think, contribute, and get on in her career. 
Each of the Mãori interviewees responded to their experiences of institutional racism in different ways: for Elly, her reaction was simply to work harder; for Kiri, the ultimate resolution was to change work environments; whereas for Jessica, her response was, "to learn how to sort out which was the fight worth fighting", although she admitted that it was not always a clear path to take and that she was occasionally, "still tilting at the wrong windmills". Each of these reactions required the Māori academics to expend extra energy and effort, and take attention away from other important areas of their work and personal lives.

\subsubsection{Case Study Three summary}

In summary, applying IPA to all five of the Case Study Three interview transcripts revealed a distinctive range of motivations to be academics. Many of the interviewees approached their academic work with a sense of duty and a belief that they owed a debt to their external Māori communities. Despite feeling privileged to be able to engage in academic activity, they considered their outputs and achievements to be on behalf of a Māori collective, rather than attributed to them individually. While motivated by the intellectual stimulation that their work provided, they also considered that they were doing important work for their Māori communities, and were driven to make a contribution to Māori capability building and development.

Their work as Māori academics was also motivated by their previous life experiences, and they were heavily influenced by their whānau beliefs and traditions. They saw their work as a natural progression from a childhood of positive Māori experiences, and considered that academic work allowed them to maintain their distinctive worldviews and values, moreso than other occupations. For the most part, the interviewees were very happy with their career choices, and described how much they love going to work each day. The cause of this contentment varied between their research activity and teaching, with one interviewee particularly relishing the opportunity to contribute to a bicultural and bilingual academic programme.

Each of the interviewees described a range of activities that they considered 
key to the role of Māori academics. They all admitted to busy workloads made up variously of teaching, research and service work. While enjoying the impact of their teaching and drawing pleasure from acting as a learning conduit or catalyst, the interviewees also found aspects of their teaching role to be challenging: from their difficulty to evaluate their programmes, to their lack of training, their need to develop their own Māori teaching pedagogies and the pressure to debunk Māori stereotyping in their classrooms. They all enjoyed their research work, with its potential to make a difference in areas such as te reo Māori and Māori youth, their sense of belonging within a broader Māori research collective and their international audience appeal. In addition, they described the representative work that they do for Māori, serving on committees and projects, often at the expense of their own research and teaching programmes.

All of the interviewees described the relationships that they had formed as part of their Māori academic role, and the extent to which they helped and hindered their work and development. They spoke extensively about the collegiality that they had experienced within the Māori academic community at their university and nationally, how being part of that collective had given them role models and mentors and helped them to develop networks with people who had the same interests and beliefs. Even the diversity within the Māori academic community was seen as a bonus that allowed members to approach research questions from different perspectives but with a shared worldview. The strengths of this community were seen to be limited by location and access, the suggestion that some Māori academics could feel intimidated by more successful colleagues, and the lament that the workload to keep those local and national networks active and effective was carried by just a few.

The interviewees also described other relationships that they maintained with their external Māori communities. They saw part of their academic role as being about giving back to the Māori communities that they came from and made sure that their research and teaching had a positive impact on those groupings. They held themselves accountable to their iwi and hapū, 
especially in relation to their research outputs and practices. They also credited their families with encouraging their academic progress, while at the same time adding pressure on them to be good parents, on top of 'good' Māori and 'good' academics.

All of the interviewees recounted having formal and informal interactions with non-Māori colleagues within the university environment - and some were supportive, caring and provided mentorship. In addition, they found their students to be both supportive and challenging, particularly when they began their academic careers.

There was also a range of pressures identified by the interviewees. One described how "being Māori makes you different" and others recounted how, in relation to identifying as a Māori person in an academic role, those differences included: feeling inadequate, lacking confidence, being more likely to suffer from ill-health, and being required to take on representative service at the expense of their own time and intellectualism. In addition, a number of the interviewees explained how, as a Māori academic, they were expected not just to perform but to excel, and to strive towards potentially unreachable standards.

Another pressure expressed by the interviewees related to the range of skills required for their roles. They described feeling unprepared and undergoing a "baptism of fire" as they began their academic careers, and they continued to face research-related pressures such as the dual scholarship requirements of, for example, working with both Pākehā methodologies and Māori knowledge. They also recounted teaching-related pressures from heavy workloads, challenging students and changing technology.

In terms of their relationships with others, the interviewees identified a range of pressures, most notably from their non-Māori peers but also from their students and other Māori colleagues. They described their experiences of cultural and social isolation, being subjected to academic elitism and having their research ignored or undervalued, or being taken advantage of 
and used by non-Māori colleagues. One interviewee noted the personal responsibility that she felt for her Māori students' failures, and others spoke of the impact that the low number of Māori academics at their institution had on their ability to influence the university environment, the high workload that they carried, and the reduced opportunities for Māori intellectual exchange.

The last of the pressures surfaced in the form of conflicts that the interviewees faced in the inbetween space between their Māori values and practices and the roles that they had within the university context. They described feeling, at times, like token or lone Māori who were forced to fight the university's monoculturalism and racism. They described examples of not being trusted, being passed over for research opportunities, and instances of tikanga Māori being challenged or undervalued. They criticised the university's lack of appreciation of core Māori research ethics or values like manaakitanga, whanaungatanga and the concepts of tuakana and teina, and suggested that even the humility epitomised in the kumara whakatauki posed a limitation on conventional academic success.

Finally, while not an overarching theme, in relation to their academic development needs the interviewees noted having received little direct training for their roles, particularly in relation to course design and teaching but also about time management, workload balance and organisational skills. They described acting on instinct, and cited a need for more academic conversation and opportunities to interrogate and critique other scholarship, including work by other Māori.

In summary, the IPA findings identified four superordinate themes for Case Study Three that emerged from the set of interviews. Each of the themes has been discussed in this section: motivation to do Māori academic work; key Māori academic roles; the nature and impact of relationships with others; and the pressures faced by Mãori academics. As a group, these themes represent the interviewees' experiences as Māori academics, their needs, challenges, goals and purpose. The four themes also relate to eachother - 
the interviewees' strong identities as Māori academics linked to their experiences of institutional racism; their relationships with Māori communities also placed high expectations on them and pressures to perform in a dual scholarship context. Together these themes identify and explain a range of contexts, scenarios and activities that were common to the interviewees and need to be carefully recognised and accounted for within any academic development programme designed specifically for Māori academic staff.

\subsection{Chapter summary}

Overall, this chapter has shared the findings and superordinate themes of the three case studies upon which this thesis is based. Each of the case studies introduced different accounts of what it is like to be a Māori academic in a New Zealand university. While the versions varied in many places, the interviewees also shared a number of common beliefs and occurrences that help to build up a deep understanding of the Māori academic experience. In the next chapter, these findings are considered further to produce a set of significant themes that emerged for all three case studies. Those over-arching themes are then considered against the backdrop of the literature that was presented in Chapter Two. 


\section{Chapter Five: Discussion}

The late Ruka Broughton, tohunga (Māori ritual expert) of Victoria's Te Herenga Waka Marae, wrote that:

According to the elders, conflicting opinions and dissensions do not necessarily blur the truth. In oratory the length of the speech does not determine the quality of its contents and often in lengthy speeches only a few important details may be extracted. Here lies the exercise. A great deal of information, some conflicting and confusing, was given by the old people, then there are the manuscripts and also the published materials, but the greatest task was to sift the facts from what may be regarded as opinions. (Broughton, 1972, p. 2 cited in; J. Williams, 2010, p. 193)

This discussion chapter can be likened to Broughton's sifting metaphor as it attempts to filter and make sense of the range of experiences and views shared by the interviewees and raised in the literature. A number of different themes and concepts emerged via the application of the IPA process to the interview sets. Some of the literature proffered conflicting or contradictory ideas and some experiences articulated in the interviews appeared at odds with each other or the literature. The purpose of this chapter is to begin to organise these different but related experiences and perceptions into a larger picture of what it is like to be a Māori academic, to reflect on how those experiences relate to the literature and, more importantly, to determine what they reveal about how to approach Māori academic development.

There are two sections to this chapter. This format is intentional and reflects Nakata's (2007) work about "rethinking" the cultural interface of Indigenous people in the academy, which, he argued, "first requires a rethinking of the space in which Islanders interact with others" and "second...requires deeper consideration of the ways in which the specificities of Islander experience are constituted in that space" (p. 196). This structure also pays tribute to Graham Smith's (2011) call to create "space" for Māori and his description of the "dual struggle" that drives 
kaupapa Māori intervention: "the first is for our cultural expression and the second is against the structures that impede us".

The notion of rethinking the Māori academic development space was first acknowledged in the title of this thesis, and continues in the structure and content of this chapter. The first section is a discussion of the space between the Māori academics in this study, and collates the key themes derived from the case studies. It then moves to a discussion about how Māori academic development is constituted within the literary space, that is, how do the case study themes link to the literature?

The second part of this chapter presents a proposed framework for academic development in New Zealand universities, one that provides space for Māori. It considers the key dimensions that emerge from the interviews and literature and attempts to contextualise them into a framework that fits within the realities of the university environment.

\subsection{Rethinking the Māori academic space}

Understanding how Māori academics experience the academy is critical to any discussion about Māori academic development. Without understanding what drives Māori academics to do what they do and what challenges they face, there is little chance of providing them with appropriate, meaningful and effective academic development. Ignoring the Māori academic experience or space only serves as a passive form of 'othering' Māori academics. Given that connection, what elements of the Māori academic experience were common or significant across the three case studies? The next section outlines how the case studies relate to each other, and filters the superordinate themes around the key principles that emerged.

\subsubsection{A Superordinate Synthesis of the case study findings}

The IPA literature is clear that transcripts should be approached afresh and themes should be allowed to emerge on their own, without actively trying to fit them into an established theme from an earlier transcript. However, once 
those themes had emerged, the IPA process allows for a reorganisation and filtering into clusters of over-arching, superordinate themes. By the end of the IPA analysis of the transcripts from Case Studies One, Two and Three, I had identified a number of different superordinate themes. Despite some clear overlaps in experiences and beliefs, the analysis essentially produced three sets of somewhat disparate themes that required further consideration in order to be a useful guide for Māori academic development. However, the IPA literature was silent about how to approach that further step. Other published IPA studies have either contained one case study with multiple transcripts or multiple case studies that involved different types of participants or research questions, and therefore produced separate sets of superordinate themes. Neither of those contexts required the researcher to collate the range of superordinate themes into one set. However, the IPA literature does encourage researchers to work towards a level of "theoretical generalisability" in order to be able to draw conclusions and apply their research findings to related contexts (J. Smith et al., 2009, p. 4). Thus, in the case of this study, it was important to create an overarching set of superordinate themes that encompass all three case studies. I achieved this by a new process, developed for this thesis, called a Superordinate Synthesis.

The Superordinate Synthesis process first required the development of a synthesis table, made up of a number of columns and rows. The purpose of the synthesis table was to be able to group similar or related experiences and ideas that had emerged within each of the superordinate themes that were generated by the case studies. However, rather than simply adding all of the existing superordinate themes together into one combined list, the goal was to group the themes under as few headings as possible, not based on frequency or uniformity across the case studies but instead looking for commonalities. This meant that some of the superordinate themes were subsumed into other groupings, whereas some, when combined with similar themes from other case studies, emerged as stand alone headings. As shown in the sample screenshot in Figure 5.1, the synthesis table exercise produced 
four distinct, yet related, dimensions of the Māori academic experience that are relevant to their Māori academic development needs. Excerpts that related to the four dimensions were taken from each of the case studies and inserted into the appropriate columns, ready to integrate into the thesis chapter.

\begin{tabular}{|c|c|c|c|}
\hline Tuakiritanga/Identity & Pūkengatanga/Skills & $\begin{array}{l}\text { Whanaungatanga/ } \\
\text { Relationships }\end{array}$ & $\begin{array}{l}\text { Tikanga/ Mãori values \& } \\
\text { practices }\end{array}$ \\
\hline $\begin{array}{l}\text { ACCIDENTAL ACADEMIC: } \\
\text { [CS1] He had not followed the } \\
\text { standard path into an academic } \\
\text { role, "falling", by his own } \\
\text { admission, into the university } \\
\text { system "by mistake". } \\
\text { [CS3] I probably never came to } \\
\text { university thinking I was going to } \\
\text { become an academic, actually I } \\
\text { wanted to be a hairdresser but } \\
\text { that's another story. } \\
\text { [CS3] without thinking about it I } \\
\text { thought, "that's something you } \\
\text { could do." }\end{array}$ & $\begin{array}{l}\text { TIME MANAGEMENT \& } \\
\text { WORKLOAD: } \\
\text { [CS1] He cited "more time...more } \\
\text { help" as his primary development } \\
\text { need yet was reluctant to appear } \\
\text { like he was unable to cope, } \\
\text { primarily in comparison with } \\
\text { others who he saw as high } \\
\text { performing Mãori academics. } \\
\text { [CS2] They described needing to } \\
\text { gain "the experience and the } \\
\text { longevity" necessary to perform } \\
\text { well in the academy } \\
\text { [CS3] They all admitted to busy }\end{array}$ & $\begin{array}{l}\text { Re MAORI ACADEMIC } \\
\text { COMMUNITY: } \\
\text { [CS1] highlighted the diversity } \\
\text { within the Mãori academic cohort } \\
\text { yet, emphasised the strong } \\
\text { collegiality he found within that } \\
\text { community } \\
\text { [CS2] felt a sense of solidarity } \\
\text { with and were inspired by others } \\
\text { in the Mãori academic community } \\
\text { who were "on the same kaupapa" } \\
\text { and able to give them a sense of } \\
\text { belonging within the academy } \\
\text { [CS2] The interviewees also }\end{array}$ & $\begin{array}{l}\text { CONFORMITY TO UNIVERSITY } \\
\text { ENVIRONMENT: } \\
\text { [CS1] was unwilling to be seen to } \\
\text { 'rock the boat' too much or } \\
\text { complain about his inability to } \\
\text { express himself as a Mãori at all } \\
\text { times, partly because of his } \\
\text { concerns about job security. He } \\
\text { had also developed a sense of } \\
\text { inevitability about the } \\
\text { monocultural context of the } \\
\text { university institution. } \\
\text { [CS3] The last of the pressures } \\
\text { surfaced in the form of conflicts }\end{array}$ \\
\hline
\end{tabular}

Figure 5.1 Screenshot of part of the Superordinate Synthesis Table developed in Microsoft Word.

Drawing from the IPA analysis of the interviews with Māori academics, the four dimensions that emerged as underpinning Māori academic realities, and therefore necessary to consider in the process of Māori academic development, are:

- Tuakiritanga (their identity as Māori, as academics and as Māori academics);

- Pūkengatanga (the academic and cultural skills necessary for them to perform their roles well);

- Whanaungatanga (the relationships that they have to navigate, honour and cultivate in order to achieve their goals); and

- Tikanga (the Māori cultural values and practices that guide their behaviour and are important in their performance as Māori academics).

Some of these elements have previously been identified and explored in relation to other Māori research topics, such as whānau resilience (Kingi \& Waiti, 2011) and the usage of social media by Māori youth (O'Carroll, 2013). However, they have not previously been applied in relation to Māori 
academic development. A summary follows of each of these dimensions, and their connections with the three case studies.

\subsubsection{Tuakiritanga (identity) in the case studies}

The first of the key dimensions that emerged from the Superordinate Synthesis process was tuakiritanga, the aspects of the Māori academic experience that relate to identity formation, maintenance and challenge. All three of the case studies included interviewees who spoke about how their identities as Māori academics were in the process of forming or had been formed, and how their sense of themselves as Māori was inseparable from their identities as academics. What emerged was a picture of a holistic, albeit uncomfortable (for some), sense of Māori academic identity.

In both Case Study One and Two, the interviewees recounted being uncomfortable with the term 'Māori academic', and finding it difficult to accept. This was linked in both cases to their notions of feeling "inauthentic" or like "imposters". It also related to the Case Study Three interviewees' admission of feeling inadequate, lacking confidence, and their strong emphasis on still being "emerging" (which was also raised in Case Study Two), despite having amassed a significant number of years in an academic role. The theme of the "accidental academic" raised in Case Study One was reiterated in Case Studies Two and Three, with many of the interviewees believing that they had "fallen" into their roles "by mistake", been employed by chance or luck, or would not meet the required standard in the current employment climate.

Another aspect of the identity dimension related to the prominence of the interviewees' Māori cultural identities and the impact that had on the way they perceived themselves as academics. For example, in Case Study Two the participants spoke about how their affinity to the Māori culture outweighed their disciplinary or institutional academic identities. This notion was reinforced in Case Study Three, with the assertion from interviewees of the primacy of their Māori identities. They also noted how "being Māori makes you different", and how as Māori academics that can 
manifest in such extremes as high expectations not just to perform but to excel (in both Māori cultural and scholarly contexts), or low expectations in terms of ill-health and wellbeing.

Despite having described how uncomfortable they were with the term 'Māori academic' they did note some positive aspects. For some interviewees it offered them the chance of "personal transformation" to an extent not possible for relatives and friends in more limited work roles (Case Study One). For others, they recounted the happiness that they drew from their career choice, and described how much they "love" going to work each day (Case Study Three).

Ultimately, whether they were comfortable with the 'Māori academic' label or not, the impact that their identities had on the way they approach their work was significant. It was also clear that in order to align an approach to academic development with the needs and experiences of Māori academics, consideration of their identity issues was a key component. Thus, tuakiritanga features as one element in a framework of Māori academic development.

\subsubsection{Pūkengatanga (skills) in the case studies}

Another of the key dimensions that emerged from the Superordinate Synthesis process was pūkengatanga, or the skills and knowledge sets necessary in order to perform their roles as Māori academics. All three case studies included responses from the interviewees about the different skills and knowledge that they needed to acquire in order to function as an academic and, equally, the cultural expertise that was necessary for their fulfilment of their academic roles as Māori. What emerged was a picture of both high expectations and excellence, alongside fears of inadequacy and failure. This often manifested in whether the interviewees perceived themselves as having attained the required standards, or not.

Participants in all three case studies recounted feelings of inadequacy and lack or preparedness - for Harry in Case Study One, this added to his levels 
of stress and was compounded by his comparisons of himself to other high performing Māori colleagues. This was reiterated in Case Study Three by comments from interviewees about having undergone a "baptism of fire" as they began their academic careers, and having developed skills by "acting on instinct", rather than by training or design. Similarly, in Case Study Two, the interviewees described needing more subject knowledge in order to transition beyond the 'emerging academic' stage.

One of the specific skills focused on by the interviewees was the ability to act as the critic and conscience of society. While recognising that such a role was common to all academics, the Case Study Two participants suggested that aspects of the role were more complex for Māori academics - such as how to approach critiques of other Māori work, and how to maintain the cultural expectations of the wider Māori community in relation to protocols and hierarchies while still performing the role of scholarly critic. This reflection continued in Case Study Three, where participants cited a need for supportive academic environments that allowed academic "conversations" to occur, and where Māori academics could interrogate and critique other Māori and non-Māori scholarship.

Not surprisingly, many of the skills development needs raised by the interviewees related to aspects of their teaching, research and service work. The Case Study Two participants were reluctant to separate those roles and preferred a more imbricated, holistic conceptualisation of their academic work. They also presented a complex set of additional responsibilities carried by Māori academics, particularly for those who take on representative roles within their institutions, along with extra teaching and research-related obligations to their external Māori communities. Despite feeling some added pressure to meet both scholarly and Māori cultural expectations in their work, the Case Study Three participants also pointed to the enjoyment they took from their research activity and teaching, enhanced by such things as the opportunity to contribute to bicultural and bilingual academic programmes. More specifically, the Case Study Three participants spoke about the pleasure they gained from teaching Māori material and 
Māori students. However, they also admitted to a range of teaching-related challenges, such as their difficulties in evaluating the effectiveness of their programmes, their lack of formal teaching and course design training, their struggle with Māori teaching pedagogies, their heavy teaching workloads, their need to keep up with changing technology, and the pressure to counter racism or misinformation about Māori in their classrooms.

As with their teaching feedback, the participants shared their love of research, the intellectual stimulation that they gained from it, and their commitment to 'making a difference' through their contribution to Māorirelated research outputs in particular. Despite this constructive approach, they also noted research-related pressures, such as the dual requirements of, for example, working with both Pākehā and Māori methodologies, the burden to leave an academic legacy and the duty to produce research that can make a positive, transformational contribution to Māori society.

In relation to their service work, they all described the kinds of representative work that they do for Māori, serving on committees and projects, often at the expense of their own research and teaching. This was seen as making both a positive contribution on behalf of Māori but also, for the Case Study Three participants at least, limiting their opportunities for advanced intellectual exchange and academic skills development.

Finally, all of the Case Study participants shared how their ability to develop and use their academic skills and knowledge was severely limited by their busy workloads and time management challenges. A recurring request from interviewees was for "more time" (Case Studies One and Two), more support and opportunities to gain scholarly "experience" (Case Study Two), and more training about organisational skills and time management (Case Study Three).

Overall, while the interviewees were all experienced, knowledgeable, capable academics, they were able to identify a range of academic and cultural skills and knowledge about which they wanted to learn more. It was clear that whatever form their academic development programme took, it 
would need to factor in a broader set of skills development that took into account their cultural responsibilities and outlooks, as much as their academic ones. Thus pūkengatanga features as another element in a framework of Māori academic development.

\subsubsection{Whanaungatanga (relationships) in the case studies}

The third of the key dimensions that emerged from the Superordinate Synthesis process was whanaungatanga, or the relationships that provide support and challenges for Māori academics. All three case studies included responses from the interviewees about the range of people and relationships that help and inspire them in their work and, conversely, the communities, contexts and people who do not. What emerged was a notion that positive relationships can greatly enhance the experience of Māori academics and provide a wealth of academic development opportunities and support, whereas negative relationships can severely worsen the experiences of Māori academics and prevent them from achieving in their roles.

All of the case studies included positive comments about the relationships and support provided by the Māori academic community within their institutions. In Case Study One, Harry described being helped by the Māori academic role models around him. Despite the diversity within the Mãori academic cohort, he enjoyed strong collegiality within that community, as did the interviewees in Case Study Two, who felt a sense of solidarity and belonging with others in the Māori academic community who were "on the same kaupapa". In a similar vein, the Case Study Three interviewees spoke of the importance of the Māori academic collective for having given them guidance, mentoring, and opportunities to learn from "different angles" from people who had the same passions. Of the negative aspects about their relationships with other Māori academics, the two key limitations that emerged were that sometimes they felt intimidated by some of their more successful Māori colleagues, or found that the relationships could be difficult to maintain over geographical or disciplinary distance. 
While the local Māori academic community featured prominently in the interviews, each of the Case Studies also included mention of relationships with the global Indigenous academic community. For some, through their relationships with international Indigenous colleagues, they had come to find an affinity in their common struggles and mutual research interests. They had also gained confidence that they had something to add and share that could help with the struggles of other Indigenous peoples. Those relationships were also constricted, however, by location and limited access.

Relationships outside the university environment also emerged as being of great importance to Māori academics. The Case Study Three interviewees spoke at length about the influence of their whānau on their career choices and purpose. From childhood experiences to family traditions, the impact of parents and extended family members was very clear on how and why the Māori academics were drawn to and undertook their academic roles. Despite gaining a sense of drive from them, the interviewees admitted to sometimes feeling alienated from their families because of their work, and also noted how family expectations added extra pressure to perform to a high standard, both professionally and personally.

This sense of pressure extended out into their relationships within the wider Māori community and interviewees spoke of the complex set of additional responsibilities for Māori academics who are beholden to the communities from which they come. Some described this as a duty or a debt and held themselves accountable to their iwi and hapū, particularly in relation to their research outputs and practices. On the other hand, the interviewees also hailed the positive connections that they had with their Māori communities, the access that gave them to te ao Māori (the Māori world), and the notion that their outputs and achievements were shared on behalf of their Māori collective and made an important contribution to Māori capability building and development.

The relationships that caused the interviewees the most difficulties and stress were with their non-Māori colleagues within the university 
environment. While many of the interviewees had experiences of supportive, collegial non-Māori academics who provided mentorship and care, they had also faced instances of misunderstanding and racism. This manifested most prominently in cultural and social isolation, but also occurred in the form of academic elitism, the undervaluing of Māori research, and being taken advantage of by non-Māori colleagues. The degree and type of discrimination varied, with Māori staff in Māori programmes seeing other units as external opposition whereas Māori in non-Māori units described having to battle internal opposition as well. Despite a positive outlook, even the Case Study One interviewee concluded that the university environment was "not perfect" and was "never ever going to be right".

Overall, the interviewees were able to draw on a range of supportive, inspiring relationships to help them with their work. It was clear that whatever form their academic development programme took, it would need to factor in an element of social interaction, and build on the capacity for Māori academics to learn both with and from each other. It would also need to acknowledge some of the challenges that Māori academics face in dealing with non-Māori colleagues. Thus whanaungatanga features as a third element in a framework of Māori academic development.

\subsubsection{Tikanga (Māori values and practices) in the case studies}

The fourth dimension that emerged from the Superordinate Synthesis process was tikanga, which in this context relates to the values and beliefs that underpin Māori practices regarding academic work. In all three case studies the Māori interviewees shared examples of how their ways of knowing and doing affected their academic practice. What emerged was an acknowledgement that care and attention needed to be given to how best to honour and give effect to these tikanga Māori within the confines of the traditional university environment and context.

Many of the interviewees described a monocultural university environment that they thought challenged them as Māori. Due to concerns over job security, some were more willing to confront this than others. Those who 
did confront it described the "battle" they faced from institutional racism and the distrust and missed opportunities that generated. They spoke of the negative impact perpetuated by the employment of only a small number of Māori academics, which forced them into "lone" and "token" Māori roles with limited ability to influence the university environment. They also described how tikanga Māori was routinely undervalued.

In contrast, the interviewees described how being Māori meant that they instinctively saw academia through a "different lens", with a set of distinctive worldviews and values that had the potential to add to the university environment. They noted the importance of core Māori concepts, such as manaakitanga, whanaungatanga, tuakana and teina (the relationship between an older/more experienced mentor (tuakana) and younger/less competent learner (teina)), and regretted the minimal recognition of these concepts within their academic institution. Even their Māori cultural propensity towards humility, epitomised in the "kumara" whakatauki, was seen to be a limitation on Māori academics applying for or being granted an academic promotion. Similarly, their relationships with their wider Māori communities and Māori students, and their duties to uphold the mana of their families, were thought to be invisible to many of their colleagues.

Ultimately, the interviewees shared how different Māori cultural beliefs and practices both enhance and impact on their academic work, with little recognition from their institutions. As a result, a culturally relevant academic development programme would need to blend these tikanga Māori into their training, to ensure that their distinctive needs as Māori academics were met. Thus tikanga features as a fourth dimension in a framework of Māori academic development.

\subsubsection{Interconnections within the Superordinate Synthesis}

While each of the dimensions discussed in this section were distinct and substantial, there were many connections and overlaps between all four. For example, the strong Māori identities held by the academics were clearly linked to their relationships with their families and wider Māori 
communities, and were reinforced by their social and professional connections within their Māori academic communities. Similarly, their pūkengatanga or range of skills needed to take account of their disciplinary interests and their Māori values and practices, their identities as Māori, and their duties to their Māori communities. In working together in the spirit of whanaungatanga, the interviewees had the potential to learn from each other, acquire new skills and knowledge from their role models, and develop further as academics. These connections are relevant because they emphasise the holistic nature of working as a Māori academic, and the interconnectedness between many of the skills, knowledge, beliefs and experiences of Māori academics. This overlap and connection is another dimension that needs to be captured in a Māori academic development framework.

Another aspect that emerged as part of the Superordinate Synthesis was the need to consider both individual and collective approaches to Māori academic development. Linked to the importance of relationships, which clearly emerged from the analysis, was the notion that Māori academic development should also be developed and delivered with a collective focus. Interviewees in Case Study Three discussed previous academic development experiences and noted how important it was that they were in Mãori groupings and environments, or they would not have engaged in the activity. Conversely, interviewees noted the intimidation that they sometimes felt from other Māori academics and that, coupled with their different styles and paces of learning, meant that opportunities need to be provided for individual development needs, which should also be acknowledged in a Māori academic development framework.

In conclusion, based on the findings from the Superordinate Synthesis, a comprehensive, culturally responsive Māori academic development framework needs to address tuakiritanga (identity), pūkengatanga (skills and knowledge), whanaungatanga (relationships) and tikanga (values and practices). In addition, the framework needs to reflect the holistic nature of Māori academic work, incorporate the interconnection and overlap across 
each of the four dimensions and take into account the need and preference for individual and collective development opportunities.

\subsubsection{A synthesis of the literature and case studies}

The second section of this chapter is, ultimately, focused on presenting a framework for Māori academic development that is cognisant of the experiences and needs of Māori academics, as expressed in both the literature and interviews in this thesis. To do that, however, first requires consideration of how the superordinate themes identified in the interviews relate to the literature reviewed in Chapter Two.

The Superordinate Synthesis of the case study findings identified four key dimensions of the experiences of Māori academics. This section summarises whether and how those dimensions featured in the literature reviewed in Chapter Two, and highlights points where they appear to merge and diverge.

\subsubsection{Tuakiritanga (identity) in the literature}

Much like in the interviews, issues around Māori academic identity featured prominently in the literature. Māori and Indigenous authors wrote about the primacy of their cultural identity over their identity as academics, and described the power and strength they drew from their cultural beliefs, histories and communities (Corntassell, 2003; Irwin, 1997; M. Maaka, 2004; Penetito, 2005; L. T. Smith, 1992b; M. Webber, 2009; P. J. Williams, 1991). This resonates with what emerged in all three case studies about the prominence and importance of their Māori identities.

Some scholars wrote about the challenges that Māori academics face in relation to questions of their authenticity as Māori, particularly in relation to their own cultural competence (Kukutai \& Webber, 2010; L. T. Mead, 1996) and their notions of being 'different' from other academics (Irwin, 1997; Kukutai \& Webber, 2011; Nikora et al., 2002; L. T. Smith, 1992b). They also highlighted the added pressure and strain that could be placed on academics due to their identification as Māori (Irwin, 1997; Kukutai \& Webber, 2011; McKinley, 2002). This too was reiterated in the interviews, particularly in 
relation to the interviewees' feelings of inadequacy, in relation to their level of 'Māoriness', and also in relation to their feelings of being academic 'imposters'.

The notion of Māori academics holding hybrid, multiple or fluid identities was dominant in the literature (Ballara, 1998; Irwin, 2007; L. T. Mead, 1996; Meredith, 1999; Moeke-Maxwell, 2005; Penetito, 2005; M. Webber, 2009) but featured very little in the case studies. It does, however, link in some ways to the idea raised in the interviews of the transformational capacity of the Māori academic role, which enables people to experience personal change, growth and learning in relation to their Māori identities and knowledge.

There was nothing in the literature about the notion of 'accidental' Māori academics, nor about being uncomfortable with the term 'Māori academic', which were additional findings in the case studies. Both are dimensions of the Māori academic experience that warrant further study.

\subsubsection{Pūkengatanga (skills) in the literature}

The case studies and the literature both included discussion about the skills and knowledge needed to be a Māori academic. Some of the writing focused on academic development for Māori academics, and highlighted a range of training needs and interests around teaching, research and enhancing their Māori language knowledge and skills (Davies \& Eruera, 2009; Hall, 2008, 2011a, 2011b; Manuel, 2010; Ratima, 2011, pp. 92-93). This literature provided a partial response to the concerns articulated in the case studies, such as Case Study Three's Jessica, who felt unprepared for her accelerated promotion, or Roha, who lacked confidence as an emerging academic.

Just as in the case studies, the literature reinforced the onerous workloads carried by many Māori academics because of the range of knowledge and skills that they bring to the role, particularly in teaching and research but also with pastoral care of students and other Māori community-related activities (Asmar \& Page, 2009; Jaime, 2008; James, 2004; Kawharu, 2010; 
Page \& Asmar, 2008; M. Webber, 2009). It described the additional expectations placed on Māori academics to protect the Māori culture and counteract racism (Alton-Lee, 2006; Coxhead, 2006; H. White et al., 2009). Some authors discussed specific Māori pedagogies and teaching practices (Adds et al., 2011; Hall, 2009; Ka'ai, 2005, 2008; Lilley, n.d.; Morrison, 1999, 2000; Penetito, 2005; Roa \& Tuaupiki, 2005) and the challenges that Indigenous academics often face when they teach Indigenous subjects within universities (Jaime, 2008; Nakata et al., 2012). Others wrote about how their research enabled Māori academics to make meaningful contributions to Māori knowledge and understanding (S. M. Mead, 1997; Stewart-Harawira, 2007), despite limited institutional support or recognition (Asmar et al., 2009; Cram, 1993; Hobson \& Hall, 2010; Irwin, 1994; Powick, 2002; Roa et al., 2009; L. T. Smith, 1999; Tawhai et al., 2004). These ideas were reinforced in the case studies, with interviewees describing their enjoyment of doing research and teaching despite the many pressures. However, absent from the literature was any record of the desire of Māori academics to develop more subject knowledge and be intellectually stimuated by their work, or the pressures and duties that they face as they attempt to be the 'critic and conscience' of society.

\subsubsection{Whanaungatanga (relationships) in the literature}

Just as they did in the case study findings, the importance of relationships emerged in the review of the literature too. Authors stressed the development power of the collective (Wenger, 1998, 2000) and the importance of social context (Billett, 2001). The interviewees spoke at length about the crucial support and collegiality that they received from other Māori academics and, similarly, the literature emphasised the impact of relationships within the Māori academic community, such as previous Māori academic collectives like Te Matawhānui and the MANU AO Academy, and beyond into global Indigenous networks. The notion of kaupapa Māori work needing to be controlled by Māori was repeatedly referred to in the literature (Bishop, 1999; Cunningham, 2000; Mikaere, 2011; Royal, 2012; L. T. Smith, 1995b; Tawhai et al., 2004; S. Walker et al., 2006) and this 
resonated with the Case Study participants' preferences to work on their academic development alongside other Māori colleagues.

The literature also reflected aspects of the interviews in relation to the motivation of Māori academics to empower their students to make a positive contribution to Māori society, and to dispel any of their previous, damaging educational experiences (Hall, 2009). In addition, scholars reinforced the importance for Māori academics of maintaining relationships with their whānau and wider Māori communities and working for their benefit (Cram, 1993; Irwin, 1997; Ka'ai, 1995; Mane, 2009; L. T. Mead, 1996; Moeke-Pickering et al., 2006). However, one point that was raised in the interviews but not reiterated in the literature was the notion of Māori academics feeling intimidated by other Māori academics.

\subsubsection{Tikanga (Māori values and practices) in the literature}

The final dimension to emerge from the Superordinate Synthesis was the importance of tikanga Māori, those values and practices that derive from Māori culture and are embedded in or influence the practice and experiences of many Māori academics. This point was also raised in the literature - such as the explanation about how kaupapa Māori theory and research arose from the Māori cultural renaissance (Bishop, 2010), and the call for universities to better acknowledge Māori cultural concepts, like whanaungatanga, whakapapa, tino rangatiratanga and mana motuhake (S. M. Mead, 1997; Paipa, 2010; Reilly, 2011; Villegas, 2010).

Some Māori authors argued that university structures should become more Māori-centred, thereby gaining greater alignment with tikanga Māori principles (Hook, 2010; P. Johnston, 2001; Lilley \& Field, 2005; Robust, 2007). Others suggested that being Māori centred does not go far enough and that universities need to provide both physical and metaphorical space for Māori (P. Johnston, 1998, 2001; L. T. Mead, 1996; Morrison, 2000; Royal, 2012; C. Smith, 2000a; G. H. Smith, 2011). 
While some writers emphasised the way that Māori academics have maintained tikanga Māori within the university context, others wrote about how the academy has worked to subvert or marginalise Māori and Indigenous academics. They described the difficulties of trying to maintain cultural integrity and not compromise on their cultural beliefs (Hook, 2008; Irwin, 1997; Mikaere, 1998; Page \& Asmar, 2008; Ratima, 2008; C. Smith, 2000a; Tierney, 1999), often leading to a sense of isolation or loneliness (Irwin, 1997; L. T. Smith, 1992b). In the case studies, the interviewees spoke of the subtle and overt racism that they had experienced in their workplaces. Similarly, there was ample evidence in the literature about microaggressions and institutional racism, and processes that (intentionally or not) attempt to assimilate Māori into the university environment (Arbon, 2008; Asmar et al., 2009; Christiansen, 2000; Corntassell, 2003; Deloria Jr, 2004; Fredericks, 2009; Gone, 2004; Jaime, 2005, 2008; Jefferies, 1997; Johnsrud, 1993; 2007; L. T. Mead, 1996; Mikaere, 2011; Morrison, 2000; Palepu et al., 1998; Roland, 2011; D. G. Smith, 1991a; L. T. Smith, 1992b; Sue, 2010; Villegas, 2010; S. Walker, 1996; A. C. Wilson, 2004).

One idea from the interviews that was not apparent in the literature was the suggestion made in Case Study Three that being an Indigenous academic caused ill health. Similarly, there was little in the literature about how tikanga Māori influences Māori academic traits, a point that was raised by a number of the interviewees.

\subsubsection{Additional factors for a Māori academic development framework}

So far this chapter has merged key findings from the literature review and case study analysis but, in addition, a number of other principles and contexts were raised in the literature or by interviewees, and need to be reflected in a Māori academic development framework. Alongside the four dimensions outlined earlier, the framework needs to:

- Be based on kaupapa Māori principles but able to be applied in a Western university context; 
- Be informed by the knowledge, skills, experiences and belief systems of Māori academics;

- Be able to accommodate the imbrication, and tensioning between the different dimensions of Māori academic experiences, Indigenous norms and the university context (Baalawi, 2008; Bunda \& White, 2009; Christiansen, 2000; Fredericks, 2008; Gone, 2004; Penetito, 2005);

- Be cognisant of the dual accountability, dual obligations and dual scholarship expected of Māori academics (A. Durie, 1995; Hook, 2008; Jaime, 2008; James, 2004; Page \& Asmar, 2008; Pohatu, 1998; Reilly, 2008; P. Stewart, 2010);

- Be transformative (Bishop et al., 2005; Mane, 2009; Paki, 2007; Penetito, 2005; G. H. Smith, 1997; S. Walker, 1996) and challenge the status quo (Cooper, 2012; L. Smith, 2000, p. 233, as cited in Mahuika, 2008, p. 2; McMurchy-Pilkington, 2001; Pihama, 2001; Pihama et al., 2002; G. H. Smith, 1995a; S. Walker, 1996; S. Walker et al., 2006);

- Be applicable at both an individual and collective level, in order to reduce silos and isolation;

- Be relevant to Māori transitioning into academic roles (Woods, 2008) as well as mid- and advanced-career Māori academics;

- Be focused on what it is like to 'be' a Māori academic, what a Māori academic needs to 'know' and what a Māori academic needs to learn to 'do' (Bawden, 1991; Henry \& Pene, 2001);

- Reflect academic development in its broadest sense and focus on academic practice generally, not just teaching (Blackmore \& Castley, 2006); and

- Acknowledge the 'transformation triangle' of the academy, scholarship and Māori community (G. H. Smith, 2011). 


\subsection{Constituting a framework for Māori academic development}

It has become common practice at Victoria to give Māori names to academic departments. Thus, the Centre for Academic Development at Victoria was long ago gifted the Māori name, Te Kōtuinga Mātauranga. In English, the name literally translates as:

$\begin{array}{ll}\text { Te } & \text { the } \\ \text { Kōtui(nga) } & \text { interlace, bind } \\ \text { Mātauranga } & \text { knowledge, education }\end{array}$

In other words, the Māori name describes a place that weaves or synthesises knowledge. In the context of the Centre, it relates to the work of the staff to connect people with knowledge about academic development. This resonates with imagery that emerged from both the case studies and the literature - such as the notions of imbrication or overlap, of duality and tension, and of triangles and tiers. Thus, a Māori academic framework lends itself to the name, Te Kōtuinga Mātauranga, and to a visual depiction that reflects the Māori weaving tradition.

\subsubsection{Te Kōtuinga Mātauranga: Weaving a Māori academic development framework}

Māori weaving has a long and detailed history and process (see, for example, Evans \& Ngarimu, 2005; H. M. Mead, 1999; Pendergrast, 1987; Tamarapa, 2011; Te Kanawa, 2006). From kete (baskets) and whāriki (mats) to korowai (cloaks), Māori weaving techniques have evolved over the last 800 years to incorporate new materials and styles. Of particular note, the design of tāniko, the decorative bands often found on the edge of korowai and piupiu (skirts), changed dramatically once Māori weavers learnt how to wrap two or more colours of twine, in turn, while maintaining a diagonal direction (Buck, 1926, p. 140). This enabled a range of highly prized, new weaving designs to emerge, featuring geometrical shapes and figures. 
Tāniko motifs evolved, as demonstrated in Figure 5.2, from narrow, parallel lines to wider bands with various combinations of triangular, chevron and lozenge motifs (Buck, 1926, p. 142). Over time, these patterns have been classified into seven different categories: aramoana and tukemata (chevrons); aronui (triangles); patikitiki (diamonds); waharua or whakarua kōpito (two mouths/openings); horizontal and vertical lines; kowhaiwhai (scrolls); and representational (e.g. stars, leaves etc.) (H. M. Mead, 1999, pp. 75-76).
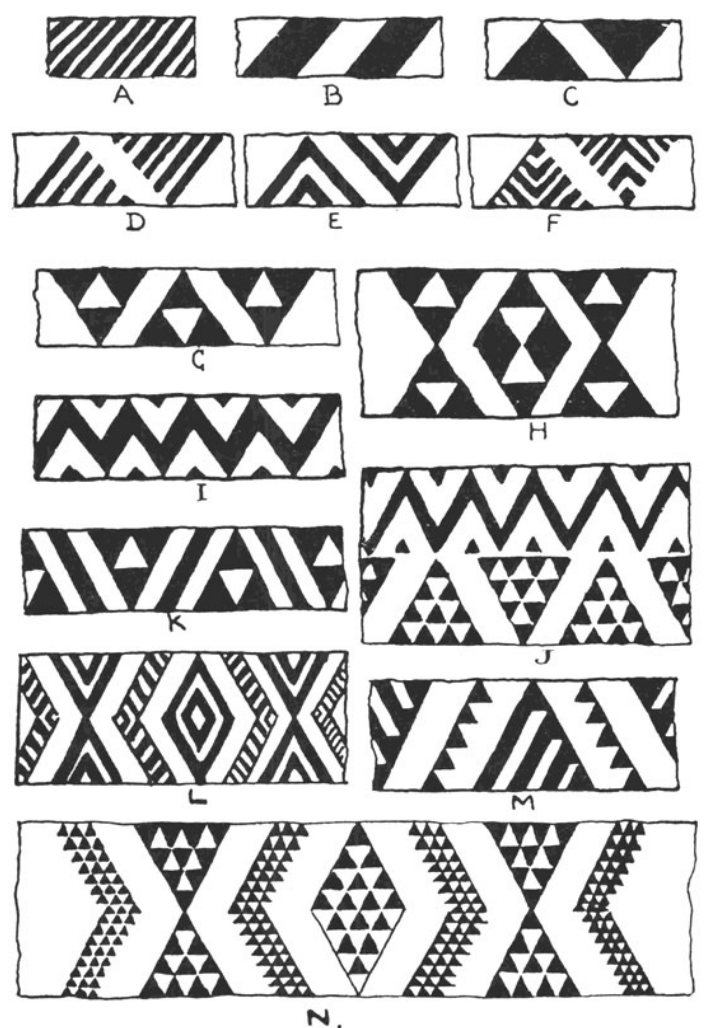

Figure 5.2 The evolution of tāniko patterns (Buck, 1926, p. 144).

Each of the tāniko patterns has a different meaning and represents aspects of te ao Māori (the Māori world). The triangular aronui pattern (shown in Figure 5.3) symbolises Te Kete Aronui, one of the three baskets of knowledge that were brought to earth by Tāwhaki or Tāne, according to Māori tribal tradition. It is the basket thought to contain "knowledge acquired through careful observation" (Moorfield, n.d.). The whakarua kōpito pattern (shown in Figure 5.4) commonly consists of vertically paired diamond shapes. One translation of the name is "a point where people or 
events cross", which serves as "a reminder that change occurs at such meeting points" (Museum of New Zealand Te Papa Tongarewa, n.d.).

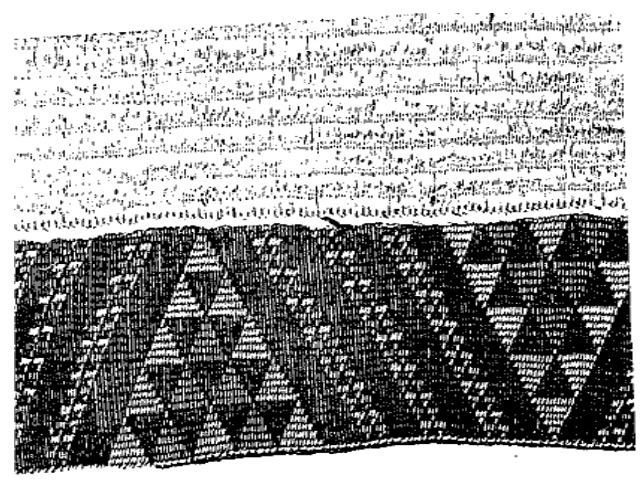

Figure 5.3 An example of the aronui pattern (H. M. Mead, 1999, p. 64).

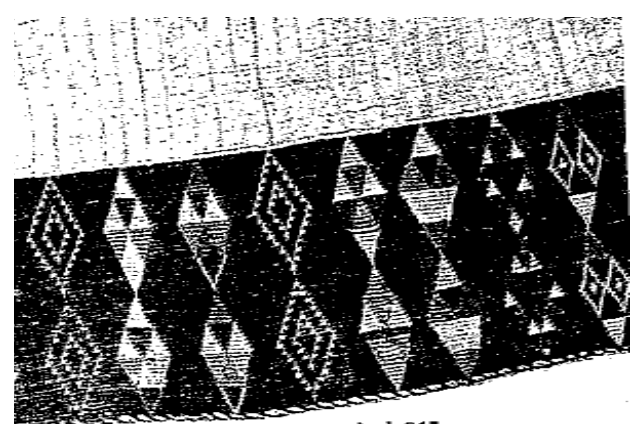

Figure 5.4 An example of the whakarua kōpito pattern (H. M. Mead, 1999, p. 64).

Tāniko patterns such as these have captured the interest of other scholars before, and been used to explain and present research in fields such as media studies and Māori education (Wilkie, 2010; J. Wilson, 2013). In this case, these tāniko motifs have inspired the visual depiction of my framework that symbolically weaves Māori academic experiences, motivations and beliefs together, under the mantle of Māori academic development.

Called Te Kōtuinga Mātauranga: A Māori Academic Development Framework, the entire framework is represented as a woven tāniko, i.e. two colours of twine wrapped around each other to form bold, variegated geometric patterns (see Figure 5.5). The triangle shape is prominent and echoes how academic development occurs within the "transformation triangle" that connects the academy, scholarship and Māori community (G. H. Smith, 2011). 


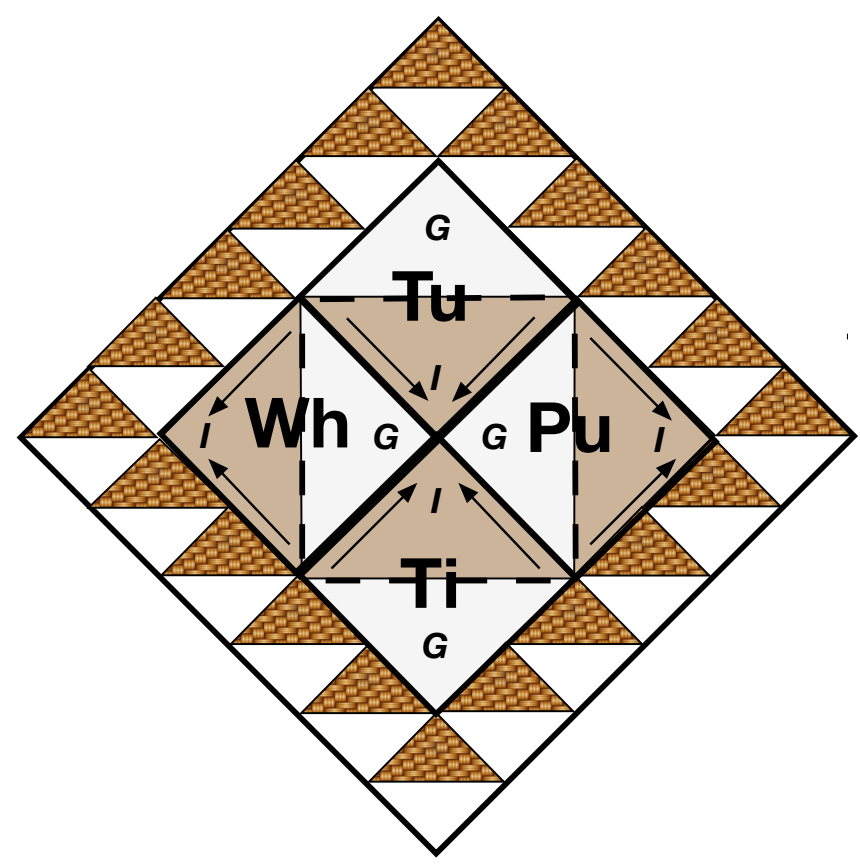

Figure 5.5 Te Kōtuinga Mātauranga: A Māori Academic Development Framework. 'Tu' refers to tuakiritanga (identity), 'Pu' refers to pukengatanga (skills), 'Ti' refers to tikanga (values and practices) and 'Wh' refers to whanaungatanga (relationships). Further elaboration about the structure and meaning of this diagram are provided in the text.

The choice of a two-toned colour palette represents a number of inherent dualities within the framework:

- It has been produced as part of a kaupapa Māori research process yet its topic is located within the university context;

- It reflects the dual accountabilities that Māori academics have to their whānau and university employers;

- It acknowledges the dual obligations placed on Māori academics to produce students and research outputs that will benefit their Māori communities and universities; and

- It embodies the dual scholarship interests of Māori academics to make a contribution to mātauranga Māori and engage with and extend Pākehā methodologies and methods.

At the centre of the framework are the four key dimensions of Māori academic development: tuakiritanga - identity (Tu), pūkengatanga - skills $(\mathrm{P} \overline{\mathrm{u}})$, tikanga - values and practices (Ti) and whanaungatanga - relationships 
(Wh). They are depicted by the diamond shapes that connect at the centre and represent, in the style of the whakarua koppito, that each of the dimensions cross or connect with each other. This symbolises their need to be considered collectively - for example, an academic development programme that focused solely on skills development, without acknowledging and reflecting Māori cultural values and practices, would not satisfactorily meet the needs of Māori academics.

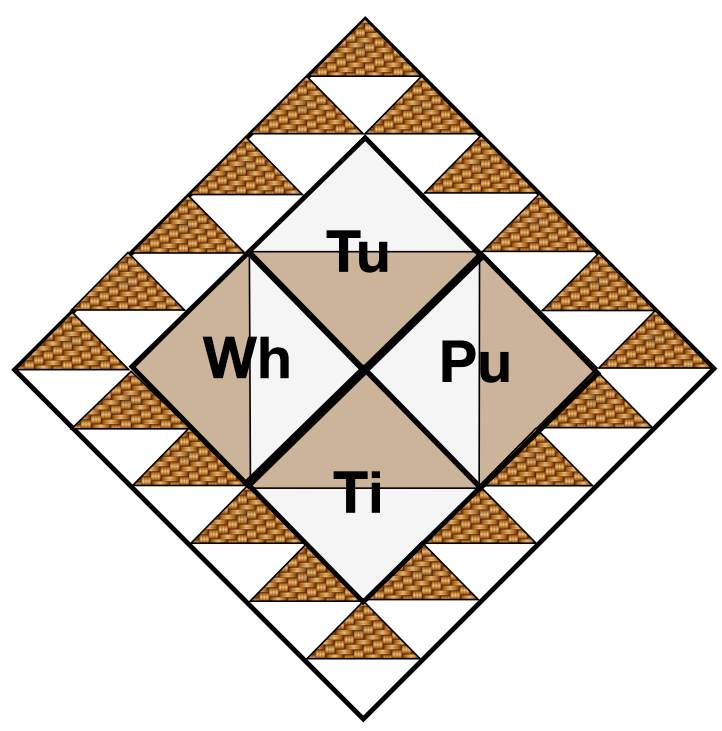

Figure 5.6 Four key dimensions of Māori academic development

These four dimensions emerged from the case studies and literature review, and are depicted in Figure 5.6 as the four key areas on which to focus academic development activities. Tuakiritanga relates to what it means to identify as a Māori person working in an academic role. As noted in the case studies, identifying as Māori impacts on a person's motivation to be an academic, their career path into academia, the way that they perceive their roles and the ways they are perceived by others. The inherent duality within the tuakiritanga dimension of the framework includes such elements as the contrast between Māori and academic identities, between Māori and Pākehā identities, between emerging and established academic identities, and between personal and professional identities.

Pūkengatanga refers to the skills and knowledge that Māori academics need to develop and demonstrate in order to fulfil their academic roles. It 
includes aspects such as teaching pedagogy and practice, research theory and skills, providing academic service and acting as a critic and conscience of society, as well as key Māori cultural skills (such as te reo and tikanga Māori). Within this element of the framework, the dualities that may emerge include the use of mātauranga Māori and Pākehā knowledge, Māori and Pākehā methodologies and pedagogies, and the need to balance Māori community expectations and the expectations of the academy.

The tikanga dimension recognises that Māori academics operate in both university and Māori community contexts and their cultural beliefs often influence their judgements and behaviour within the academy. It acknowledges that any academic development activities or goals need to be cognisant of these dual contexts in which Māori academics operate. Thus duality includes such things as observing Māori practices of manaakitanga within the university environment, acknowledging Māori concepts such as tuakana/teina within academic promotion processes, and balancing the ethical requirements of the academy and the Māori community.

Finally, the whanaungatanga dimension reflects the importance of internal and external relationships in the academic development of Māori staff. Again, the depiction of this element within the framework includes a duality that relates to the benefits of Māori academics forming and maintaining supportive relationships with Māori academics in the same and different programmes, the relationships that Māori academics have within their work teams and with other non-Māori colleagues, the disciplinary and institutional relationships that develop as they progress in their academic careers, and the relationships that they develop and maintain with the wider Māori community beyond the university - all of which influence their academic development needs and aspirations.

The diamond shapes, as shown in Figure 5.7, are also divided in half to represent that each of the dimensions is relevant to Māori academics at both an individual and collective level. The darker area represents the academic development needs of individual (I) Māori academics. It provides space for 
Māori academics to access development opportunities that meet their specific needs, without fear of being intimidated by or compared with others. The lighter area represents the preference by many Māori academics to access academic development opportunities in groups (G), to build on the shared values and identities of that community, and enhance their skills and potential to contribute to the Māori collective (both within and outside the university environment).

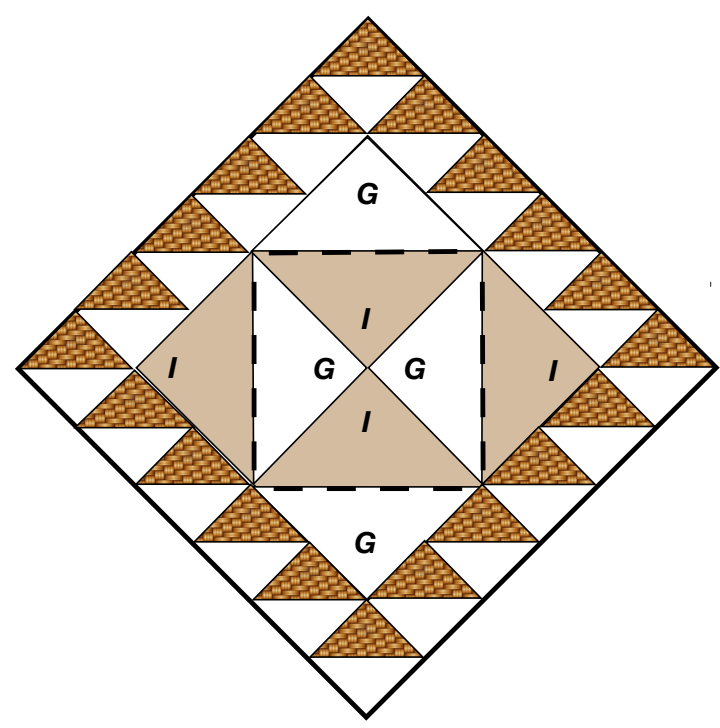

Figure 5.7 Provision for academic development for Māori individuals (I) and groups (G).

Within the darker triangles that represent individual academic development, the base of the triangles represents the larger cohort of early career Māori academics and Māori postgraduates wanting to transition into academic roles. As the Māori academics move through their careers they (metaphorically) move along the triangle towards its apex, representing progression towards professorship or some other form of academic success. As indicated in Figure 5.8, the arrows in the diagram indicate the direction of individual Māori academic career development and progression. 


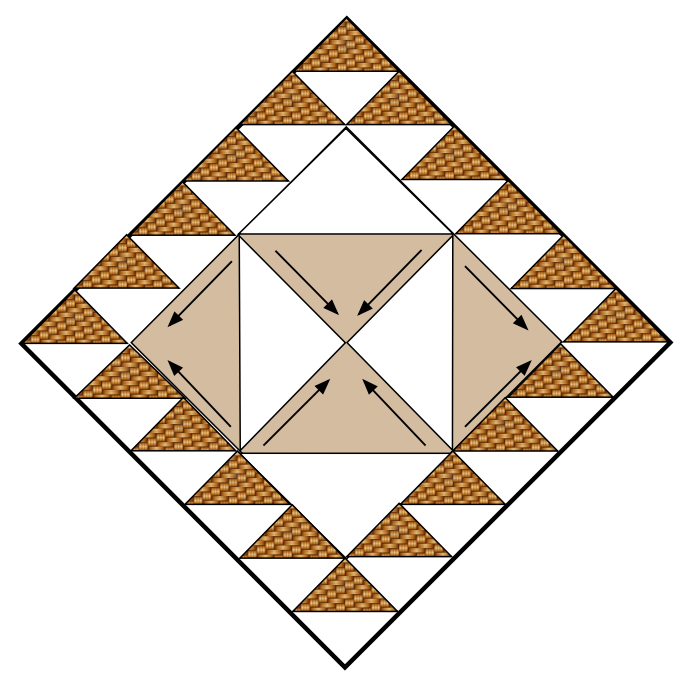

Figure 5.8 Direction of Māori academic career development and progression.

The border of the framework takes inspiration from the aronui motif, and represents how Māori academics work in the context of both the Māori community and the university environment. The three points of each triangle are a reminder that the various dimensions of Māori academic development need to simultaneously focus on 'being', 'knowing' and 'doing' (Bawden, 1991; Henry \& Pene, 2001), and the entire tāniko pattern emphasises the holistic nature of Māori academic development - while each part or feature has a purpose, they come together to form a whole design.

Finally, the form of this framework has been inspired by two distinct tāniko patterns and, in drawing them together to form a new design, marks not only an evolution in art form but also signals a transformation in the way that Māori academic development can be understood and delivered. Each of the layers of the framework has been explained in this section, but they also come together into one tāniko that depicts a holistic approach to Māori academic development.

\subsubsection{Comparisons with other academic development models}

Two other academic development models - Te Toka Āhuru (Davies \& Eruera, 2009) and Blackmore's (2009) ISIS model - were discussed previously in the literature review. Te Kōtuinga Mātauranga framework shares some aspects with both but varies from them in significant ways. 
Staff at Te Wānanga o Aotearoa developed Te Toka Āhuru (see Figure 5.9), so its context is a tertiary education environment that is led by Māori, for Māori. This is the basis for the key points of difference between the two frameworks. Māori world views and practices that can be assumed and taken for granted in a wānanga environment need to be made more explicit in the university context.

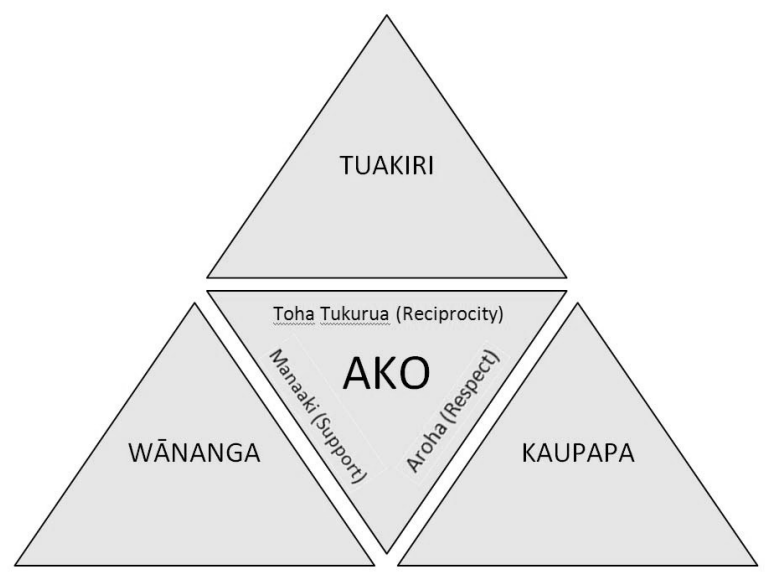

Figure 5.9 Te Toka Āhuru Framework (Davies \& Eruera, 2009, p. 1)

Design-wise, both frameworks share some elements. Just like Te Kōtuinga Mātauranga framework, Te Toka Āhuru drew on triangular shapes to convey connections with traditional Māori symbols, in this case representing strength (kawau maro and niho taniwha) and sustenance (pātiki) (Davies \& Eruera, 2009, p. 1). The 'ako' core, with its focus on teaching and learning, was flanked and protected by three outer facets. The first, 'tuakiri' is the root word of the term used in Te Kōtuinga Mātauranga framework, that is, tuakiritanga. However, instead of emphasising the influence of Māori cultural identity on academic development, in this framework it was defined as the "individual strengths and needs of each kaiako" (teacher) (Davies \& Eruera, 2009, p. 2). It emphasised individuality and did not mention the collective. In contrast, the power and importance of the Māori academic community as a group is highlighted in Te Kōtuinga Mātauranga framework because it emerged from the case studies as a key element of Māori academic development need and success. 
'Wānanga', the second facet highlighted in Te Toka Āhuru, was explained as "knowledge, wisdom, ideas" that are disseminated through training workshops and development activities (Davies \& Eruera, 2009, p. 2). It related more to the form, rather than the focus, of academic development. It is similar to the pūkengatanga dimension in Te Kōtuinga Mātauranga framework but did not articulate the kinds of teaching, research, service or Māori cultural skills or knowledge that would be developed.

The explanation of the third facet, 'kaupapa', was given as "thoughts, directions and goals" as well as support in the form of mentoring and communities of practice (Davies \& Eruera, 2009, p. 2). The emphasis on directions and goals related in part to the tuakiritanga and tikanga dimensions, while the mention of communities of practice related to the whanaungatanga dimension of Te Kōtuinga Mātauranga framework. Ultimately, while some elements of Te Toka Āhuru overlap with aspects of Te Kōtuinga Mātauranga framework, the former focused primarily on the individual staff member's rather than the institutional or cultural context whereas the latter takes both into account.

In comparison, Blackmore's (2009) ISIS model shares some common academic development principles with Te Kōtuinga Mātauranga framework, albeit in a completely different form and context. Instead of prescribing the content and focus of the development provision, the ISIS model proposed a set of guidelines with which to assess an academic development approach.

The first element in the ISIS model, 'inclusion', was based on the notion that, "an inclusive approach may be employed as a means of promoting equity of treatment across a wide range of staff in an institution" (Blackmore, 2009, p. 655). In a similar vein, the purpose of developing Te Kōtuinga Mātauranga framework was to be more 'inclusive' of Māori academics within the academic development process.

The second element of the ISIS model, 'strategy', suggested that development processes need to be aligned with the institution's "core purposes" (Blackmore, 2009, p. 665). Te Kōtuinga Mātauranga framework 
differs from this approach in that it advocates for an approach to academic development that is cognisant of the university's purpose but is aligned with Māori community goals and needs.

The third aspect of the ISIS model, 'integration', argued that development opportunities should address teaching and research skills and roles together, rather than in a complicated "patchwork" of separate support (Blackmore, 2009, p. 666). This holistic approach to academic development is echoed in Te Kōtuinga Mātauranga framework, which not only draws teaching and research development under the mantle of pūkengatanga, but also combines the skills needed to fulfil academic service and Māori cultural roles too.

Finally, the fourth element of the ISIS model, 'scholarship', highlighted the importance of grounding development work in high quality, evidence-based research and making sure that it was fit for context (Blackmore, 2009, p. 666). Applying that guideline to Te Kōtuinga Mātauranga, the framework is the result of taking a kaupapa Māori research methodology and IPA method to develop an approach to academic development that is fit for the Māori academic context in New Zealand universities.

Overall, Te Kōtuinga Mātauranga framework closely maps the principles of the ISIS model. As shown in Figure 5.10, this is best depicted visually using the assessment diagram that represents how well a development programme maps on to the ISIS model in terms of its "orientation to development" (Blackmore, 2009, p. 671). Following the ISIS guidelines, Te Kōtuinga Mātauranga framework is inclusive in that it "avoids denial of legitimate difference" (Blackmore, 2009, p. 671) in the Māori academic experiences of the academy. It is strategic, in that it incorporates multiperspective views of both university and Māori contexts. It is integrated and recognises the interrelatedness of four key dimensions of Māori academic development. Finally, it is scholarly, being based on research literature and evidence yielded from case studies. 


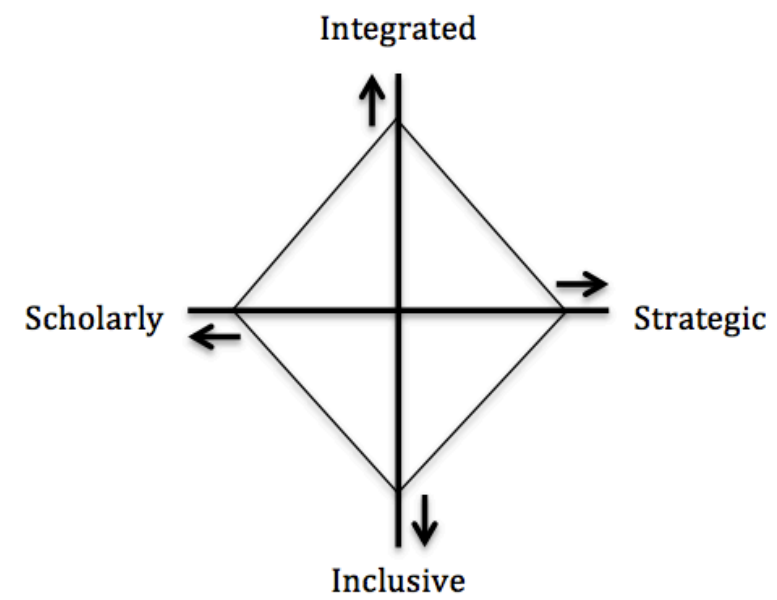

Figure 5.10 Te Kōtuinga Mātauranga profile based on the ISIS model.

While both Te Toka Āhuru and the ISIS model offer relevant and useful ideas, neither fully applies to the context of Māori academic development within a New Zealand university context. Thus, while drawing on similarities with these other models, Te Kōtuinga Mātauranga: A Māori Academic Development Framework provides a different approach that could become a useful guide for mentors of Māori academic staff or academic developers who are interested in Māori academic development.

\subsection{Chapter summary}

This chapter began with a metaphor from Broughton (1972) about the need to sift through the mass of information to get to the core. It has culminated in the presentation of Te Kōtuinga Mātauranga, a framework for Māori academic development. To get to that point required rethinking and creating space for Māori cultural expression in relation to their academic experiences and development. It then required reconceptualising how Māori academic development could, and should, be constituted. As a result, Te Kōtuinga Mātauranga framework builds from both the case studies and literature about the experiences of Māori academics and is proposed as an inclusive, strategic, integrated way to deliver culturally relevant, Māori academic development. It also joins the collection of Māori scholarship that draws from the design and meaning of tāniko motifs developed by Māori weavers of the past. It is not, however, the lone solution for Māori academic 
development. As Smith (2011) explained, “Our struggle is not one struggle. One silver bullet will not address all issues". Similarly, one framework will not 'fix' Māori academic development in New Zealand universities. Alongside this framework, other critical factors will impact on Māori academic development, such as the skills and knowledge of the academic developers, the time and importance given to academic development initiatives, and the number and location of Māori academic staff within universities. Each of these topics is worthy and in need of further research. 


\section{Chapter Six: Conclusion}

In the opening chapter of the Higher Education Research \& Development (HERD) Anthology, Kandlbinder wrote that, "higher education literature deals with what matters to universities" (Kandlbinder \& Peseta, 2011, p. 14). In the same year, Graham Smith (2011) observed that in the university context, "knowledge is selected, and knowledge is selected out" with the implication being that, historically, Māori knowledge has been selected out. While these quotes were made in quite different contexts, both link to a notion that was raised in the introduction of this thesis - that Māori academics have been invisible, ignored or on the margins of academic development scholarship and practice. They (and their knowledge) have not featured in higher education literature to date and their specific academic development needs have not been met.

Another approach to Māori academic development was needed; one that could acknowledge the issues and goals expressed by Māori for Māori, and weave them together with culturally relevant academic development opportunities. This conclusion chapter summarises the findings and discussion from the previous chapters that led to the development of a Māori academic development framework. In doing so, it reposes the research questions from the introduction chapter, considers the key limitations of this thesis, and suggests directions for further research in this area.

\subsection{Research questions revisited}

Cram (1993) observed that, "much research about Māori is also merely descriptive, telling us what we already know, yet not proposing any solutions or action that can be taken for change" (p. 28). Parts of this thesis are descriptive, sharing the words and experiences of Māori academics. However, this thesis is also based on kaupapa Māori research that took an etmic approach in order to positively contribute to the academic 
development offered to Māori academics and advance the theorising about Māori academic development.

The first research question, posed in the introduction of this thesis, was:

- What are the key aspects of the current Māori academic staff experience in New Zealand universities?

The answer to this question was found in both the review of literature about the experiences of Māori academics in the academy, and the findings of the three case studies that were conducted in accordance with kaupapa Māori methodology and the IPA method. At the conclusion of both processes, the four dimensions that emerged as central to the experiences of Māori academics were:

- Tuakiritanga (their identity as Māori, as academics and as Māori academics);

- Pūkengatanga (the academic and cultural skills necessary for them to perform their roles well);

- Whanaungatanga (the relationships that they have to navigate, honour and cultivate in order to achieve their goals); and

- Tikanga (the Māori cultural values and practices that guide their behaviour and are important in their performance as Māori academics).

One of the motivations for this thesis, as explained in Chapter One, was the call from Māori academics that they wanted to be Māori and academics with integrity. This thesis has shown how that means different things for different people but includes being able to work for and with Māori communities, and being able to maintain Māori worldviews and observe Māori customs and practices. At the same time, the Māori academics in the case studies wanted to do well in their work. They wanted to be good scholars who produced critical, well-informed research, delivered excellent 
teaching that engaged students, and met all of the expectations of their academic institutions. For example, not only did they want to succeed in the PBRF process but they also wanted to meet the high standards set by their tipuna (ancestors).

A challenge faced by the interviewees was finding and maintaining the space within their universities to be Māori and be academics and to do both well, with integrity and credibility. Not every Māori academic needed or wanted to be able to stand as comfortably on the paepae (Māori orator's platform) as they did at the lectern and vice versa. But for those who did, and this research suggested that such a dual function is a common goal for Māori academics, a way needed to be paved to make that not only possible but desirable.

In addition, this research found that Māori academics wanted to be supported to develop in ways that recognised a broad range of pūkengatanga or skills, including the disciplinary and cultural expertise needed to operate effectively in both the Māori and university worlds. In order to be relevant, any Māori academic development framework needed to model and support that dual development.

It was clear in the interviews how much Māori academics value community - they described a strong sense of whanaungatanga within their Māori academic communities, which was reinforced through hui, whakapapa, and formal and informal group work. In Māori terms, the importance of the collective was well recognised and this research found that Māori academics were keen to work together to achieve their personal and professional goals, maintain their cultural integrity, and achieve success in ways that were appropriate to them.

Lastly, the interviewees spoke, in different ways, of their commitment to acknowledging tikanga Māori in their professional and personal lives. It was therefore important that any Māori academic development framework was able to help preserve and champion Māori customary practices in the face of any pressure or disdain from others in the academy. 
The second question posed at the start of this thesis was:

- How could those key aspects inform a kaupapa Māori academic development framework to support Māori academic staff at New Zealand universities?

In response, this research produced an integrated framework for conceptualising and delivering culturally relevant, academic development for Māori academics. The visual depiction of Te Kōtuinga Mātauranga: A Māori Academic Development Framework drew on the traditional Māori weaving style of tāniko as a metaphor for both the interconnectedness of the framework, as well as the importance of understanding academic development from an Indigenous viewpoint. The framework highlighted the four dimensions that emerged as key to Māori academic development (i.e. tuakiritanga (identity), pūkengatanga (skills and knowledge), whanaungatanga (relationships) and tikanga (values and practices)). It also reflected the holistic nature of Māori academic work, and took into account the need and preference for individual and collective academic development opportunities. While it shared some aspects with two other educational development models - Te Toka Āhuru (Davies \& Eruera, 2009) and Blackmore's (2009) ISIS model - as explained in this thesis, the framework varied from both in significant ways.

\subsection{Limitations of this research project}

While the topic of this thesis is broad, its research design was intended to keep the project manageable and suited to the doctoral thesis format. As such, a key limitation of this research is it's small sample size. While appropriate and valid for the IPA method and its target of "theoretical generalisability" (J. Smith et al., 2009, p. 4), a larger data set that included Māori academic staff from a wider range of New Zealand universities would likely increase the level of generalisability.

In addition, the key ideas for Māori academic development that have emerged from this research have been presented in the form of a framework. 
This is because the findings are, as yet, untested so it would be premature to describe them as a model. This, therefore, is another limitation of this project. Other limitations of this research have been identified in the next section as areas for further research.

\subsection{Directions for further research}

The research conducted for this thesis not only responded to the original questions but also raised new ones. Some of the questions arose from the review of existing literature and others from the limitations of the present study. A selection of those questions is raised here as possible areas for further research.

From the literature review came a realisation about the lack of data on the proportionately low numbers of Māori academics in New Zealand universities. A survey could provide the kind of quantitative and qualitative data needed to fully appreciate the scale and location of Māori academic appointments at each of the eight New Zealand universities. It could also collect and compare the experiences of Māori academics, look at gender and location-based variations, and build a more comprehensive picture of Māori academic development needs on a national scale.

From the case studies came questions about the notion of 'accidental' Māori academics, the discomfort with the term 'Māori academic', and the specific challenges faced by Māori academics as they attempt to be a 'critic and conscience' of society. In addition, both the literature review and case studies revealed examples of microaggression and systemic racism. Each of these ideas could be explored further in future research.

In relation to the kind of academic development that Māori want, questions were raised about the need to develop more subject knowledge and be intellectually stimuated by their work, and how tikanga Māori influences Māori academic traits. In addition, further research is needed on some of the other critical factors that will impact on Māori academic development, such as the skills, knowledge and cultural responsiveness training of the 
academic developers themselves, and how much time and importance is given to academic development work (by both academic developers and Māori academics). In fact, the application of the Maori academic development framework developed for this thesis is suitable for an entire action research project. Evaluating the effectiveness of the framework would provide important information for other Māori academics and academic developers (Stefani, 2011).

Other issues raised by this research were not related to the topic but rather to the methodology and method used. The potential of merging kaupapa Māori methodology with the IPA method deserves further consideration. Prior to this thesis it had only been attempted in one health-related study (B. Jones et al., 2010). More thought is needed about what other topics or areas would be suitable for this kind of amalgamated approach.

In relation to IPA specifically, the use of the NVivo software tool to complete the analysis was a departure from the IPA literature and marks a development that is worthy of further research. Another innovation was the inclusion of a group interview as one of the case studies, which was not simple to analyse using the IPA process but was, nevertheless, successful as an academic development activity. For example, the discussion about the key roles of Māori academics, which occurred as part of the group interview, resulted in epiphanies for some of the participants.

Also, more attention could be given to the Superordinate Synthesis process developed for this thesis. The identification of a set of over-arching principles across the three case studies was made possible through the creation of a systematic, structured technique for blending the findings from the separate case studies. This too could be the subject of further exploration.

\subsection{Concluding remarks}

Indigenous scholars have called for a rethinking of the cultural interface of Indigenous people in the academy, yet the academic development literature 
is largely silent on the needs of Māori academics. For Māori academics working in universities in New Zealand, their culture has a significant impact on their work experiences, career goals and academic development needs. Thus, the needs of Māori academics should be better reflected in the scholarship and practice of academic developers. However, this research was not about simply creating a new or alternative framework to challenge the existing one. Doing so would have had the effect of treating kaupapa Māori as 'other'. Instead it is a reassertion of traditional, long-standing and deeply embedded cultural practices relating to how Māori academics approach their teaching, research, service and career success. Ultimately, this thesis calls for a rethinking of how academic development can be theorised and delivered in ways that centre the cultural aspirations, preferences and practices of Māori academics, and encourages academic developers to be more inclusive in their practice.

As members of a minority culture in Aotearoa New Zealand, Māori academics may forever remain on the margins of academic development within universities; however, their stories and desires, as retold in this thesis, have proved illuminating. For the purposes of this thesis, they have been brought to the centre. So, what will be written in the margins of this thesis? Will it be used by other Māori academics to start a conversation by scrawling their experiences beside those of the interviewees? Hopefully it can be a folio upon which Indigenous academics around the world will scribe their own academic goals, needs and development framework. 


\section{References}

"Ministry of Social Development". (n.d.) Retrieved 4 May 2013, from http://www.msd.govt.nz

"Rangahau". (n.d.) Retrieved 4 February 2011, from http://www.rangahau.co.nz

"The Governor General". (n.d.) Retrieved 4 May 2013, from http://www.gg.govt.nz

Adams, J. (2008). Strategic review of the Performance-Based Research Fund: The assessment process. Wellington: Tertiary Education Commission.

Adds, P., Hall, M., Higgins, R., \& Higgins, T. (2011). Ask the posts of our house: Using cultural spaces to encourage quality learning in higher education. Teaching in Higher Education, 16(5), 541-551.

Adds, P., Hall, M., Pohe, E., \& Rata, A. (2012). Researching Māori student course completions: A Mãori Studies case study. A presentation at the Māori Association of Social Science Conference, Christchurch.

Airini., Brown, D., Curtis, E., Johnson, O., Luatua, F., O’Shea, M., Rakena, T., Reynolds, G., Sauni, P., Smith, A., Su'a Huirua, T., Tarawa, M., \& UlugiaPua, M. (2010). Success for all: Improving Māori and Pasifika student success in degree-level studies. Wellington: Teaching \& Learning Research Initiative.

Alfred, T. (2004). Warrior scholarship: Seeing the university as a ground of contention. In D. A. Mithesuah \& A. C. Wilson (Eds.), Indigenizing the academy: Transforming scholarship and empowering communities. Lincoln: University of Nebraska Press.

Alton-Lee, A. (2006). How teaching influences learning: Implications for educational researchers, teachers, teacher educators and policy makers. Teaching and Teacher Education, 22(5), 612-626.

Ambrose, S., Huston, T., \& Norman, M. (2005). A qualitative method for assessing faculty satisfaction. Research in Higher Education, 46(7), 803-830.

Anderson, C., Bunda, T., \& Walters, M. (2008). Indigenous higher education: The role of universities in releasing the potential. The Australian Journal of Indigenous Education, 37, 1-8.

Arbon, V. (2008). Arlathirnda ngurkarnda ityirnda: Being-knowing-doing Decolonising Indigenous tertiary education. Teneriffe, Queensland: Post Pressed.

Asmar, C., Mercier, O. R., \& Page, S. (2009). 'You do it from your core': Priorities, perceptions and practices of research among Indigenous academics in Australian and New Zealand universities. In A. Brew \& L. Lucas (Eds.), Academic research and researchers. Maidenhead: McGraw Hill.

Asmar, C., \& Page, S. (2009). Sources of satisfaction and stress among Indigenous academic teachers: Findings from a national Australian study. Asia Pacific Journal of Education, 29(3), 387-401.

AUT University. (2011). Auckland University of Technology: Strategic Plan 2012-16. Auckland: AUT University.

AUT University. (2013). AUT University Annual Report 2012. Auckland: AUT University. 
Baalawi, Z. (2008). Investigating the provision of academic development initiatives - a case study of a tertiary institution in the United Arab Emirates. (PhD), University of Leicester, Leicester.

Ballara, A. (1998). Iwi: The dynamics of Maori tribal organisation from 1769 to c.1945. Wellington: Victoria University Press.

Barrett-Ohia, 0. (2006). Engaging Maori in research about land: Some challenges to achieving acceptable outcomes for both Maori and a crown agency. A presentation at the Practice Change for Sustainable Communities: Exploring footprints, pathways and possibilities: Australasia Pacific Extension Network International Conference, Beechworth, Victoria, Australia.

Barrow, M., Grant, B., \& Brailsford, I. (2010). Heroic aspirations: The emergence of academic development in a New Zealand university. New Zealand Journal of Educational Studies, 45(1), 33-47.

Battiste, M. (2008). Research ethics for protecting Indigenous knowledge and heritage: Institutional and researcher responsibilities. In N. K. Denzin, Y. S. Lincoln \& L. T. Smith (Eds.), Handbook of critical and indigenous methodologies (pp. 497-510). Thousand Oaks: Sage.

Bawden, C. (1991). Praxis: The essence of systems for being. A presentation at the Higher Education Research Development Society of Australasia Conference, Wellington.

Berger, P. (1979). In praise of particularism: The concept of mediating structures. In P. Berger (Ed.), Facing up to modernity: Excursions in society, politics and religion (pp. 167-180). Middlesex: Penguin Books.

Bevan-Brown, J. (2005). Providing a culturally responsive environment for gifted Māori learners. International Education Journal, 6(2), 150-155.

Biermann, S., \& Townsend-Cross, M. (2008). Indigenous pedagogy as a force of change. The Australian Journal of Indigenous Education, 37 (Supplement), 146-154.

Billett, S. (2001). Learning in the workplace: Strategies for effective practice. Crows Nest, NSW: Allen \& Unwin.

Bishop, R. (1995). Collaborative research stories: Whakawhanaungatanga. (PhD), University of Otago, Dunedin.

Bishop, R. (1998). Freeing ourselves from neo-colonial domination in research: A Māori approach to creating knowledge. Qualitative Studies in Education, 11(2), 199-219.

Bishop, R. (1999). Kaupapa Maori research: An indigenous approach to creating knowledge. Paper presented at the Maori and Psychology: Research and Practice Conference, Hamilton.

Bishop, R. (2003). Changing power relations in education: Kaupapa Māori messages for 'mainstream' education in Aotearoa/New Zealand. Comparative Education, 39(2), 221-238.

Bishop, R. (2010). Diversity and educational disparities: The role of teacher education. In T. Burns \& V. Shadoian-Gersing (Eds.), Educating teachers for diversity: Meeting the challenge (pp. 119-136). Paris: OECD Press.

Bishop, R., Berryman, M., Cavanagh, T., \& Teddy, L. (2005). Te Kōtahitanga Phase 3 Whanaungatanga: Establishing a culturally responsive 
pedagogy of relations in mainstream secondary school classrooms. Wellington: Ministry of Education.

Bishop, R., Berryman, M., Cavanagh, T., \& Teddy, L. (2009). Te Kotahitanga: Addressing educational disparities facing Māori students in New Zealand. Teaching and Teacher Education, 25, 734-742.

Bishop, R., \& Glynn, T. (1999). Culture counts: Changing power relations in education. Palmerston North: Dunmore Press.

Blackmore, P. (2007). Developing tribes and territories. Educational Developments, 8, 1-4.

Blackmore, P. (2009). Concepts of development in higher education institutions. Studies in Higher Education, 34(6), 663-676.

Blackmore, P., \& Castley, A. (2006). Capability development in universities. London: Leadership Foundation for Higher Education.

Bogdan, R. C., \& Biklen, S. K. (1998). Qualitative research for education: An introduction to theory and methods. Needham Heights, MA: Allyn \& Bacon.

Brew, A. (Ed.). (1995). Directions in staff development. Buckingham: Society for Research into Higher Education and Open University.

Broughton, R. (1972). The origins of Ngaa Rauru Kiitahi. Wellington: Department of Māori Affairs.

Brunton, M. (2009). [Oral report at MANU AO regional coordinators meeting].

Buck, P. H. (1926). The evolution of Maori clothing Part IX. The Journal of the Polynesian Society, 35(138), 111-149.

Bunda, T., \& White, N. (2009). Tiddas showin' up, talkin' up and puttin' up: Indigenous women and educational leadership. Sydney: Australian Government Office for Learning and Teaching.

Callister, P. (2009). Which tertiary institutions are educating young, lowskill Māori men? A research note. Wellington: Institute of Policy Studies.

Cheung, M. (2008). The reductionist - holistic worldview dilemma. MAI Review, 3. Retrieved from http://web.its.auckland.ac.nz/ojs.review.mai.ac.nz/index.php/MR/ar ticle/viewFile/186/196

Chinlund, E., \& Hall, M. (2010). Views from Last Resort: Experiences of Māori undergraduate students who transitioned from tertiary bridging programmes. Paper presented at the Making the Links: Learning, Teaching and High Quality Student Outcomes Proceedings of the 9th Conference of the New Zealand Association of Bridging Educators Conference, Wellington.

Christiansen, A. (2000). Cultural hybridity, gender, and identity: A Pacific Islander woman in the academy. Frontiers: A Journal of Women Studies, 21(3), 187-196.

Çinlar, N., \& Dowse, J. (2008). Human resource trends in the tertiary academic workforce: A working paper contributing to the independent strategic review of the Performance-Based Research Fund. Wellington: Tertiary Education Commission. 
Clegg, S. (2007). Academic identity and intellectual enquiry - breaking the research/teaching dualism? A presentation at the R\&T Colloquium, Southampton Solent University.

Clegg, S. (2009). Forms of knowing and academic development practice. Studies in Higher Education, 34(4), 403-416.

Cole, S., \& Barber, E. (2003). Increasing faculty diversity: The occupational choices of high achieving minority students. Cambridge, MA: Harvard University Press.

Conroy, S. (2006). A pathway for interpretive phenomenology. International Journal of Qualitative Methods, 2(3), 36-62.

Cooper, G. (2012). Kaupapa Māori research: Epistemic wilderness as freedom? New Zealand Journal of Educational Studies, 47(2), 64-73.

Corntassell, J. (2003). An activist posing as an academic. American Indian Quarterly, 27(1), 160-171.

Coxhead, C. (2006). Assisting Indigenous students to succeed: Let's start by giving them a safe learning environment. A presentation at the Australasian Law Teachers Association (ALTA) Annual Conference Legal Knowledge: Learning, Communicating and Doing, Victoria University, Melbourne.

Cram, F. (1993). Ethics in Māori research: A working paper. A presentation at the Cultural Justice and Ethics Symposium held at the Annual Conference of the New Zealand Psychological Society, Victoria University of Wellington.

Cram, F. (2001). Rangahau Māori: Tona tika, tona pono - The validity and integrity of Māori research. In M. Tolich (Ed.), Research Ethics in Aotearoa New Zealand. Auckland: Longman.

Cram, F. (2009). Maintaining Indigenous voices. In D. Mertens \& P. Ginsberg (Eds.), Handbook of social science research ethics (pp. 308-322). Thousand Oaks: Sage.

Cram, F. (2011). Poverty. In T. McIntosh \& M. Mulholland (Eds.), Māori and Social Issues (Vol. 1). Wellington: Huia Publishers.

Cunningham, C. (2000). A framework for addressing Maori knowledge in research, science and technology. Pacific Health Dialog, 7(1), 62-69.

Curtis, E., Townsend, S., Savage, T., \& Airini. (2008). Success for all: Improving Māori and Pasifika student success in foundation-level study. A presentation at the Bridging Education in New Zealand: A Pathway to the Future Conference, Rotorua.

Davies, S., \& Eruera, N. (2009). Te Toka Āhuru: An indigenous framework for whakaako (academic development). MAI Review, 3. Retrieved from http://web.its.auckland.ac.nz/ojs.review.mai.ac.nz/index.php/MR/ar ticle/viewFile/267/290

Debowski, S. (2011). Locating academic development: The first step in evaluation. In L. Stefani (Ed.), Evaluating the effectiveness of academic development: Principles and practice. New York: Routledge.

Dei, G. J. S. (2000). Rethinking the role of indigenous knowledges in the academy. International Journal of Inclusive Education, 4(2), 111-132.

Dei, G. J. S., Hall, B., \& Rosenberg, D. (2000). Indigenous knowledges in global contexts: Multiple readings of our world. London: University of Toronto Press. 
Deloria Jr, V. (2004). Marginal and submarginal. In D. A. Mihesuah \& A. C. Wilson (Eds.), Indigenizing the academy: Transforming scholarship and empowering communities (pp. 16-30). Lincoln: University of Nebraska Press.

Denzin, N., \& Lincoln, Y. (2011). The SAGE handbook of qualitative research. Thousand Oaks, California: Sage.

Denzin, N., Lincoln, Y., \& Smith, L. T. (2008). Handbook of critical and Indigenous methodologies. Los Angeles: Sage.

Department of Justice. (1989). Principles for Crown Action on the Treaty of Waitangi. Wellington: Department of Justice.

Dewes, T. K. (1975). The case for oral arts. In M. King (Ed.), Te Ao Hurihuri: The World Moves On: Aspects of Maoritanga (pp. 55-85). Wellington: Hicks Smith.

Durie, A. (1995). Kia hiwa ra: Challenges for Maori academics in changing times. He Pūkenga Kōrero: A Journal of Māori Studies, 1(1), 1-9.

Durie, M. (2004). Exploring the Interface between science and Indigenous knowledge. A presentation at the 5th APEC Research and Development Leaders Forum, Christchurch.

Durie, M. (2009). Towards social cohesion: The indigenisation of higher education in New Zealand. A presentation at the Vice Chancellor's Forum: How far are universities changing and shaping our world?, Kuala Lumpur, Malaysia.

Eketone, A. (2008). Theoretical underpinnings of kaupapa Māori directed practice. MAI Review, 2008(1). Retrieved from http://www.review.mai.ac.nz/index.php/MR/article/viewFile/98/1 $\underline{06}$

Erai, M. (2008). Reflections on my path to academia. MAI Review, 3. Retrieved from http://web.its.auckland.ac.nz/ojs.review.mai.ac.nz/index.php/MR/ar ticle/view/181/195

Evans, M., \& Ngarimu, R. (2005). The art of Māori weaving: The eternal thread/Te aho mutunga kore. Wellington: Huia Publishers.

Fordham, S. (1988). Racelessness as a factor in Black students' school success: Pragmatic strategy or pyrrhic victory? Harvard Educational Review, 58(1), 54-85.

Fredericks, B. (2008). The need to extend beyond the knowledge gained in cross-cultural awareness training. The Australian Journal of Indigenous Education, 37 (Supplement), 81-89.

Fredericks, B. (2009). Look before you leap: The epistemic violence that sometimes hides behind the word "inclusion". The Australian Journal of Indigenous Education, 38 (Supplement), 10-16.

Freire, P. (1974). Research methods. Literary Discussion, Spring, 134.

Gaff, J., \& Simpson, R. (1994). Faculty development in the United States. Innovative Higher Education, 18(3), 167-176.

Gallhofer, S., Haslam, J., Nam Kim, S., \& Mariu, S. (1999). Attracting and retaining Maori students in Accounting: Issues, experiences and ways forward. Critical Perspectives on Accounting, 10, 773-807.

Giddens, A. (1991). Modernity and self-identity. Cambridge: Polity Press. 
Glover, M. (2002). Kaupapa Mãori health research methodology: A literature review and commentary on the use of a kaupapa Màori approach within a doctoral study of Māori smoking cessation. Auckland: Applied Behavioural Science, University of Auckland.

Gone, J. (2004). Keeping culture in mind: Transforming the academic training in professional psychology for Indian Country. In D. A. Mithesuah \& A. C. Wilson (Eds.), Indigenizing the Academy: Transforming scholarship and empowering communities (pp. 124-142) Lincoln: The University of Nebraska Press.

Gorinski, R., \& Abernethy, G. (2007). Māori student retention and success: Curriculum, pedagogy and relationships. In T. Townsend \& R. Bates (Eds.), Handbook of teacher education: Globalization, standards and professionalism in times of change (pp. 229-240). Dordrecht: Springer Netherlands.

Gosling, D. (2009). Academic development identity and positionality. SRHE Academic Development Network.

Graham, J. (2009). Whakatangata kia kaha: Toitu te whakapapa, Toitu te tuakiri, toitu te mana - an examination of the contribution of Te Aute to Māori advancement. (PhD), Massey University, Palmerston North.

Grant, B., Lee, A., Clegg, S., Manathunga, C., Barrow, M., Kandlbinder, P., Brailsford, I., Gosling, D., \& Hicks, M. (2009). Why history? Why now? Multiple accounts of the emergence of academic development. International Journal for Academic Development, 14(1), 83-86.

Greenwood, J., \& Te Aika, L. H. (2009). Hei tauira. Wellington: Ako Aotearoa.

Griffiths, M. (2009). Parent and child experiences of childhood cancer: An interpretative phenomenological analysis approach. (PhD), Queensland University of Technology, Brisbane.

Groenewald, T. (2004). A phenomenological research design illustrated. International Journal of Qualitative Methods, 3(1), 42-55.

Gunstone, A. (2008). Australian university approaches to Indigenous policy. The Australian Journal of Indigenous Education, 37 (Supplement), 103-108.

Gwynne, C. (2009). Artistic practices, representations of Māori women and the paradox of Kaupapa Māori. MAI Review, 1. Retrieved from http://web.its.auckland.ac.nz/ojs.review.mai.ac.nz/index.php/MR/ar ticle/view/210/230

Hall, M. (2007). Māori Academic Staff Forum notes. Ako Victoria 2007. Victoria University of Wellington.

Hall, M. (2008). Engaging Indigenous academics. A presentation at the Higher Education Research and Development Society of Australasia (HERDSA) Conference, Rotorua.

Hall, M. (2009). The Indigenous learner experience: How do indigenous teachers contribute? A presentation at the Higher Education Research and Development Society of Australasia (HERDSA) Conference, Darwin.

Hall, M. (2010a). Acting with integrity: Understanding the complexity of Māori academic identities. A presentation at the Academic Identities in the 21st Century Conference, Glasgow http://www.cad.vuw.ac.nz/wiki/images/2/23/AIC_2010.pdf. 
Hall, M. (2010b). In Ngata's footsteps: Experiences of Māori postgraduate students. New Zealand Education Review. Retrieved from http://www.educationreview.co.nz/postgrad-andresearch/september-2010/in-ngatas-footsteps/ - .UqwvKaXhytg

Hall, M. (2010c). Learning by example: Quality teaching of Indigenous course content in higher education. A presentation at the International Consortium of Educational Developers (ICED) Conference, Barcelona.

Hall, M. (2010d). Shooting for the A*s: Journal rankings and the Mãori academic community. A presentation at the Māori Association of Social Science Conference, Auckland.

Hall, M. (2011a). Getting real: How Mãori academics are making academic development work for them. A presentation at the Higher Education on The Edge: Higher Education Research and Development Society of Australasia (HERDSA) Conference, Gold Coast, Australia. http://www.cad.vuw.ac.nz/wiki/images/d/d2/HERDSA_2011.pdf.

Hall, M. (2011b). Treasure in the margins: Rethinking Mãori academic development. A presentation at the Tertiary Education Research in New Zealand (TERNZ) Conference, Wellington. http://www.cad.vuw.ac.nz/wiki/images/2/23/TERNZ_2011.pdf.

Hall, M. (2011c). You model what you want to see from them. New Zealand Journal of Teachers' Work, 8(1), 68-77.

Hall, M. (2012). Personal pronouns and 'flexible minds': Shaping Māori academic identities. A presentation at the Academic Identities for the 21st Century Conference, Auckland. http://www.cad.vuw.ac.nz/wiki/images/5/59/AIC_2012.pdf.

Hall, M. (2013). Māori academic staff at Victoria University of Wellington. Unpublished raw data.

Hall, M., \& Sharman, S. (2012). Reconnecting with Māori students: Building an online training module for tutors. A presentation at the Māori Association of Social Science Conference, Christchurch.

Hawk, K., Cowley, E., Hill, J., \& Sutherland, S. (2001). Relationships: The critical factor in teaching Māori and Pasifika students. A presentation at the NZARE Conference, Christchurch.

Health Research Council of New Zealand. (n.d.). Health Research Council of New Zealand. Retrieved 4 May 2013, from http://www.hrc.govt.nz

Henkel, M. (2005). Academic identity and autonomy revisited. In I. Bleiklie \& M. Henkel (Eds.), Governing knowledge (pp. 145-165). Netherlands: Springer.

Henry, E., \& Pene, H. (2001). Kaupapa Māori, locating Indigenous ontology, epistemology and methodology in the academy. Organization, $8(2)$, 234-242.

Herbert, A. (2011). Māori perspectives on parenting in Aotearoa New Zealand. In T. McIntosh \& M. Mulholland (Eds.), Mãori and social issues. Wellington: Huia Publishers.

Hicks, M. (2005). Academic developers as change agents: Caught in the middle. A presentation at the Higher Education in a Changing World, Higher Education Research and Development Society of Australasia (HERDSA) Conference, Sydney, Australia. 
Higgins, R. (2004). He tānga ngutu, he Tūhoetanga, te mana motuhake o te tā moko wāhine: The identity politics of moko kauae. (PhD), Otago University, Otago.

Higgins, R., \& Hall, M. (2011). Te pataka kai iringa o te kupu, o te kōrero. He Pūkenga Kōrero: A Journal of Māori Studies, 10(1), 9-15.

Hitchcock, L. (2006). Methodology in computing education research: A focus on experiences. A presentation at the 19th Annual Conference of the National Advisory Committee on Computing Qualifications, Wellington.

Hobson, J., \& Hall, M. (2010). Publish or perish? The challenge of journal rankings for Māori-related research. MAI Review, 3. Retrieved from http://web.its.auckland.ac.nz/ojs.review.mai.ac.nz/index.php/MR/ar ticle/viewFile/408/552

Hokowhitu, B., Kermoal, N., Anderson, C., Petersen, A., Reilly, M., AltamiranoJimenez, I., \& Rewi, P. (Eds.). (2010). Indigenous identity and resistance: Researching the diversity of knowledge. Dunedin: Otago University Press.

Holdaway, M. A. (2002). A Maori model of primary health care nursing. (PhD), Massey University, Palmerston North.

Hook, G. (2008). Cultural relativism and academic freedom within the universities of New Zealand. MAI Review, 1. Retrieved from http://web.its.auckland.ac.nz/ojs.review.mai.ac.nz/index.php/MR/ar ticle/viewFile/83/111

Hook, G. (2010). A national Māori university. MAI Review, 2. Retrieved from http://web.its.auckland.ac.nz/ojs.review.mai.ac.nz/index.php/MR/ar ticle/view/296/481

hooks, b. (1994). Teaching to transgress - Education as the practice of freedom. London: Routledge.

Hurtado, S., Milem, J., Clayton-Pedersen, A., \& Allen, W. (1999). Enacting diverse learning environments: Improving the climate for racial/ethnic diversity in higher education. Washington, DC: The George Washington University.

Indigenous Higher Education Advisory Council. (2008). Submission to the Review of Australian Higher Education.

Irwin, K. (1994). Māori research methods and processes: An exploration. Sites, 28, 24-43.

Irwin, K. (1997). Becoming an academic: Contradictions and dilemmas of a Māori feminist. In S. Middleton \& A. Jones (Eds.), Women and education in Aotearoa 2. Auckland: Auckland University Press and Bridget Williams Books.

Irwin, K. (2007). Maori women and leadership in Aotearoa/New Zealand. In J. Green (Ed.), Making space for Indigenous feminism. Nova Scotia, Canada: Fernwood Publishing.

Jaime, A. (2005). Narrated portraits: The lived experience of Native women in academia. (PhD), Purdue University. Retrieved from http://docs.lib.purdue.edu/dissertations/AAI3204076/

Jaime, A. (2008). Native women: Decolonization and transcendence of identity. International Journal of Multicultural Education, 10(2), 1-13. 
James, K. (2004). Corrupt state university: The organizational psychology of Native experience in higher education. In D. A. Mihesuah \& A. C. Wilson (Eds.), Indigenizing the academy: Transforming scholarship and empowering communities (pp. 48-68). Lincoln: University of Nebraska Press.

Janis, I. (1982). Groupthink: Psychological studies of policy decisions and fiascoes. Boston: Houghton Mifflin.

Jefferies, R. (1997). Maori participation in tertiary education: Barriers and strategies to overcome them. Wellington: Te Puni Kōkiri.

Johnson, D. (2011, 21 February). Book lovers fear dim future for notes in the margins, New York Times, p. A10.

Johnsrud, L. (1993). Women and minority faculty experiences: Defining and responding to diverse realities. New Directions for Teaching and Learning, 53, 3-16.

Johnston, P. (1998). He Ao Rereke. Education Policy and Maori Educational Under-achievement: Mechanisms of Power and Difference. (PhD ), University of Auckland, Auckland.

Johnston, P. (2001). "Watch this spot and whose in it": Creating space for Indigenous educators? Australian Journal of Teacher Education, 26(1).

Johnston, P. (2004). When Indigenous knowledge questions the limits: A lesson about wisdom. A presentation at the Higher Education Research and Development Society of Australasia (HERDSA) Conference, Curtin University.

Johnston, S. (1997). Academics hard at work: The place of teaching and professional development related to teaching. Teachers and Teaching: Theory and practice, 3(2), 257-272.

Jones, A. (2010). Examining the public face of academic development. International Journal of Academic Development, 15(3), 241-251.

Jones, B., Ingham, T., Davies, C., \& Cram, F. (2010). Whānau Tuatahi: Māori community partnership research using a Kaupapa Māori methodology. MAI Review, 3. Retrieved from http://web.its.auckland.ac.nz/ojs.review.mai.ac.nz/index.php/MR/ar ticle/viewFile/392/548

Ka'ai, T. (1995). Te tātari i te kaupapa. (PhD), University of Waikato, Hamilton.

Ka'ai, T. (2000). Ngā hua o te mātauranga Māori i roto i te Whare Wānanga: The value of Mãori studies in the university. A presentation at the Inaugural Professorial Lecture, University of Otago.

Ka'ai, T. (2005). Indigenising the academy: Indigenous scholars as agents of change. A presentation at the 3rd Annual Hawai'i International Conference on Education, Honolulu, Hawai'i.

Ka'ai, T. (2008). The role of marae in tertiary education institutions. Te Kaharoa, 1.

Kahi, H. (2013, 19 November). [Personal communication].

Kana, F., \& Tamatea, K. (2006). Sharing, listening, learning and developing understandings of kaupapa Māori research by engaging with two Maori communities involved in education. Waikato Journal of Education, 12, 9-20. 
Kandlbinder, P., \& Peseta, T. (Eds.). (2011). Higher Education Research \& Development Anthology. Milperra, NSW: Higher Education Research and Development Society of Australasia (HERDSA).

Kaomea, J. (2001). Dilemmas of an Indigenous academic: a Native Hawaiian story. Contemporary Issues in Early Childhood, 2(1), 67-82.

Kawharu, M. (2010, 16 April). Presentation about community and Iwi relationships from a Māori woman academic's perspective. Paper presented at the MANU AO Leadership Wānanga, University of Auckland, Auckland.

Kidman, J. (1999). A people torn in twain: Colonial and indigenous contexts of university education in New Zealand. Interchange, 30(1), 73-91.

Kingi, T., \& Waiti, J. (Presenters). (2011). Whānau resilience: A case study. Ngā Pae o te Māramatanga Seminar Series.

Kohere, R. T. (1951). He konae aronui: Māori proverbs and sayings. Wellington: Reed.

Kukutai, T., \& Webber, M. (2010). Barriers and solutions: Views from the Margins. A presentation at the Critical MASS: Building a national Māori Association of Social Sciences Conference 2008, Wellington.

Kukutai, T., \& Webber, T. (2011). Navigating the 'space between': Authenticity and identity in 'Māori' social science. New Zealand Sociology, 26(Special Issue), 4-20.

Kuokkanen, R. (2007). Reshaping the university: Responsibility, Indigenous epistemes, and the logic of the gift. British Columbia: UBC Press.

Lambert, S. (2007). Māori writing retreats: Advancing Māori postgraduates. Paper presented at the Association of Tertiary Learning Advisors of Aotearoa New Zealand Conference 2006, Auckland.

Land, R. (2001). Agency, context and change in academic development. International Journal for Academic Development, 6(1), 4-20.

Lave, J., \& Wenger, E. (1991). Situated learning: Legitimate peripheral participation. Cambridge: Cambridge University Press.

Leonard, V. (1994). A Heideggerian phenomenological perspective on the concept of person. In P. Benner (Ed.), Interpretive phenomenology: Embodiment, caring, and ethics in health and illness. Thousand Oaks: Sage Publications Ltd.

Lilley, S. (n.d.). The marae as an information ground. Retrieved 19 August 2010, from http://ibec.ischool.washington.edu/pubs/maraeInfoGround.pdf

Lilley, S., \& Field, S. (2005). Ki te ao marama, ki te ao matauranga: Into the world of light, into the world of information. A presentation at the Inform, Connect, Engage: Library and Information Association of New Zealand Aotearoa Conference, Christchurch.

Lincoln University. (2013a). Annual Report 2012. Canterbury: Lincoln University.

Lincoln University. (2013b). Lincoln University Strategic Plan 2014-2018. Canterbury: Lincoln University.

Lopez, G. R. (1998). Reflections on epistemology and standpoint theories: A response to 'a Māori approach to creating knowledge'. International Journal of Qualitative Studies in Education, 11(2), 225-231. 
Maaka, M. (2004). E kua takoto te mānuka tūtahi: Decolonization, selfdetermination and education. Educational Perspectives, 37(1), 3-13.

Maaka, R., \& Fleras, A. (2005). The politics of indigeneity: Challenging the State in Canada and Aotearoa New Zealand. Dunedin: University of Otago Press.

Mahuika, M. (2008). Kaupapa Māori theory is critical and anti-colonial. MAI Review, 2008(3). Retrieved from http://web.its.auckland.ac.nz/ojs.review.mai.ac.nz/index.php/MR/ar ticle/viewFile/153/180

Mane, J. (2009). Kaupapa Māori: A community approach. MAI Review, 3. Retrieved from http://web.its.auckland.ac.nz/ojs.review.mai.ac.nz/index.php/MR/ar ticle/viewFile/243/282

MANU AO Academy. (2010) Retrieved 21 September 2011, from http://www.manu-ao.ac.nz

Manuel, R. (2010). What is tika when teaching small groups in a university setting in Aotearoa New Zealand? MAI Review, 3. Retrieved from http://web.its.auckland.ac.nz/ojs.review.mai.ac.nz/index.php/MR/ar ticle/viewFile/400/544

Manuel, R., Dunphy, C., \& Hema, G. (2011). Tuākana learning community: Enhancing academic success for Māori and Pasifika students. A presentation at the HERDSA 2011: Higher Education on the Edge, Gold Coast, Australia.

Marie, D. (2010). Maori and criminal offending: A critical appraisal. The Australian and New Zealand Journal of Criminology, 42(2), 282-300.

Massey University. (2003). Māori@Massey. Palmerston North: Massey University.

Massey University. (2013). The engine of the new New Zealand: Annual report 2012. Retrieved 1 November 2013, from https://http://www.massey.ac.nz/massey/fms/About Massey/Documents/Annual-Report-2012.pdf

Matthews, N. (2001). An exploration of Kaupapa Mãori policy and practice in tertiary education institutions in the Wellington region. (MEd), Victoria University of Wellington, Wellington.

Matthews, N. (2011). Reflecting on Māori academic leadership. MAI Review, $3,1-4$. Retrieved from http://web.its.auckland.ac.nz/ojs.review.mai.ac.nz/index.php/MR/ar ticle/viewFile/457/689

Mayes, T. (2006). L E X: The learner experience of e-Learning methodology report. Glasgow: Glasgow Caledonian University.

McFarlane, B., \& Hughes, G. (2009). Turning teachers into academics? The role of educational development in fostering synergy between teaching and research. Innovations in Education and Teaching International, 46(1), 5-14.

McIntosh, T. (2003). Kanohi ki te kanohi: Face to face, local government and Māori. Auckland: University of Auckland.

McKinley, E. (2002). Brown bodies in white coats: Maori women scientists and identity. Journal of Occupational Science, 9(3), 109-116. 
McMurchy-Pilkington, C. (2001). Maori education: Rejection, resistance, renaissance. In V. Carpenter, H. Dixon, E. Rata \& C. Rawlinson (Eds.), Theory in practice for educators (pp. 161-188). Palmerston North: Dunmore Press.

Mead, H. M. (1999). Te whatu tāniko: Tāniko weaving: Technique and tradition. Auckland: Reed.

Mead, H. M. (2003). Tikanga Māori: Living by Māori values. Wellington: Huia Publishers.

Mead, L. T. (1996). Ngā aho o te kākahu mātauranga:The multiple layers of struggle by Mãori in education. (PhD). University of Auckland, Auckland.

Mead, S. M. (1983). Te toi mātauranga Māori mo ngā rā kei mua: Māori Studies tomorrow. The Journal of the Polynesian Society, 92(3), 333351.

Mead, S. M. (1997). Landmarks, bridges and visions: Aspects of Maori culture. Wellington: Victoria University Press.

Merchanta, J., \& Bishr Omaryb, M. (2010). Underrepresentation of underrepresented minorities in academic medicine: The need to enhance the pipeline and the pipe. Gastroenterology, 138(1), 19-26.

Mercier, O. R. (2007). Close encounters of the Maori kind - Talking interaction in the films of Taika Waititi. New Zealand Journal of Media Studies, 10(2), 37-51.

Mercier, O. R., Asmar, C., \& Page, S. (2011). An academic occupation: Mobilisation, sit-in, speaking out and confrontation in the experiences of Māori academics. The Australian Journal of Indigenous Education, 40, 81-91.

Mercier, O. R., Douglas, S., Hall, M., McFadgen, B., Adds, P., Bargh, M., \& Wilson, T. (2013). Promoting engagement through a student-built digital atlas of Maori Studies. In C. Wankel \& P. Blessinger (Eds.), Increasing learner engagement through cutting-edge technologies (pp. 121-158). Bingley, UK: Emerald Publishing Group.

Meredith, P. (1999). Hybridity in the third space: Rethinking bi-cultural politics in Aotearoa/New Zealand. He Pūkenga Kōrero: A Journal of Māori Studies, 4(2), 12-16.

Metge, J. (1995). New growth from old: The whänau in the modern world. Wellington: Victoria University Press.

Mikaere, A. (1998). Taku titiro: Viewpoint: Rhetoric, reality and recrimination: Striving to fulfill the bicultural commitment at Waikato Law School. He Pūkenga Kōrero: A Journal of Māori Studies, $3(2), 4-14$.

Mikaere, A. (2011). From Kaupapa Māori research to researching kaupapa Māori: Making our contribution to Māori survival. Paper presented at the Kei Tua o Te Pae Hui Proceedings, Pipitea Marae, Wellington.

Ministry for Culture and Heritage. (n.d.-a). New Zealand History Online. Retrieved 4 May 2013, from http://www.nzhistory.net.nz

Ministry for Culture and Heritage. (n.d.-b). Te Ara The Encyclopaedia of New Zealand. Retrieved 4 May 2013, from http://www.teara.govt.nz

Misa, T. (2009, 11 May 2009). Full marks to preference for minorities, Opinion, New Zealand Herald. Retrieved from 
http://www.nzherald.co.nz/nz/news/article.cfm?c_id=1\&objectid=1 0571519.

Moeke-Maxwell, T. (2005). Bi/Multiracial Maori women's hybridity in Aotearoa/New Zealand. Discourse, 26(4), 497-510.

Moeke-Pickering, T., Hardy, S., Manitowabi, S., Mawhiney, A., Faries, E., Gibson-van Marrewijk, K., Tobias, N., \& Taitoko, M. (2006). Keeping our fire alive: Towards decolonising research in the academic setting. WINHEC.

Moewaka-Barnes, H. (2000). Kaupapa Māori: Explaining the ordinary. Auckland: Whariki Group, Massey University.

Moewaka-Barnes, H. (2006). Transforming science: How our structures limit innovation. Social Policy Journal of New Zealand(29), 1-16.

Moon, P. (2009). A chequered renaissance: The evolution of Maori society, 1984-2004. Te Kaharoa, 2, 23-41.

Moorfield, J. C. (n.d.). Te Aka Online Māori Dictionary Retrieved 26 May 2013, from http://www.maoridictionary.co.nz

Morgan, D. (2003). Appropriation, appreciation, accommodation: Indigenous wisdoms and knowledges in higher education. International Review of Education, 49(1-2), 35-49.

Morris, A. (2007). 'He aha te kaupapa tawhito': An exploratory study of policy expectations for district health board Kaupapa Mãori mental health services in New Zealand. (MPM), Victoria University of Wellington., Wellington.

Morrison, A. (1999). Space for Māori in tertiary institutions: Exploring two sites at the University of Auckland. (MA), University of Auckland, Auckland.

Morrison, A. (2000). Space for Māori in tertiary institutions. A presentation at the Fourth Pacific Rim - First Year in Higher Education Conference: Creating Futures for a New Millennium, Queensland University of Technology.

Museum of New Zealand Te Papa Tongarewa. (n.d.). Topic: Taniko Retrieved 26 October 2013, from http://collections.tepapa.govt.nz/theme.aspx?irn=3644

Nakata, M. (2004a). Indigenous Australian studies and higher education. A presentation at the Wentworth Lectures, Australian Institute of Aboriginal and Torres Strait Islander Studies, Canberra.

Nakata, M. (2004b). Ongoing conversations about Aboriginal and Torres Strait Islander research agendas and directions. The Australian Journal of Indigenous Education, 33, 1-6.

Nakata, M. (2006). Australian Indigenous studies: A question of discipline. The Australian Journal of Anthropology, 17(3), 265-275.

Nakata, M. (2007). Disciplining the savages, savaging the disciplines. Canberra: Aboriginal Studies Press.

Nakata, M., Nakata, V., Keech, S., \& Bolt, R. (2012). Decolonial goals and pedagogies for Indigenous Studies. Decolonization: Indigeneity, Education \& Society, 1(1), 120-140.

Nepe, T. (1991). E hao nei e tenei reanga te toi huarewa tipuna: Kaupapa Mãori, an educational intervention system. (MA), University of Auckland, Auckland. 
Nikora, L., Levy, M., Henry, J., \& Whangapirita, L. (2002). Addressing the recruitment and retention of Maori students in tertiary education institutions: A literature review. Hamilton: Māori \& Psychology Research Unit, University of Waikato.

O'Carroll, A. D. (2013). An analysis of how rangatahi Māori use social networking sites. MAI Journal, 2(1), 46-59.

Openshaw, R., \& Rata, E. (2008). Flax rope or iron fetter? How cultural essentialism threatens intellectual freedom in the New Zealand tertiary education sector. New Zealand Journal of Tertiary Education Policy, 3(1).

Page, S., \& Asmar, C. (2008). Beneath the teaching iceberg: Exposing the hidden support dimensions of Indigenous academic work. The Australian Journal of Indigenous Education, 37 (Supplement), 109117.

Paipa, K. (2010). Te whakapapa o te reo i roto i te whanau. MAI Review, 3. Retrieved from http://web.its.auckland.ac.nz/ojs.review.mai.ac.nz/index.php/MR/ar ticle/viewFile/383/534

Paki, V. (2007). Kimihia, rangahaua ngā tikanga heke iho, he taonga huahua e riro mai - Exploring whakapapa as a tool towards a Kaupapa Mãori assessment framework in early childhood education. (MEd), University of Waikato, Hamilton.

Palepu, A., Carr, P., Friedman, R., Amos, H., Ash, A., \& Moskowitz, M. (1998). Minority faculty and the academic rank in medicine. The Journal of the American Medical Association, 280(9), 767-771.

Pendergrast, M. (1987). Te aho tapu: The sacred thread: Traditional Maori weaving. Auckland: Reed Methuen Publishers.

Penehira, M., Cram, F., \& Pipi, K. (2003). Kaupapa Maori governance. Retrieved from http://www.katoa.net.nz/past-projects/kaupapamaori-governance

Penetito, W. (2005). A sociology of Mãori education - Beyond mediating structures. (PhD), Victoria University of Wellington, Wellington.

Pere, R. (1982). Ako: Concepts and learning in the Maori tradition. Wellington: Te Kohanga Reo National Trust.

Peseta, T., \& Grant, B. (2011). Working imaginatively with/in contradiction. International Journal for Academic Development., 16(1), 1-4.

Pewewardy, C. (2004). So you think you hired an "Indian" faculty member? The ethnic fraud paradox in higher education. In D. A. Mithesuah \& A. C. Wilson (Eds.), Indigenizing the Academy: Transforming Scholarship and Empowering Communities (pp. 200-217). Lincoln: University of Nebraska Press.

Pihama, L. (2001). Tihei mauri ora: Honouring our voices. Mana wahine as a Kaupapa Māori theoretical framework. (PhD), University of Auckland, Auckland.

Pihama, L., Cram, F., \& Walker, S. (2002). Creating a methodological space: A literature review of Kaupapa Māori research. Canadian Journal of Native Education, 26(1), 30-44.

Pipi, K., Cram, F., Hawke, R., Hawke, S., Huriwai, T., Mataki, T., Milne, M., Morgan, K., Tuhaka, H., \& Tuuta, C. (2004). A research ethic for 
studying Māori and iwi provider success. Social Policy Journal of New Zealand(23), 141-153.

Pohatu, G. (1998). The university, Maori studies and Treaty praxis. (PhD), University of Otago, Dunedin.

Powick, K. (2002). Māori research ethics: A literature review of the ethical issues and implications of kaupapa Māori research and research involving Māori for researchers, supervisors and ethics committees. Hamilton: School of Education, University of Waikato.

Puketapu, I. P. (1966). Ngata, Sir Apirana Turupa. In A. H. McLintock (Ed.), An Encyclopaedia of New Zealand. Wellington: Government Printer.

Rapley, T. (2001). The art(fulness) of open-ended interviewing: Some considerations on analysing interviews. Qualitative Research, 1(3), 303-323.

Rata, E. (2007). Cultural relativism. Ingenio, Autumn, 38.

Ratima, M. (2008). Making space for kaupapa Māori within the academy. MAI Review, 2008(1). Retrieved from http://web.its.auckland.ac.nz/ojs.review.mai.ac.nz/index.php/MR/ar ticle/viewFile/124/122

Ratima, M. (2011). Case Study 1: Whaia te pae tawhiti: Māori academic development at the University of Auckland. In L. Stefani (Ed.), Evaluating the effectiveness of academic development: Principles and practice. New York: Routledge.

Reid, K., Flowers, P., \& Larkin, M. (2005). Exploring lived experience. The Psychologist, 18(1), 20-23.

Reilly, M. (2008). What is Maori Studies? Retrieved 11 February 2011, from http://eprintstetumu.otago.ac.nz/56/

Reilly, M. (2011). Māori Studies, past and present: A review. The Contemporary Pacific 23(2), 340-370.

Rigney, L. (1999). Internationalization of an Indigenous anticolonial cultural critique of research methodologies: A guide to Indigenist research methodology and its principles. Wicazo Sa Review, 14(2), 109-121.

Roa, T., Beggs, J. R., Williams, J., \& Moller, H. (2009). New Zealand's Performance Based Research Funding (PBRF) model undermines Māori research. Journal of the Royal Society of New Zealand, 39(4), 233-238.

Roa, T., \& Tuaupiki, J. (2005). Tikanga Tainui; Tikanga Whare Wananga. He Puna Kōrero, 6(2), 3-8.

Robust, T. (2007). Developing Indigenous infrastructure in the university: Another era or another error? MAI Review, 1. Retrieved from http://web.its.auckland.ac.nz/ojs.review.mai.ac.nz/index.php/MR/ar ticle/viewFile/31/31

Roland, K. (2011). Creating inclusive space for aboriginal scholars and scholarship in the academy. Canadian Journal of Educational Administration and Policy(118), 1-33.

Ross, C. (2010). Culturally relevant peer support for Māori and Pasifika student engagement, retention and success. Wellington: Open Polytechnic. 
Rossi, U. (2008). Being here and there: In-betweeness, double absence, and the making of a multi-layered academic citizenship. Area, 40(3), 401406.

Rowe, L. (2007). Kua whakaorangia ko te taonga taiaha: An integrated kaupapa Māori process for substance abuse treatment. (MSc), Victoria University of Wellington, Wellington.

Rowland, S. (2003). Academic development: A practical or theoretical business? In H. Eggins \& R. Macdonald (Eds.), The scholarship of academic development. London \& Philadelphia: Society for Research into Higher Education \& Open University Press.

Royal, T. C. (1998). Te ao marama: Wisdom and spirituality. A presentation at the Healing our Spirit Worldwide Indigenous Conference, Rotorua.

Royal, T. C. (2009). MANU AO seminar: Te kaimānga - Towards a new vision for mātauranga Māori.

Royal, T. C. (2012). Politics and knowledge: Kaupapa Maori and matauranga Maori. New Zealand Journal of Educational Studies, 47(2), 30-37.

Ryan, P. M. (1997). The Reed dictionary of modern Māori. Auckland: Reed.

Saba, W. (2007). Walking in two worlds: A Kaupapa Mãori research project examining the experiences of Māori nurses working in district health boards, Māori mental health services. (MA (Applied)), Victoria University of Wellington, Wellington.

Sadao, K. (2003). Living in two worlds: Success and the bicultural faculty of color. The Review of Higher Education, Volume 26(4), 397-418.

Shadbolt, M. (2013, 19 November). [Personal communication].

Sharples, P. (Ed.). (1995). Cultural justice. Auckland: Legal Research Foundation.

Sheridan, J. (2004, 28 April). York alum takes a special path to professorship, YFile: York's Daily Bulletin.

Smith, C. (2000a). Straying beyond the boundaries of belief: Māori epistemologies inside the curriculum. Educational Philosophy and Theory, 32(1), 43-51.

Smith, D. G. (1991a). The challenge of diversity: Alienation in the academy and its implications for faculty. Journal on Excellence in College Teaching, 2, 129-137.

Smith, G. H. (1990a). Notes on: The Business Roundtable and the privatization of education: Individualism and the attack on Māori. In L. Gordon \& J. Codd (Eds.), Education policy and the changing role of the State (pp. 99-106). Palmerston North: Massey University.

Smith, G. H. (1990b). Research issues related to Mãori education. A presentation at the NZARE Special Interest Conference, Massey University.

Smith, G. H. (1991b). Reform and Māori educational crisis: A grand illusion. Auckland: Research Unit for Maori Education, University of Auckland.

Smith, G. H. (1992a). Tane-nui-a-rangi's legacy: Propping up the sky. Kaupapa Màori as resistance and intervention. A presentation at the NZARE/AARE Joint Conference, Deakin University Australia.

Smith, G. H. (1993). Kaupapa Māori: Educational resistance and intervention in Aotearoa (New Zealand). In G. H. Smith (Ed.), Higher education for 
indigenous peoples. Auckland: Research Unit for Māori Education, University of Auckland.

Smith, G. H. (1995a). Whakaoho Whānau: New formations of whānau as an intervention into Māori cultural and educational crises. He Pūkenga Kōrero: A Journal of Māori Studies, 1(1), 18-36.

Smith, G. H. (1997). The development of kaupapa Māori: Theory and praxis. (PhD), University of Auckland.

Smith, G. H. (2003). Kaupapa Māori theory: Theorizing indigenous transformation of education and schooling. A presentation at the NZARE/AARE Joint Conference, Kaupapa Māori Symposium, Auckland.

Smith, G. H. (2011). MANU AO Seminar - Transforming Education. Victoria University of Wellington.

Smith, J. (1996). Beyond the divide between cognition and discourse: Using interpretative phenomenological analysis in health psychology. Psychology and Health, 11(2), 261-271.

Smith, J., Flowers, P., \& Larkin, M. (2009). Interpretative phenomenological analysis: Theory, method and research. London: Sage Publications Ltd.

Smith, J., \& Osborn, M. (2007). Interpretative phenomenological analysis. In J. A. Smith (Ed.), Qualitative psychology: A practical guide to research methods. London: Sage Publications Ltd.

Smith, L. T. (1992b). Ko taku ko ta te Maori: The dilemma of a Maori academic. A presentation at the NZARE/AARE Joint Conference, Deakin University, Geelong, Australia.

Smith, L. T. (1992c). Kura kaupapa Māori and the implications for curriculum. In G. McCulloch (Ed.), The school curriculum in New Zealand. Palmerston North: Dunmore Press.

Smith, L. T. (1995b). Toward kaupapa Maori research. A presentation at the Matawhanui Conference (Maori University Teachers Conference), Massey University.

Smith, L. T. (1999). Decolonizing methodologies: Research and Indigenous peoples. Dunedin: University of Otago Press.

Smith, L. T. (2000b). Kaupapa Māori research. In M. Battiste (Ed.), Reclaiming Indigenous voice and vision (pp. 225-247). Canada: UBC Press.

Smith, L. T., \& Reid, P. (2000). Māori research development: Kaupapa Māori principles and practices: A literature review: International Research Institute for Maori and Indigenous Education (IRI), University of Auckland, with Te Ropu Rangahau Hauora a Eru Pomare, Wellington School of Medicine, University of Otago.

Smithies, G. (2011, 13 March). Treasure in the margins, Sunday Star Times, p. F28.

Soldier, H., \& Flechs, D. (1999). Native American underrepresentation in predominantly white institutions. A presentation at the People of Color in Predominantly White Institutions Fourth Annual National Conference, University of Nebraska-Lincoln.

Statistics New Zealand. (2006). QuickStats about culture and identity 2006 Census. Retrieved 4 February 2011, from 
http://www.stats.govt.nz/Census/2006CensusHomePage/QuickStat s/quickstats-about-a-subject/culture-and-identity.aspx

Stefani, L. (Ed.). (2011). Evaluating the effectiveness of academic development: Principles and practice. New York: Routledge.

Stewart, G. (2007). Kaupapa Māori science. (Doctor of Education), University of Waikato.

Stewart, P. (2010). Trent leads in recognition of Indigenous knowledge, CAUT Bulletin. Retrieved from http://www.cautbulletin.ca.

Stewart-Harawira, M. (2007). Practicing Indigenous feminism: Resistance to imperialism. In J. Green (Ed.), Making space for Indigenous feminisms. Fernwood, Canada: Zed Books.

Sue, D. W. (Ed.). (2010). Microaggressions and marginality: Manifestations, dynamics, and impact. New Jersey and Canada: John Wiliey \& Sons Inc.

Taiaroa, H. (2007). Weaving the contemporary position of Maatauranga Maaori within nursing practice. (PhD), Victoria University of Wellington, Wellington.

Taki, M. (1996). Kaupapa Māori and contemporary iwi resistance. (MA), University of Auckland, Auckland.

Tamarapa, A. (Ed.). (2011). Whatu kākahu: Māori cloaks. Wellington: Te Papa Press.

Tawhai, V., Pihera, K., \& Bruce-Ferguson, P. (2004). Does the PBRF need reshaping? A new Mãori educational institution's perspective. A presentation at the Higher Education Research and Development Society of Australasia (HERDSA) Conference, Sarawak.

Te Hiwi, E. (2007). Disrupted spaces: Racism and the lived experience of Mãori identity formation. A presentation at the Claiming Spaces: Proceedings of the 2007 National Maori and Pacific Psychologies Symposium, Hamilton.

Te Kanawa, D. (2006). Weaving a kakahu. Tauranga: Puwaha ki te Ao Trust.

Te Momo, F. (2010). Assimilation or organic development: Rethinking a Māori position in the field of social science. A presentation at the Critical MASS Conference, Wellington.

Te Punga Somerville, A. (2007). He korero. NZJMS, 10(2), 31-36.

Te Punga Somerville, A. (2010). My poetry is a fire. In B. Hokowhitu, N.

Kermoal, C. Anderson, A. Petersen, M. Reilly, I. Altamirano-Jimenez \& P. Rewi (Eds.), Indigenous identity and resistance: Researching the diversity of knowledge (pp. 37-54). Dunedin: Otago University Press.

Te Punga Somerville, A., Pirini, J., \& Hall, M. (2010). Hitting the mark: Developing good practice in targeted tutorials. A presentation at the Higher Education Research and Development Society of Australasia (HERDSA) Conference, Melbourne.

Teaiwa, T. (1995). Scholarship from a lazy native. In E. Greenwood, K. Neumann \& A. Sartori (Eds.), Work in Flux (pp. 59-60). Melbourne: University of Melbourne Press.

Tertiary Education Commission. (2010). Tertiary Education Strategy 20102015.

The University of Auckland. (2012). The University of Auckland Strategic Plan 2013-2020. Auckland: The University of Auckland. 
The University of Auckland. ((n.d.)). Key statistics. Retrieved 24 March 2012, from http://www.auckland.ac.nz/uoa/key-statistics

The University of Otago. (2007). Maori Strategic Framework 2007-2012. Dunedin.

The University of Otago. ((n.d.)). Staff profile Retrieved 15 July, 2011, from http://www.otago.ac.nz/about/quickstats.html - staff

The University of Waikato. (2010). Strategic Plan 2010-2013. Hamilton: The University of Waikato.

Thompson, K., \& Barnett, A. (2007). Interpreting and practicing Kaupapa Māori research in a community setting: The ins and outs. Paper presented at the Claiming Spaces: Proceedings of the 2007 National Maori and Pacific Psychologies Symposium, Hamilton.

Tierney, W. G. (1999). Education models of minority college-going and retention: Cultural integrity versus cultural suicide. The Journal of Negro Education, 68(1), 80-91.

Timotijevic, L., \& Breakwell, G. (2000). Migration and threat to identity. Journal of Community \& Applied Social Psychology, 10, 355-372.

Tinto, V. (2002). Promoting student retention: Lessons learned from the United States Retrieved 14 July, 2011, from http://www.lanecc.edu/inservice/fall06/documents/Tinto Speech-LessonsLearned.pdf

Tooley, C. (2000). Maori education policy in the new millenium: Political rationality \& government mechanisms. (MA), University of Auckland, Auckland.

Treaty of Waitangi (1840).

Trudgett, M. (2009). Build it and they will come: Building the capacity of Indigenous units in universities to provide better support for Indigenous Australian postgraduate students. The Australian Journal of Indigenous Education, 38, 9-18.

Umbach, P. (2006). The contribution of faculty of color to undergraduate education. Research in Higher Education, 47(3), 317-345.

University of Canterbury. (2012). UC Investment Plan 2013-2015. Christchurch: University of Canterbury.

University of Canterbury. (2013). UC Facts Retrieved 19 November 2013, from http://www.canterbury.ac.nz/theuni/plans/facts.shtml

University of Waikato. (2013). University of Waikato Annual Report 2012. Hamilton: University of Waikato.

Victoria University of Wellington. (2009a). Strategic Plan 2009-2014. Wellington: Victoria University of Wellington.

Victoria University of Wellington. (2009b). Treaty of Waitangi Statute.

Victoria University of Wellington. (2013). Victoria University of Wellington Annual Report 2012. Wellington: Victoria University of Wellington.

Villegas, M. (2010). 500 Maori PhDs in five years: Insights from a successful Indigenous higher education initiative. (Doctor of Education), Harvard University.

Villenas, S. (1996). The colonizer? Colonized Chicana ethnographer: Identity, marginalisation, and co-optation in the field. Harvard Educational Review 66(4), 713-731. 
Viskovic, A. (2005). Academic staff development and communities of teaching practice. A presentation at the Higher Education Research and Development Society of Australasia (HERDSA) Conference, Sydney. Waitangi Tribunal. (n.d.). Waitangi Tribunal. Retrieved 4 May 2013, from http://www.waitangi-tribunal.govt.nz

Walker, R. (1992). The relevance of Maori myth and tradition. In M. King (Ed.), Tihe mauri ora: Aspects of Maoritanga. Auckland: Methuen Publications.

Walker, S. (1996). Kia tau te rangimarie: Kaupapa Māori theory as a resistance against the construction of Māori as the 'other'. (MA), Auckland University, Auckland.

Walker, S., Eketone, A., \& Gibbs, A. (2006). An exploration of kaupapa Māori research, its principles, processes and applications. International Journal of Social Research Methodology, 9(4), 331-344.

Ward, T. (2013, 22 April 2013). [Personal communication].

Warren, T. (2006). Constructing 'traditional' concepts: The case of Maori governance (Vol. CIGAD Working Paper Series 3/2006). Palmerston North: Massey University.

Watts, R., Herbison, J., Johnston, T., \& Myers , R. (1987). New Zealand's universities: Partners in national development. Report of the Universities Review Committee to the New Zealand Vice Chancellors' Committee. Wellington.

Webber, B. (Ed.). (1996). He paepae korero: Research perspectives in Māori education. Wellington: New Zealand Council for Educational Research.

Webber, M. (2009). The multiple selves and realities of a Māori researcher. MAI Review, 1. Retrieved from http://review.mai.ac.nz/index.php/MR/article/viewFile/195/200

Wenger, E. (1998). Communities of practice; learning, meaning and identity. New York: Cambridge University Press.

Wenger, E. (2000). Communities of practice and social learning systems. Organisation, 7(2), 225-246.

Wenger, E. (2006). Communities of practice. Retrieved 20/09/2011, from http://www.ewenger.com/theory/

Wenger, E., McDermott, R., \& Snyder, W. (2002). Cultivating communities of practice: A guide to managing knowledge. Boston, MA: Harvard Business School Press.

Whatman, S., McLaughlin, J., Willsteed, S., Tyhuis, A., \& Beetson, S. (2009). Quality and efficacy of the Indigenous Tutorial Assistance Scheme (ITAS) for university students. The Australian Journal of Indigenous Education, 37 (Supplement), 118-130.

White, H., Oxenham, T., Tahana, M., Williams, K., \& Matthews, K. (2009). Ma te huruhuru ka rere te manu: How can langauge and literacy be optimised for Maori learner success? Education Counts. Wellington: Ministry of Education.

White, P., \& Grice, J. (2008). Participation and performance by Māori and Pacific peoples researchers in the Performance-Based Research Fund, 2003-2006: A working paper contributing to the independent strategic review of the Performance-Based Research Fund: Tertiary Education Commission. 
Wiggins, G., \& McTighe, J. (1998). Understanding by design. Alexandria, VA: Association for Supervision and Curriculum Development.

Wilkie, M. (2006). Kaupapa Maori intervention in postgraduate education: Ko te pae tawhiti arumia kia tata: Seek to bring the distant horizons closer. New Zealand Annual Review of Education, 15, 45-63.

Wilkie, M. (2010). Te taumata - te timata: The pinnacle - the first step. (PhD), Victoria University of Wellington, Wellington.

Williams, H. W. (1992). Dictionary of the Maori Language (7th ed.). Wellington: Legislation Direct.

Williams, J. (2010). Towards a model for Indigenous research. In B. Hokowhitu, N. Kermoal, C. Anderson, A. Petersen, M. Reilly, I. Altamirano-Jimenez \& P. Rewi (Eds.), Indigenous identity and resistance: Researching the diversity of knowledge. Dunedin: Otago University Press.

Williams, P. J. (1991). The alchemy of race and rights. Cambridge, MA: Harvard University Press.

Wilson, A. C. (2004). Reclaiming our humanity. In D. A. Mihesuah \& A. C. Wilson (Eds.), Indigenizing the academy: Transforming scholarship and empowering communities. Lincoln: University of Nebraska Press.

Wilson, J. (2013). Whiripapa: Tāniko, whānau and kōrero-based film analysis. (PhD), University of Auckland, Auckland.

Winter, R. (2009). Academic manager or managed academic? Academic identity schisms in higher education. Journal of Higher Education Policy and Management, 31(2), 121-131.

Woods, H. (2008). Indigenous space in institutions: Frameworks around Māori legal academics at Waikato. MAI Review, 2. Retrieved from http://web.its.auckland.ac.nz/ojs.review.mai.ac.nz/index.php/MR/ar ticle/viewFile/154/160 


\section{Appendix A: Human Ethics Committee Approval}

TE WHARE WĀNANGA O TE ŪPOKO O TE IKA A MĀUI

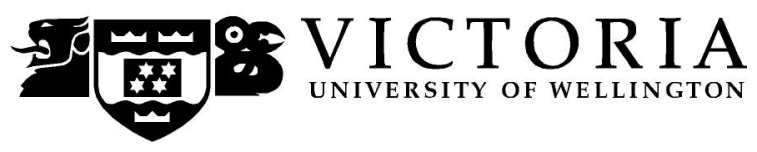

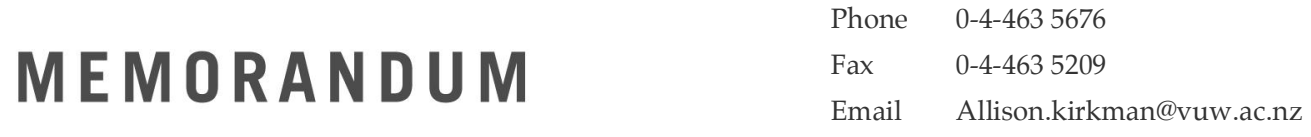

\begin{tabular}{l|l}
\hline TO & Meegan Hall \\
\hline COPY TO & Ocean Mercier, Kathryn Sutherland \\
\hline FROM & Dr Allison Kirkman, Convener, Human Ethics Committee \\
\hline \multicolumn{2}{|l}{} \\
\hline DATE & 20th May 2010 \\
\hline PAGES & 1 \\
\hline SUBJECT & $\begin{array}{l}\text { Ethics Approval: No 17645 the experiences of Maori } \\
\text { Academics in New Zealand Universities }\end{array}$
\end{tabular}

Thank you for your application for ethical approval, which has now been considered by the Standing Committee of the Human Ethics Committee.

Your application has been approved from the above date and this approval continues until 31 December 2011. If your data collection is not completed by this date you should apply to the Human Ethics Committee for an extension to this approval.

Best wishes with the research.

Allison Kirkman

Convener 


\section{Appendix B: Participant Information Sheet}

Participant Information Sheet for a Study about the Experiences of Māori Academics in New Zealand Universities.

Researcher: Meegan Hall

Ngāti Ranginui, Ngāi Te Rangi, Ngāti Tūwharetoa and Tainui.

Supervisors: Dr Ocean Mercier, Te Kawa a Māui School of Māori Studies Dr Kathryn Sutherland, University Teaching Development Centre

Tēnā koe,

I am undertaking doctoral research about the experiences of Māori academics in New Zealand universities. As an academic developer at Victoria University of Wellington, I am keen to gather this information to help identify appropriate and effective academic development strategies for supporting the achievement and success of Māori academics.

This research project has been approved by the Victoria University Human Ethics Committee (approval \#17645).

I would like to conduct interviews with Māori academic staff at different universities in New Zealand. Each interview participant will be asked to talk about their experience of being a Māori academic in a university. I expect that these interviews will take approximately one hour per interviewee.

Participation in this project is entirely voluntary. The interviews will be soundrecorded; if this is unacceptable to an interviewee then they may refuse to participate in this research project. 
Responses collected in the interviews will form the basis of a PhD thesis and it is intended that one or more resultant articles will be submitted for publication in scholarly journals and/or presentation at academic conferences. Responses will also be used to inform academic development training offered to Māori academics at Victoria University, and can be made available for academic development purposes at other Universities, at the request of the interviewees.

The interviewees will not be anonymous, however the information that they share will be kept confidential and their details will not be included in future publications. In addition, the identities of any students and/or colleagues mentioned in these interviews will remain confidential and be replaced in any publication with generic terms (for example: the interviewee referred to a colleague who ...). The researchers will take the utmost of care to protect student and other staff identities in these cases.

All interviewees will be sent a transcript of their interview for their approval. In addition, all interview material will be held securely and no other person besides the researchers will see the full interview transcripts. All interview recordings will be destroyed three years after the end of the project.

If you have any questions or would like to receive further information about the project, please contact Meegan on XXX-XXXX or XXXXXXXXXXXXXXXXXXXXX

Nāku noa, nā

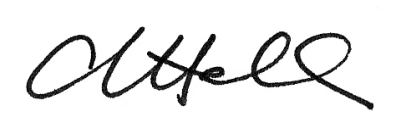

Meegan Hall 


\section{CONSENT TO PARTICIPATE IN RESEARCH}

\section{Title of project: A Study about the Experiences of Māori Academics in New Zealand Universities.}

I have been given and have understood an explanation of this research project. I have had an opportunity to ask questions and have them answered to my satisfaction.

I understand that:

- I may withdraw myself (or any information I have provided) from this project (before data collection and analysis is complete) without having to give reasons or without penalty of any sort.

- My interview will be sound recorded to allow accurate interpretation of my opinions and the recording will be destroyed three years after the research project has concluded.

- I will receive a transcript of my interview.

- The data I provide will not be used for any other purpose (besides those noted in the information sheet) or released to others without my written consent.

- I do not have to answer any question I feel uncomfortable with.

Tick to indicate agreement:

I agree to take part in this research.

I give permission for my interview to be sound-recorded.

Signed:

Name of participant:

(Please print clearly)

Date: 